\title{
Control del deterioro de la madera mediante la acción de nano-impregnantes y \\ recubrimientos sol-gel a base de silanos
}

\author{
Lic. Paula Vanesa Alfieri \\ Tesis para obtener el grado de \\ Doctora de la Facultad de Ciencias Agrarias y Forestales
}

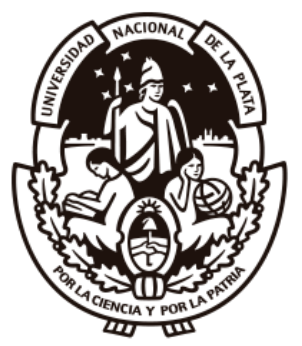

Facultad de Ciencias Agrarias y Forestales

Universidad Nacional de La Plata

2018 
$>$ Este trabajo se llevó a cabo en el Laboratorio de Entrenamiento Multidisciplinario para la Investigación Tecnológica (LEMIT) y en el Centro de Investigación y Desarrollo en Tecnología de Pinturas (CIDEPINT), bajo la dirección del Dr. Guillermo Blustein

$>$ Se presenta a la consideración de las autoridades de la Universidad Nacional de La Plata para aspirar al grado académico de Doctora de la Facultad de Ciencias Agrarias y Forestales 


\section{A G R A D E C I M I E N T O S}

* A1 Dr. Guillermo Blustein por su valiosa dirección.

* Al Dr. Guidice y a la Dra. Canosa porque fueron parte importantísima de mi formación académica y profesional

* Al personal del LEMIT, particularmente los integrantes del Área Restauración del Patrimonio Cultural; al personal del CIDEPINT por su colaboración en la parte experimental y a los integrantes del laboratorio INMIBO, en particular a las Dras. Alejandra Fazio e Isabel Cinto por el aporte y apoyo tanto científico como personal.

* A la Comisión de Investigaciones Científicas de la Provincia de Buenos Aires por financiar este trabajo.

* A familiares y amigos por su apoyo y afecto incondicional 


\section{PRÓLOGO}

El aumento constante del consumo de madera como material ha llevado a la necesidad de introducir en el mercado especies de crecimiento rápido las cuales poseen propiedades inferiores desde el punto de vista de la resistencia a la degradación. La extracción de madera en el pasado fue indiscriminada, sin medir las consecuencias del deterioro de los bosques naturales; se extraían grandes volúmenes de madera de crecimiento lento, que demoraban siglos en madurar, dejando en pie aquellos árboles de menor calidad.

La consecuencia de esta sobreexplotación significó finalmente la búsqueda de la protección de aquellas construcciones de madera para mejorar su durabilidad y aumentar su vida en servicio. Por otra parte, se buscó, y actualmente se continúa buscando, la forma de utilizar especies de madera variadas, principalmente aquellas de rápido crecimiento, mejorando sus propiedades fisco-mecánicas.

Por estos motivos, en los países con desarrollo científico-tecnológico se intenta dar una respuesta adecuada a la amplia variedad de temas involucrados en la correcta protección de la madera y la preservación de bosques naturales vírgenes. Así, los requisitos necesarios para resolver el problema de la preservación de la madera son conocer con profundidad la composición química y biológica, así como también la estructura y las propiedades del material a proteger. Además de conocer con profundidad también los agentes degradantes a los cuales puede ser expuesta la madera, lo que dependerá fundamentalmente del destino que se le dará a la madera como material. La importancia de conocer y estudiar lo antes mencionado radica en la correcta elección de los sistemas protectores desde el punto de vista de la eficiencia, el impacto ambiental y la economía.

Los microorganismos son seres vivos para los cuales el carbono es el mayor constituyente celular, el cual es requerido y obtenido de fuentes diversas. Existe una diversidad de estos microorganismos celulolíticos, entre ellos bacterias y hongos aeróbicos o anaeróbicos que utilizan la celulosa, hemicelulosa y lignina de la madera como fuente de carbono. Esta gran variedad metabólica hace que sea muy difícil controlar su ataque o crecimiento sobre cualquier 
sustrato ya que tienen la capacidad de adecuar su metabolismo a las condiciones del medio, aún cuando éstas son extremas.

Paralelamente, las maderas de baja y media densidad presentan una reducida resistencia a la penetración del fuego y una insuficiente capacidad para formar una capa carbonizada que permita el mantenimiento de sus propiedades mecánicas durante una conflagración.

La formulación del plan de tesis surge entonces de la necesidad de desarrollar modernos productos tecnológicos no contaminantes para la protección de la madera y que además construya un puente entre los conocimientos básicos generados como producto de la investigación científica y la ciencia aplicada. Este trabajo de tesis intenta abordar un análisis multidisciplinario aplicando los conocimientos de la ingeniería química y biología como herramientas aptas para evaluar los factores fundamentales que afectan el problema y encontrar las soluciones tecnológicas más adecuadas.

El objetivo fundamental del presente plan de tesis fue aplicar dos nuevas tecnologías nacientes para la protección de maderas de baja densidad que se emplean en el ámbito civil e industrial. Por un lado, otorgarle hidrorrepelencia, resistencia al biodeterioro y resistencia a la acción del fuego. Para ello se utilizarán silanos curados por el proceso sol-gel y nanocompuestos. Estos tratamientos otorgarán una mayor durabilidad a la madera, fomentando la utilización de maderas de crecimiento rápido obteniendo la misma calidad en servicio que una madera de crecimiento lento. Además, es de destacar que los tratamientos de protección de la madera que se implementarán son más seguros para el medioambiente que los actualmente empleados.

Con el propósito de llevar a cabo el plan de tesis y luego de una exhaustiva revisión bibliográfica, en el primer capítulo se incluyó una introducción a la problemática que enmarca la tesis incluyendo generalidades sobre maderas, sus patologías más frecuentes y el estado del arte actual en cuanto a degradación por agentes biológicos y por acción del fuego. En el segundo capítulo se incluyó características particulares de maderas, especialmente todo aquello referido a la madera como material biológico y lo necesario para comprender los tratamientos protectores. También se detallarán exhaustivamente los principales componentes escogidos para llevar a cabo el plan de tesis: los silanos y los nanocompuestos. En esta parte se detallarán generalidades, 
particularidades, caracterización y fundamentación de su elección como así también los procesos químicos involucrados al ponerse en contacto con la madera.

En el segundo capítulo se detalló los materiales específicos empleados, métodos de impregnación de la madera utilizada y por último, el desarrollo experimental de la tesis.

En el tercer capítulo se discutieron los resultados de la parte experimental: se formularon y elaboraron en escala de laboratorio impregnantes con características repelentes al agua, biocidas e ignífugos, respectivamente. Los resultados altamente satisfactorios permitieron inferir que el mecanismo de protección está sustentado en la formación de polímeros inorgánicos de altamente reticulados formados en la pared celular que componen los, modificándola químicamente con la particularidad de no obturar los poros evitando así numerables fallas.

Finalmente, en el cuarto capítulo o se expusieron las conclusiones generales del presente proyecto.

En resumen, la ejecución del plan de tesis permitió el desarrollo de nuevos impregnantes y recubrimientos para controlar no sólo el deterioro de la madera sino también para permitir la comprensión de los múltiples aspectos que involucran la utilización con éxito de modernos materiales que simultáneamente exhiban eficiencia hidrófuga, ignífuga y biocida, que resulten económicos, que cumplan con los requisitos para reducir la contaminación del medio ambiente y que conciencien a los organismos pertinentes a fin de conducir a legislaciones más severas que otorguen un cuidado ambiental exhaustivo sin olvidar la seguridad de la población al aplicar los materiales en el hábitat urbano.

Si bien sobre modificación química mediante silanos, se publicaron 117 artículos entre 2010 y 2016, es un tema muy estudiado pero a nivel tecnológico: la mayoría de los trabajos publicados con este tema focalizan en la funcionalidad de los silanos y los nanocompuestos en cuanto a sistemas protectores, pero no hay estudios de como este afecta a nivel microanatómico a la madera, ni como las diferentes condiciones de aplicación varían no solamente el composite final, sino también que se ubican en un espacio celular diferente, como se realizó en la presente tesis. 
Cabe destacar además que, si bien los silanos y el proceso sol- gel, así como las nanopartículas están estudiado, fue necesario retomarlo también para poder demostrar el hipotético efecto sinérgico inicial de estas dos tecnologías, lo cual pudo demostrarse a lo largo de la tesis.

Además, también se logró que todo el estudio tenga aplicabilidad a las problemáticas de protección actuales, como es el caso de protección de bienes patrimoniales. Por último, el estudio exhaustivo que presenta esta tesis en cuanto a variables de formulación, estructura de la madera (cabe destacar lo importante de partir del conocimiento completo del material a conservar para poder discernir en el mejor método) y el resultante comportamiento frente a agentes degradadores, permite que esta sea una base de conocimiento de formulación y protección de la madera y no solo un estudio acotado de algunos sistemas de protección estancos. 


\section{Capítulo I. Introducción}

I.1 La madera como material 1

I.2 Estado actual de bosques en Argentina y disponibilidad de especies 3

I.3 Importancia del uso de la madera como material 6

I.4 La madera: origen biológico 10

$\begin{array}{ll}\text { I.4.1 La pared celular } & 12\end{array}$

$\begin{array}{ll}\text { I.4.2 Composición química de la pared celular } & 17\end{array}$

$\begin{array}{ll}\text { I.5 Importancia de la preservación de la madera } & 21\end{array}$

I.6 Agentes degradadores de la madera 22

I.6.1 Agentes bióticos 23

I.6.1.1 Hongos 24

$\begin{array}{ll}\text { I.6.1.2. Bacterias } & 30\end{array}$

1.6.1.3 Insectos 31

\begin{tabular}{ll} 
I.6.1.4 Moluscos y Crustáceos & 32 \\
\hline
\end{tabular}

$\begin{array}{ll}\text { I.6.1.5 Aves } & 32\end{array}$

I.6.2 Agentes abióticos $\quad 32$

$\begin{array}{ll}\text { I.6.2.1 Humedad } & 32\end{array}$

$\begin{array}{ll}\text { I.6.2.2 Fuego } & 37\end{array}$

I.6.2.3 Acción climática y desgaste mecánico $\quad 42$

$\begin{array}{ll}\text { I.6.2.4 Radiación solar } & 43\end{array}$

I.7 Preservantes 43

I.7.1 Modificación química de la madera $\quad 47$

$\begin{array}{ll}\text { I.7.1.1 Precursores de formulación: silanos y nanopartículas } & 47\end{array}$

I.7.1.2 Polimerización: proceso sol-gel 49

I.7.2 Recubrimientos protectores 58

$\begin{array}{ll}\text { Bibliografía } & 61\end{array}$

\section{Capítulo II. Materiales y métodos}

II.1 Materiales

$\begin{array}{ll}\text { II.1.2 Madera: Especie utilizada } & 71\end{array}$

$\begin{array}{ll}\text { II.1.3 Modificadores químicos: siloxanos, silanos y nanopartículas } & 73\end{array}$

II.1.4 Agentes biodeteriorantes a ensayar: hongos xilófagos 82

II. 2. Métodos 83

II.2.1 Criterios de formulación y condiciones del proceso sol-gel elegidas 83

$\begin{array}{ll}\text { II.2.2 Probetas } & 88\end{array}$

$\begin{array}{ll}\text { II.2.3 Aplicación de los sistemas protectores } & 90\end{array}$

$\begin{array}{ll}\text { II.3 Ensayos } & 94\end{array}$

$\begin{array}{ll}\text { II.3.1 Resistencia a la acción fúngica } & 94\end{array}$ 
II.3.2 Estabilidad dimensional frente a humedad 95

II.3.3 Fuego

II.3.4 Ensayos generales

II.4 Análisis estadístico

Bibliografía

\section{Capítulo III. Resultados y discusión}

III. 1 Caracterización de la madera.

103

III. 2. 3 Estudio de la modificación química

104

III. 3 Hidrorrepelencia y estabilidad dimensional

III. 4 Resistencia al biodeterioro

140

III.5 Resistencia al fuego

153

IV. 6 Análisis global de resultados

156

Bibliografia

160

\section{Capítulo IV. Conclusiones}

Conclusiones

166

Publicaciones que enmarcan esta tesis

172 


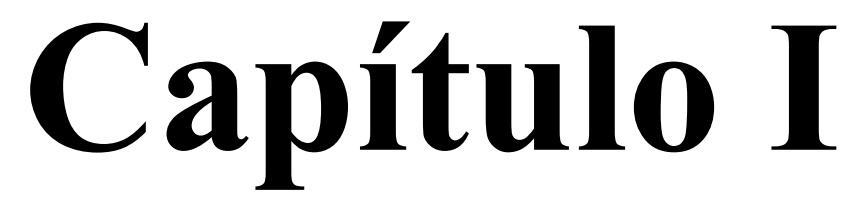

Introducción 


\section{I.1 La madera como material}

La madera es uno de los materiales más nobles con que el hombre aún cuenta para los más de 2000 millones de habitantes del planeta. Fue uno de los primeros elementos que se utilizó para la confección de herramientas, armas, navíos, viviendas, como productos primarios; y caucho, gomas, sustancias medicinales, aceites, resinas, corcho, fibras, entre otros.

Actualmente, su versatilidad es utilizada con gran diversidad de formas tanto para producir papel como para tableros de partículas o aglomerados, tableros de fibras como los MDF (Medium Density Fibreboard) o los hardboard; terciados, laminados y multilaminados entre otros. $\mathrm{Su}$ manufactura la ha transformado en casas, cercas, juguetes, muebles, instrumentos musicales, soporte de alambrados, tendidos eléctricos, telegráficos o telefónicos, decoración, etc.

Pese a la generación y evolución de otros materiales, sus características tecnológicas hacen que la madera siga siendo una materia prima imprescindible, esto se refleja en el aumento de su demanda año tras año. Estudios recientes indican que, a mayor nivel de vida de una población, mayor es el consumo de madera per cápita. En Argentina, la industria forestal cuenta con establecimientos dedicados a distintos tipos de producciones que van desde la industria procesadora de la madera, como es la del aserradero, hasta la producción de objetos más elaborados relacionados con la industria del mueble. Dentro de esta gama de actividades, la industria de la celulosa y papel y la del aserradero, son las mayores demandantes de rollizos de madera de especies cultivadas [1-3].

El problema central del uso de este material es su procedencia: cada año el área boscosa mundial va disminuyendo abruptamente. La importancia de los bosques radica en los roles que los àrboles cumplen en la naturaleza: la conservación de los suelos y la regulación climática; es el ecosistema que concentra la mayor riqueza y variedad de flora y fauna, así como los insumos necesarios para la producción de medicinas y alimentos; son reguladores de las altas temperaturas por ser fijadores de dióxido de carbono como así también poseen una gran capacidad para absorber el agua de lluvia por lo que contribuyen en una eficaz barrera contra las inundaciones [4-7].

Se conoce que en la prehistoria los bosques cubrían las dos terceras partes de la superficie terrestre, mientras que ya en la década de 1980, estudios realizados sostenían que por la acción 
del hombre sólo quedaba la mitad de dicha superficie. Lamentablemente en estos 20 años la situación ha empeorado y la deforestación y la degradación de bosques continúa en mayores proporciones. Actualmente nuestro país cuenta con una superficie de 31.443 .873 hectáreas de bosques nativos, lo que representa tan sólo el 30\% de las masas forestales originales producto del avance de la frontera agrícola y la explotación maderera, siendo las regiones más afectadas el Parque Chaqueño, la Selva Misionera y la Selva Tucumano Boliviana [8].

La gran intensidad y velocidad de explotación de bosques nativos no permite la regeneración de los bastiones ecológicos llevando a pérdidas de especies nativas invaluables e irrecuperables. Este resultado se observó principalmente en la década de 1990 con el aumento de la inversión en infraestructura, la introducción de transgénicos y siembra directa, el fenómeno de desmonte con maquinaria pesada, la ampliación de la frontera agropecuaria y la producción de soja, entre otros $[9,10]$. Esta sobreexplotación maderera junto con la ausencia de un posterior manejo recuperador llevaron a reemplazar especies nativas por cultivos agrícolas y/o por especies exóticas de crecimiento rápido (por ejemplo, pinos). Esto último generó un gran impacto ambiental debido a un cambio brusco en el ecosistema, el cual presentaba la misma fisonomía boscosa pero carente de especies de valor. Más grave aún es que esto último fue promovido mediante subsidios y créditos en los cuales se incluía el costo del desmonte.

Indudablemente, se está rompiendo un equilibrio, por ello es fundamental cuidar estos aspectos desde cualquier disciplina en la cual se trabaje ya que es necesario un aporte universal para poder revertir o mejorar esta situación. Lo mencionado no intenta decir que la madera deje de ser utilizada como material, sino que opuestamente, significa tener conciencia y utilizarlo de manera prudente, siguiendo pautas de planeamiento sustentable a la hora de explotar este recurso natural: esto debe basarse fundamentalmente en asegurar la descendencia de cada árbol cortado y en que la madera obtenida de ese árbol tenga una elevada durabilidad en servicio para así lograr un rendimiento sostenido.

Lo primero se logra con la plantación de árboles, así como se siembra los productos comestibles para luego, con el debido manejo, selección y correcto aprovechamiento, cosechar madera en cantidad, de calidad, de buen precio y lo más importante a perpetuidad. Lo segundo, se enmarca el contenido de la presente tesis y se logra mediante la utilización de tratamientos que hagan una 
madera aserrada más duradera, atacando los puntos débiles de este material como ser el deterioro por acción de agentes bióticos y abiòticos.

El presente trabajo de tesis intenta dar una solución sustentable en lo que respecta al aumento de la durabilidad de la madera. Se espera que este trabajo sea un aporte no sólo desde el punto de vista de la generación de conocimientos, sino también transferible al sector industrial.

\section{I.2 Estado actual de bosques en Argentina y disponibilidad de especies}

Según indican los datos del primer inventario forestal de bosques nativos realizado por la Secretaría de Ambiente y Desarrollo Sustentable de la Nación en el año 2002, sólo quedan en la Argentina 33 millones de hectáreas, contra los 105 millones que apuntaba el censo forestal de 1914, Figura I.1. lo grave es que el proceso de deforestación se acentuó en los últimos años: entre 1998 y 2006 la superficie deforestada fue de 2.295.567 hectáreas (lo que equivale a más de 250.000 hectáreas por año,) y sólo entre 2002 y 2006, la deforestación creció un $42 \%$ respecto a los cuatro años anteriores, debido sobre todo al avance de la frontera agropecuaria con el cultivo de soja.

Actualmente, la secretaría está trabajando en un anteproyecto de nueva normativa de promoción nacional al desarrollo sustentable de las masas forestales nativas argentinas, con el objeto de diseñar una política de incentivos sobre promoción de inversiones forestales, de crear mecanismos institucionales de participación, de aplicar las disposiciones emergentes de la Ley 13.273 en lo referente a la declaración de las formaciones nativas como bosques protectores, de generar organismos de control efectivos que impidan desvíos respecto de los objetivos propuestos

y de formar un sistema nacional de certificación voluntaria y principalmente se busca la creación de un Servicio Forestal Nacional que pueda concentrar y nuclear las actividades y cumplimiento de leyes.

Entre el 2007 y el 2009 en nuestro país se logró un gran incremento de los bosques implantados: actualmente cubren una superficie cercana a las 800.000 hectáreas y se encuentran formados en un $50 \%$ por coníferas (pinos), $30 \%$ de eucaliptos, $16 \%$ de sauces y álamos y $4 \%$ de otras 
(gmelina, pawlonia, etc.), siendo la región mesopotámica es la principal zona de bosques cultivados [8-10], Figura I.2.

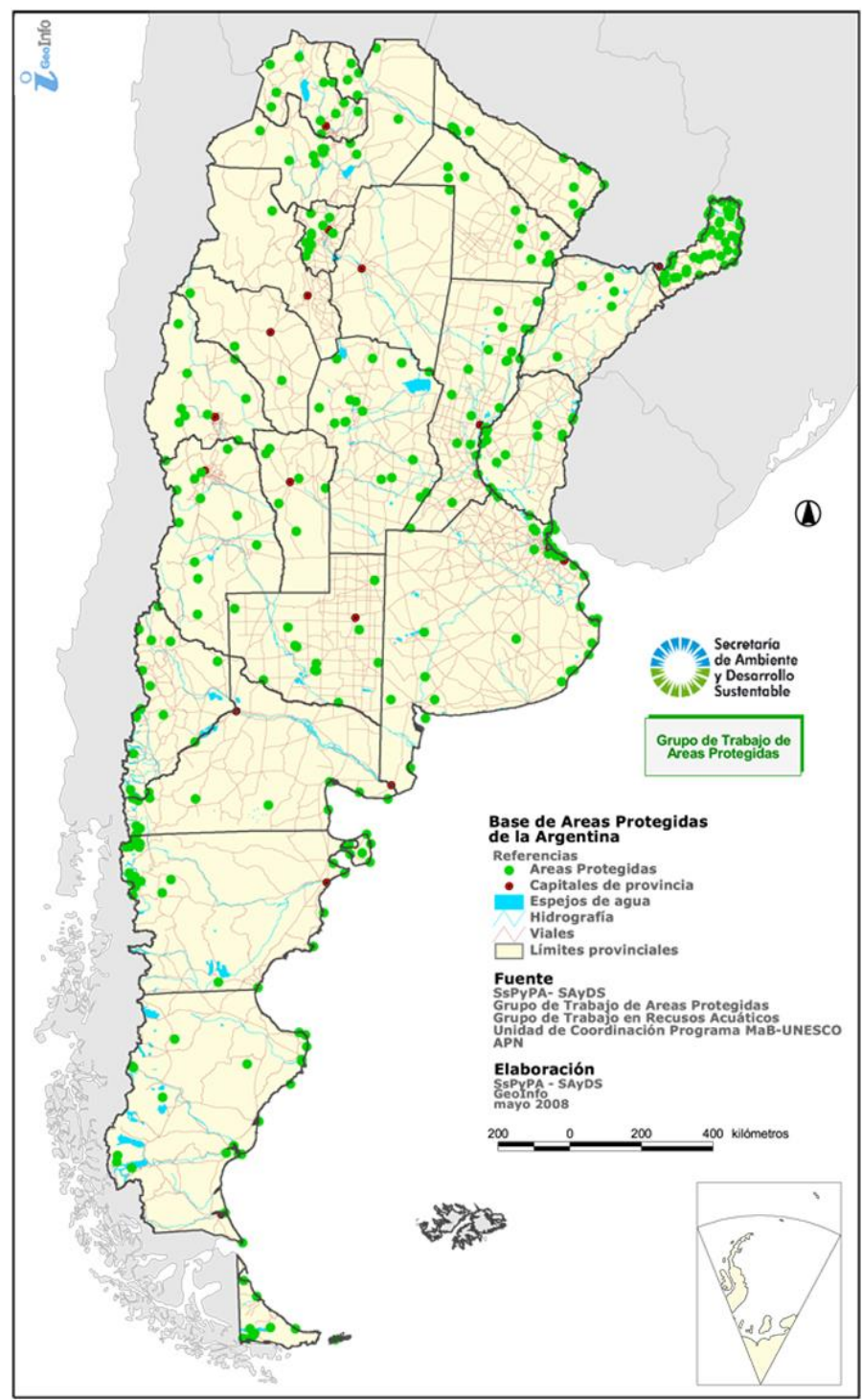

Figura I.1. Mapa de la Argentina en el cual se muestra con puntos verdes las áreas actualmente protegidas. Se observa que la provincia que más áreas protegidas tiene es Misiones, siendo una de las provincias con más actividad maderera.

La actividad forestal màs importante del país se encuentra en la provincia de Misiones, sus bosques de cultivo están basados principalmente en especies de coníferas, teniendo la principal concentración de pinos cultivados del país (se han implantado màs de 200.000 hectáreas de 
coníferas); las variedades principales son los pinos norteamericanos Pinus elliottii Engelm y Pinus taeda L y desde hace algunos años el híbrido entre Pinus elliottii var. elliottii y Pinus caribaea var. Hondurensis, Pinus ponderosa y Araucaria angustifolia conocidos como Araucaria misiónense, Pino Paraná o Brasil o curý. Por otra parte, las plantaciones de eucalipto registran muy elevadas tasas de crecimiento; las especies más comunes son Eucalyptus grandis y Eucalyptus dunnii. Otras especies cultivadas en la provincia son el paraíso (Melia azedarach) y el kiri (Paulonia fortunei) [8-11].

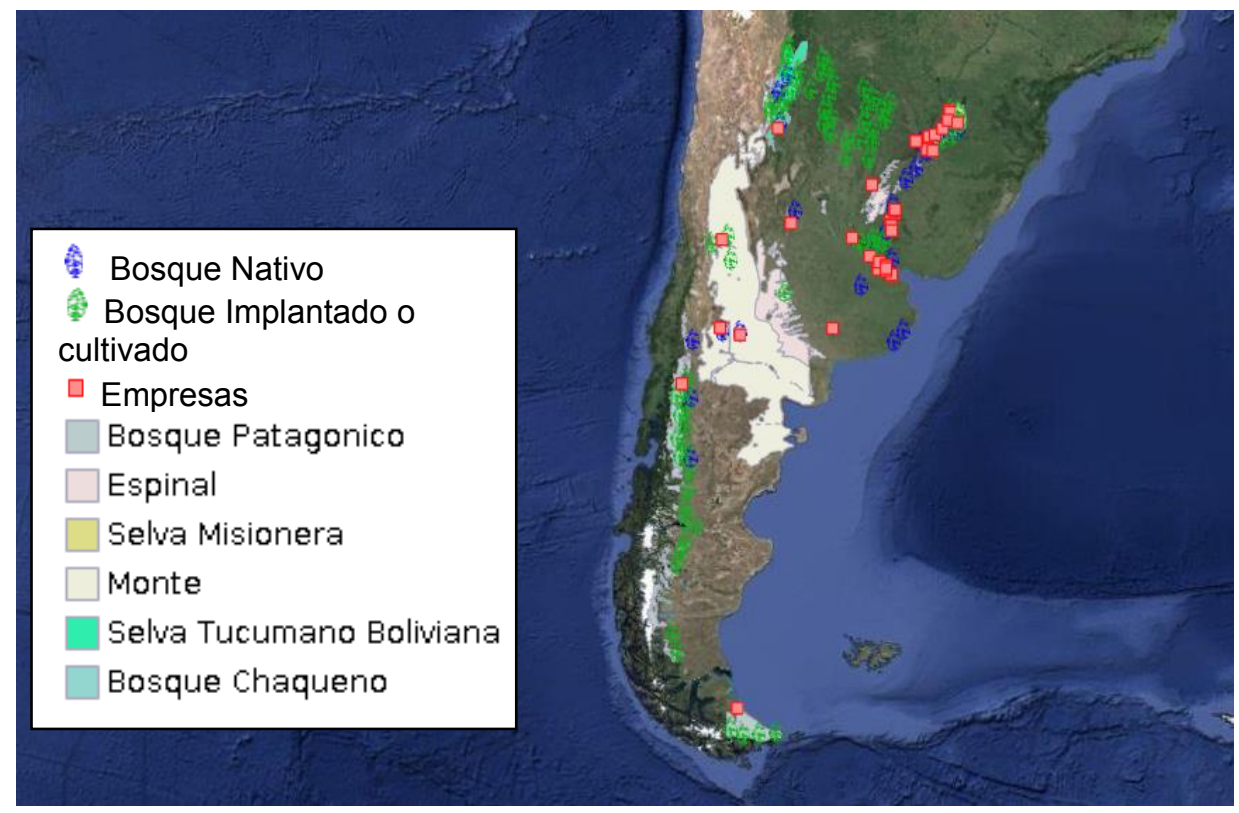

Figura I.2. Mapa de la Argentina en el cual se muestra la distribución de bosques y empresas: azul para los bosques nativos, verde para los implantados y rojo para las empresas. En este se observa la mayor cantidad bosques implantados respecto a de bosques nativos así como también una concentración estratégica empresarial según disponibilidad de áreas explotables.

La zona del litoral, a orillas del río Uruguay, que bordea las provincias de Corrientes y Entre Ríos se caracterizan por sus suelos arenosos los cuales son ideales para el cultivo de eucaliptos (Eucalyptus grandis) y pinos. En el valle de Calamuchita, provincia de Córdoba existe más de 30.000 hectáreas de bosques de pinos cultivados (Pinus elliottii) y diversas especies de pino mexicano. En el noroeste argentino, que abarca las provincias de Jujuy, Salta y Tucumán las tierras son aptas para la plantación de pinos mexicanos (Pinus patula y Pinus greggi) y también para Pinus taeda y algunas especies de eucaliptos [8-11]. 
En la provincia de Buenos Aires, las implantaciones forestales se han realizado para la protección de los cultivos o en pequeños lotes para la producción de madera donde en general abundan varias especies de eucaliptos, pero, con una producción insuficiente para satisfacer la demanda de la industria. En la zona del Delta del Paraná, cercana a los importantes mercados de Buenos Aires, se han implantado álamos y sauces, particularmente en las islas Delta donde diques de contención aseguran un óptimo nivel de agua para el crecimiento forestal [8-11].

La Patagonia posee más de un millón de hectáreas aptas para la forestación, siendo la región de mayor potencial se sitúa cerca de la frontera con Chile, donde se pueden plantar especies como el Pinus ponderosa, el Pinus contorta y el Pseudotsuga menziesii, con una producción a costos relativamente bajos. También se encuentra especies de Araucaria o Pehuén (Araucaria araucana), también llamada piñonera, pino araucaria o pino de brazos (árbol nativo de Chile y Argentina) que hoy en día se encuentra distribuido en zonas muy restringidas de la Cordillera de los Andes y en una pequeña población de la Cordillera de la Costa chilena. En esa zona, se han relavado araucarias de hasta 1.000 años de edad [8-11].

Por último, respecto a las especies de madera más utilizadas en la cadena de valor industrial el Pino, el Eucalipto y el Cedro siguen siendo las más elegidas por los industriales de nuestro país. Es por ello que en la presente tesis se trabajó con coníferas, específicamente con Pinus ponderosa por su gran impacto industrial $[8,11]$.

\section{I.3 Importancia del uso de la madera como material}

Enfocado en satisfacer la demanda de los consumidores de madera, desde hace varios años un sector de la ingeniería de los materiales trabaja para mejorar procesos y desarrollar productos con valor agregado que mantengan, mejoren e incrementen el sector de la industria forestal. Asímismo han surgido numerosas innovaciones con el fin de aunar las ventajas de emplear productos de madera frente a otros materiales, satisfaciendo las necesidades de la industria de la construcción y de los consumidores [12].

En el campo de la ingeniería, se toma un material para construir un producto con un proceso industrial perfectamente planificado con el fin de lograr prestaciones estructurales, dimensionales, 
térmicas y/o de apariencia. En el marco de la ingeniería de los materiales está implicada también la modificación o tratamiento de estos para mejorar su performance en servicio. Específicamente para la el éxito de la ingeniería aplicada en maderas se debe optimizar la calidad de los productos provenientes de los recursos forestales desde el momento de la roda [12-13].

Los productos de madera en el mercado incluyen productos decorativos (suelos, armarios, muebles, carpintería, revestimientos, etc.), productos remanufacturados o prefabricados estructurales (vigas, paredes, forjados, paneles aislantes) y otros usos aplicados en la construcción provenientes de productos intermedios del proceso de industrialización de madera como ser madera aserrada (parquets, muebles, molduras y torneados), laminados y enchapados (para revestir paneles, terciados, aglomerados o placas), compensados (que se obtienen a través de la unión de dos o más láminas), tableros de partículas (también denominados aglomerados), tableros de fibras (aglomerados con diferente grado de procesamiento), etc.

La ingeniería o tecnología de productos de madera ha experimentado un gran auge en los últimos años, con grandes innovaciones en las principales líneas de aplicaciones: laminados, chapas de frondosas y coníferas, contrachapado o madera terciada, tablero LVL (del inglés Laminated Veneer Lumbre) o chapas de madera laminadas, OSB (del inglés Oriented Strand Board) o tableros de fibra orientada y MDF (del inglés Medium Density Fibreboard) o Fibrofácil [14].

La evolución del sector industrializado de la madera presenta una gran correlación con la del sector forestal: las fábricas más importantes poseen plantaciones forestales propias para abastecerse de sus insumos y concentran un gran porcentaje de la producción nacional. Estos junto a los pequeños y medianos productores instalados hace años en las principales provincias madereras del país, son parte de un sector de fuerte capitalización nacional [15-18]

Actualmente, en el marco de la realización de construcciones sustentables con el medioambiente, han aumentado los estudios y técnicas para realizar construcciones de viviendas realizadas completamente en madera [19-23]. Las casas de madera presentan la ventaja de ser una opción de viviendas más económica y más rápida de fabricar que el sistema de construcción tradicional , lo cual es un aporte importante en el ámbito social principalmente porque este tipo de construcción disminuye el impacto ambiental con respecto a otros productos como el aluminio, hierro, cemento, ladrillos, plásticos, entre otros. También, se la considera más ecológica que la 
construcción convencional debido a que no se utilizan materiales derivados del petróleo o de la minería, y además, la madera es un material que puede biodegradable y reciclable.

Desde el punto de vista económico, el costo de la construcción de una vivienda con materiales convencionales equivaldría a la construcción de tres viviendas de madera de iguales dimensiones y prestaciones. En caunto a tiempos, con el lapzo que se tarda en edificar una vivienda de material, se terminan cuatro de madera.

En esta conjunción de aspectos económicos, sustentables y cuidado del mediambiente, también es relevante mencionar que las viviendas de madera poseen una aislación seis veces mejor que una de ladrillo, lo que implica ahorro de energía en calefacción y refrigeración, ni olvidar el ahorro de energía en la producción de los materiales empleados.

Desde hace varios años, el INTA Concordia viene trabajando en el diseño de este tipo de casas junto con la Universidad Tecnológica Nacional, Facultad Regional Concepción del Uruguay y cuentan además, con el "know-how" que adoptó tras capacitarse en el EMOICQ de Canadá (École des Métiers et Occupations de l'Industrie de la Constructions de Quebec), cuyos profesionales son especialistas líderes en este tipo de actividad y en un país donde el $90 \%$ de las viviendas son de madera, con construcciones de hasta seis pisos. Estas viviendas ya cuentan con el Certificado de Aptitud Técnica (CTA), que extiende la Subsecretaría de Vivienda de la Nación.

La última tendencia en construcción de madera en nuestro país es la de ladrillos fabricados con este material [21-24]. El sistema permite la construcción de una vivienda y se conoce como BME (Bloques de Madera Encastrados), Figura I.3. En este tipo de construcción, los bloques o ladrillos se superponen unos a otros unidos a través de listones, tarugos de madera y clavos metálicos, lo que garantiza una perfecta vinculación formando un entramado de madera y metal que finalmente se transforma en las paredes de la vivienda. Posteriormente, la madera es protegida con sellador de juntas elásticas asegurando la ausencia de filtraciones de aire.

Estos bloques son fabricados con madera de forestaciones de Pinus ponderosa en la Patagonia argentina; las principales ventajas que presenta su utilización son la rápida construcción, la resistencia en paredes portantes y no portantes, la disminución en las cargas de la edificación, no utiliza agua por lo que lo se obtiene una construcción con menor carga de humedad, ahorra 

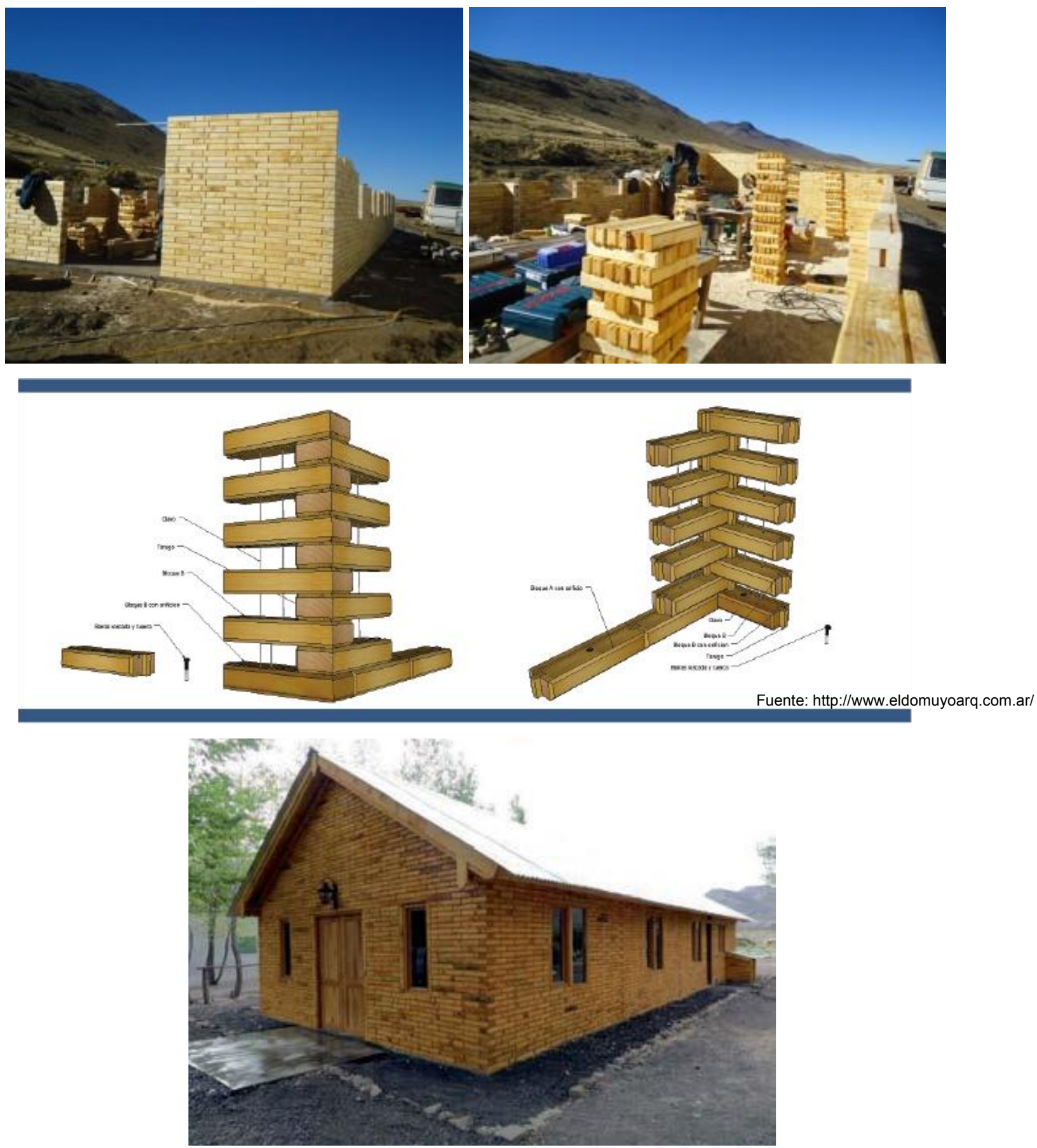

Figura I.3. Tecnología de construcción con Bloques de madera encastrados (BME): los bloques o ladrillos se superponen unos a otros unidos a través de listones, tarugos de madera y clavos metálicos, lo que garantiza una perfecta vinculación formando un entramado de madera y metal que finalmente se transforma en las paredes de una vivienda Construcción en seco con estos ladrillos en Colipilli, Neuquén. Gza. Corfone S.A 
tiempos en la construcción ya que no hay que esperar el fraguado de los materiales, reduce sustancialmente la generación de desperdicios en obra, reduce el esfuerzo físico del los obreros y por lo tanto las horas hombre, entre otros. Además, otorga beneficiosas cualidades a las edificaciones como la obtención de muros robustos, térmicos, acústicos, antisísmico, estéticos por las vetas naturales de la madera, no condensa la humedad, durables y son de fácil mantenimiento (por ejemplo, barnizado).

Es importante remarcar que, con el aumento de la tecnología de la madera, es fundamental que rijan entes que certifiquen el uso de la misma y controlen la explotación de este recurso natural. Es decir que mediante prácticas cada vez más sustentables y certificadas por sostén ambiental, social y económico, garantizan acceder a un producto renovable y reciclable [24-26].

\section{I.4 La madera: origen biológico}

La madera es un material natural, un recurso renovable, posee un ciclo de vida cerrado, es decir, es reciclable, en su constitución almacena carbono y es un material que permite su tecnificación.

Las características de la madera varían según la especie del árbol origen e incluso dentro de la misma especie por las condiciones del lugar de crecimiento. Aun así, hay algunas características cualitativas comunes a casi todas las maderas: es un material anisótropo (sus propiedades varían según la dirección de las fibras en muchas de sus características, por ejemplo, en su resistencia o elasticidad, esta en el eje axial es de 20 a 200 veces mayor que en el eje transversal), ortótropo (la elasticidad depende de la dirección de deformación) e higroscópico (puede absorber humedad tanto del ambiente como por inmersión en agua, en distinta forma y cantidad dependiendo de la dirección de las fibras) [28-30].

Además, la madera es un material polar con lo cual lo hace fácilmente tratable con sustancias polares tales como agua, barnices y pegamentos de base acuosa. Este material, tiene la particularidad de presentar propiedades físico-mecánicas muy buenas (densidad, resistencia a la compresión, flexión, corte, etc.). Esto hace que pueda ser trabajada manualmente o con maquinaria de manera satisfactoria. Los tonos y variantes de corte le proveen aspecto estético muy agradable [28-30]. 
La estructura microscópica es una parte fundamental que hay que entender, conocer y saber a la hora de utilizar la madera como un material. El conocimiento celular, en cuanto a estructura y función, permite conocer las virtudes y debilidades de este material, como así también es lo fundamental para el diseño de tratamientos protectores.

El tejido del tronco, raíces y ramas (madera) está formado por el conjunto de células que forman el tejido xilemático o xilema. Lejos de tratarse de una unidad homogénea, la xilema está formado por un conjunto de células morfológicamente muy diferentes, cuya organización varía de unas especies a otras y especialmente entre coníferas y frondosas, Figura I.4. Estas células son un conjunto de elementos lignificados, denominado traqueidas o vasos respectivamente. Estos elementos celulares son centrales en el estudio de la madera como material, ya que son los responsables de la estabilidad dimensional y de la susceptibilidad a la degradación por distintos agentes que presenta este material.
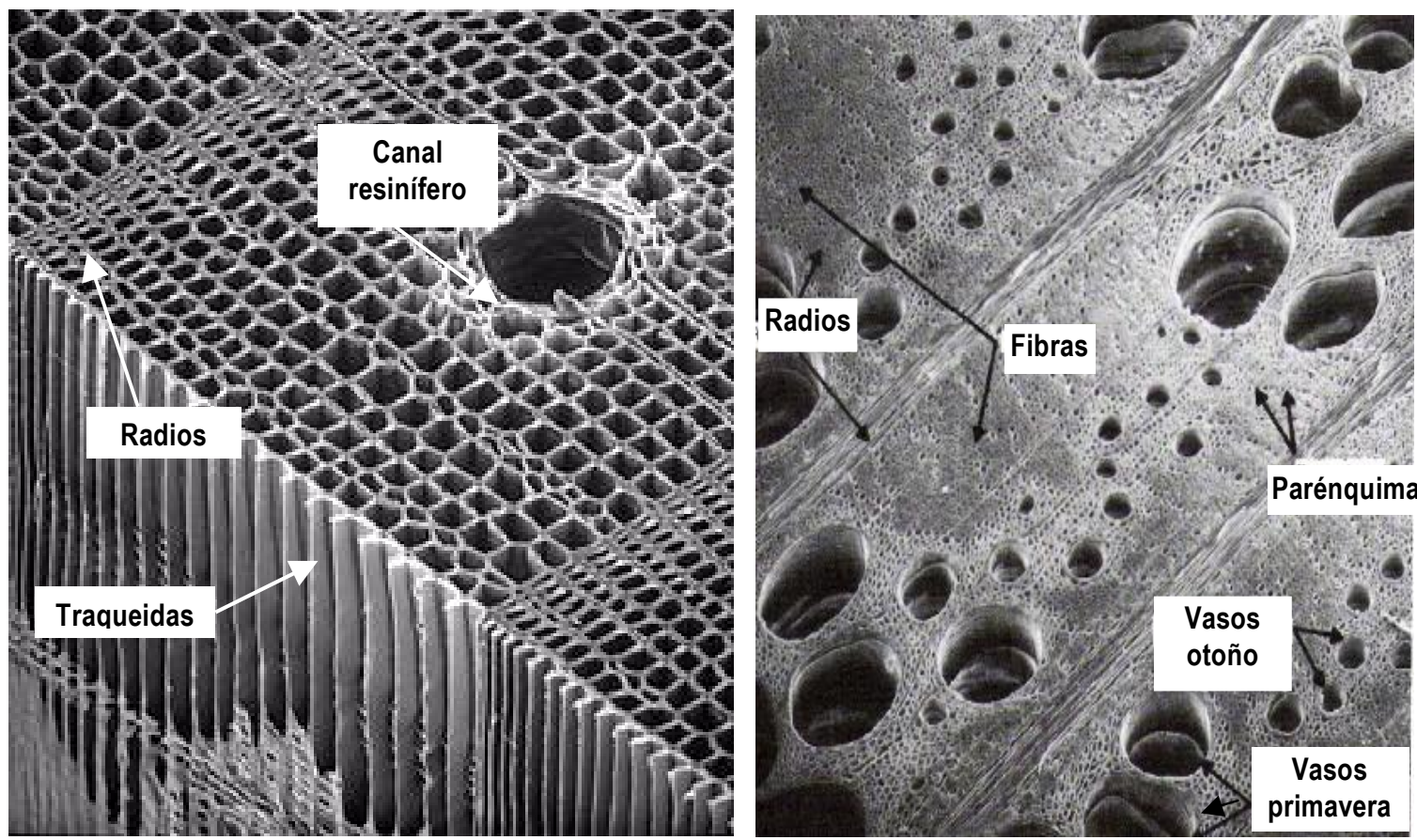

Fuente: Clase Dr. Luis Acuña Rello (2014)

Figura I.4. Microscopía electrónica de madera de conífera (izquierda) y una madera de angiosperma (derecha): Nótese la diferencia estructural entre ambas, una presenta un patrón muy homogéneo (las células que integran el cámbium vascular son únicamente traqueidas) mientras que la otra es heterogénea (dado por diferentes tipos celulares que integran el tejido vascular) tanto intra como interespecificamente, lo cual es muy relevante al estudiar la madera como material. 
Las Gimnospermas difieren botánica y estructuralmente de las Angiospermas: el leño de las Gimnospermas (coníferas) es homogéneo, y el de las latifoliadas o angiospermas es heterogéneo. Esta gran diferencia hace que la madera como material de estas dos clases sea tan diferente. Esto es así porque la madera es el xilema secundario, por lo tanto, la estructura descripta es la estructura microscópica del material. Lo descripto anteriormente remite a que cualquier tratamiento que se elija tiene que ser pensado en que se va a interactuar con estas características, es por eso que la relevancia de este capítulo radica en conocer con profundidad la anatomía biológica de la madera. En la citada figura se observa el patrón homogéneo, que se menciona en la introducción de este capítulo, esto es beneficioso en cuanto al diseño de tratamientos y su posibilidad de extrapolación a otras especies pertenecientes a coníferas sin necesidad de ensayarlas.

La especie elegida para realizar este trabajo pertenece al grupo de las coníferas son árboles de crecimiento rápido y baja densidad siendo maderas fáciles de trabajar y de escasa resistencia a la degradación. Son bastante más económicas que las maderas duras, por eso su uso es tan extendido en la construcción, en la carpintería o en la fabricación de papel y de tableros de fibras.

\section{I.4.1 La pared celular}

Conocer su estructura y su composición química de la pared celular es fundamental en el ámbito de la protección de madera, ya que, de manera minimalista, se puede definir a la madera como un conjunto de células en tándem; por lo cual saber la composición química de una célula es saber la composición de la madera en su totalidad.

Además, esto nos define que grado de susceptibilidad tendrá este material frente a distintos agentes deteriorantes: saber su composición también ayudará a entender los fenómenos de deterioro y es lo que ayudará a generar herramientas para determinar rápidamente cuando una madera es susceptible a ser degradada o en que estado se encuentra la misma dentro de una estructura. 
Las células que forman el xilema son las responsables del comportamiento en servicio de la madera: son las responsables de la absorción de agua, de la resistencia mecánica, fuente de alimento para muchos organismos, etc. [31-39].

La pared celular es una envoltura semirígida que rodea externamente a la membrana plasmática de las células de las bacterias, algas, plantas y hongos. En cada grupo tiene diferente composición química y estructura. En la planta las principales funciones que esta presenta es la de soporte mecánico y estructural de la planta, determinación y mantenimiento de la forma de la célula y de la planta entera ya que actúa como el "esqueleto" de las plantas, determinación la dirección del crecimiento, regulación del volumen celular por ejercer presión de turgencia, protegen contra ataque de patógenos y la deshidratación [31-39].

La formación de la misma está dada por el comienzo de la división celular cambial (meristema), alargamiento y crecimiento radial, estiramiento de la pared celular primaria, formación de la pared celular secundaria y muerte de la célula por la pérdida de protoplasma. Durante la citada división se determinan varias capas, debido a la diferenciación celular, desde adentro hacia afuera de la membrana plasmática, Figura I.5:

- Laminilla media: Es la primera estructura que aparece durante la división celular. Es el lugar que une las paredes primarias de dos células contiguas; es de naturaleza principalmente pectínica, pero a menudo, en las células más viejas se lignifica [31-39].

- Pared celular primaria: Relativamente flexible y extensible. Se forma durante el crecimiento, usualmente mide entre 100 y $200 \mathrm{~nm}$ de espesor y es producto de la acumulación de 3 o 4 capas sucesivas de microfibrillas de celulosa [31-39].

- Pared celular secundaria: es sintetizada cuando la célula deja de crecer y ser biológicamente activa. Es la capa adyacente a la membrana plasmática. Esta posee mayor rigidez, durabilidad y está formada por un depósito de microfibrillas de celulosa en la pared primaria una vez que esa célula deja de estar viva; esta disposición que toman permite distinguir 3 capas. Estas tres capas se designan como $S_{1}, S_{2}$ y $S_{3}$ y forman la pared secundaria de la célula, Figura I.6. En las células del xilema (traqueidas y 
elementos de vaso), las paredes secundarias se encuentran muy engrosadas debido su lignificación [31-39].
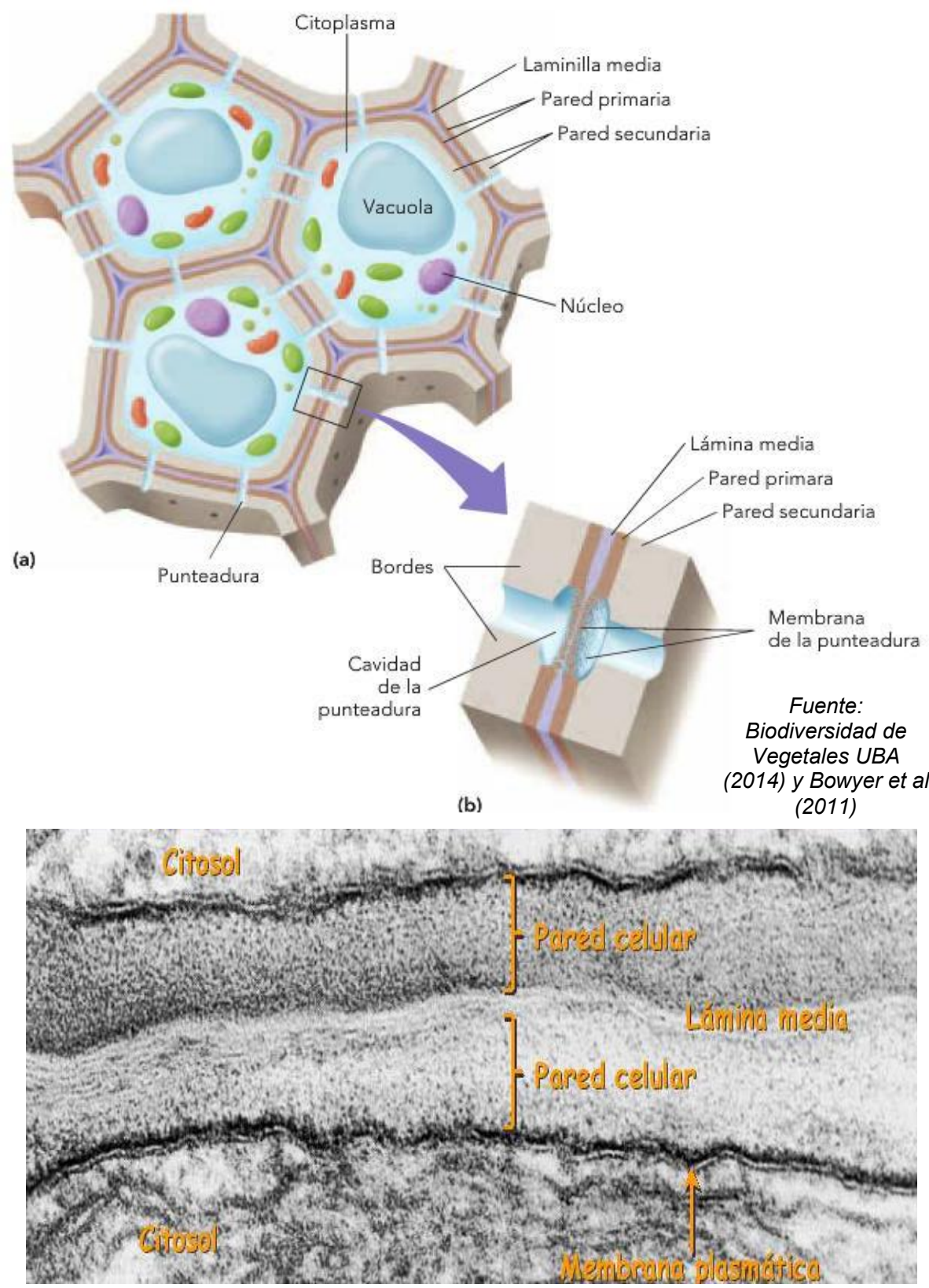

Figura II.5. Pared secundaria de una célula vegetal, arriba se muestra esquemáticamente la estructura celular y donde se encuentra ubicada las mencionadas capas que la forman; abajo microscopia de estas capas donde se diferencias claramente unas a otras. 

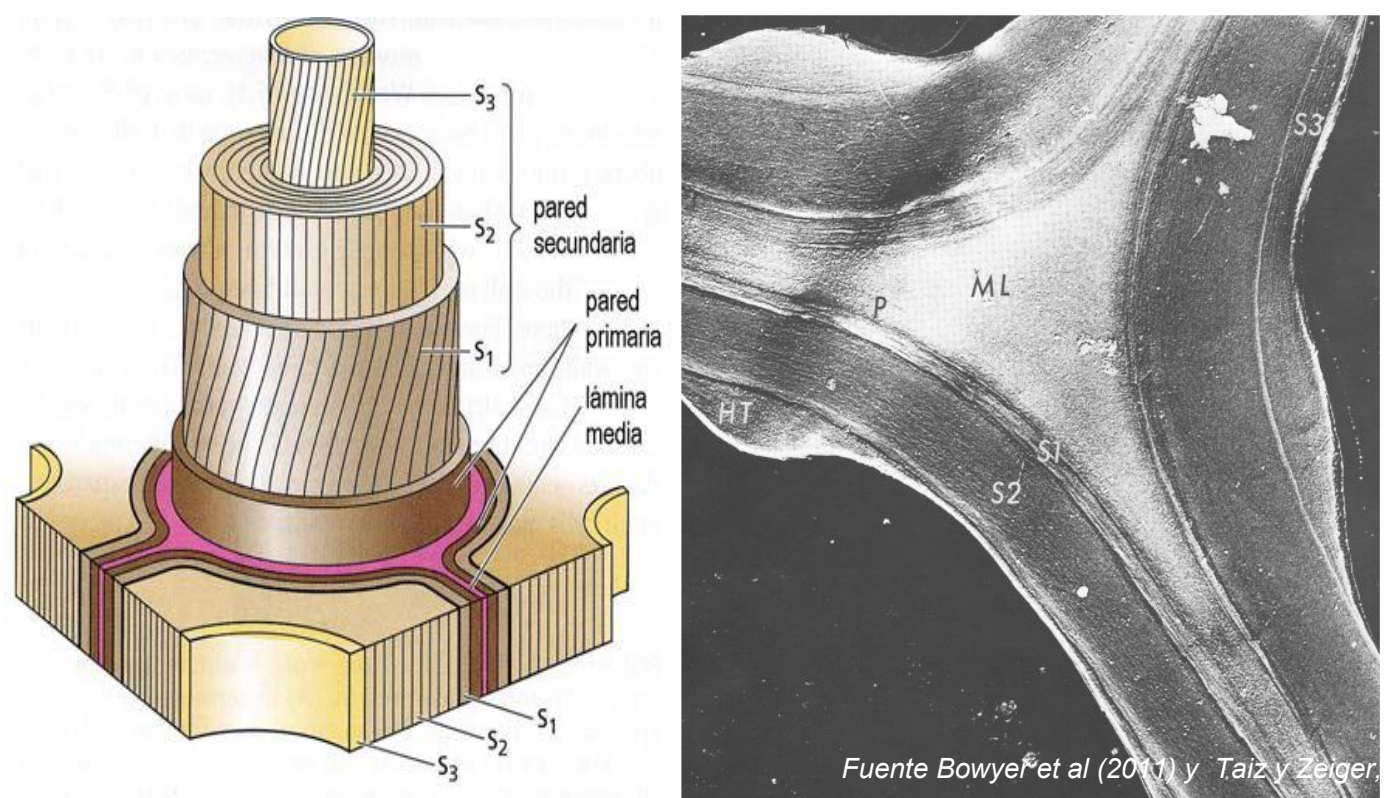

Figura I.6. Izquierda, diagrama de la estructura de la pared celular de las traqueidas y otras células que presentan pared celular gruesa. S1, S2 y S3 corresponden a las tres capas de la pared secundaria que se forman en el interior de la pared primaria. La lámina media está formada por material amorfo, con alto contenido en ligninas y mantiene unidas a las células adyacentes. Derecha, microscopía donde se observan las capas mencionadas (ML, lámina media; $P$, pared primaria, HT, engrosamiento helicoidal)

Centrándonos en la pared secundaria, las tres capas mencionadas están constituida por microfibrillas de celulosa orientadas de diferente manera en cada capa que, a su vez, están rodeadas y se mantienen ligadas entre sí por moléculas de hemicelulosa y ligninas, Figura I.7: En la capa $S_{1}$ de la pared secundaria (la más externa de las tres) las microfibrillas se orientan de manera más precisa disponiéndose paralelamente entre sí y con cierta inclinación respecto del eje longitudinal de la célula. En la capa S2, la más gruesa de las tres capas, las microfibrillas se disponen paralelas entre sí y discurren casi paralelas al eje longitudinal de la célula. En la capa más interna, la denominada S3, las microfibrillas, de nuevo paralelas entre sí, vuelven a orientarse con cierta inclinación respecto del eje de la célula y, en consecuencia, la separación de la pared secundaria en capas resulta principalmente de la orientación de las fibrillas: en una casi horizontal, en la siguiente casi vertical, y en la tercera nuevamente casi horizontal [28-36]. 

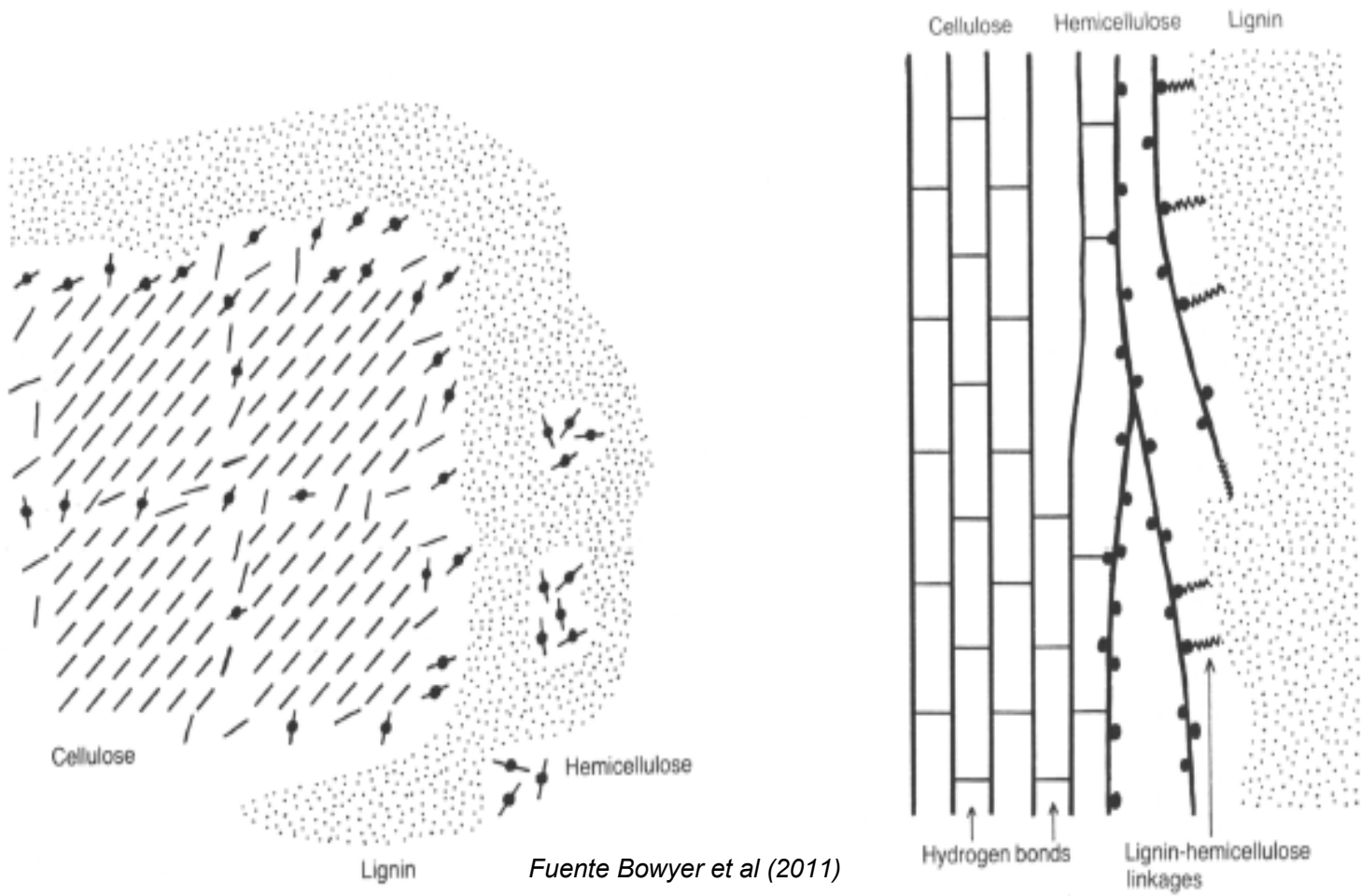

Figura I.7. Microdistribución de los componentes de la pared celular: si se tratara de un composite, la celulosa actuaría como las fibras, la lignina como la matriz y la hemicelulosa como agente aglutinante.

A diferencia de la secundaria, en la pared primaria las microfibrillas forman una capa más o menos tenue en las que se hallan irregularmente orientadas, mientras que las hemicelulosas revisten las fibrillas de celulosa y cristalizan con ella, uniéndolas Figura I.8. Por otra parte, se encuentran los mucílagos de la pared celular son especialmente ricos en polisacáridos no celulósicos que terminan de formar el composite.

En referencia a los compuestos pectínicos de la laminilla media, estos están formados por moléculas de ácido pectínicos unidas entre sí mediante puentes de $\mathrm{Ca}^{2+}$.

Por último, como en todas las membranas, se encuentran proteínas de la pared son ricas en los aminoácidos serina e hidroxiprolina, y están ligadas con azúcares como arabinosa, glucosa y galactosa. Se cree que dichas glucoproteínas actúan como elementos estructurales, porque forman cadenas que pueden ligar entre sí otros componentes. 


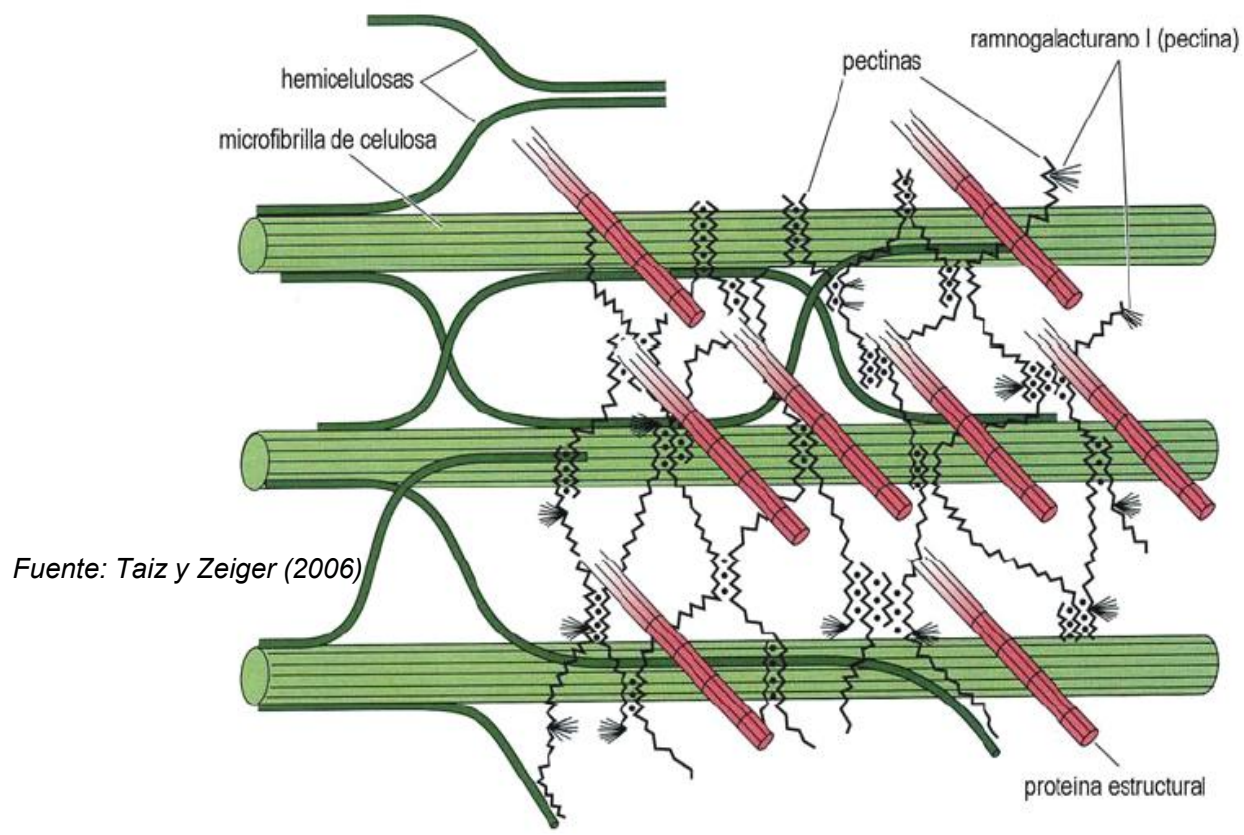

Figura I.8. Esquema de los principales componentes estructurales de la pared primaria y de su posible organización. Las microfibrillas de celulosa se unen entre sí mediante hemicelulosas que las mantienen unidas. Las pectinas forman una matriz que confiere resistencia al conjunto.

\section{I.4.2 Composición química de la pared celular}

Como se mencionó anteriormente la composición química y orientación microfibrilla difieren en cada una de estas capas: una capa está compuesta por microfibrillas de celulosa y lignina unidos por hemicelulosa, una pared celular primaria compuesta principalmente de pectina (hidrato de carbono complejo relacionado con hemicelulosa) y microfibrillas de celulosa.

Las paredes celulares vegetales están constituidas por un componente cristalino o porción fibrosa (esqueleto) y un componente amorfo (matriz no fibrosa) altamente hidratado, semejante a un gel. Esta estructura se parece a la de las fibras de refuerzo, en los cuales las fibras cristalinas rígidas se usan para reforzar la matriz epoxi más flexible tal como se presenta en la Figura I.7.

En este composite, loc compuestos químicos màs relevantes $\mathrm{y}$ los que definen el comportamiento de la madera son la hemicelulosa, la celulosa y la lignina, Figura I.9. 


\section{- Componente cristalino}

Está representado por las cadenas celulósicas que pueden alcanzar $4 \mu \mathrm{m}$ de longitud (cadenas lineales de enlaces covalentes 1-4 $\beta$ D glucosa que, debido a la alterna configuración espacial de las cadenas glucosídicas, la unidad repetitiva de la celulosa es la celobiosa, un enlace disacárido $1 \rightarrow 4$ B-D glucosa), dispuestas de modo ordenado mediante enlaces puente hidrógeno, formando una estructura cristalina o paracristalina (que contiene algunas regiones no cristalinas). Esos enlaces le otorgan propiedades cristalinas, rigidez y fortaleza a la pared y suministran resistencia contra las fuerzas de tensión, además de hacer que la celulosa sea muy difícil de hidrolizar (inaccesible al ataque enzimático). En la pared primaria las fibrillas están entrelazadas, dispuestas aparentemente al azar mientras que en la pared secundaria están dispuestas paralelamente, Figura I.8.

\section{- Matriz de la pared celular}

Está compuesta por tres tipos de macromoléculas: hemicelulosas, pectinas y glucoproteínas estructurales. Puede lignificarse. Las hemicelulosas son polisacáridos no celulósicos flexibles (xilanos, glucanos, galactanos, mananos, fructanos, xiloglucanos, glucomananos, arabinoxilanos, calosaglucanos) compuestos producidos por los dictiosomas. Revisten las fibrillas de celulosa y cristalizan con ella, uniéndolas.

Las hemicelulosas, por lo tanto, forman cadenas (sogas) que atan a las microfibrillas de celulosa juntas formando una cadena cohesiva, o bien actúan como un revestimiento resbaladizo que impide el contacto directo entre microfibrillas. Las microfibrillas se combinan mediante las hemicelulosas, éstas se unen químicamente a la celulosa formando una estructura llamada macrofibrilla de hasta medio millón de moléculas de celulosa en corte transversal. Esta estructura es tan sólida como la del concreto reforzado, Figura I.7.

La hemicelulosa y las pectinas (homogalacturonanos, rhamnogalacturonanos, arabinanos, galactanos) contribuyen a unir las microfibrillas de celulosa, al ser altamente hidrófilas contribuyen a mantener la hidratación de las paredes jóvenes. Las pectinas forman una fase "gel" en la cual la cadena de celulosa-hemicelulosa está embebida. Esto determina la permeabilidad de la pared celular a las macromoléculas. 
En la pared primaria es dominante la matriz amorfa, formada por hemicelulosas y polisacáridos no celulósicos. Está compuesta, sobre la base del peso seco, por aproximadamente $25 \%$ de hemicelulosa, $35 \%$ de pectinas y 1-8 \% de proteínas estructurales. La fase fibrilar está reducida al $8-25 \%$ de celulosa. También la pared primaria contiene mucha agua que se localiza mayoritariamente en la matriz (que está compuesta por un 75-80\% de agua).

En la pared secundaria domina la fase fibrilar (celulosa, 60\%) y la matriz amorfa está formada por hemicelulosas y lignina $(30 \%)$, los compuestos pectínicos y las proteínas prácticamente desaparecen.

La estructura en que se presenta la celulosa hace que sea muy estable y sólo se colapsa en momentos específicos del desarrollo, como la senescencia o la abscisión. Solamente algunas bacterias, hongos y protozoos pueden degradar la pared celular, ya que tienen el sistema de enzimas necesario.

\section{- Modificaciones de la pared celular}

Las modificaciones de la pared no afectan la apariencia de las células sino las propiedades físicas y químicas de las paredes. Las sustancias adicionales se depositan por incrustación. La incrustación (= intususcepción) es la intercalación de nuevas partículas entre las existentes en la pared.

Este preceso sucede porque la celulosa por si sola es resistente a la tensión, pero no soporta la compresión. Es por ello que en las células de sostén (madera) hay siempre incrustación en la matriz o fase amorfa de sustancias que la endurecen como, por ejemplo: lignina y compuestos minerales [30, 40-42].

La Lignina es uno de los componentes más importantes de la pared secundaria, y después de la celulosa, el polímero vegetal más abundante, Figura I.9. La pared secundaria tiene $2 / 3$ de celulosa y 1/3 de lignina. Aumenta la resistencia mecánica. Pueden lignificarse paredes secundarias, primarias y laminilla media. Es un polímero de cuerpos fenólicos (monolignoles) que son exocitados por dictiosomas. Se entrelazan en una red tridimensional alrededor de las 
microfibrillas por la acción de las proteínas enzimáticas que se encuentran en la membrana plasmática.
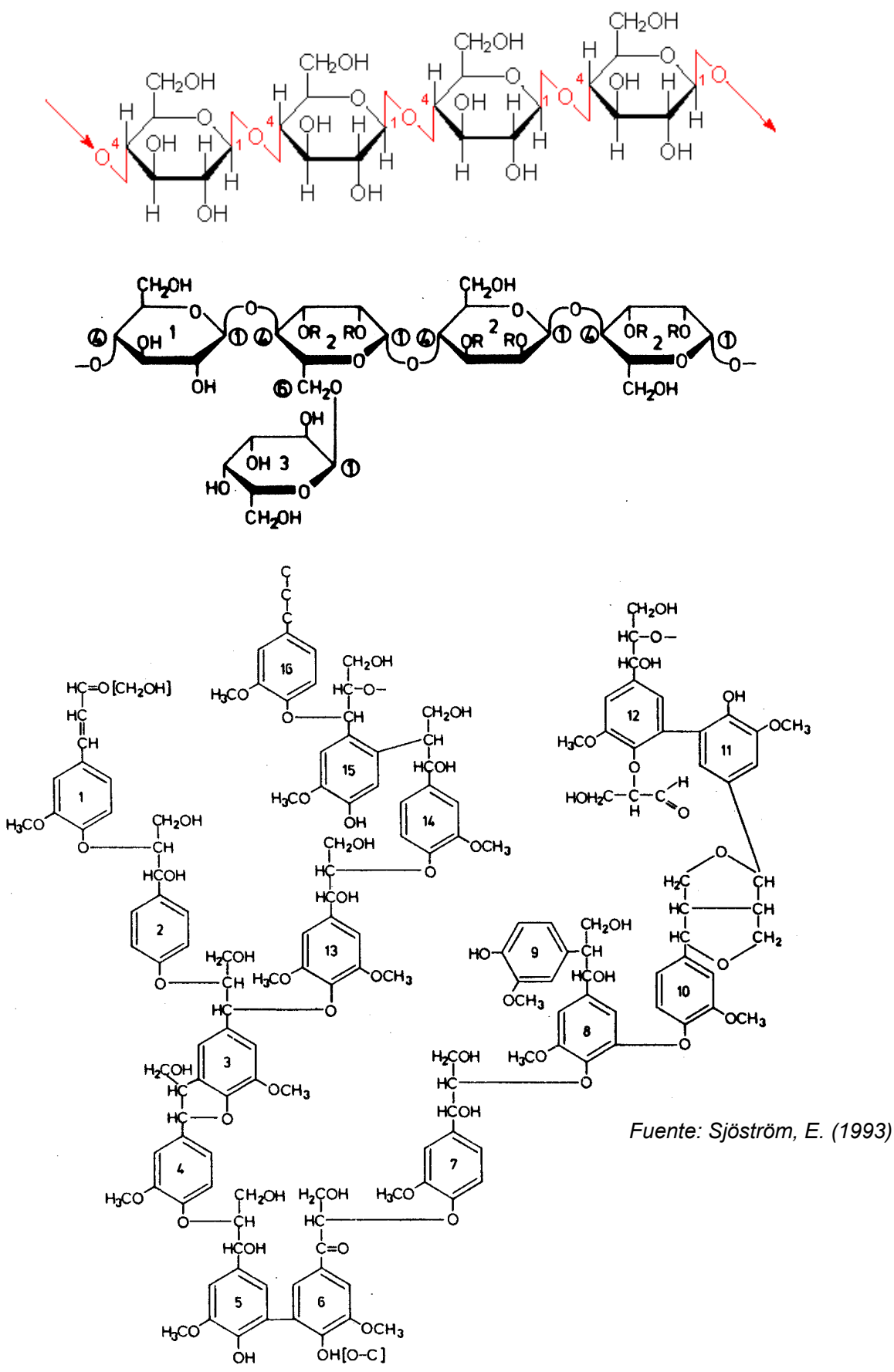

Figura I.9. Estructura química de los principales componentes de la pared celular Arriba, celulosa, medio hemicelulosa (Galactoglucomananos). Abajo lignina de coníferas. 


\section{I.5 Importancia de la preservación de la madera}

Se entiende como preservación de maderas al conjunto de técnicas que aplican sustancias protectoras para evitar que sean afectadas por agentes deteriorantes. Las ventajas de utilizar estas técnicas incluyen el aprovechamiento de maderas de menor valor por su baja durabilidad natural lo que permite el ahorro de maderas de especies nativas; utilizar especies de bosques cultivados de rápido crecimiento disminuyendo así la presión sobre los bosques nativos y aumentar la vida útil de maderas ahorrando divisas e incrementando los recursos forestales lo cual implica mayores beneficios ambientales [43-45].

Una de las características más importantes al utilizar un material con cualquier fin es su durabilidad. La durabilidad es la propiedad de permanencia de la estabilidad física y química o de sus características originales frente a la acción de distintos agentes degradantes, a lo largo del tiempo [46-48].

La durabilidad en maderas depende de distintos factores tales como [49-54]:

(i) las características de la albura: parte rica en azúcares y almidones lo cual la hacen más susceptible al ataque fúngico y al ataque de insectos

(ii) las características del duramen: posee sustancias antisépticas y/o extractivos inhibidores para el desarrollo de estos organismos, y/o presencia de tílides (latifoliadas) y obstrucción de punteaduras por desplazamiento de toros (coníferas) los cuales son preservantes naturales de la madera (su presencia y/o concentración depende de las de las presiones ambientales)

(iii) las características anatómicas de la madera: presencia de vasos grandes (ataque de líctidos), o la proporción de tejido parenquimático (de reserva)

(iv) la biología de los organismos xilófagos en su ambiente natural (es decir, en el hábitat donde se desarrollo la madera)

(v) la ecología del ambiente donde crece: agua disponible, accesibilidad a la luz solar, densidad de siembra, etc.

(vi) condiciones climáticas del lugar y,

(vii) el manejo de las maderas en su procesamiento. 
Una forma de clasificar las maderas según la durabilidad es la siguiente [54]:

- Clase 1: Muy durables (más de 30 años) por ejemplo: Ciprés del sur, Curupay, Guayacán, Mora colorada, Quebracho colorado, Quina colorada, Urunday, Urundel

- Clase 2: Durables (10 a 30 años) por ejemplo: Algarrobo, Anchico colorado, Calden, Cancharana, Coihue, Lapacho, Roble pellín

- Clase 3: Poco durables (5 a 10 años): Azota caballo, Caroba, Cedro, Espina corona, Eucalipto saligna/grandis, Grapia o Ibirá peré, Guaraniná, Guatambú blanco, Guayaibí, Guayaibí amarillo, Incienso, Laurel, Lenga, Loro blanco, Marmelero o Ibirá puitai, Nogal criollo, Palo amarillo, Palo blanco, Palo rosa, Paraíso, Pehuén (Pino de Neuquén), Persiguero, Peteribí, Pino chileno, Pino del cerro, Pino resinoso nacional (ellioti y taeda), Pino spruce, Quebracho blanco, Raulí, Roble del país, palo trébol o Cerejeira, Tipa blanca, Virapitá, Viraró

- Clase 4: Muy poco durables (menos de 5 años): Álamo, Araucaria, Carne de vaca, Kiri, Pino Brasil o Paraná o Misionero o Ponderosa, Sauce, Zapallo caspi.

Observando la clasificación presentada es lógico pensar que las maderas elegidas como materiales son aquéllas de las primeras clases, donde la durabilidad es alta, es aquí donde se visualiza claramente lo planteado a lo largo de este capítulo: obtener un equilibrio entre el cuidado del medio ambiente y la producción/comercialización de productos de alta calidad y durabilidad, que es la principal demanda que posee cualquier material en cualquier industria.

\section{I.6 Agentes degradadores de la madera}

La madera puede deteriorarse por acción de (i) agentes bióticos: micro y macroorganismos heterótrofos; o (ii) agentes abióticos como el producto de las anomalías producidas durante el crecimiento del árbol, agentes atmosféricos, humedad y temperatura propias del ambiente, agentes mecánicos y químicos y el fuego. 


\section{I.6.1 Agentes bióticos}

La madera, por su composición química, es muy susceptible a la acción de agentes biológicos, fundamentalmente microbiológicos. El ataque biológico ocurre en diferentes partes de la pared celular, dependiendo del tipo de organismo agresor y de sus características metabólicas.

El biodeterioro de la madera es un fenómeno complejo que implica alteraciones de las propiedades físico-químicas y mecánicas de la misma por acción de los organismos. A ello hay que añadirle las modificaciones del aspecto estético que se producen en los objetos afectados [55]. La intensidad de las alteraciones, se produce en función de los componentes orgánicos disponibles según el tipo de sustrato y de las condiciones ambientales. Los organismos son capaces de deteriorar la madera son:

Existe una gran diversidad de microorganismos celulolíticos que utilizan la celulosa, la hemicelulosa y la lignina de la madera como fuente de energía. Esta variedad metabólica hace que sea muy difícil controlar su ataque o crecimiento sobre cualquier sustrato ya que tienen la capacidad de adecuar su metabolismo a las condiciones del medio, aún cuando éstas son extremas.

La actividad de las diferentes especies de hongos y bacterias se ve favorecida por varios factores, que incluyen: la humedad relativa, las fluctuaciones de la temperatura, la luz, la naturaleza de los nutrientes del sustrato, el contenido de humedad del mismo, las propiedades físicas de la superficie del objeto, el mecanismo de adsorción-desorción de la humedad del material, el pH, la presencia de polvo, el movimiento del aire ambiental y su grado de penetración en el objeto, las concentraciones de oxígeno y dióxido de carbono en la atmósfera, etc. [56, 59].

\section{I.6.1.1 Hongos}

Son organismos eucariota complejos que para desarrollarse necesitan que la humedad del sustrato se encuentre entre el 30 y 50\% (este rango de humedad está por encima del punto de saturación de las fibras de la madera); una temperatura entre los 20 y los $30^{\circ} \mathrm{C}$ (cesan su actividad por debajo de $3^{\circ} \mathrm{C}$ y por encima de $40^{\circ} \mathrm{C}$ ); pequeñas cantidades de oxigeno [60, 61]. 
Como se mencionó en el apartado anterior, la composición química de la madera es lo que genera que sea susceptible de ser atacada ya que basándose en su peso seco el componente mayoritario es fuente de carbono para diversos microorganismos. Los componentes son celulosa (40-55\%), lignina (17-35\%), hemicelulosa (15-30\%), productos extraíbles (1-10\%) y minerales o cenizas (cercanos al 1\%) [62].

Los hongos producen enzimas extracelulares que atacan al sustrato; en el caso de los xilófagos estas enzimas atacan la pared celular [63]. Los productos que excretan son los que producen diferentes patologías a las maderas; entre ellos, se reconocen enzimas tales como la celulasa, proteasas y también ácidos orgánicos (oxálico, fumárico, acético, láctico, glucónico, glucurónico, etc.), los cuales se depositan sobre la superficie del sustrato, modificando sus propiedades químicas lo cual conduce a cambios físico-mecánicos [64,68].

Las características del crecimiento de los microorganismos en la madera y el tipo de sistema de degradación que producen proporcionan diferentes patrones de deterioro, los cuales se dividen en tres categorías de deterioro en la madera [64]. Los nombres para estas categorías se basan en las características visuales del deterioro en estado avanzado (Tabla I.1).

- Hongos de la pudrición blanda: dada por géneros correspondientes a la división Ascomycota y Fungi Imperfecti (hongos imperfectos). La pudrición blanda se caracteriza como "madera podrida en contacto con humedad excesiva", sin embargo, también pueden ocurrir en ambientes secos $[75,76]$. Los hongos de pudrición blanda son especialmente activos en condiciones que son desfavorables para la actividad de otros hongos, como, por ejemplo, alta carga de preservantes, alto contenido de humedad y generalmente están asociados con bacterias degradadoras de madera [67-69].

El ataque de hongos de pudrición blanda en la madera de Gimnospermas resulta en la formación de cavidades en la pared secundaria, que aparecen como huecos en las secciones transversales. En perfiles longitudinales estas cavidades aparecen orientadas de forma paralela a las microfibrillas de celulosa [70]. Estas características son exclusivas del ataque de estos hongos y se utiliza para distinguirla del ataque de otros hongos. El ataque de pudrición blanda puede estar asociado con grandes pérdidas de resistencia en la madera ya que las cavidades formadas así 
como la extensa degradación de la celulosa pueden dar lugar a una disminución significativa de la resistencia [71].

\begin{tabular}{||c||c||c||}
\hline \hline Tipo de hongo & $\begin{array}{c}\text { Componente de la madera que } \\
\text { degrada }\end{array}$ & Características del deterioro \\
\hline \hline Pudrición blanca & $\begin{array}{c}\text { Todos los componentes de la pared } \\
\text { celular. Algunas especies atacan } \\
\text { preferentemente a la lignina }\end{array}$ & $\begin{array}{c}\text { Erosión progresiva de todas las capas de la pared } \\
\text { celular inclusive la laminilla media }\end{array}$ \\
\hline \hline Pudrición parda & $\begin{array}{c}\text { Celulosa y hemicelulosa. Puede } \\
\text { haber algo de lignina degradada }\end{array}$ & Despolimerización de celulosa \\
\hline \hline Pudrición blanda & $\begin{array}{c}\text { Celulosa y hemicelulosa. Puede } \\
\text { haber algo de lignina degradada }\end{array}$ & $\begin{array}{c}\text { Tipo 2: Erosión progresiva de la pared secundaria } \\
\text { sin degradación de la laminilla media }\end{array}$ \\
\hline \hline
\end{tabular}

Tabla I.1. División de los hongos xilófagos según el tipo de podrición, dado por las características visuales obtenidas de maderas con deterioro en estado avanzado

- Hongos de pudrición blanca: son degradadores agresivos debido a su capacidad para degradar lignina, hemicelulosa y celulosa, a menudo generando un material blanco enriquecido en celulosa (por ello su nombre). Perteneces a los Basidiomycetes y son comunes en la naturaleza ya que actúan particularmente en los ecosistemas forestales, debido a que degradan las porciones de troncos que quedan fijadas al suelo y los desechos sobrantes de la tala de los árboles [72]. Su capacidad de metabolizar grandes cantidades de lignina es única entre los microorganismos.

La formación de canales de erosión o formación de cavidades en las paredes celulares de la madera es una característica morfológica de este tipo de ataque. La pérdida de resistencia no es significativa hasta las últimas etapas del deterioro [73]. Los hongos de pudrición blanca son parásitos comunes del duramen en los árboles vivos y son agresivos descomponedores de restos de madera en los ecosistemas forestales [74].

- Hongos de pudrición parda: estos se desarrollan sobre maderas de coníferas y representan sólo el $7 \%$ de los basidiomicetes degradadores de madera. Aunque ellos también pueden 
degradar polisacáridos de la madera, solo modifican parcialmente la lignina, la cual torna a un color pardo (lignina oxidada). Uno de los rasgos más característicos del ataque de la pudrición parda es que la celulosa es rápidamente despolimerizada incluso en las primeras etapas de descomposición. Por lo tanto, las pérdidas de resistencia de la madera debido al ataque de la pudrición parda pueden ser enormes, incluso cuando la madera parece sólida [75].

A pesar de que por la degradación las paredes celulares resultan altamente porosas, la forma original de las células a menudo se mantiene sin cambios [76-80]. Una característica macroscópica típica son las grietas cúbicas en madera podrida que se torna color marrón. Microscópicamente, el deterioro debido a la pudrición parda se puede distinguir fácilmente de otros ataques de hongos debido a una combinación de características que incluye la pérdida de la birrefringencia, la ausencia de canales y cavidades de erosión y la apariencia morfológica normal de células cercanas a la madera degradada.

En la Figura I.10 se muestra la morfología de algunos de estos organismos en su hábitat natural.

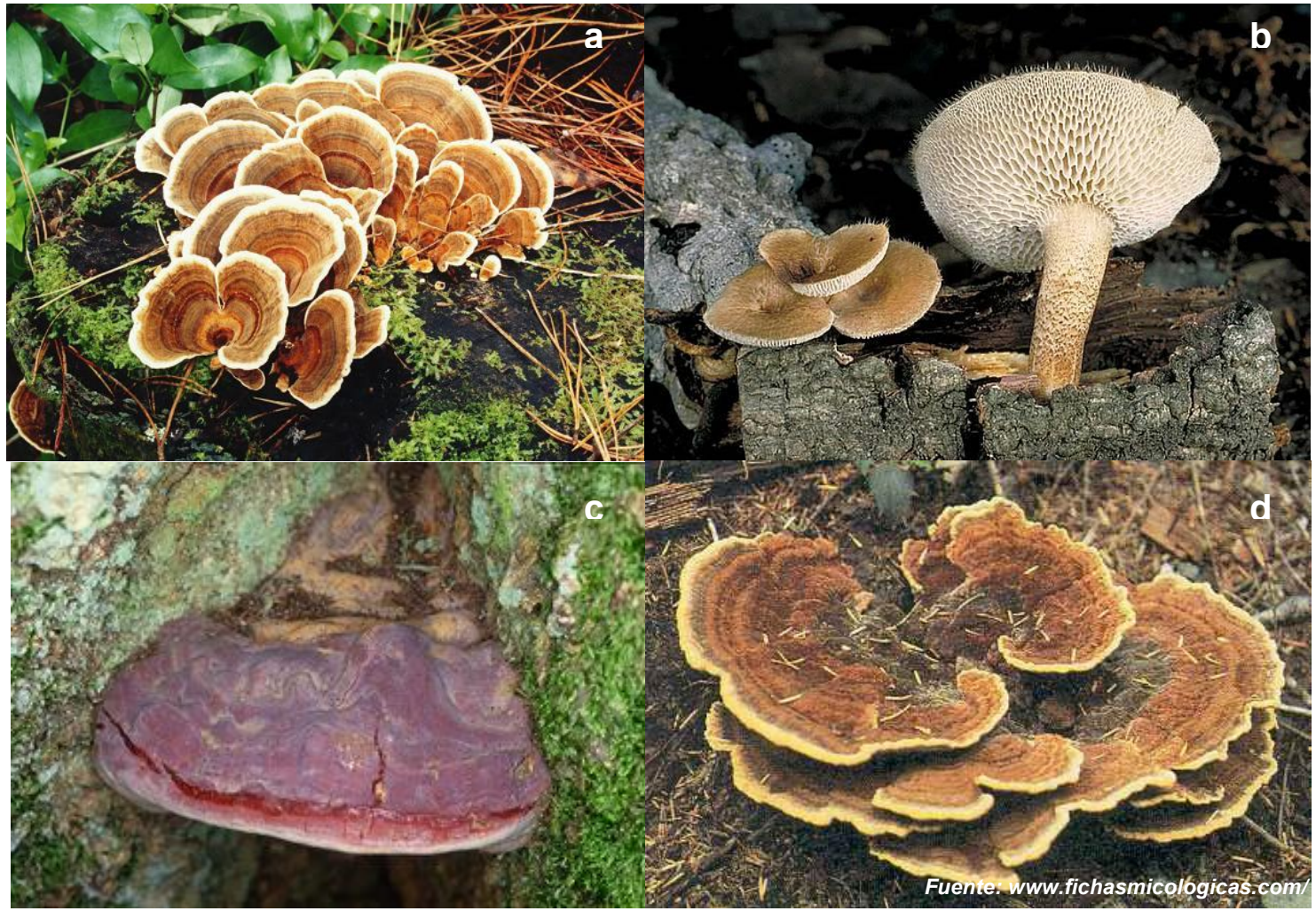

Figura I.10. Algunos ejemplares de hongos xilófagos en su ámbito natural: tronco de árboles: a) Trametes versicolor, b) Polyporus arcularius, c) Ganoderma pfeifferi y d) Phaeolus schweinitzii 


\section{- Mecanismo de degradación}

Como se mencionó, los microorganismos capaces de degradar madera secretan un sistema complejo de enzimas extracelulares, celulasas, y xilanasas, que actúan en forma conjunta en la degradación de la madera.

Para llegar a estas primero el hongo necesita eliminar las fibras de lignina que se encuentran intercaladas entre las fibras de celulosa (es lo que le da estabilidad): primero libera las enzimas lacasas que rompen las cadenas de lignina por oxidación de las mismas y luego, libera la celulasa que degrada la celulosa en monómeros simples y estos son los que usa como fuente de carbono [81].

Una vez liberadas, las fibras de celulosa son degradadas esencialmente por un sistema enzimático compuestos principalmente por tres tipos de enzimas: endoglucanasas, exoglucanasas y celobiasas. Estos tres tipos de enzimas actúan en forma sinérgica (juntas, en forma cooperativa) en la degradación de la celulosa. La endoglucanasa descompone los enlaces internos $\beta-1,4$ y así altera la estructura cristalina de la celulosa y expone las cadenas polisacáridas de celulasa individual.

La exoglucanasa parte de a 2 o 4 unidades de glucosa desde los extremos de las cadenas expuestas producidas por la endoglucanasa, produciendo tetrasacáridos o disacáridos como la celobiosa [82]. Finalmente, la celobiasa hidroliza estos productos, obteniendo los monosacáridos individuales de glucosa, Figura I.11.

En esta se muestra el mecanismo de la degradación de los componentes de la pared celular, en ocurre degradación de celulosa donde actúan tres tipos de actividades celulolíticas en forma sinérgica (A, la degradad de forma no hidrolítica), degradación de hemicelulosa donde están implicadas la xilosidasas y endoxilasas (B), degradación de lignina donde están implicadas las lacasas y peroxidasas que catalizan reacciones oxidativas generando radicales libres inestables que favorecen a la despolimerización (C). Todas las enzimas que intervienen en la degradación de madera: se trata de proteínas complejas las cuales presentan varias estructuras secundarias y terciarias así como varios dominios catalíticos (D). 
Este mecanismo se puede resumir en tres pasos: un evento inicial de acondicionamiento que consiste en la desorganización de sectores cristalinos; otro de despolimerización extracelular que genera pooles de oligosacáridos hasta celobiosa o incluso glucosa; y un último paso en el que se produce la hidrólisis de la glucosa.

La desorganización de la estructura lignocelulósica es clave para exponer la celulosa al ataque enzimático y aumentar el área susceptible a la despolimerización. No obstante, algunos microorganismos, como los hongos causantes de pudrición parda de la madera, degradan en células (vegetales) intactas la celulosa de la capa $S_{2}$ de la pared celular a través de un sistema no enzimático involucrando especies reactivas de oxígeno [83-86].

En la despolimerización enzimática de la celulosa actúan tres grupos de enzimas: las endoglucanasas, endo 1,4- $\beta$-D-glucano-4-glucanohidrolasas, que catalizan en forma aleatoria la hidrólisis de los enlaces glucosídicos de la cadena de celulosa; las exoglucanasas, celobiohidrolasas (exo 1,4- $\beta$-D-glucano-4-celobiohidrolasas), que liberan celobiosa o glucosa desde el extremo no-reductor de la celulosa; y las $\beta$-glucosidasas, también conocidas como celobiasas que hidrolizan celobiosa y otras celodextrinas solubles a glucosa [85].

La degradación de la lignina ha sido estudiada con mayor énfasis en representantes del género Basidiomycetes que son los que más frecuentemente están asociados a maderas, en los que se han descripto un número de enzimas oxidativas (lacasa, LiP, MnP, VP) y mecanismos de ataque de la lignina [85-90].

Muchos trabajos reportan los mecanismos involucrados en la degradación de lignina por hongos causantes de pudrición blanca de la madera, las enzimas que intervienen, y las condiciones que favorecen el proceso [91]. Aunque las reacciones de las enzimas ligninolíticas con compuestos modelos de lignina están bien caracterizadas, no está claro si estas enzimas puedan oxidar la lignina polimérica nativa. Esto sugiere que otras reacciones podrían estar también involucradas en el estado inicial de la despolimerización de lignina. En contraste con los hongos causantes de pudrición blanca, que sintetizan un arsenal de enzimas oxidativas extracelulares que despolimerizan lignina, los hongos causantes de la pudrición parda solo hidrolizan la celulosa [92-93]. 


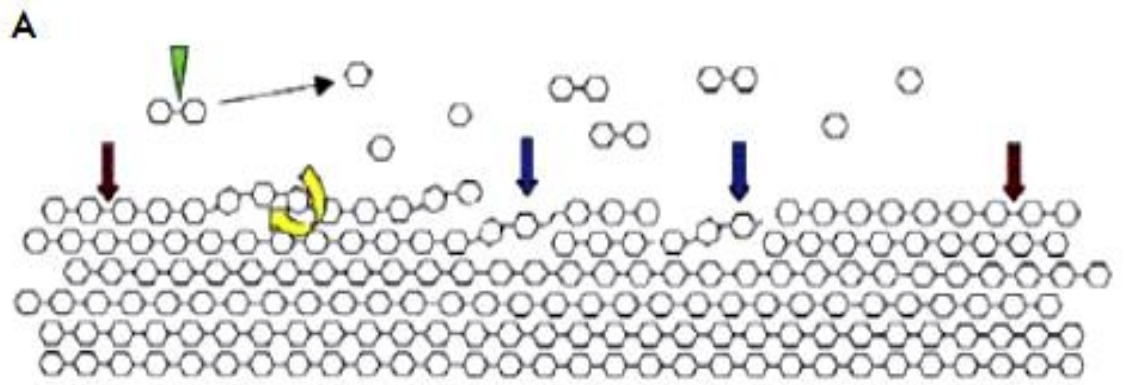

G Glucose

B

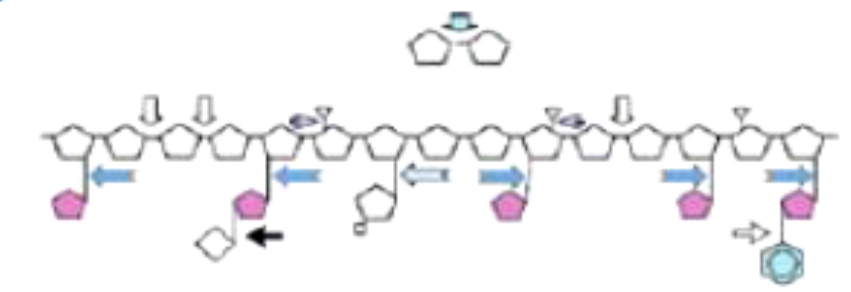

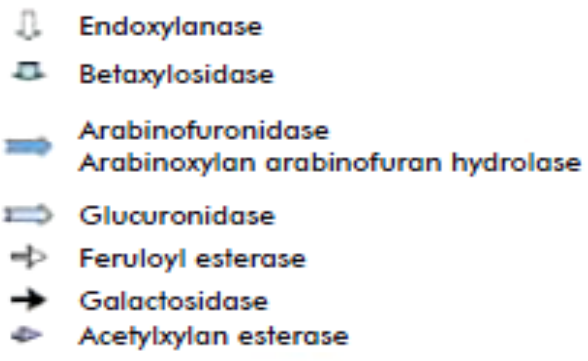

C
D-xylose

L-arabinose

4-methyl-Dgalocturonic acid Ferulic acid

D D-galactose

$\nabla$ Acetyl moiety
B. Swollenin

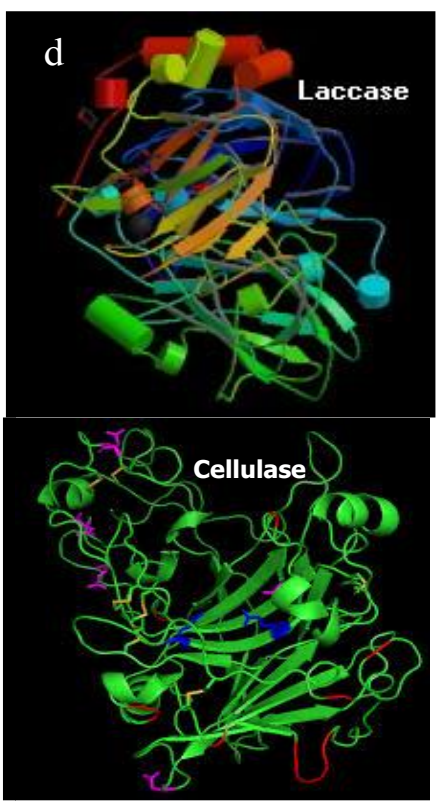

Fuente: Quiroz Castañeda R.E and Folch Mallol, J.L (2011)

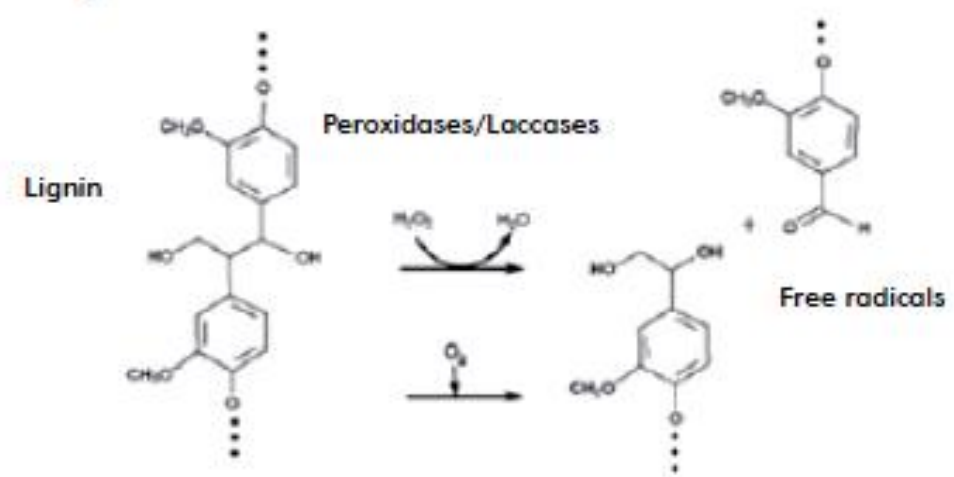

Figura I.11 Arriba, mecanismo de la degradación de los componentes de la pared celular: A) degradación de celulosa donde. B) Degradación de hemicelulosa C) Degradación de lignina. D) estructura molecular de las principales enzimas que intervienen en la degradación de madera 
La asimilación de carbono consiste en incorporarlo a la biomasa microbiana el cometabolismo es definido como la transformación de un compuesto llamado co-sustrato en presencia de un sustrato asimilable. Mientras que la celulosa es una fuente de carbono y energía asimilada por los microorganismos, la degradación de lignina provocada por hongos de la pudrición blanda es considerada un proceso cometabólico [94].

Es importante destacar que las enzimas involucradas en el proceso degradativo se tratan de un conjunto de heterodímeros de alto peso molecular (38-100 KDa aproximadamente cada una de ellas) las cuales necesitan unirse al sustrato mediante puentes de hidrógeno que los forma entre los $-\mathrm{OH}$ de la celulosa y los $-\mathrm{OH}$ del sitio activo para estabilizarse acercarse más, hasta encontrarse con los enlaces 1,4 $\beta$ glucosídicos y comenzar con la hidrólisis de estos [94].

Dicho esto, una de las estrategia para prevención del deterioro entonces es evitar la formación de los puentes de hidrógeno para que la celulasa no pueda degradar; teniendo en cuenta que la distancia máxima en la que puede formarlos es de $4 \AA$ y que es su volumen es significativo en el espacio intracelular, cualquier cadena que se le agregue a la celulosa que haga exceder esta distancia por simple impedimento estérico o que haga que forme puentes de hidrógeno con ese agregado y no con la celulosa servirá como biocida [95-97].

\section{I.6.1.2. Bacterias}

Las bacterias son organismos procariotas, unicelulares que generalmente se desarrollan a $\mathrm{pH}$ entre 7 y 8 y temperaturas entre 25 y $38^{\circ} \mathrm{C}$, aunque muchas especies toleran temperaturas inferiores a $0{ }^{\circ} \mathrm{C}$ y otras, como las termófilas, resisten más de $45^{\circ} \mathrm{C}$. Estas segregan pectinasas que disuelvan las membranas de las punteaduras del parénquima, que son de naturaleza péctica.

Su poder destructivo es inferior al de los hongos salvo en ataques intensos donde destruyen también las punteaduras areoladas, aumentando considerablemente la permeabilidad de la madera y facilitando el ataque posterior de otros organismos principalmente el de hongos convirtiéndose así en un verdadero problema.

Como consecuencia de esto se está probando el uso de pectinasas para mejorar la penetrabilidad de algunas maderas y posibilitar su impregnación [98-102]. 


\subsubsection{Insectos}

Los insectos que atacan la madera son las termitas pertenecientes al orden Isóptera; familias Kalotermitidae, Termopsidae y Rhinotermitida y los coleópteros del orden Coleóptera; familias Anobiidae, Lyctidae, Curculionidae, Cerambycidae y Bostrichidae [103-109], Figura I.12.

Aquéllos pertenecientes al orden coleóptero son los que provocan los mayores daños. Dentro de estos se encuentran: Carcomas (Anobiidae); Líctidos o polillas de madera (Lyctidae); Escolitidos (Curculionidae); Taladro (Cerambycidae); Escarabajo (Bostrichidae).

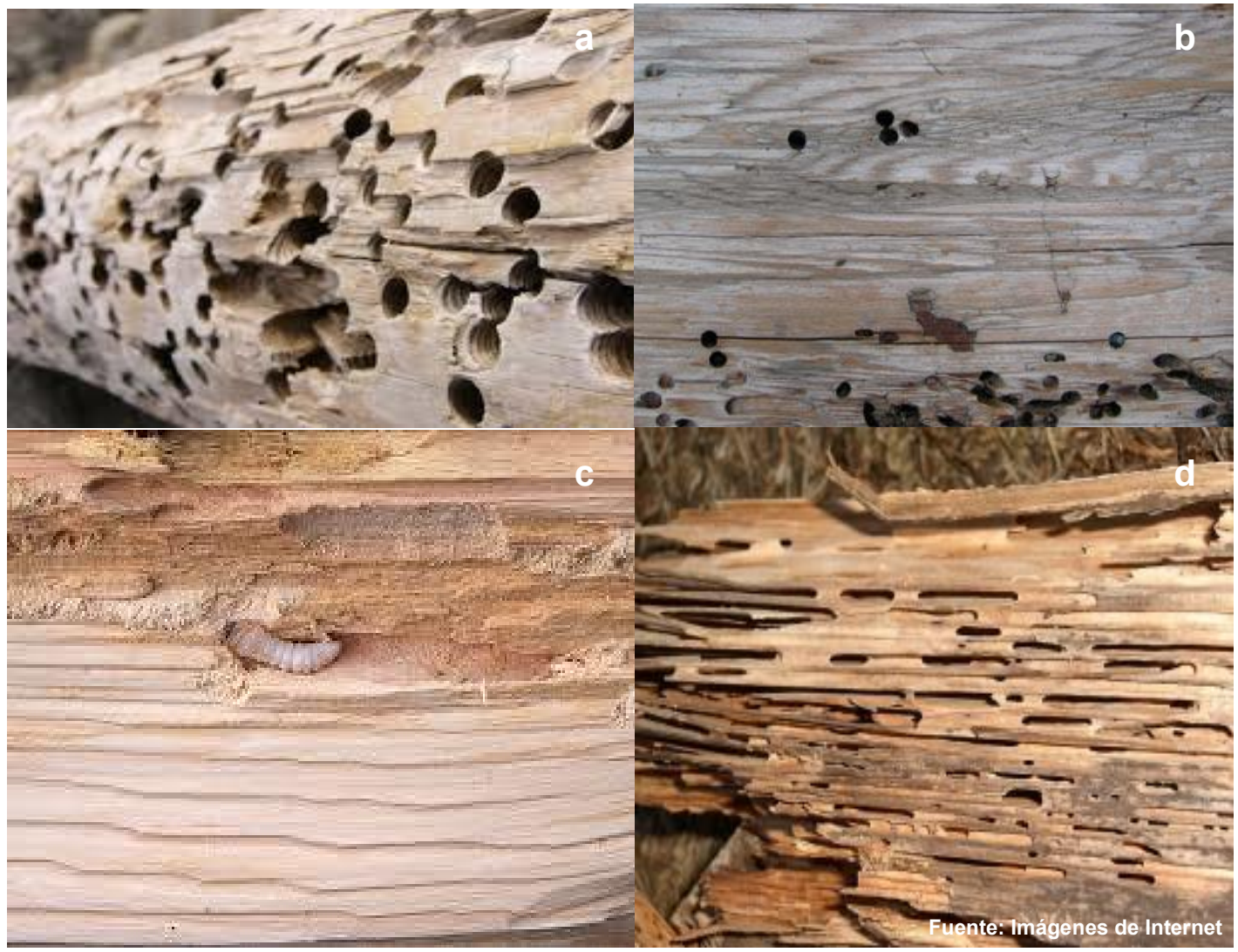

Figura I.12. Aspecto de madera luego de ser atacada por insectos xilófagos: a) carcomas (Anobiidae), b) polillas (Lyctidae), c) larva de taladro (Cerambycidae) y d) termita (Rhinotermitida)

Dentro del orden isóptero se encuentran las termitas que son insectos que viven en grandes colonias; hay grupos que atacan maderas secas, otros, madera húmeda. Pueden atacar maderas 
duras como los quebrachos colorados, quina, curupay, algarrobos, etc. Muy pocas maderas en el mundo son resistentes a las termitas; se consideran como tales a las que tiene aceites esenciales y sílice en abundancia.

\section{I.6.1.4 Moluscos y Crustáceos}

Aplica solo en caso de maderas sumergidas en agua de mar. Los más importantes son los géneros Teredo, Bankia y Martesia. Cavan galerías de más de 1 metro de longitud. Tienen un crecimiento rápido y dejan en las galerías una capa fina de una sustancia calcárea. Los crustáceos son más pequeños que los anteriores. Uno de los géneros más importante es Limnoria, que ha sido encontrado en todos los mares del mundo. Pocas son las especies resistentes a sus ataques; se consideran como tales a algunas con elevado contenido en sílice [110].

\subsubsection{Aves}

Es importante el ataque de pájaros carpinteros en el norte de nuestro país. Producen orificios de $10 \mathrm{~cm}$ de diámetro y de profundidad, según la especie, afectando seriamente la resistencia físicomecánica de la madera. Se los encuentra en postes de líneas aéreas, preferentemente de palmeras. Atacan árboles y madera seca por igual ya que su fuente de alimento son los insectos que se encuentran sobre o dentro de la madera. Los orificios más grandes los hacen para nidificar [111].

\section{I.6.2 Agentes abióticos}

\section{I.6.2.1 Humedad}

Los factores ambientales influyen en gran medida en la descomposición del sustrato y uno de ellos es la humedad, el cual es un agente degradante significativo para la madera ya que produce su degradación ya sea por pérdida de estabilidad dimensional o por el crecimiento de agentes microbianos degradantes. Es por ello que, para prevenir el deterioro de la madera, la humedad debe reducirse por debajo del punto de saturación de la fibra (es decir, la cantidad de humedad suficiente para saturar la pared celular y permitir un poco de agua libre presente en el lúmen de las células), de 28 a 30\%. Un contenido de humedad de la madera del 20\% (basándose en peso 
seco) es considerado el mejor para asegurar la estabilidad dimensional y que el crecimiento microbiano no se produzca [112].

La relevancia de la humedad como agente deteriorante se fundamenta en la interacción existente entre el agua y la madera: la pared celular de la madera se compone principalmente de polímeros con hidroxilo y otros grupos que contienen oxígeno, los cuales tienen la capacidad de atraer la humedad ambiente a través de enlaces puentes de hidrógeno. A medida que se añade agua a la pared celular, el volumen de madera aumenta casi proporcionalmente al volumen de agua añadida. Esto hace que la madera se hinche hasta que la pared celular se satura. Este punto se denomina punto de saturación de la fibra, y varía de 20 a 50 por ciento en ganancia de peso. El agua, más allá de este punto, es agua libre en la estructura y no contribuye al aumento de volumen de la madera. Este proceso es reversible, y la madera se contrae a medida que pierde humedad por debajo del punto de saturación de la fibra [112-113].

La celulosa y hemicelulosa son más higroscópicas que la lignina y, por lo tanto, son las principales responsables de la absorción de humedad. Estudios han demostrado que sólo el 60 por ciento de los grupos hidroxilo totales en madera de pino son accesibles al agua y que el 65 por ciento de la celulosa de la madera es cristalina, por tanto, no accesible al agua. Por ejemplo, para Eucalyptus regnans se encontró que la contribución fraccional de cada polímero que compone la pared celular para la absorción total de agua es del $47 \%$ para la celulosa, el $37 \%$ para la hemicelulosa $37 \%$ y el $16 \%$ para la lignina. Esto significa que la lignina (en un grado pequeño), las hemicelulosas (son no cristalina en la naturaleza), la porción no cristalina de la celulosa, y las superficies de cristalitos de celulosa son responsables de la absorción de humedad en la madera. Esta interacción hace que la madera sea un material higroscópico de hecho, en el árbol en pie la madera tiene como función el transporte de agua de la raíz hasta las hojas [122$123]$.

Además, el hecho que tenga la capacidad de hincharse y contraerse la hace un material anisotrópico, lo que significa que se hincha y se contrae en un grado diferente en las tres direcciones anatómicas, Figura I.12. Los cambios dimensionales en la dirección longitudinal son generalmente muy pequeños, siendo la tangencial la que más cambios dimensionales sufre; los cambios radiales son más pequeños, por lo general alrededor de 40 a $70 \%$ respecto a la tangencial. La hinchazón de la madera en contacto con humedad ejerce fuerzas muy grandes, se 
ha determinado que la presión de hinchamiento teórico es de 1.630 atmósferas con lo cual demuestra que estas elevadas fuerzas hacen que pierda su estabilidad dimensional debido a los daños que se producen en las fibras [114-115].

El contenido de humedad (MC, Moisture Content) de la madera tiende hacia el equilibrio con la de la atmósfera circundante. Así, para cada humedad relativa (RH, Relative Humidity) y temperatura del aire, hay un correspondiente contenido de humedad de equilibrio de madera (EMC, Equilibrium Moisture Content), lo cual se denominan isotermas de absorción de humedad, Figura I.12.

Fuente: Padfield, $T$ Conservation Physics 1996 exhibition made for the IIC congress in Copenhagen "Archaeological conservation and its consequences"
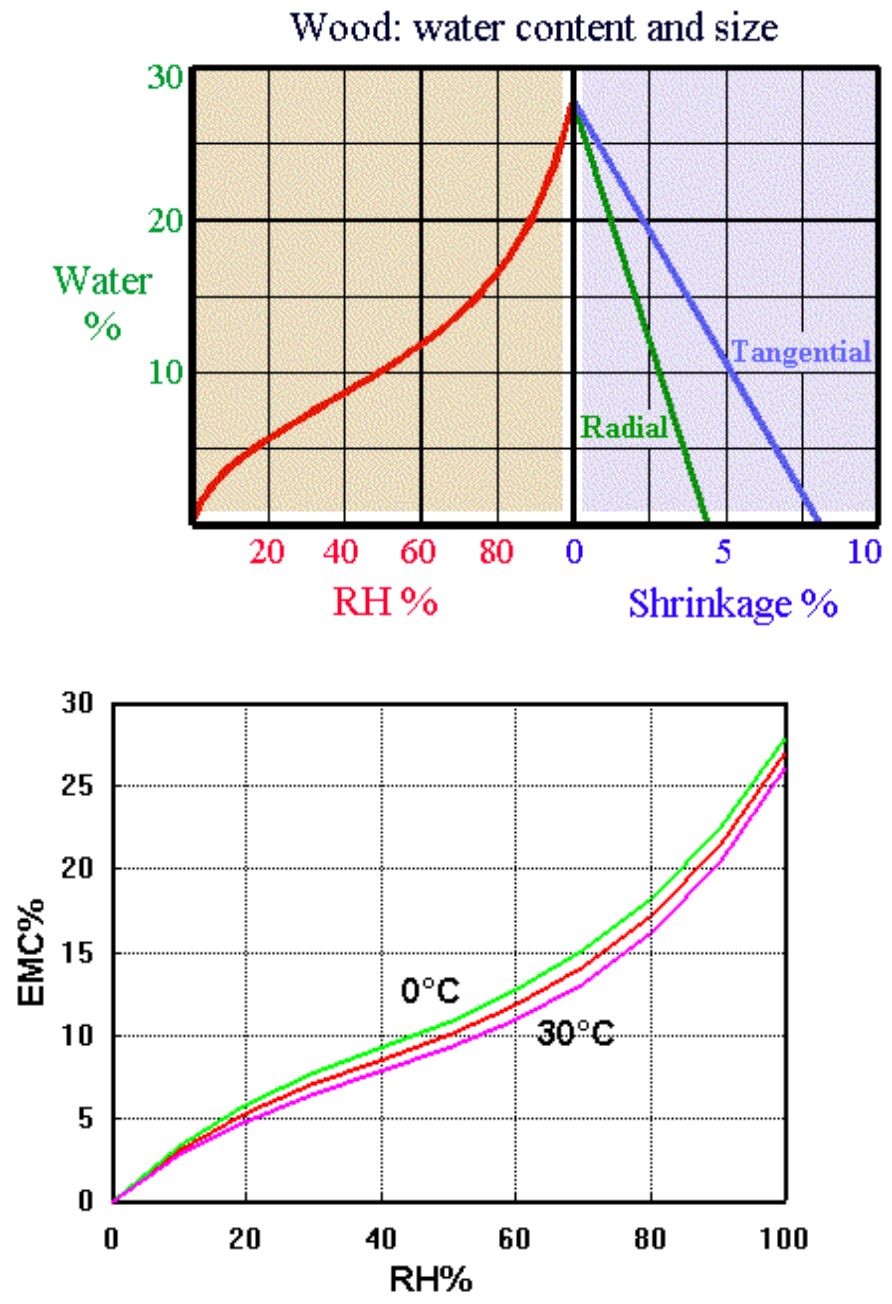

Figura I.12. Arriba: Diagrama de agua contenida versus humedad relativa y la contracción de la madera (verde). Abajo: Contenido de agua de la madera en equilibrio con una humedad relativa dada 
Estas son isotermas con forma sigmoidea con el EMC correspondiente al $100 \%$ de humedad relativa que oscila entre un $20 \%$ y un $50 \%$ y se plancha alrededor del $28-30 \%$ para muchas especies. En este último contenido de humedad (punto de saturación de la fibra) la pared celular tiene su máxima cantidad de agua absorbida, mientras que los lúmenes de células siguen estando libres de agua.

El agua que fue adsorbida por la pared de celular hace que la madera se hinche mientras que el agua que ingresa a los lúmenes celulares por fuerza capilar no causa cambios dimensionales. En especies ricas en extractos la saturación de las fibras se produce a menos de $28-30 \%$ de $\mathrm{MC}$, con cambio dimensional correspondientemente menor [116-117].

Para la madera se hinche desde el estado seco, el agua o algún otro agente de hinchamiento debe entrar en la pared celular. Entrada puede resultar dada por un flujo de masa que ingresa a los lúmenes celulares y hace que entre en contacto con la pared celular o por difusión de vapor de agua dentro de los lúmenes celulares en donde esta condensa y allí se une a la pared celular. En la mayoría de situaciones, ambos procesos ocurren [116-117].

La madera es mucho más permeable en la dirección longitudinal que en la radial o tangencial debido a la capacidad de absorción capilar que sus células ya que la madera es un medio capilar. La estructura de "poro capilar" se define por el lumen de las células y las aberturas de la pared celular (pits) debido a la interconexión que existen entre ellas.

Los tratamientos para reducir la tendencia de tomar humedad se pueden dividir en dos categorías: los repelentes de agua y estabilizadores dimensionales. A pesar de que estos dos se utilizan a menudo como sinónimos, en realidad son enfoques para controlarla completamente diferentes. La eficacia del tratamiento de repelencia al agua se puede definir como la capacidad de un tratamiento para prevenir o controlar la tasa de absorción de agua líquida, un ejemplo de estos es la inmersión de madera en cera o silicona [112, 116-117].

En contraste, la eficacia de tratamiento de estabilización dimensional se puede definir como su capacidad para reducir o prevenir la hinchazón y contracción de la madera resultante de la absorción de humedad; la estabilidad dimensional entonces depende de la medida de absorción de agua y no de la tasa de absorción, es decir, una tasa de absorción de agua reducida indica una 
mayor repelencia mientras que la reducción de la hinchazón indica una mayor estabilidad, Figura I.13.

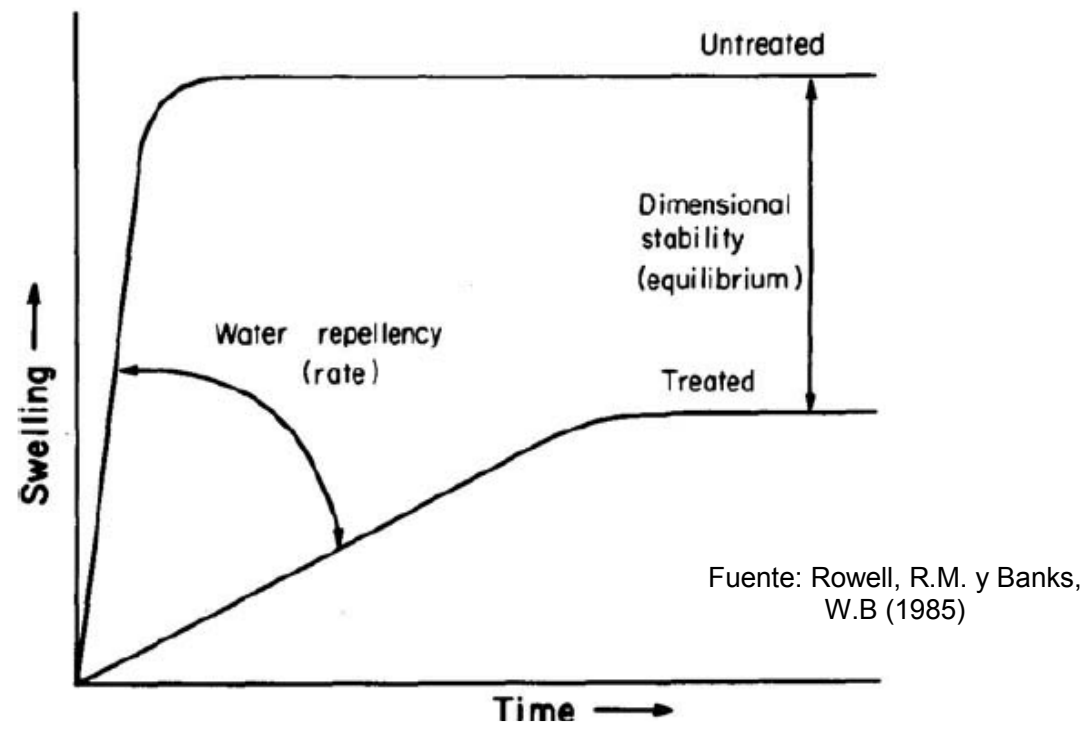

Figura I.13. Gráfico de hinchazón versus tiempo que muestra la curva típica para muestras de madera tratadas y no tratadas

Una de las maneras de analizar los tratamientos implementados respecto a repelencia y estabilidad es mediante las curvas resultantes de graficar hinchazón en función del tiempo, Figura I.14:

Para curvas del tipo I indica que el tratamiento reduce la tasa de absorción de humedad, pero con el tiempo el grado de hinchazón es casi el mismo que la madera no tratada por lo tanto es un tratamiento que repele el agua, pero no la estabilidad dimensional.

La curva tipo II indica que el tratamiento reduce la extensión de la hinchazón, pero no la velocidad a la que la madera absorbe humedad, tal tratamiento otorgaría estabilidad dimensional pero no repelencia al agua.

Por último, un tratamiento que de una curva del tipo III reduce tanto la velocidad de hinchamiento y el grado de hinchazón, tal tratamiento podría mejorar la repelencia al agua y la estabilidad dimensional [122]. Este tipo de análisis es el que se utilizará en la presente tesis. 

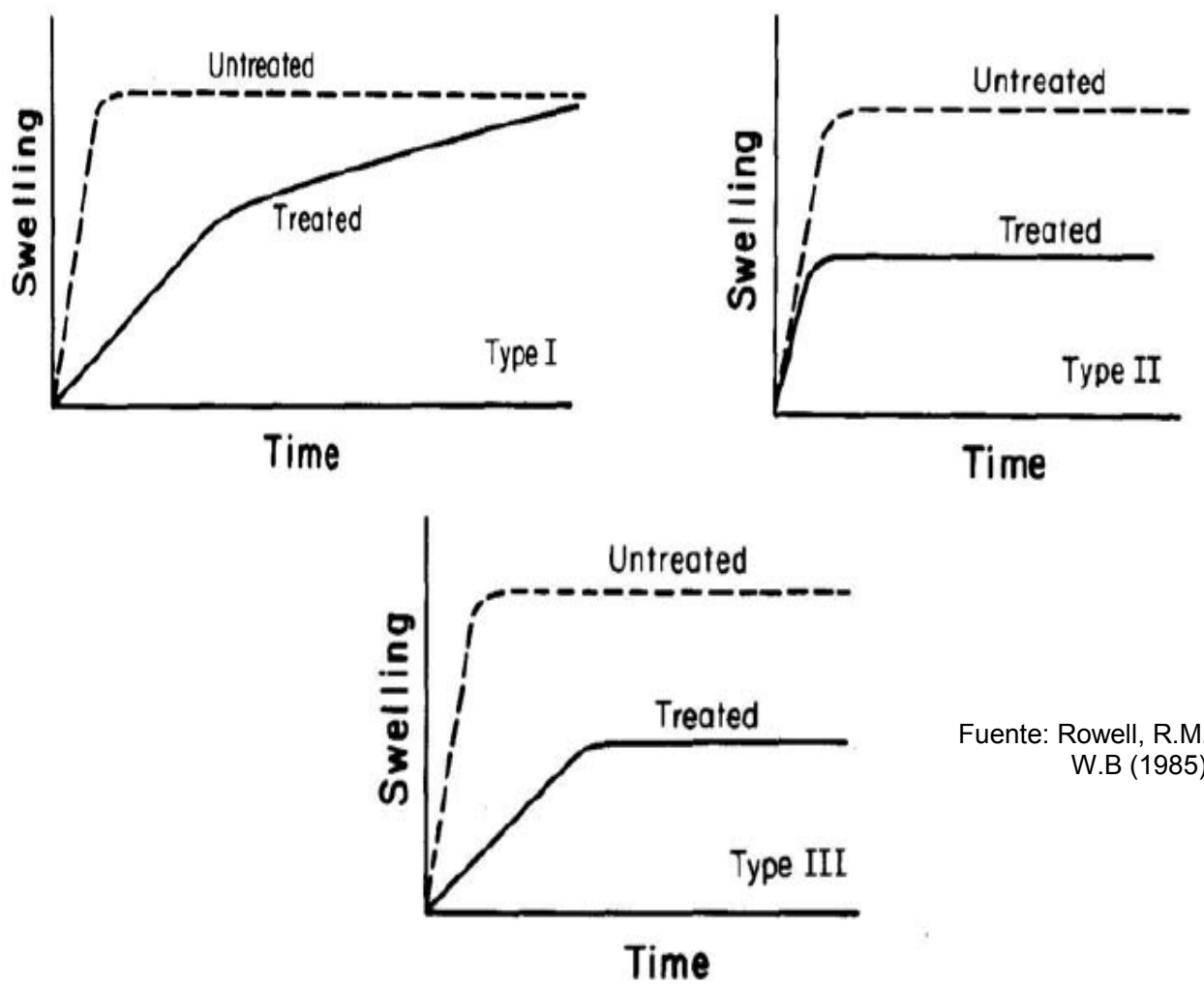

Fuente: Rowell, R.M. y Banks, W.B (1985)

Figura I.14: Curvas que describen contra que actúa el tratamiento (repelencia, estabilidad dimensional o ambas)

\section{I.6.2.2 Fuego}

La acción del fuego sobre los materiales de la construcción es significativa a nivel seguridad, ya que la reacción de los mismos frente al fuego dependerá su naturaleza química. Así, por ejemplo, los calcáreos colapsan rápidamente por dilatación de los núcleos y por concentración durante la desecación mientras que los cementíceos exhiben satisfactoria respuesta a altas temperaturas si se encuentran perfectamente anclados [118-120].

Por su parte, el hormigón armado presenta adecuado comportamiento hasta los $300-330{ }^{\circ} \mathrm{C}$ si sus agregados áridos son de reducido tamaño; los hierros de la armadura comienzan a perder resistencia cuando se alcanza una temperatura crítica de $500-550^{\circ} \mathrm{C}$. En lo referente al yeso, éste se deshidrata gradualmente por encima de los $120{ }^{\circ} \mathrm{C}$ y hasta los $180{ }^{\circ} \mathrm{C}$, pulverizándose por pérdida de cohesión a los 700-800 ${ }^{\circ} \mathrm{C}$ [121]. 
Los sistemas de hierro y acero portantes realizados por forjado o laminado se deforman plásticamente por acción del calor fundamentalmente cuando la presión de las masas soportadas pierde su equilibrio estático; aproximadamente a $500{ }^{\circ} \mathrm{C}$ este material disminuye a la mitad su resistencia estructural [122].

La madera y los productos derivados fueron ampliamente usados en la construcción de edificios históricos; a pesar de comportarse como materiales combustibles y de resultar vulnerables en casos de incendio, presentan en general una considerable resistencia al fuego. El diseño y los detalles constructivos conforman un grupo de variables con significativa gravitación técnica y económica. Al incendiarse un edificio, en cuestión de minutos todos los materiales metálicos pierden su resistencia y se destruyen, mientras que en el mismo lapso las estructuras de madera mantienen una elevada resistencia estructural. Ésta aumenta su resistencia a medida que la temperatura se incrementa y llega a perderla en la etapa de carbonización [123].

La citada resistencia al fuego de la madera se debe a la reducida penetración del mismo, la cual es atribuible a la baja conductividad técnica y a la formación de una capa carbonizada superficial que retarda la velocidad de propagación por su propiedad aislante [123].

La combustión de la madera comienza cuando esta es expuesta a temperaturas elevadas, lo cual produce que aumente su temperatura y con ello comienzan a ocurrir cambios en su estructura: los tres componentes poliméricos de la madera empiezan a descomponerse térmicamente a una mezcla de gases volátiles tal como el levoglucosano y se comienza a formar el residuo carbonoso (char). La descomposición es a menudo considerada como la superposición de los mecanismos de descomposición de cada uno de los componentes individuales: la hemicelulosa es el primer polímero que se descompone $\left(180-350{ }^{\circ} \mathrm{C}\right)$, seguido de la celulosa $\left(275-350{ }^{\circ} \mathrm{C}\right)$ y lignina $\left(250-500^{\circ} \mathrm{C}\right)$. La estabilidad térmica de la lignina se considera que es debido a su gran estructura reticulada y de alto peso molecular [124-125].

Luego se producen reacciones de reticulación (cross-linking) entre la celulosa deshidratada y el levoglucosano lo cual hace que se repolimerice mediante la producción de estructuras aromáticas, convirtiéndose en estructuras de grafito de carbono cuando el sistema alcanza temperaturas que rondan $\operatorname{los} 500{ }^{\circ} \mathrm{C}$. Este proceso de descomposición se denomina pirólisis. La pirólisis de madera ha sido objeto de una amplia investigación en los últimos años. Tales 
estudios han demostrado la superficie de la madera carbonizada (char) puede tener temperaturas de $800{ }^{\circ} \mathrm{C}$, mientras que la pirólisis principal de la madera comienza a temperaturas superiores a $225^{\circ} \mathrm{C}$ y termina por debajo de $500{ }^{\circ} \mathrm{C}$ [126-127].

Cuando se ha alcanzado una concentración de aire-combustible volátil apropiado, la oxidación de los gases de pirólisis conduce a la combustión con llama [128]. En contraste, la oxidación del char remanente produce una combustión incandescente o intermitente (arde sin llama). La pirólisis y combustión de la madera ha sido ampliamente estudiada [124-128] por lo que se conoce que los rangos de temperaturas de la pirólisis y combustión de la madera son, Figura I.15:

- A temperaturas mayores a $100^{\circ} \mathrm{C}$ se produce la evaporación del agua y todo aquello que no se encuentra químicamente unido.

- En el rango de los $160-200{ }^{\circ} \mathrm{C}$, los tres componentes poliméricos de madera comienzan a descomponerse lentamente. Los gases formados en esta etapa son incombustibles (principalmente se libera vapor de agua) [123].

- Entre los $200-225^{\circ} \mathrm{C}$, la pirólisis de la madera aún es muy lenta, y la mayoría de los gases producidos son incombustibles.

- Entre los $225-275{ }^{\circ} \mathrm{C}$, comienza la pirólisis principal y la combustión con llama si hay presencia de una llama piloto (constante).

- En el rango de los $280-500{ }^{\circ} \mathrm{C}$, los gases producidos ahora son volátiles (CO, metano, etc.) y las partículas de humo son visibles. Se forma rápidamente el char carbonoso y la estabilidad física de la madera decae.

- A temperaturas mayores a los $500{ }^{\circ} \mathrm{C}$ la producción de volátiles es completa. El char sigue ardiendo sin presencia de llama oxidándose (color grisáseo) en $\mathrm{CO}, \mathrm{CO}_{2}$ y $\mathrm{H}_{2} \mathrm{O}$.

El char tiene origen dado que durante la pirólisis se producen dos formas de productos gaseosos de madera: los que escape fácilmente del residuo sólido y los que no lo hacen. Aquellos que lo hacen se tratan de casi todos los compuestos que se separaron de la celulosa y lignina en las primeras etapas de la pirólisis y son más ricos en hidrógeno, oxígeno, o en ambos, que las cadenas poliméricas originales. Por lo tanto, el residuo no volátil se enriquece en carbono; los enlaces carbono-carbono en las estructuras de carbono (grafito) formadas son irrompibles por la pirólisis, solo pueden romperse a temperaturas superiores a $3000{ }^{\circ} \mathrm{C}$ [125]. Además, la pirólisis 
exotérmica continúa sobre los productos gaseosos complejos que no se escapan fácilmente del residuo sólido, dejando un residuo más altamente carbonoso (char secundario).

a)

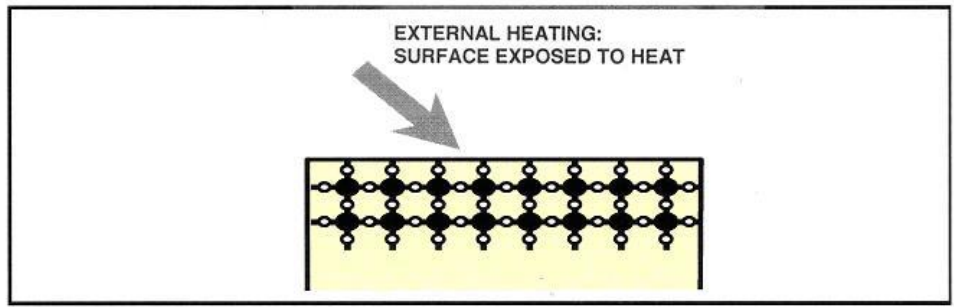

b)

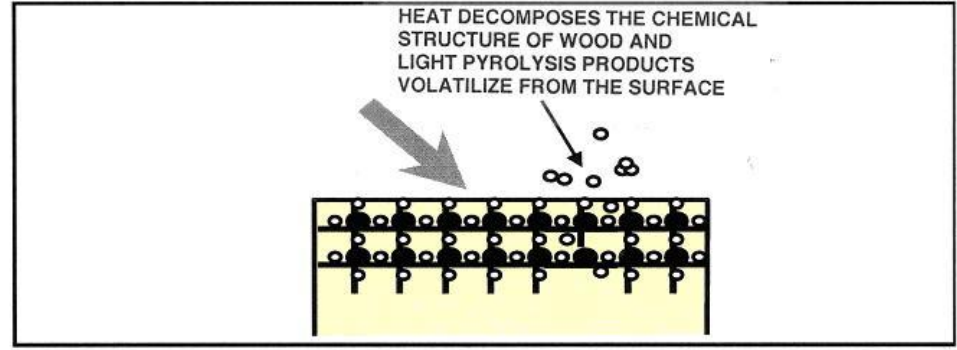

c)

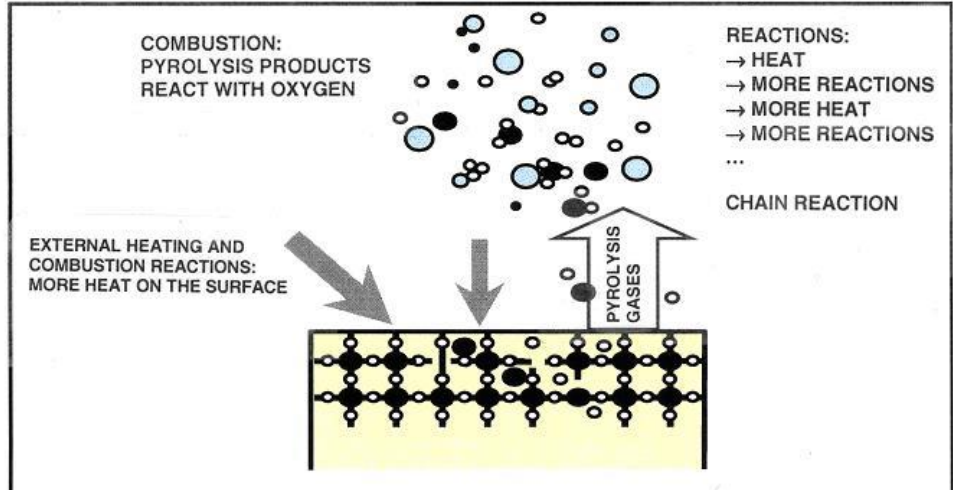

Fuente: InnoFireWood, http:// http://virtual.vtt.fi/

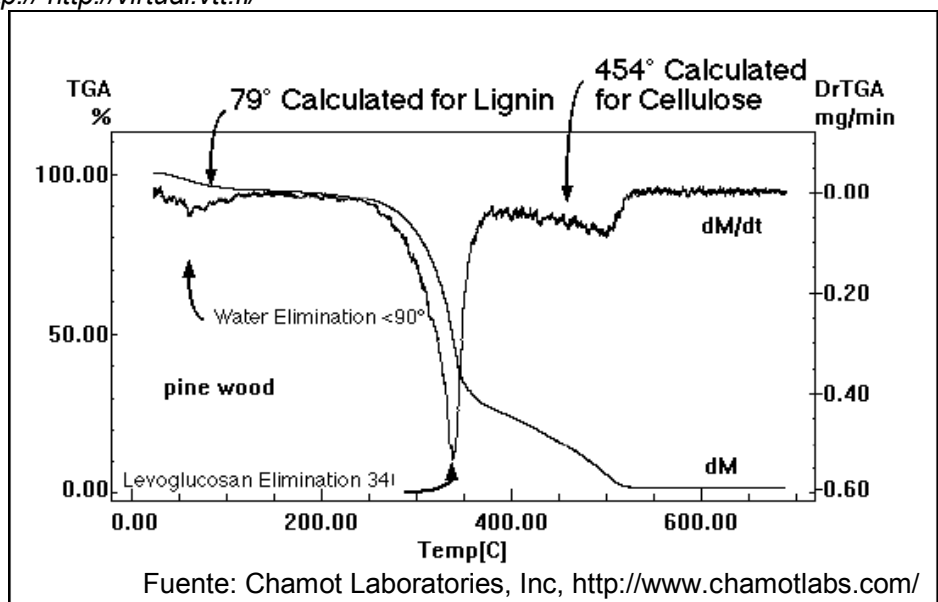

Figura I.15. Arriba, esquema de la pirólisis y la combustión de la madera. Abajo, descomposición de la madera frente a la acción del fuego, el grafico pérdida de peso en función de la temperatura (TGA, Thermal Gravimetric Analysis) 
La citada capacidad de producir un aislante térmico (char) como producto de su combustión hace que sea más resistente a la acción de fuego frente a otros materiales: la formación de char tiene un efecto significativo en la descomposición ya que claramente, si el material que se descompone queda en la fase sólida como aislante haciendo que la descomposición de la madera subyacente sea más lenta, Figura I.16.

Si bien el char no imparte resistencia mecánica para el material restante, actúa como una resistencia térmica creciente entre la madera subyacente y la parte de pirólisis que avanza. Esto se traduce en una disminución de la tasa de liberación de calor y actúa como una barrera para el oxígeno del aire disminuyendo los reactivos de combustión y también para el transporte de masa de volátiles liberados aportando más residuo carbonoso aislante [123-124].

La estructura del char varía ampliamente dependiendo de la especie de madera, tratamiento retardante de fuego y velocidad de calentamiento. En cuanto a su estabilidad e integridad está influenciada por muchas características, incluyendo la densidad, la continuidad, la resistencia a la oxidación, las propiedades de aislamiento térmico y su permeabilidad. Su producción depende en gran medida de la tasa y la duración del calentamiento: fuertes aumentos de temperatura producen menos char que cuando el aumento es gradual, ya que la producción carbón depende de las reacciones de deshidratación a baja temperatura [125-128].

La descomposición de la lignina es conocida por hacer una contribución significativa al rendimiento global char. Mientras que la adición de retardadores de ignición a menudo aumenta el rendimiento de carbón de madera, la tasa de carbonización típicamente permanece sin cambios.

Las tasas de carbonización típicas de maderas blandas, como las que se emplearon en la presente tesis, son del orden de $0,6 \mathrm{~mm} \mathrm{~min}^{-1}$ sin embargo, estos valores pueden variar ya que dependen de factores importantes incluyendo la densidad, espesor de la capa carbonizada, contenido de humedad, concentración de oxígeno y flujo de calor externo [128-130]. 


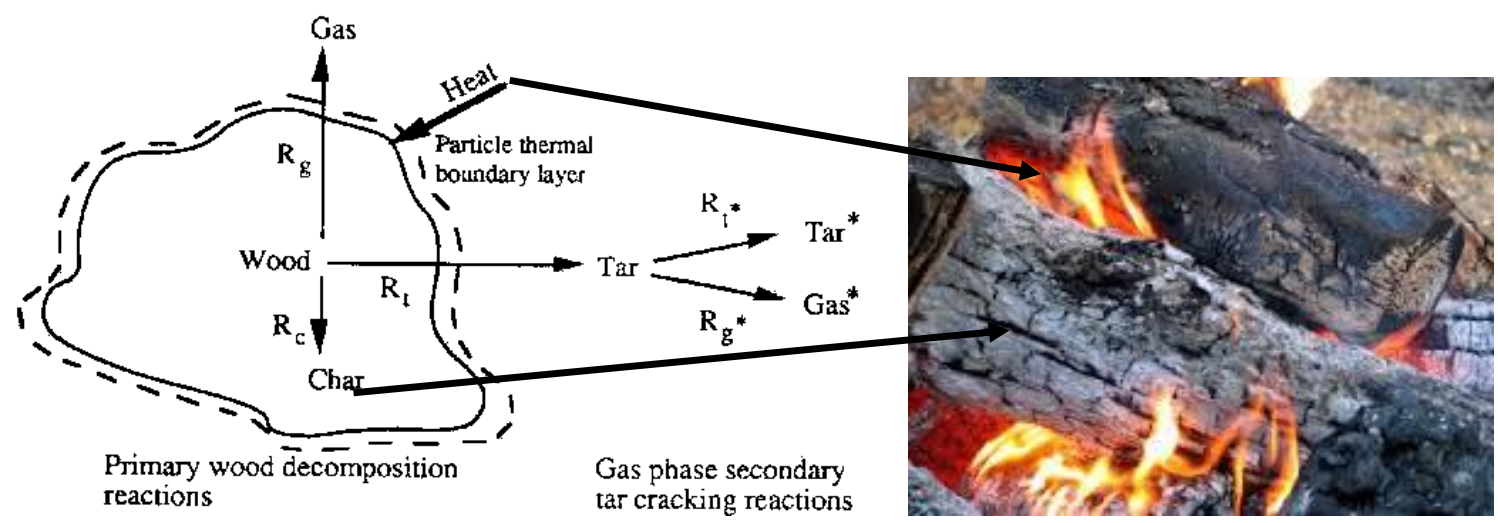

a)

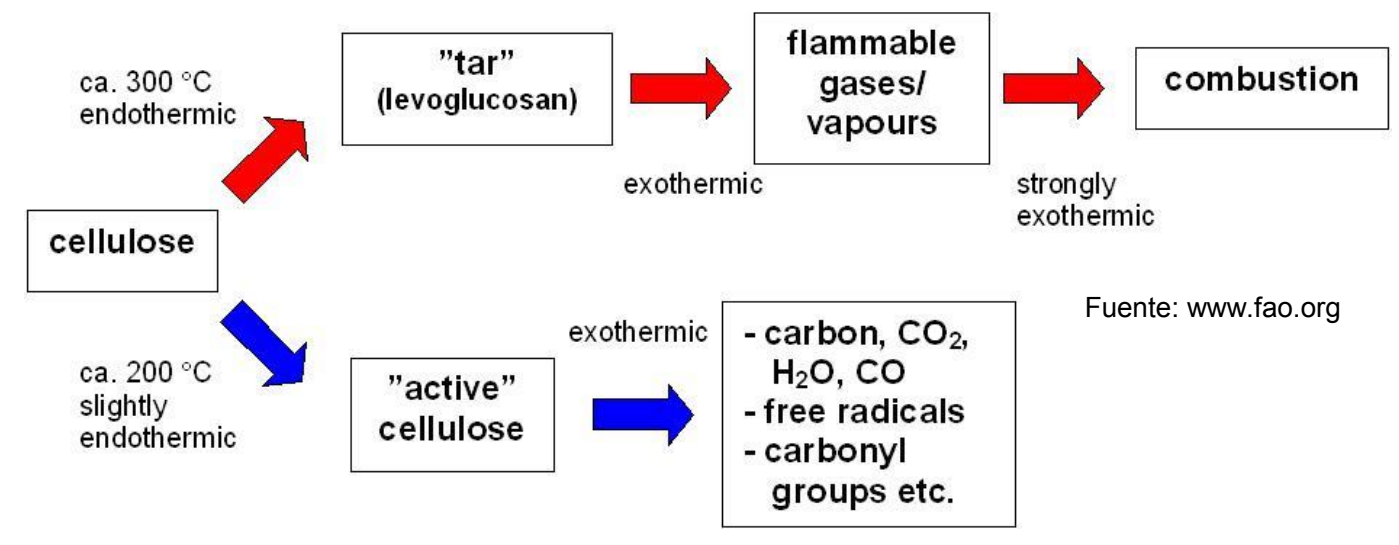

Figura I. 16. La madera a medida que se va quemando produce un residuo carbonoso que tiene propiedades aislantes (char) por eso se la considera un material más resistente comparado con otros materiales de construcción

\section{I.6.2.3 Acción climática y desgaste mecánico}

Las fluctuaciones de temperatura y de humedad, causan ciclos de contracción/expansión de las capas superficiales, formando pequeñas grietas y desfibramientos de la madera. Con el paso del tiempo la madera se desfibra, produciéndose en sus caras hendiduras y fisuras que se convierten en grietas o rajaduras.

El clima influye en la durabilidad de las maderas no tratadas; el tiempo húmedo y cálido favorece la pudrición de la madera expuesta a la intemperie en mayor medida que el tiempo seco y frío.

Por otro lado, toda pieza de madera que está expuesta a condiciones de movimiento, sufre un deterioro por desgaste, producto del roce. Éste es provocado por el polvo y la arena arrastrados 
por el viento, el granizo, etc. El efecto de fricción rompe las fibras disminuyendo sus propiedades fisicomecánicas [131-133].

\section{I.6.2.4 Radiación solar}

La radiación solar está constituida por un amplio rango de longitudes de onda entre los cuales se encuentra la luz ultravioleta (295 a $400 \mathrm{~nm}$ ) que posee gran cantidad de energía y por lo tanto genera deterioros significativos, aunque solo constituye el 5\% de la luz solar; la luz visible (400 a $700 \mathrm{~nm}$ ) la cual si bien no tiene energía suficiente para romper uniones químicas, causa variaciones en el color de la madera, en este caso constituye el $45 \%$ de la luz solar y por último, la luz infrarroja (700 a $2500 \mathrm{~nm}$ ) la cual produce calor y por ende acelera los procesos de degradación, esta constituye el 50\% de la luz solar.

Cuando la madera se expone a la luz solar cambia de color. En un primer momento si es clara se oscurece y si es oscura se aclara; luego, todas las maderas se tornan grises produciéndose además una fotodegradación física y química de las células superficiales de la madera.

Los aspectos más importantes de la degradación química son la formación la generación de radicales libres, oxidación por acción de la fracción UV de la luz solar en presencia de oxígeno, y la producción de un efecto post-radiación que se comprueba por la formación de dióxido de carbono, hidrógeno, agua, metanol, formaldehído y ácidos orgánicos; la reducción de la cantidad de lignina y aumento de la acidez y por la formación de productos volátiles [131-133].

\section{I.7 Preservantes}

Los preservantes son productos que se emplean para tratar la madera contra algún agente degradador específico. Un buen preservante debe reunir aspectos tales como ser tóxico sólo para los agentes degradadores (fungicida y/o insecticida, etc.), no ser combustible, tener buena penetración, ser químicamente estable, no descomponerse con el tiempo, no ser soluble en agua y tener buena permanencia. 
Ningún producto disponible en el mercado reúne todos los requisitos deseables; es por esto que uno de los objetivos planteados en la tesis es buscar preservantes que reúnan adecuadamente todos estos requisitos y además que proteja simultáneamente la degradación biótica y abiótica (más específicamente la acción fúngica, la absorción de agua y la acción del fuego) [134-136].

Muchos son los compuestos químicos que se utilizan y/o utilizaron para proteger a la madera de uso estructural. En este grupo se encuentra una variedad de sustancias, que se ha ido desarrollando recientemente tomando en cuenta que su característica principal es ser solubles en solventes oleosos derivados del petróleo. La eficiencia de estos productos químicos puede variar en función de las concentraciones y los solventes utilizados para su aplicación.

Los tratamientos en los que se emplean estos preservantes son clasificados según son aplicados en tres categorías [137-138]:

- Los que se incorporan mediante la impregnación: utilizado en madera en su estado previo o después de la fabricación del producto. Existen varios métodos de impregnación que lo que tienen en común es el uso de autoclave, donde es posible generar vacio y/o presión para facilitar el ingreso del impregnante, Figura I.17.

- Los que se incorporan mediante inmersión: estos generalmente se utilizan solo en maderas en su estado previo a la manufactura. Existen varios métodos donde se incluye el baño de tablas de maderas en las soluciones impregnantes a temperatura ambiente y $\sin$ agitación, el cual consta simplemente en introducir madera en un recipiente de volumen adecuado y reposar hasta que la madera este hundida; o el uso del sistema desarrollado para poder trabajar un amplio rango de temperaturas $\left(30^{\circ} \mathrm{C}-80^{\circ} \mathrm{C}\right)$ con agitación y durante un tiempo determinado, Figura I.17.

- Los que se incorporan en las capas superficiales de la madera después de terminado el producto, bien en las propias fábricas o in-situ; estas son las pinturas y recubrimientos aplicados por pulverización o pincelado, Figura I.17

Los preservantes empleados contra agentes bióticos son aplicados mediante impregnación o inmersión. No existen recubrimientos que sean específicos para esta función ya que la protección por efecto barrera no es eficiente para la acción de los organismos, hasta incluso es general actúa como vehículo colonizador [139-140]. 
En cuanto a la protección contra la acción del fuego, se realiza mediante impregnación o mayormente mediante la aplicación de recubrimientos intumescentes o retardantes de llamas. La acción de los retardantes reduce en el tiempo la pérdida de peso que sufre por carbonización la masa leñosa, al mismo tiempo que puede limitar la tendencia a la permanencia de la llama y/o brasa que aparece en la madera encendida.

Dentro de los compuestos ignífugos o retardadores de fuego se distinguen los que impiden que llegue oxígeno a la madera durante algunos minutos y los que basan su acción ignífuga en que reaccionan, en presencia de calor, emitiendo sustancias que acaparan el oxígeno del aire, impidiendo que la madera se queme [141-144].

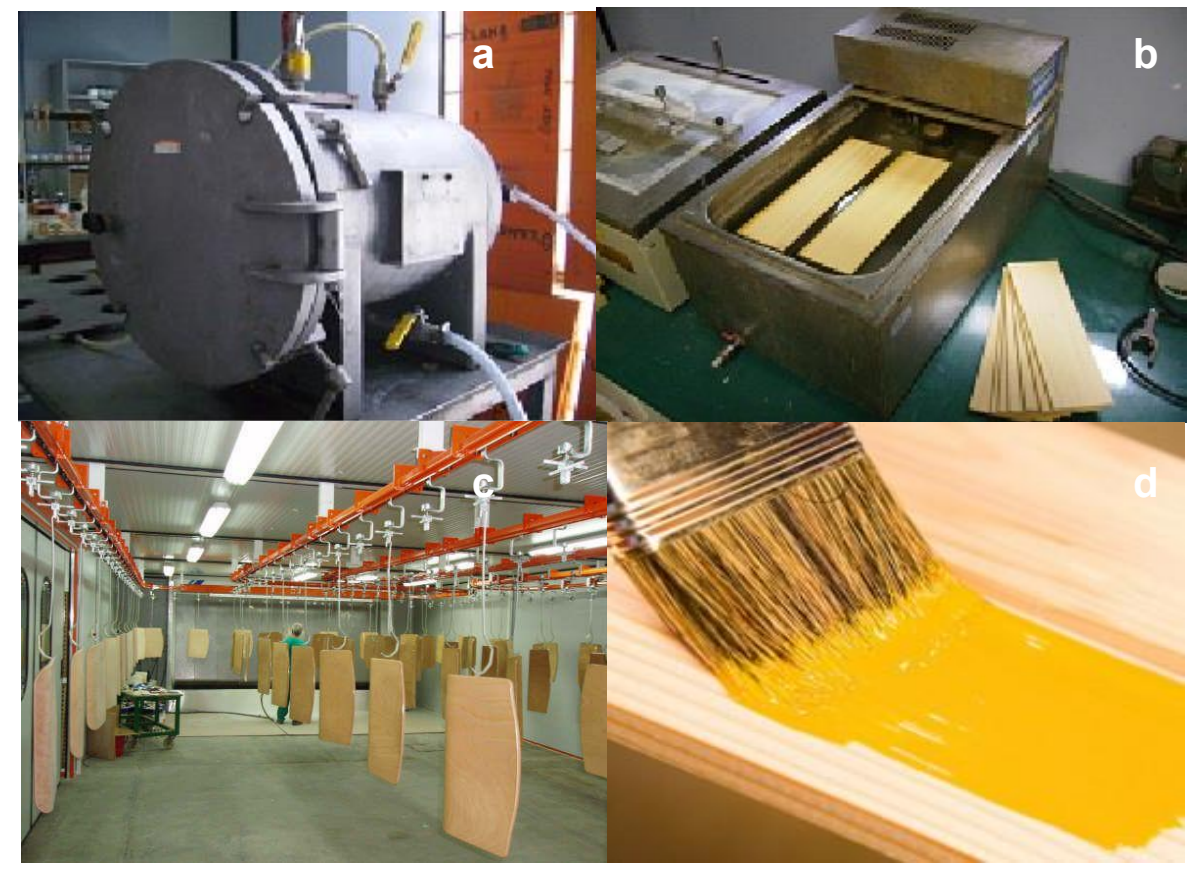

Fuente: Imágenes de Internet

Figura 1.17. Diferentes métodos de aplicación de los tratamientos preservantes para maderas: a) impregnación, la foto muestra el autoclave en donde se introducen las maderas con la solución impregnante; b) inmersión, se observa dispositivo donde las maderas son sometidas a agitación, inmersas en la solución impregnante; c) cámara de pintado por pulverización, utilizado generalmente para líneas de fabricación de piezas de madera y d) pintado con pincel, método comúnmente empleado para la aplicación de pinturas protectoras.

En cuanto a la hidrorrepelencia, se encuentran varias limitaciones que muchos investigadores han demostrado a lo largo del tiempo: en general los repelentes permiten un control significativo de la absorción de agua solo para un período de tiempo razonable pero luego esta se pierde. Esta 
pérdida está asociada a la no-unión o unión débil entre la pared celular y el hidrófugo, con lo cual el agua lo termina desplazando. Una forma de superar este efecto puede ser para unir el hidrófobo químicamente sobre la pared celular [146-148]: esta línea de modificación de la pared celular de la madera será la principal línea a seguir en todos los métodos de protección que se emplearán en esta tesis debido a que este asegura la durabilidad, permanencia y por lo tanto eficacia del sistema protector que se le aplique a la madera contra cualquier agente degradante.

La presente tesis se desarrollará en el marco de dos actuales tendencias: el uso de silanos y nanocompuestos (más específicamente nanoóxidos) con el fin de modificar químicamente la madera, de manera individual o en mezcla de ambos, con el objetivo principal de otorgar a este material protección simultanea frente a los principales agentes degradadores del orden biótico (hongos) y abióticos (humedad y fuego).

\section{I.7.1 Modificación química de la madera}

\section{I.7.1.1 Precursores de formulación: silanos y nanopartículas}

Los silanos, específicamente los alcoxisilanos son compuestos químicos derivados del silicio que consisten de un átomo de silicio unido a un grupo orgánico a través de un átomo de oxígeno (SiOR). Estos compuestos son muy versátiles debido a que el enlace Si-OR puede permanecer intacto o hidrolizarse en la aplicación final para formar polímeros con diferentes propiedades [149].

La fórmula general de un alcoxisilano es $\mathrm{R}_{n} \mathrm{SiOR}^{\prime}$ (4-n) donde $\mathrm{R}$ es un grupo funcional orgánico no hidrolizable que puede ser un alquilo, aromático, organofuncional, o una combinación de cualquiera de estos grupos. Estos grupos proporcionan la compatibilidad orgánica que permite al silano formar una red polimérica interpenetrante, o en el caso de silanos organofuncionales reactivos, co-reaccionar con otro polímero o sustrato. El grupo OR' representa grupos alcoxi, más típicamente metoxi o etoxi, que reaccionan con las diversas formas de grupos hidroxilo y liberan metanol o etanol al reaccionar (hidrólisis). Estos grupos pueden proporcionar el vínculo con sustratos inorgánicos, pigmentos o cargas. Los grupos metoxi también son capaces de 
reaccionar con polímeros funcionales que tengan grupos hidroxilo como es el caso de la madera [149-150].

La unión de silicio-silicio puede ser comparada a la unión de carbono-carbono de muchas maneras: el carbono es la columna vertebral de la vida y puede formar cadenas estables de longitud infinita, pero a diferencia de este, la estabilidad de las cadenas de silicio disminuye con la longitud. Esto se debe a que 1) el enlace Si-Si es ligeramente más débil que el enlace C-C, 2) el enlace $\mathrm{Si}-\mathrm{H}$ es más débil que el enlace $\mathrm{C}-\mathrm{H}, 3$ ) el silicio es menos electronegativo que el hidrógeno mientras que el carbono es más electronegativo que el hidrógeno, y 4) el silicio es más grande (proporciona una mayor área superficial), y tienen electrones de baja energía (orbitales d) los cuales promueven el ataque nucleofílico [149-153].

Los óxidos de silicio son más estables que la unión de silicio-silicio formando enlaces del tipo Si-O-Si. Estas cadenas son las que forman los silanos, que son los monómeros que constituyen a los siloxanos que a su vez son los oligómeros que componen a los polisiloxanos, Tabla I.1 [149154]. Resulta importante definir estos términos dado la diversidad de usos que tienen en distintas fuentes bibliográficas.

La tendencia actual en el campo de la protección de materiales además de los silanos es el uso de nanocompuestos ya que además de tener propiedades excelentes como biocida, anticorrosivos e ignífugos permiten generar sistemas amigables con el medio ambiente (ya que no se necesitan altas concentraciones y pueden ser dispersados en soluciones acuosas), de bajo costo y alta eficiencia.

Los nanomateriales poseen propiedades únicas, que pueden ser totalmente diferentes de las características en su estado elemental [155]. En algunos casos puede observarse un efecto potencial que se atribuye al pequeño tamaño de la nanopartícula, cuyo correlato es el incremento de la superficie específica disponible para reaccionar, al igual que mejora la facilidad de dispersión de las partículas, resolviendo de esa manera los problemas de penetración en las maderas y los de la dispersión dentro de una formulación de pinturas. 


\begin{tabular}{|l|l|}
\hline SILANOS & \multicolumn{2}{|l|}{ SILOXANOS } \\
\hline Son las moléculas de silicona más pequeñas & Polímeros lineales \\
\hline $\begin{array}{l}\text { Baja tensión superficial y baja viscosidad } \\
\text { - excelente distribución y penetración en la } \\
\text { mayoría de las superficies }\end{array}$ & $\begin{array}{l}\text { Baja tensión superficial - excelente distribu- } \\
\text { ción sobre la mayoría de las superficies }\end{array}$ \\
\hline $\begin{array}{l}\text { Profundidad de penetración y exclusión del } \\
\text { agua; permitiendo a la vez el pasaje del } \\
\text { vapor de agua }\end{array}$ & $\begin{array}{l}\text { La estructura helicoidal de los siloxanos } \\
\text { repelen el agua al estado liquido (perlado), } \\
\text { pero permiten el pasaje del vapor de agua }\end{array}$ \\
\hline $\begin{array}{l}\text { Los alcoxi-silanos utilizados como hidrorre- } \\
\text { pelentes reaccionan consigo mismos y con } \\
\text { cualquier grupo funcional OH formando una } \\
\text { malla de resina de silicona }\end{array}$ & $\begin{array}{l}\text { Diferentes químicas posibilitan la reactividad } \\
\text { con la superficie o con otros siloxanos }\end{array}$ \\
\hline $\begin{array}{l}\text { La penetración se combina con la estabi- } \\
\text { lidad a la oxidación y a los rayos UV/calor } \\
\text { logrando una excelente durabilidad }\end{array}$ & $\begin{array}{l}\text { Sumamente resistentes a la degradación } \\
\text { causada por los rayos UV, el calor y la } \\
\text { oxidación }\end{array}$ \\
\hline \multicolumn{2}{|c|}{$\begin{array}{l}\text { Las siliconas se presentan en muchas formas y diversos grupos funcinales, y } \\
\text { a menudo se las utiliza combinadas para obtener las propiedades requeridas. }\end{array}$} \\
\hline
\end{tabular}

Tabla I 2. Diferencias entre silanos y siloxanos, Dow corning el oligómero. Esta diferencia es importante ya que sus características se modifican sustancialmente.

Se han reportado investigaciones preliminares orientadas a la evaluación de soluciones y suspensiones preservantes elaboradas sobre la base de nanopartículas de cobre, de zinc y de boro, en algunos casos adicionados con plata (cuyos efectos bactericidas son conocidos), con o sin la adición de algún tipo de surfactante [155], orientadas a proteger la madera de microorganismos (muy orientado a bacterias y no a hongos) pero no hay muchos datos con respecto al deterioro por acción del fuego o al biodeterioro que sufren las pinturas por los microorganismos y por las condiciones ambientales naturales.

El estudio y desarrollo de biocidas en general se inicia con los primeros antibióticos [156]; desde esa época se conoce que el tamaño de los agentes antimicrobianos es un factor clave en su eficacia; en otras palabras, la eficiencia biocida depende de la zona activa expuesta del compuesto utilizado con tal fin [157-158].

Durante la última década, se ha informado de moléculas nanométricas que presentan una actividad mejorada en comparación con sus homólogos a granel. En base a esto se comenzó a diseñar sistemas protectores contra la degradación para diversos sustratos (textiles, papel, 
concreto, acero, etc.). Específicamente, en madera se comenzó a utilizar estos nanocompuestos con el fin de que cumplan funciones biocidas, uno de los puntos vulnerables de este material que lleva a la pérdida de sus propiedades físico-mecánicas [159-160].

Las nanoestructuras poliméricas se pueden clasificar según la cantidad de dimensiones que tiene esa estructura. Las unidimensionales se han aplicado en muchas áreas interesantes debido a sus propiedades únicas, tales como la elevada área superficial. El ejemplo más conocido de estas dimensiones son los nanotubos de carbono y nanofibras que fueron empleados en muchos trabajos para la obtención de "nanocomposites" debido principalmente a sus propiedades tales como la elevada resistencia mecánica y sus propiedades eléctricas y térmicas $[152,157]$.

En el campo de la investigación antimicrobiana, las nanoestructuras unidimensionales son polímero que se utilizan como primer para la preparación de nanofibras inorgánicas o como sustratos para la carga de antibacterial planteando un método de liberación controlada del biocida adosado a ese nanopolímero [152].

Entre los nanoestructurados bidireccionales (en capas), se destacan como más conocidas las nanoarcillas, entre las que se destcan montmorillonita, bentonita, hectorita, sepiolita, saponita y mica sintética. Por último, se encuentran las tridimensionales que son básicamente las nanopartículas, representan la transición entre los materiales de naturaleza microscópica y las estructuras moleculares o atómicas. Cabe destacar que actualmente hay varios trabajos donde estas son aplicadas en maderas junto con formulaciones poliméricas para generar una modificación química màs eficiente del sustrato, dado que estas se unen a la madera con facilidad estimulando el agregado de particulas a ellas. [158]. De este tipo es el que se utilizó en la impregnación de maderas para la hidrorrepelencia y la protección contra el biodeterioro y la acción del fuego en esta tesis.

\section{I.7.1.2 Polimerización: proceso sol-gel}

El proceso sol-gel es una técnica de síntesis para la fabricación de una red integrada (llamado gel) de óxidos metálicos o de polímeros híbridos. Como precursores, comúnmente se utilizan metal-inorgánicos (nanocompuestos), sales como cloruros metálicos y compuestos metalorgánico tales como los alcóxidos (silanos) [160-166]. 
Las reacciones químicas que ocurren durante un proceso sol-gel son hidrólisis y policondensación. Durante la hidrólisis y policondensación, se forma un coloide (sol), que consiste en nanopartículas dispersadas en un solvente (2-200 nm; 103-109 átomos por partícula). El sol luego, se transforma en un sistema difásico gelatinoso, que consiste en un líquido y una fase sólida, llamado gel. Este último, es una red (porosa) tridimensional formada por interconexión de partículas sólidas en un medio líquido, su crecimiento lo limita el recipiente ya que químicamente es ilimitado. El tamaño y formación puede variar desde partículas coloidales discretas a polímeros de cadena continuas; esto dependerá de las condiciones químicas en el que se dé este proceso, es decir, dependerá principalmente del $\mathrm{pH}$ al cual se realiza el proceso, Figura I.18 [160-163].

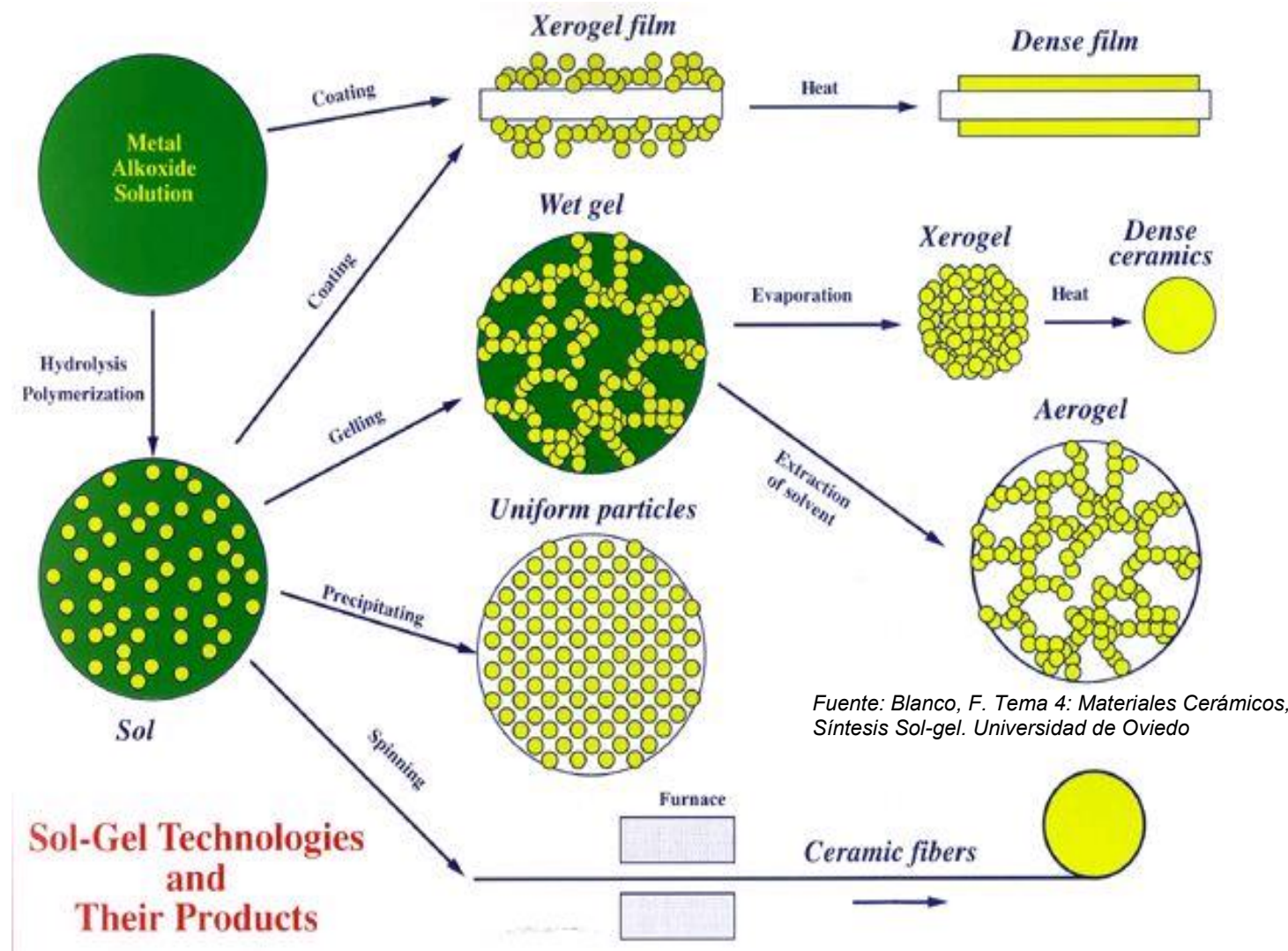

Figura I.18. Tecnología Sol-gel y sus productos los cuales difieren según sean manipulados las condiciones del proceso.

El desarrollo del proceso de sol-gel de sílice en la ciencia de materiales comienza con una solución de precursor, un alcóxido de silicio $\mathrm{Si}(\mathrm{OR})$ en un alcohol u otro disolvente orgánico de bajo peso molecular. 
En comparación con la química coloidal, la ruta alcóxido puede ser más fácilmente controlada mediante el control de hidrólisis y reacciones de condensación (condensación de agua y de alcohol): en términos generales, la reacción de hidrólisis (1-4), consiste en sustituir los grupos alcóxidos (-OR) por grupos hidroxilo $(-\mathrm{OH})$ y la liberación de las correspondientes moléculas de alcohol ROH. Se obtiene una hidrólisis completa (4) cuando la relación estequiométrica molar de agua $/ \mathrm{Si}(\mathrm{OR})_{\mathrm{n}}$ es 4 . Las especies intermedias $\left[(\mathrm{OR})_{2}-\mathrm{Si}-(\mathrm{OH})_{2}\right]$ o $\left[(\mathrm{OR})_{3}-\mathrm{Si}-(\mathrm{OH})\right]$ sería considerado el resultado de una hidrólisis parcial (3a, 3b). Una pequeña cantidad de agua conduce a una hidrólisis lenta debido a la concentración de reactante reducida, mientras que una gran cantidad de agua da una hidrólisis lenta debido a la mayor dilución de reactivo. Reacciones de condensación subsiguientes implican a los grupos silanol $(\mathrm{SiOH})$, producen enlaces de siloxano (Si-O-Si) y agua como subproductos y el alcohol [160-166]:

$$
\begin{aligned}
& \equiv \mathrm{Si}-\mathrm{OR}+\mathrm{HOH} \underset{\text { reesterification }}{\stackrel{\text { hydrolysis }}{\rightleftharpoons}} \equiv \mathrm{Si}-\mathrm{OH}+\mathrm{ROH} \\
& \text { water } \\
& \text { condensation } \\
& \equiv \mathrm{Si}-\mathrm{OH}+\equiv \mathrm{Si}-\mathrm{OH} \quad \underset{\text { hydrolysis }}{\stackrel{\text { condensation }}{\rightleftharpoons}} \equiv \mathrm{Si}-\mathrm{O}-\mathrm{Si} \equiv+\mathrm{HOH} \\
& \equiv \mathrm{Si}-\mathrm{OH}+\equiv \mathrm{Si}-\mathrm{OR} \quad \frac{\begin{array}{l}
\text { alcohol } \\
\text { condensation }
\end{array}}{\underset{\text { alcoholysis }}{\rightleftharpoons}} \equiv \mathrm{Si}-\mathrm{O}-\mathrm{Si} \equiv+\mathrm{ROH} \\
& \mathrm{R}=-\mathrm{C}_{2} \mathrm{H}_{5} \\
& (\mathrm{OR})_{3}-\mathrm{Si}-\mathrm{OH}+\mathrm{HO}-\mathrm{Si}-(\mathrm{OR})_{3} \rightarrow\left[(\mathrm{OR})_{3} \mathrm{Si}-\mathrm{O}-\mathrm{Si}(\mathrm{OR})_{3}\right]+\mathrm{H}-\mathrm{O}-\mathrm{H} \\
& (\mathrm{OR})_{3}-\mathrm{Si}-\mathrm{OR}+\mathrm{HO}-\mathrm{Si}-(\mathrm{OR})_{3} \rightarrow\left[(\mathrm{OR})_{3} \mathrm{Si}-\mathrm{O}-\mathrm{Si}(\mathrm{OR})_{3}\right]+\mathrm{R}-\mathrm{OH} \\
& \mathrm{Si}(\mathrm{OR})_{4}+4 \mathrm{H}_{2} \mathrm{O} \rightarrow \mathrm{Si}(\mathrm{OH})_{4}+4 \mathrm{R}-\mathrm{OH}
\end{aligned}
$$

Fuente: Blanco, F. Tema 4:Materiakes Ceramicos, Sintesis Solgel. Universidad de Oviedo

Bajo la mayoría de condiciones, la condensación puede comenzar antes de una hidrólisis completa. Las condiciones tales como $\mathrm{pH}$, relación $\mathrm{H}_{2} \mathrm{O} / \mathrm{Si}$ molar (r) y el catalizador puede forzar la hidrólisis completa antes de que comience la condensación. Debido a la miscibilidad del alcóxido y el agua, un disolvente mutuo, un alcohol, se utiliza como agente de 
homogeneización para facilitar el proceso de hidrólisis. La reacción de condensación es seguida por un proceso de polimerización con la formación de nanopartículas de $\mathrm{SiO}_{2}$. Este proceso es fuertemente dependiente del $\mathrm{pH}[160-166]$.

La reacción de los silanos implica cuatro etapas: Inicialmente, se produce la hidrólisis de los grupos alcoxi (OR') seguido de la condensación de los oligómeros hidrolizados (siloxanos) [167-170]:

La polimerización por crecimiento en etapas genera polímeros lineales cuando esta incluye homocondensaciones de silanos o en forma de red cuando se generan heterocondensaciones donde los implicados son los grupos silanol. La geometría de los orbitales electrónicos y sus interacciones estabilizan la estructura del silanol y fortalece al silicio para que se enlace a un grupo hidroxilo (este tiene un carácter de doble enlace parcial); dado que el grupo silanol es a la vez un buen donante y aceptor de protones, las interacciones moleculares son altas y hace que el silanol forme puentes de hidrógeno fácilmente tanto de manera intermolecular como intramolecular. Estas interacciones del grupo terminal silanol son consideradas como catalizadores de la policondensación; este fenómeno es muy eficaz cuando las cadenas son cortas, pero con el alargamiento de la cadena disminuye la eficacia debido a que la longitud aleja las moléculas en el espacio impidiendo que se formen los puentes de hidrógeno [170-180].

Esta secuencia de condensaciones requiere tanto una despolimerización de la polimerización reciente (apertura del anillo) como disponibilidad de monómeros (especies que pueden ser producidos por despolimerización). Sin embargo, en las disoluciones alcohólicas especialmente a pH bajo la tasa de despolimerización es muy baja [175] por lo cual se presenta menor probabilidad de ocurrir una nueva polimerización sucesiva de modo que la condensación es irreversible. Los siloxanos no puede ser hidrolizado una vez que ya se formaron, por lo que termina dándose un proceso de policondensación clásica de un monómero orgánico polifuncional, resultando una red molecular tridimensional.

De las observaciones de los alcoxigeles de óxido de silicio, se concluyó que generalmente que un sol catalizado por una base ( $\mathrm{pH}$ alcalino) resulta en una especie discreta formada por agregación de monómeros como si fuesen racimos, lo cual generan polímeros más compactos y muy ramificado (se ven afectados por la sedimentación y fuerzas de la gravedad). En cuanto a 
los soles catalizados por un ácido ( $\mathrm{pH}$ ácido) deriva en cadenas de polímero altamente enredados mostrando una microestructura muy fina y poros muy pequeños que aparecen bastante uniformes por todo el material. Por lo tanto, condiciones ácidas conducen a redes microporosa densas (tamaño de poro $<2 \mathrm{~nm}$ ) y en condiciones alcalinas se obtienen geles mesoporosos $(2 \mathrm{~nm}$ $<$ tamaño de poro $<50 \mathrm{~nm})[160-166]$ :

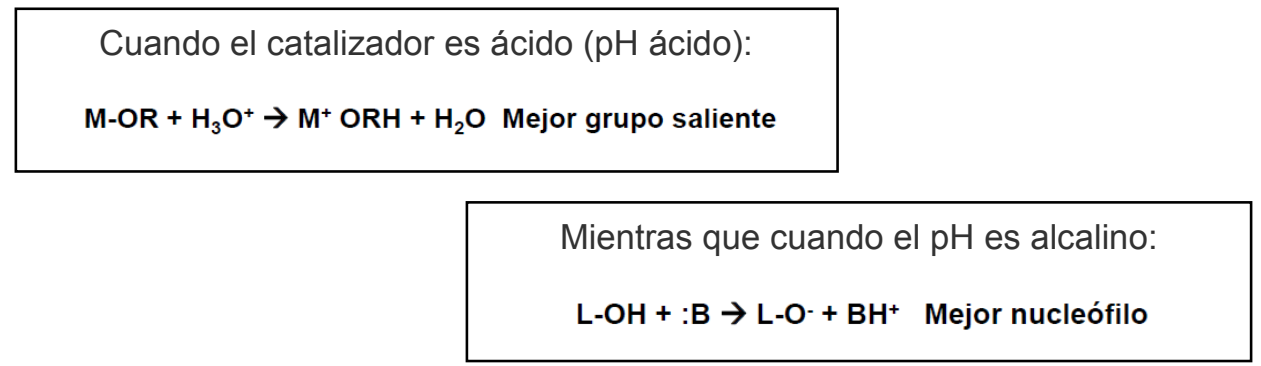

Fuente: Blanco, F. Materiales Cerámicos, Síntesis Sol-gel. Universidad de Oviedo

Bajo condiciones más básicas se obtienen sistemas estables (no gelificantes). La tasa de condensación global se maximiza a $\mathrm{pH}=8$ y se minimiza a $\mathrm{pH} 2,2$. A $\mathrm{pH} 2,2$ corresponde al punto isoeléctrico de la sílice: los grupos silanol superficiales son protonados y desprotonados a pH inferior y superior, respectivamente. Debido a que los silanoles se vuelven más ácidos con el grado de condensación de la red de siloxano están adscritos al cambio mínimo de pH: por ejemplo, a pH 4,5 hay condensación de monómeros mientras que a $\mathrm{pH}$ 2,2 hay condensación polidispersa y polímeros de orden superior.

Cuando el $\mathrm{pH}<2$ hay muchos $\left[\mathrm{H}^{+}\right]$en solución estos reaccionan con los grupos SiOR impidiendo que se formen agregados por bloqueo y "obligando" a que se formen polímeros lineales:

$$
-\operatorname{SiOR}\left(\mathrm{OH}_{2}\right)^{+}+\mathrm{H}^{+} \leftrightarrow \quad-\operatorname{SiOR}\left(\mathrm{OH}_{2}\right)^{+}
$$

Además, las partículas tienen baja solubilidad por lo tanto esto también impide la formación de agregados. 
Cuando el $\mathrm{pH}=2$ no hay repulsión debido a que es el punto isoeléctrico de la sílice ( $\mathrm{pH} 2,2)$, por lo cual hay crecimiento y agregación de partículas, pero a su vez hay baja solubilidad por lo cual se lo llama equilibrio metaestable debido a que no se observan cambios en el sistema.

En condiciones catalizadas por ácido, la cinética de la hidrólisis se ve favorecida en lugar de la condensación, que generalmente se inicia cuando se complete la hidrólisis.

En las reacciones catalizadas por álcali, la condensación es más rápida que la hidrólisis, lo que resulta en una especie altamente condensada que pueden aglomerarse en partículas finas. Cuando el $\mathrm{pH}>7$ hay presencia de partículas cargadas lo cual hace que los monómeros formen agregados grandes. Además, las partículas tienen alta solubilidad en el sol por ello es que se obtienen estructuras más porosas.

Independientemente de la causa, la dependencia del $\mathrm{pH}$ sugiere que silanoles protonados y desprotonados están implicados en el mecanismo catalizador ácido y base. A pH elevado las reacciones de condensación proceden a buen ritmo, pero la gelificación no se produce. Con esta condición se forman partículas de régimen de $\mathrm{pH}$ que después de alcanzar un tamaño crítico se vuelven estables debido a los efectos de repulsión.

Con respecto a la evolución estructural, la extensión de la ramificación es lo que se busca controlar: partículas frente a geles poliméricos, aparición de fractales, espinabilidad, etc. Todo esto puede ser manejado considerando el $\mathrm{pH}$, la dependencia $\left[\mathrm{H}_{2} \mathrm{O}\right]$ de la hidrólisis, condensación y velocidades de disolución.

Los geles de partículas lisas (no-fractales) ocurren cuando hay una fuente continua de recursos completamente funcionales de monómeros y la condensación es limitada en la reacción $(\mathrm{pH}$ ácido y sin presencia de agua, caso llamado silano en la presente tesis).

La formación de clústeres se da por la funcionalidad reducida del anillo resultado en fracciones débilmente ramificadas o fractales superficiales $(\mathrm{pH}$ alcalino y sin presencia de agua, caso llamado sol en la presente tesis), Figura I.18.

Hay tres condiciones de $\mathrm{R}=\mathrm{H}_{2} \mathrm{O} / \mathrm{Si}$ : bajos, medio y alto. El efecto más evidente dado por el aumento de relaciones $\mathrm{Si} / \mathrm{H}_{2} \mathrm{O}$ es la promoción de la hidrólisis. También se conocen otros dos 
efectos: adiciones de agua por estequiometria $(\mathrm{R}<4$ ) genera la condensación dando producción de alcohol lo cual favorece al proceso sol-gel, mientras que con $\mathrm{R} \gg>4$ el exceso de agua provoca la promoción de la despolimerización del anillo generando sucesivas despolimerizaciones hidrolíticas que dan más agua como subproducto [180-185].

En resumen, el control de variables permite obtener el polímero que se desea

\section{$p H$ ácido $+r$ bajo $=$ polímeros más ramificados pH alcalino $+r$ alto $=$ polímeros más particulados $($ agregados $)$}

Este efecto se debe a la variación de la solubilidad de los precursores [167-174].

Del análisis globa del proceso se observa que, la tasa de hidrólisis alcóxidos de silicio presenta un mínimo a $\mathrm{pH}=7 \mathrm{y}$ aumenta exponencialmente tanto a $\mathrm{pH}$ más bajo como más alto, contrariamente a la condensación que a ese $\mathrm{pH}$ presenta una tasa máxima. Siendo la hidrólisis la que regula el proceso sol gel, en la presente tesis se utilizó este criterio para asegurar que los silanos no reaccionen fuera de la madera manteniendo una tasa mínima de esta. Además, como otra regulación, se utilizó un $\mathrm{r}$ bajo para asegurar que haya ramificación, formando así un film y no un agregado particulado.

Por otro lado, se sabe que los sustituyentes de los silanos también juegan un rol importante en las propiedades del polímero final, por ello se eligieron silanos que difieren en sustituyentes.

Los sustituyentes tienen la capacidad de aportar más electrones al sistema lo cual ayuda a estabilizar las cargas positivas en desarrollo de la reacción, debido a su capacidad de estabilizar la carga negativa que toma el silicio, disminuyendo la tasa de hidrolisis. Esto indica entonces que, a mayor cantidad de electrones (mayor cadena hidrocarbonada en los sustituyentes), disminuye la tasa, por ello este factor también se tuvo en cuenta en la elección de los silanos [178-183].

El retraso de la hidrólisis con el aumento de los sustituyentes indica que este mecanismo está sujeto a efectos inductivos que se traduce en la carga que le da el medio a los estados de 
transición durante el proceso, generando una mayor o menor estabilidad de los mismos lo cual incrementará o disminuirá la velocidad de reacción.

Esta línea de razonamiento conduce a decir que, en condiciones ácidas, la velocidad de hidrólisis disminuye mientras que, en condiciones básicas, la velocidad aumenta junto con el aumento de los aceptores de electrones (-OH). Por ello, es que es fundamental el manejo del pH y los diferentes sustituyentes elegidos en los sistemas propuestos, Figura I.19.

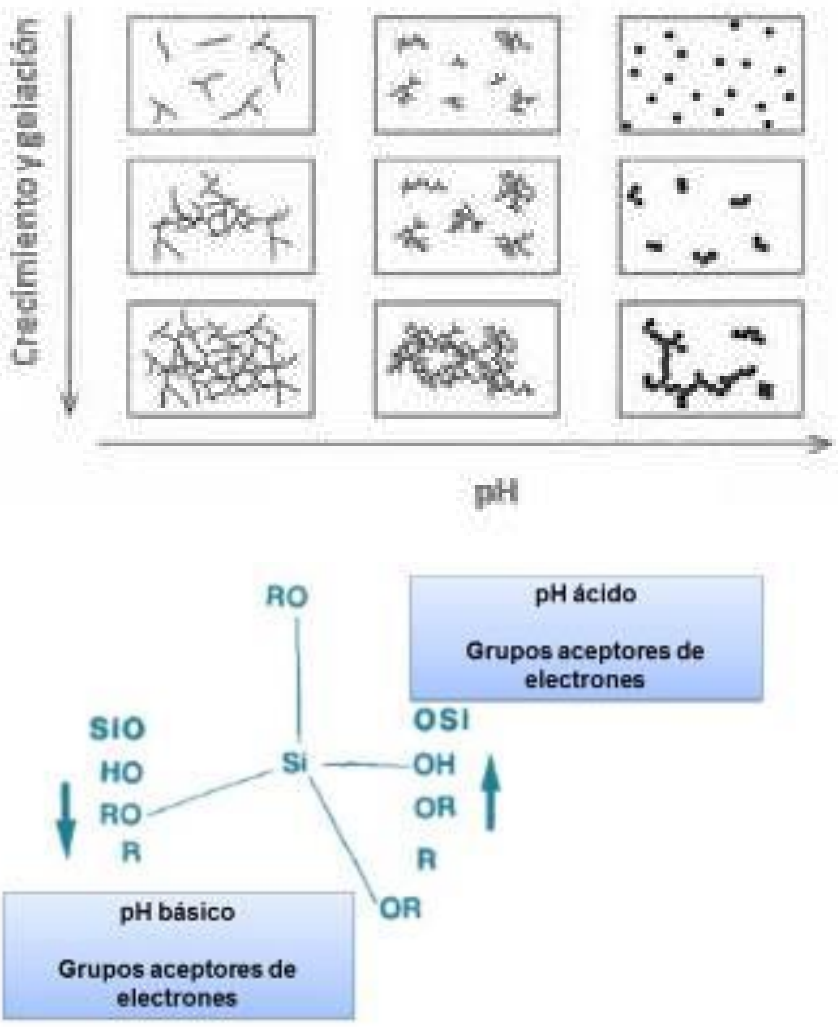

Figura I.19 Efecto de pH en el crecimiento y gelación. Cuadno se agrega también la variable sustituyentes, todo el sistema sufre un efecto inductivo aumentando la reactividad de los precursores poliméricos.

El uso de los silanos para la protección de materiales se debe a que son capaces de formar uniones covalentes con el sustrato a través de la parte inorgánica (OR') de la molécula (se restringe a materiales que tengan $-\mathrm{OH}$ en su composición química), Figura I.20. 

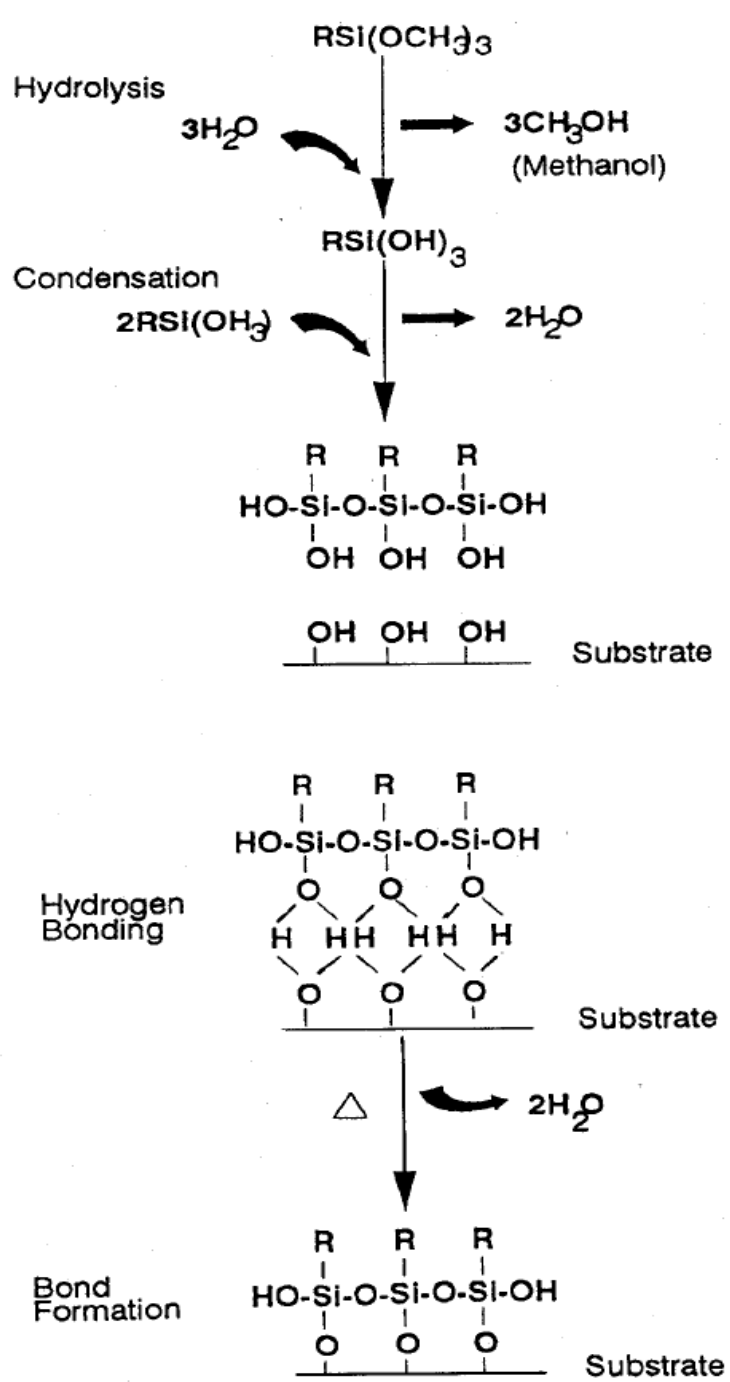

Figura I.20 Reacción de los alcoxisilanos entre sí y/o con el sustrato por reacciones de hidrólisis y condensación (proceso sol-gel). En el caso de la madera, los silanos reaccionan con los -OH de la celulosa que compone la pared celular de las células (traqueidas) modificándola químicamente

Esto se logra mediante la reacción de la unión Si-O-C con el agua (reacción de hidrólisis) para dar silanoles $(\mathrm{Si}-\mathrm{OH})$, que posteriormente reaccionan con los óxidos y/o hidróxidos presentes en la superficie del material formando uniones covalentes del tipo Si-O-Sustrato.

En pinturas donde se emplearon estos compuestos, por ejemplo, se utilizaron alquilo y arilo silanos para mejorar el brillo, poder cubriente, tiempo de mezclado, y otras propiedades 
relacionadas con la mejora de la dispersión del pigmento. Por otra parte, estos también son para proporcionar superficies hidrófobas en aplicaciones tales como repelentes de agua [165].

Otra posibilidad de reacción para los grupos silanol es la de reaccionar entre ellos formando uniones Si-O-Si con otras moléculas de siloxano. Así, puede formarse un polímero de siloxanos unido covalentemente al material, Figura I.20 [166-174].

Específicamente, en el caso de las maderas, lo silanos reaccionan con los oxidrilos de la celulosa que compone la pared secundaria de las traqueidas, lo cual hace que la madera quede químicamente modificada [183]. Este tipo de tratamiento es el que se emplea en la presente tesis.

\section{I.7.2 Recubrimientos protectores}

Las pinturas o recubrimientos superficiales revisten una extraordinaria importancia en nuestra vida diaria, prácticamente casi todos los objetos de la vida cotidiana, edificios, estructuras, etc. se encuentran pintados o con un recubrimiento superficial de naturaleza generalmente orgánica.

Los recubrimientos se aplican como elemento de decoración, como protección (proteger de pudrición, corrosión, etc.) o por algún otro propósito funcional (pinturas conductoras, sanitizadas, etc.).

Como elemento de protección, las pinturas actúan principalmente por efecto barrera, es decir separando el elemento a proteger del agente agresor, esto requiere la aplicación de un espesor mínimo que garantice la protección durante el tiempo adecuado. También en algunos casos pueden contener sustancias que contribuyan a proteger al sustrato.

La durabilidad de una pintura va a depender del espesor aplicado y de la naturaleza química de la misma (para unas condiciones ambientales dadas), por tanto, sobrepasado este periodo se habrá de proceder a unos trabajos de mantenimiento para aumentar la vida útil del sistema protector [186-190]. 
La madera durante su vida en servicio está sometida a constantes fluctuaciones ambientales; lo que incluye cambios en la humedad tanto interna como externa, así como los efectos de la lluvia y de condensación. Esto puede provocar movimientos en la madera lo cual hay que tener en cuenta al formular y especificar un tipo de recubrimiento para este sustrato, ya que la velocidad a la que se produce el movimiento en la madera depende de la mayor o menor permeabilidad del agua a través del recubrimiento. Aunque el recubrimiento puede influir sobre la velocidad del movimiento de la madera, no puede impedirlo.

Así pues, el recubrimiento debe de tener la suficiente extensibilidad para expandirse y contraerse con la madera y además presentar una suficiente adhesión para resistir las tensiones interfaciales entre sustrato y recubrimiento. El agua, cuando es absorbida por el recubrimiento, actúa como plastificante y aunque esto ayuda a la extensibilidad puede facilitar el desprendimiento del recubrimiento.

Además, es posible que sustancias solubles de bajo peso molecular sean transportadas por el agua a la interfase con el sustrato creando una capa de débil adhesión. Si la adhesión es baja el recubrimiento será vulnerable al blistering (ampollamiento), especialmente si la presión de vapor es alta y la permeabilidad baja. Las ampollas son provocadas por una adhesión débil combinada con una flexibilidad alta, pero debe de haber una fuerza impulsora que puede ser presión de vapor, hinchamiento, presión osmótica o exudación de resina. Algunos polímeros, como los que contienen enlaces éster, tienen tendencia a la hidrólisis, por lo que es conveniente no utilizarlo en zonas permanentemente húmedas [190-193].

Por otro lado, la radiación solar provoca en la madera reacciones físicas y químicas que están básicamente confinadas a la superficie. Muchas de estas reacciones requieren también la presencia de humedad y aire. En condiciones secas la madera no protegida tiende a una coloración marrón, que se transforma en gris en intemperie húmeda. Tales cambios reflejan reacciones catalizadas por radiación que llevan consigo oxidación, despolimerización y en general rotura de la lignocelulosa; los productos de rotura son solubles y son lixiviados por el agua dejando una superficie desnaturalizada agrisada. Las implicaciones de esto son importantes en un recubrimiento transparente, ya que si la superficie se degrada puede hacer que los recubrimientos se desprendan. 
También pueden presentarse problemas con pinturas opacas si se aplican sobre un sustrato que se encuentre degradado. La reducción de la durabilidad de las maderas expuestas a la luz puede ser bastante importante y reducir el periodo de tiempo en el que es necesario un mantenimiento. Otro factor a considerar en la interacción de la luz solar con la madera, es el de la radiación infrarroja, es decir el calor: pinturas oscuras se pueden alcanzar temperaturas de hasta $40^{\circ}$ más altas que colores claros o blanco lo que puede exacerbar problemas como la exudación de resinas [190-193].

La duración de este tipo de tratamiento en madera es de dos años o más lo cual depende principalmente de la elasticidad del vehiculo, la carga de pigmentos, la capacidad hidrorrepelente, la forma de aplicación, tipo de madera y zona climática.

Cabe destacar, que para asegurar una buena protección de la madera no se debe considerar sólo el recubrimiento de la misma, sino que para una máxima protección se debe obtener una buena combinación de diseño preservativo adecuado y el recubrimiento apropiado a las condiciones finales de la vida en servicio.

Entre los aspectos del diseño cabe destacar la utilización de la madera aplicada, protegerla en lo posible de la lluvia o acumulación de agua, buena aireación, etc. También tener en cuenta que la mayor absorción de agua se produce por los extremos que presentan los vasos abiertos, por lo que se deberán sellar, así como masillar las juntas para evitar almacenamiento y penetración de agua, o entre madera y vidrio, redondeo de perfiles en ventanas para evitar la acumulación, permitir movimiento de madera en suelos, entarimados o chapados para evitar combado de la madera, etc. [193]

En la presente no se tratará aspectos de diseño, sino solo la protección final de la madera en servicio, pero esto es mencionado, porque sin una buena preparación del sustrato, el tratamiento puede no ser efectivo. 


\section{Bibliografía}

1. Molchanov, A.A. (1963) The hydrological role of forests, $407 \mathrm{pp}$.

2. STRECK, C. and SCHOLZ, S.M. (2006) the role of forests in global climate changes: whence we come and where we go. International Affaires, 82 (5): 861-879

3. Campbell, B.M. and Locker, M.K. (2002) Towards understanding the role of forests in rural livelihoods. People and Plants Conservation Series In: Uncovering the hidden harvest: valuation methods for woodlands and forest resources. London, UK, Earthscan Publications, pp. 1-12.

4. Gustafson, L. et. al (2012) Retention Forestry to Maintain Multifunctional Forests: A World Perspective, BioScience, 62 (7): 633-645.

5. Brasier, G. (2004) Tendencias y Perspectivas del Sector Forestal al año 2020. Informe Nacional No 1. Secretaría de Ambiente y Desarrollo Sustentable. SAGPyA.

6. Di Paola, M.M (2005) Expansión de la frontera agropecuaria, Apuntes agroeconómicos, Año 3, $\mathrm{N}^{\circ} 4$, ISSN 1667-3212.

7. Pengue, W. (compilador) 2008. La apropiación y el saque de la naturaleza, Fundación Heinrich Böll, GEPAMA, $145 \mathrm{pp}$.

8. Majada, J., et al. (2013) Innovación de procesos y productos en el sector de la madera, $6^{\circ}$ Congreso Forestal Español, Sociedad Española de Ciencias Forestales

9. Shackelford, J.F. (2005), Introducción a la Ciencia de Materiales para Ingenieros, Pearson Alhambra. 84-205-4451-5.

10. Jiménez, F; Vignote, S (2000) Tecnología de la Madera, $2^{\circ}$ Edición, Ministerio de Agricultura, Pesca y Alimentación, Secretaría General Técnica Madrid, España.

11. Callister, W.D. (1997) Introducción a la Ciencia e Ingeniería de los Materiales, Barcelona: Editorial Reverté, S.A., 524 pp.

12. Kúdela, J. and Babiak M. (2012) Wood the Best Material for Mankind, Arbora Publishers, Zvolen, Slovakia, $117 \mathrm{pp}$.

13. United Nations Economic Commission for Europe (2006) Forest Products Annual Market Review UNECE/FAO Timber Section United Nations Publications Sales No. 06. II.E.11, 142 pp.

14. Maslaton, C. (2005) Potencial del complejo maderero argentino. Propuestas para el desarrollo de la cadena madera-muebles y su inserción en el mercado mundial. Documento de trabajo $\mathrm{N}^{\circ}$ 2. INTI. $95 \mathrm{pp}$.

15. Martinez Nogueira, R. (1994) Empresas familiares: una mirada multidisciplinaria. Diagnóstico y Análisis organizacional. Alta Gerencia $\mathrm{N}^{\circ} 37$. Año I. Tomo II, 37-50.

16. Kiely, R. (1995) Sociology and development. The impasse and beyond. Londres. University College of London Press.

17. Bercovich, N. (2000) Evolución y Situación Actual del Complejo Forestal en Argentina. División de Desarrollo Productivo y Empresarial de la Comisión Económica para América Latina y el Caribe. Centro Internacional de Investigaciones para el Desarrollo (CIID/IDRC)

18. Montalba Navarro, R, Carrasco Henriquez, N. y Araya Cornejo, J. (2005) Contexto económico y social de las plantaciones forestales en Chile. El caso de la Comuna de Lumaco, región de la Araucanía. Movimiento mundial por los Bosques Tropicales. Ed. Rosgal. 72 pp.

19. Valtriani, A. (2008) Modelos de desarrollo forestal, sus conflictos y perspectivas en el sector de micro PyMEs forestales. Estudio de caso en la región noroeste y centro de la provincia del Chubut, Tesis doctoral en Econoía, Universidad de Buenos Aires, 2206-2214.

20. Vishal Puri, Pradipta Chakrabortty, Swapan Majumdar (2014) A Review of Low Cost Housing Technologies in India Advances in Structural Engineering, 1943-1955.

21. Sánchez Acosta, M. M., Servin, A., Yelín, N., Garnier, R. (2011) Casa canadiense de madera de eucalipto de interés social en Concordia. Etapa II. Proyecto "Un techo digno para todos", XXV Jornadas Forestales de Entre Ríos, Concordia, Entre Ríos, 20 y 21 de Octubre de 2011 actas, Asociación Ingenieros Agrónomos del Nordeste de Entre Ríos, Sección VII, 1-18.

22. Steiger, L., Hugues, T., Weber, J. (2009) Construcción con madera. Detalles, productos, ejemplos, Editorial Gustavo Gili, España, 110 pp.

23. Giallatini Durand, E. (2013) Certificado de aptitud técnica de BME UNIVERSIDAD NACIONAL DE CÓRDOBA, $104 \mathrm{pp}$. 
24. Tamarit U., J.C., 2003, Análisis del escenario de la certificación forestal en el contexto del desarrollo sustentable, Madera y Bosques.

25. Maslatón, C. (2011) Plan Estratégico Industrial-Argentina 2020, INTI - Economía Industrial, 41p.

26. Vignote Peña, S. (2006) Tecnología de la madera, $3^{\mathrm{a}}$ edición, Mundi prensa libros, $678 \mathrm{pp}$.

27. Walker, J.C.F. (2006) Primary wood processing, Principles and practice, Springer, The Netherlands, Second Edition, Netherlands

28. Wilson, K., White, D.J.B., White, J.B. (1986) The Anatomy of Wood, Stobart Davies Ltd, United Kingdom

29. Kim, Y.S., Funada, R. Singh, A. P. (2016) Secondary Xylem Biology: Origins, Functions, and Applications, Academic Press, 2016, pp. 416.

30. Beck, C.B. (2010) An Introduction to Plant Structure and Development: Plant Anatomy for the Twenty-First Century

31. Sheeler, P. y Bianchi, D.E. (1980) Cell Biology: Structure, Biochemistry, and Function. John Wiley \& Sons.

32. Curtis H., (2000). Biología Ed. Panamericana. Buenos Aires, 160pp.- De Robertis (h.) E.M.F, Hib J. y Ponzio R. (1996) Biología Celular y Molecular. Ed. El Ateneo.

33. Rost, T. L., Barbour, M.G., Thornton, R.M., Weier, T.E. y Stocking, C.R. (1979) Botany. A Brief Introduction to Plant Biology. John Wiley \& Sons.

34. Sjöström, E. (1993) Wood Chemistry. Fundamentals and Applications, 2nd edition, Academic Press, San Diego, CA, USA, 293 p

35. Office of Scientific and Technical Information. Molecular Organization in the Native State of Wood Cell Walls: Studies of Nanoscale Structure and Its Development, United States. Department of Energy. Chicago Operations Office, United States. Department of Energy. pp. 1-5.

36. Hayashi, T. (2006) The Science and Lore of the Plant Cell Wall: Biosynthesis, Structure and Function Universal-Publishers, pp. 368 pages

37. Fromm, J. (2013) Cellular Aspects of Wood Formation Springer Science \& Business Media, pp. 260

38. DimitriI, M., Orfila, E. (1985) Tratado de morfología y sistemática vegetal. Ed. ACMAs, 21-125.

39. Evert, R.F. (2006) Anatomía Vegetal. 3ra. edición. Ed. Omega

40. Raven, P.H., Evert, R.F. y Eichhorn, S.E.(2005) Biology of plants. Ed. WH Freeman \& Co.

41. FOA Forestry Department (1986) Wood perservation manual, Mechanical Wood Products Branch Forest, Industries División, vol. 76, 159 pp.

42. Tinto, C. (1997) Tecnología de las Maderas Argentinas y del Mundo Agro Vet,, 565 pp.

43. Conafor (Comisión Nacional Forestal Coordinación General de Educación y Desarrollo Tecnológico Gerencia de Desarrollo y Transferencia de Tecnología) (2010) Manual para la protección contra el deterioro de la madera, $87 \mathrm{pp}$.

44. Ulrika Råberg et al. (2005) Testing and evaluation of natural durability of wood in above ground conditions in Europe - an overview (2005) Journal of Wood Science

45. Volume 51, Issue 5, pp 429-440

46. South African Wood Preservers Association and Timber Preservers Association of Australia (2014) Understanding timber preservation, http://www.sawpa.org.za/

47. Calderón, A. D. Preservación de Maderas, Cátedra Dasonomía, Facultad de Ciencias Agrarias, Universidad Nacional de Cuyo, $33 \mathrm{pp}$

48. Brischke, C. et al. (2014) Wood natural durability testing under laboratory conditions: results from a round-robin test European Journal of Wood and Wood Products, 72, (1): 129-133

49. Rafael Capuz Lladró (2005) Materiales orgánicos: maderas, Ed. Univ. Politéc. Valencia, 279 pp.

50. Scheffer, T.C.; Morrell, Jeffrey J. (1998) Natural durability of wood : a worldwide checklist of species Forest Research Laboratory, Oregon State University. Research Contribution 22, 58p.

51. Taylor, A. M (2002) Heartwood Formation and Natural Durability-A Review Society of Wood Science \& Technology, 34 (4) 587-611

52. Shmulsky, R. and Jones, P.D (2011) Forest Products and Wood Science, John Wiley \& Sons, 532 pp.

53. U.S. Department of Agriculture (2013) The Encyclopedia of Wood, Skyhorse Publishing, Inc., 496 pp.

54. INTI, Madera y muebles (2002) Clasificación de las maderas por su durabilidad natural, http://www.inti.gob.ar/maderaymuebles/pdf/durabilidad.pdf 
55. Norma IRAM 9.600 (1998) Preservación de maderas. Maderas preservadas mediante procesos con presión en autoclave, Instituto Argentino de Racionalización de Materiales. 23 pp.

56. Brock, T. D. (2009). Biología de los Microorganismos, $12^{\circ}$ Edición, Addison-Wesley, 1296 pp.

57. Webster, J. and Weber, R. (2007) Introduction to Fungi, Cambridge University Press, 841 pp.

58. Luley, C.J. (2005) Wood Decay Fungi Common to Urban Trees in Northeast and Central United States, $60 \mathrm{pp}$.

59. Schwarze, F.W (2007) Wood decay under the microscope, Fungal Biology Reviews 21,133-170

60. Stokland, J.N., Siitonen, J., Jonson, B.G. (2012) Biodiversity in Dead Wood Cambridge University Press, $509 \mathrm{pp}$.

61. Sjöström, E. (1993) Wood Chemistry. Fundamentals and Applications, 2nd edition, Academic Press, San Diego, CA, USA, 293 p

62. Barnett J.R., Jeronimidis G. (2003) Wood quality and its biological basis. CRC Press- Blackwell Publishing, pp. 226.

63. Blanchette, R.A., (1998) A guide to wood deterioration caused by microorganisms and insects, In: Dardes, K. and Rotne A. (Eds), The structural conservation of panel paintings, Getty Conversion Institute, Los Angeles, pp. 55-68.

64. Zabel, R. A. y Morrell, J.J. (1992) Wood microbiology, Decay and its prevention, Academics Press Inc., pp. 476.

65. Blanchette, R.A., Simpson, E. (1992) Soft rot and wood pseudomorphs in an ancient coffin (700 BC) from Tumulus MM at Gordion, Turkey, International Association of Wood Anatomists Bulletin, NS. 13, 201-213.

66. Blanchette, R.A., Nilsson, T., Daniel, G., Abad, A., (1990) Biological degradation of wood. In: Rowell, R.M., Barbour, R.J. (Eds.), Archaeological Wood: Properties, Chemistry, and Preservation, Advances in Chemistry Series, vol. 225. American Chemical Society, Washington, DC, pp. 141-74.

67. Santhakumaran, L.N. \& Singh, A.P. (1992) Destruction of two tropical timbers by marine borers and microorganisms in Goa water (India). Int. Res. Group Wood Preserv. IRG /WP Document No. 4417692.

68. Singh, A.P., Hedley, M.E., Page, D.R., Han, C.S. \& Atisongkroh, K. (1992) Microbial degradation of CCA-treated cooling tower timbers, IAWA Bull. n.s. 13: 215-231.

69. Singh, A.P. \& Wakeling, R.N. (1997) Presence of widespread bacterial attacks in preservative treated cooling tower timbers. New Zeal. For. Sci. 27: 79-85.

70. Singh, A.P., Wakeling R.N. (1996) Novel observations on the micromorphology of soft rot attack of wood, Int. Res. Group Wood Preserv. IRG /WP Document No. 96-10176.

71. Nilsson, T. (1976) Soft-rot fungi decay patterns and enzyme production. Material u. Organismen 13: $103-112$.

72. Nilsson, T., Daniel, G., Kirk, T.K., Obst, J.R. (1989) Chemistry and microscopy of wood decay by some higher ascomycetes, Holzforschung 43: 11-18.

73. Mohebby, B., Militz, H. (2002) Soft rot decay in acetylated wood Chemical and anatomical changes in decayed wood. The international research group on wood preservation IRG/WP 02-4023.

74. Eriksson, K.E.L., Blanchette R.A., Ander P. (1990) Microbial and enzymatic degradation of wood and wood components, Springer Series in Wood Science, pp. 333.

75. Saparrat, M.C.N., Guillén F., Arambarri, A.M., Martínez, A.T., Martínez, M.J. (2002) Induction, isolation, and characterization of two laccases from the white rot basidiomycete Coriolopsis rigida, Appl Environ Microbiol, 68:1534-1540.

76. Schwarze, F.W.M.R. \& Fink, S. (1998) Host and cell type affect the mode of degradation by Meripilus giganteus. New Phytol. 139, 721-731.

77. Rayner, A.D.M., Boddy, L. (1988) Fungal Decomposition of Wood: Its Biology and Ecology, Wiley, New York, pp 587.

78. Wakeling, R.N. \& Singh, A.P. (1993) Premature failure of CCA-treated vineyard posts from brown rot. Int. Res. Group Wood Preserv. IRG /WP Document No. 93-10016.

79. Eaton, R.A., Hale, M.D.C. (1993) Wood: decay, pests and protection. Chapman \& Hall, London, pp. 576.

80. Wilcox, W.W. (1993) Comparative morphology of early stages of brown rot wood decay, IAWA J., $14,127-138$. 
81. Green, F., Highley, T.L. (1997) Mechanism of Brown-Rot Decay: Paradigm or Paradox, International Biodeterioration \& Biodegradation, 39, 2(3), 113-124

82. Jennings, D.H., Bravery, A.F., (1991) Serpula lacrymans: Fundamental Biology and Control Strategies. Wiley, New York, pp. 217.

83. Vane, C. H., et al. (2001) The effect of fungal decay (Agaricus bisporus) on wheat straw lignin using pyrolysis-GC-MS in the presence of tetramethylammonium hydroxide (TMAH). Journal of Analytical and Applied Pyrolysis 60(1), 69-78.

84. Wood, T.M. McCrae, S.I., Bhat, K.M. (1989) The mechanism of fungal cellulase action. Synergism between enzyme components of Penicillium pinophilum cellulase in solubilizing hydrogen bondordered cellulose, Biochemical Journal 260, 37-43.

85. Zhou, S., Ingram, L.O. (2000) Synergistic hydrolysis of carboxymethyl cellulose and acid-swollen cellulose by two endoglucanases (EGY and EGZ) from Erwinia chrysanthemi, Journal of Bacteriology, $182,5676-5682$.

86. Steffen, K.T. (2003) Degradation of recalcitrant biopolymers and polycyclic aromatic hydrocarbons by litter-decomposing basidiomycetous fungi. Thesis. Division of Microbiology. Department of Applied Chemistry and Microbiology. Viikki Biocenter, University of Helsinki, Finland. http://ethesis.helsinki.fi, pp. 69.

87. Singh, A., Hayashi, K. (1995) Microbial cellulase, protein architecture, molecular properties and biosynthesis, Advances in Applied Microbiology. 40, 1-44.

88. Lynd, L.R., Weimer, P.J., Van Zyl, W.H., Pretorius, I.S. (2002) Microbial cellulose utilization: fundamentals and biotechnology, Microbiology and Molecular Biology Reviews, 66, 506-577.

89. Graham, J.E, et al. (2011) Identification and characterization of a multidomain hyperthermophilic cellulase from an archaeal enrichment, Nature Communications. 2, 375.

90. Quiroz Castañeda R.E and Folch Mallol, J.L (2011) Cell wall remodeling proteins. Biotecnología Aplicada 28 (4), 205-215

91. Martínez, A.T., Speranza, M., Ruiz-Dueñas, F.J., Ferreira, P., Camarero, S.,Guillén, F., Martínez, J.M., Gutiérrez, A., del Río, J.C. (2005) Biodegradation of lignocellulosics: microbiological, chemical and enzymatic aspects of fungal attack to lignin, International Microbiology, 8, 95-204.

92. Saparrat, M.C.N., Rocca, M., Aulicino, M.B., Arambarri, A.M., Balatti, P.A. (2008) Celtis tala and Scutia buxifolia leaf litter decomposition by selected fungi in relation to their physical and chemical properties and the lignocellulolytic enzyme activity, European Journal of Soil Biology. 44: 400-407.

93. Saparrat, M.C.N., Arambarri, A.M., Balatti, P.A. (2007) Growth response and extracelular enzyme activity of Ulocladium botrytis LPSC 813 cultured on carboxymethylcellulose under a pH-range, Biology and Fertility of Soils, 44, 383-386.

94. García-Rivero,M., Peralta-Pérez, M.R. (2008) Cometabolismo en la biodegradación de hidrocarburos, Revista Mexicana de Ingeniería Química, 7, 1-12.

95. Chaparro, D.F., Rosas, D.C., Varela, A. (2009) Isolation of wood-decaying fungi and evaluation of their enzymatic activity (Quindío, Colombia) Revista Iberoamericana de Micología 26,(4), 238-243.

96. Domınguez, R., Souchon, H., Lascombe, M.B. and Alzari, P.M. (1996) The Crystal Structure of a Family 5 Endoglucanase Mutant in Complexed and Uncomplexed Forms Reveals an Induced Fit Activation Mechanism, J. Mol. Biol., 257, 1042-1051.

97. Nijdam, J.J.; Lehmann, E.; Keey, R.B. (2004) Application of neutron radiography to investigate changes in permeability in bacteria treated Pinus radiata timber. Maderas. Ciencia y tecnología, 6 (1): 19-31

98. Béguin, P.; Aubert, J. P. Cellulases, J. Lederberg (ed.) (2000). Encyclopedia of microbiology, Academic Press, San Diego, California, USA, pp. 744-758

99. Nilsson, T., Björdal, C. (2008) Culturing wood-degrading erosion bacteria, International Biodeterioration \& Biodegradation, 61 (1), 3-10.

100.Daniel, G., Nilsson, T. (1998) Developments in the study of soft rot and bacterial decay, A. Bruce, J.W. Palfreyman (Eds.), Forest Products Biotechnology, Taylor \& Francis, London, 37-62

101.Schmidt, O., Moreth, U., Schmitt, U. (1995) Wood degradation by a bacterial pure culture, Material und Organismen, 20, 289-293

102.Liotta, G. (2000) Los insectos y sus daños en la madera: problemas de restauración, Editorial NEREA, $144 \mathrm{pp}$. 
103.Majeed, M.Z. et al. (2012) Xylophagous termites: A potential sink for atmospheric nitrous oxide, European Journal of Soil Biology, Volume 53, 121-125

104.Zanni, E (2008) Patología de la madera, Editorial Brujas, $241 \mathrm{pp.}$

105.Pauchet, Y (2014) Identification and characterization of plant cell wall degrading enzymes from three glycoside hydrolase families in the cerambycid beetle Apriona japónica, Insect Biochemistry and Molecular Biology, 49, 1-13.

106. Allison, D., Borden, J.H., Seybold, S.J (2004) A review of the chemical ecology of the Cerambycidae (Coleoptera) Chemoecology, 14 . 123-150

107.Louis, M., Grégoire, J.C, Pélisson, P.F (2014) Exploiting fugitive resources: How long-lived is "fugitive"? Fallen trees are a long-lasting reward for Ips typographus (Coleoptera, Curculionidae, Scolytinae), Forest Ecology and Management, 331, 129-134.

108.Ebeling, W. (2002) Wood-Destroying Insects and Fungi, Chapter 5, Ed. Entomology UC Riverside, University of California, Division of Agricultural Sciences, 128 - 216.

109.Cragg, S.M., Pitman, A.J., Henderson, S.M. (1999) Developments in the understanding of the biology of marine wood boring crustaceans and in methods of controlling them, International Biodeterioration \& Biodegradation, 43, (4), 197-205.

110.Zurita, G.A., Zuleta, G.A (2009) Bird use of logging gaps in a subtropical mountain forest: The influence of habitat structure and resource abundance in the Yungas of Argentina, Forest Ecology and Management, 257 (1), 271-279.

111.Rowell, R. M.; Banks, W. B. (1985) Water repellency and dimensional stability of wood. Gen. Tech. Rep. FPL-50. Madison, WI: U.S. Department of Agriculture, Forest Service, Forest Products Laboratory, pp. 24.

112.Stamm, A. J. (1959) The dimensional stability of wood, Forest Products Journal, 9(10), 375-381.

113.Khazaei, J. (2008) Water absorption in three wood varieties, Cercetări Agronomice în Moldova, XLI, 2 (134) pp. 16.

114.Severa, L., Buchar J., Krivanek I. (2003) The influence of the moisture content on the fracture of the notched wood beam. 8th International IUFRO Wood Drying Conference

115.Baronas, R., Ivanauskas, F., Juodeikienè, I., Kajalavicius, A., (2001) Modelling of Moisture Movement in Wood during Outdoor Storage. Nonlinear Analysis: Modelling and Control, 6 (2), 3-14.

116.Banks, W.B. (1973) Water uptake by Scots pie and its restriction by the use of water repellents. Wood Sci. and Tech. 7:271-284

117.Capote, J.A., Alvear, D., Lázaro, M., Espina, P., Fletcher, I. A., Welch, S., Torero, J. L. (2006) Analysis of Thermal Fields Generated by Natural Fires on the Structural Elements of Tall Buildings, Proceedings, International Congress Fire Safety in Tall Buildings, Santander, Spain, 2006, 93-109.

118.Usmani, A.S., Rotter, J.M., Lamont, S., Sanad, A.M., Gillie, M. (2001) Fundamental Principles of Structural Behaviour under Thermal Effects, Fire Safety J., 36, 8, 721-744.

119.Lamont, S., Usmani, A.S., Gillie, M. (2004) Behaviour of a Small Com posite Steel Frame Structure in a "Long-Cool" and a "Short-Hot" Fire, Fire Safety J., 39, 5, 327-357.

120.Browne, F.L. (1958) Theories of the combustion of wood and its control - a survey of the literature, FPL report number 2136. Forest Products Laboratory, Madison.

121.Dietenberger, M. (2002) Update for combustion properties of wood components. Fire and Materials, $26,255-267$.

122. Yang, H., Yan, R., Chen, H., Zheng, C., Lee, D., Liang, D.T. (2006) In depth investigation of biomass pyrolysis based on three major components: hemicellulose, cellulose and lignin. Energy Fuels 20, 388 393.

123.Winandy, J.E. (2001) Thermal degradation of fire retardant treated wood: Predicting residual service life, Forest Products Journal, 51 (2), pp. 4754.

124.Bland, K.E. (1991) Behaviour of wood exposed to fire: a review and expert judgement procedure for predicting assembly failure. Dissertation, Worcester Polytechnic Institute

125.Reszka, P. (2008) In-depth temperature profiles in pyrolzing wood. Dissertation. University of Edinburgh, Scotland.

126. Yang, L., Chen, X., Zhou, X., Fan, W. (2003) The pyrolysis and ignition of charring materials under an external heat flux, Combustion and Flame 133, 407-413.

127.Babrauskas, V. (2002) Ignition of wood: a review of the state of the art, Interflam, 71-88. 
128.Svensson, G. (1989) Humidity resistant flame retardants for wood. Stockholm: Swedish Institute for Wood Technology Research, pp. 44.

129. Churchouse, A.H. (1968) Wood carbonisation in Manufactured Carbon, Davidson, J.H. et al, Pergamon Press, Oxford, U.K., 72-80.

130.Zabel, R.A. (2012) CHAPTER 2 - Wood Deterioration Agents, Wood Microbiology, Decay and Its Prevention, 21-51.

131. Ajuong, E. (2010) Degradation of Wood, Shreir's Corrosion, Corrosion and Degradation of Engineering Materials, 3, 2439-2446.

132. Rowell, R.M. (2005) Chemical modification of wood. In Handboook of Wood Chemistry and Wood Composite; Rowell, R.M. (ed.), Taylor and Francis, CRC Press, 420 pp.

133. Encinas, O (2004) Conservación de maderas, Universidad de Los Andes, 22 pp.

134.Canadian Wood Council (1995) Wood Reference Handbook. Canadian Wood Council, Ottawa, Ontario. $561 \mathrm{p}$.

135. Majada, J., et al. (2013) Innovación de procesos y productos en el sector de la madera" In: $6^{\circ}$ Congreso Forestal Español 10 al 14 de junio de 2013, Palacio de Congresos y Exposiciones Europa de VitoriaGasteiz

136. Militz, H. (2002) Treatment Technologies in Europe: Scientific Background and Technological Stateof-Art. In: Proceedings of Conference on "Enhancing the durability of lumber and engineered wood products” February 11-13, 2002, Kissimmee, Orlando. Forest Products Society, Madison, US.

137.Zabel, R.A. and Morrell, J.J. (1992) Wood Microbiology: Decay and its Prevention. Academic Press. San Diego, California, USA. $476 \mathrm{p}$

138. Wood Protection Council (1993) Wood Protection Guidelines, Protecting wood from decay fungi and termites. Understanding Biodeterioration of Wood in Structures. Wood Protection Council, National, Institute of Building Sciences. 53 pp.

139. Kiliaris, P., Papaspyrides, C.D. (2010) Polymer/layered silicate (clay) nanocomposites: An overview of flame retardancy, Progress in Polymer Science (Topical Issue on Nanocomposites), 35 (7), 902 958.

140.Shuyu, L., Neisius, N.M, Sabyasachi, G. (2013) Recent developments in flame retardant polymeric coatings, Progress in Organic, Coatings, 76 (11), 1642-1665.

141.Gu, J.W., Zhang, G.-C., Dong, S.L., Zhang, S.L., Kong, J. (2007) Study on preparation and fireretardant mechanism analysis of intumescent flame-retardant coatings, Surface and Coatings Technology, 201, 7835-7841

142. Gardelle B., Duquesne, S., Rerat V., Bourbigot, S. (2013) Thermal degradation and fire performance of intumescent silicone-based coatings, Polymers for Advanced Technologies, 24, 62-69

143. Giudice, C. A., Alfieri, P.V., Canosa, G. (2013) Siloxanes synthesized "in situ" by sol-gel process for fire control in wood of Araucaria angustifolia"; Fire Safety Journal, 61 348-354.

144.Wang, X., Chai, Y., Liu, J. (2013) Formation of highly hydrophobic wood surfaces using silica nanoparticles modified with long-chain alkylsilane. Holzforschung, 394(1), 97-112.

145. Yanjun, Xie, et al. (2013) Effects of hydrophobation treatments of wood particles with an amino alkylsiloxane co-oligomer on properties of the ensuing polypropylene composites. Composites Part A: Applied Science and Manufacturing, 44, 32-39.

146. Tshabalala, M.A., Kingshott, P., VanLandingham, M.R., Plackett, D. (2003) Surface chemistry and moisture sorption properties of wood coated with multifunctional alkoxysilanes by sol-gel process. Journal of Applied Polymer Science, 88(12), 2828-2841

147.Witucki, G. L. (1993) A Silane Primer: Chemistry and Applications of AIkoxy Silanes, journal of coatings technology, 65 (822) 57-60

148. Mittal, K. L. (2009) Silanes and Other Coupling Agents, Volumen 5, Ed. Brill, pp. 348

149.Jones, R.G., Ando, W., Chojnowski, J. (2001) Silicon-Containing Polymers: The Science and Technology of Their Synthesis and Applications, Springer Science \& Business Media, pp. 768

150.Wernfried, H. (2005) Silicone Resins and Their Combinations, Vincentz Network GmbH \& Co KG, pp. 102

151.Koerner, G. (1992) Silicones, chemistry and technology, CRC Press, pp. 125

152.Zeigler, J. M. and Fearon, F. W. (1990) Silicon-Based Polymer Science. The American Chemical Society; Washington DC 
153. Goddio, M. F., Mancini, S. I.,. Gervasio, S. G y López, G. D (2013) Nanotecnologia aplicada a la preservación de maderas, $13^{\circ}$ Congreso Internacional en Ciencia y Tecnología de Metalurgia y Materiales (SAM - CONAMET 2013), 1-6.

154.Baker-Austin, C, Wright, M.S., Stepanauskas, R., McArthur, J.V. (2006) Co-selection of antibiotic and metal resistance, Trends Microbiol. 14, 176-182.

155.McDonnell, G. y Russell, A.D. (2011) Antiseptics and Disinfectants: Activity, Action, and Resistance, Clin. Microbiol Rev. 14(1), 1-227.

156. Roya Dastjerdi, Majid Montazer, (2010) A review on the application of inorganic nano-structured materials in the modification of textiles: Focus on anti-microbial properties, Colloids and Surfaces B: Biointerfaces, 79, 5-18.

157.Verran, J., Sandoval, G., Allen, N.S., Edge, M., Stratton, J. (2007) Variables affecting the antibacterial properties of nano and pigmentary titania particles in suspension, Dyes and Pigments, 73, 298-304.

158. Mahsa Mazloomi-Rezvani, Mehdi Salami-Kalajahi, Hossein Roghani-Mamaqani, Amin Pirayesh (2018) Effect of surface modification with various thiol compounds on colloidal stability of gold nanoparticles ., 32 (2) 4079

159. Jones, R.G., Ando, W., Chojnowski, J. (2001) Silicon-Containing Polymers: The Science and Technology of Their Synthesis and Applications, Springer Science \& Business Media, pp. 768

160. Wernfried, H. (2005) Silicone Resins and Their Combinations, Vincentz Network GmbH \& Co KG, pp. 102

161.Koerner, G. (1992) Silicones, chemistry and technology, CRC Press, pp. 125

162.Zeigler, J. M. and Fearon, F. W. (1990) Silicon-Based Polymer Science. The American Chemical Society; Washington DC

163.Fink, J.K. (2013) Silicones reactive polymers fundamentals and applications, In: A Concise Guide to Industrial Polymers, $2^{\circ}$ Ed., pp. 217-233.

164.Tshabalala, M.A., Kingshott, P., VanLandingham, M.R., Plackett, D. (2003) Surface chemistry and moisture sorption properties of wood coated with multifunctional alkoxysilanes by sol-gel process, J. Appl. Polym. Sci., 88(12), 2828-2841.

165.Zavala R. J. (1999) Construcción y operación del sistema para la obtención de alcóxidos de Silicio a nivel planta piloto. Tesis de Licenciatura Universidad de Guanajuato

166.Arkles, B. (2006) Hydrophobicity, Hydrophilicity and Silane Surface Modification, Gelest, Inc., pp. 76

167.Wang, X., Chai, Y., Liu, J. (2013) Formation of highly hydrophobic wood surfaces using silica nanoparticles modified with long-chain alkylsilane, Holzforschung, 394(1), 97-112.

168.Donath, S., Militz, H., Mai, C. (2004) Wood modification with alkoxysilanes, Wood Sci. Technol., 38, $555-566$.

169.Gallardo de Ross, M.G. (1981) The Properties of Silicon Tetrachloride as a Potential Wood Preservative, University of New Hampshire.

170.Hill, C.A.S., Farahani, M.R.M., Hale, M.D.C. (2004) The use of organo alkoxysilane coupling agents for wood preservation, Holzforschung, 58, 316-325.

171.Christodoulou, C., Goodier, C.I., Austin, S.A., Webb, J., Glass, G.K. (2013) Long-term performance of surface impregnation of reinforced concrete structures with silane, Construction and Building Materials, 48, 708-716.

172.MacMullen, J., Radulovic, J., Zhang, Z., Dhakal, H.N., Daniels, L., Elford, J., Leost, M.A., Bennett, N. (2013) Masonry remediation and protection by aqueous silane/siloxane macroemulsions incorporating colloidal titanium dioxide and zinc oxide nanoparticulates: Mechanisms, performance and benefits, Construction and Building Materials, 49, 93-100.

173.Xie, Y., Callum, A.S.H., Xiao, Z., Militz, H., Mai, C. (2010) Silane coupling agents used for natural fiber/polymer composites: A review, Composites Part A: Applied Science and Manufacturing, 41(7), 806-819.

174.Cui, Gong et al. (2012) Study on silane impregnation for protection of high performance concrete, Procedia Eng., 27, 301-307.

175. Christodoulou, C. et al. (2013) Long-term performance of surface impregnation of reinforced concrete structures with silane, Constr. Build. Mater., 48, 708-716.

176.Bücker, M., Jäger, C., Pfeifer, D., Unger, B. (2014) Evidence of Si-O-C bonds in cellulosic materials modified by sol-gel-derived silica, Wood Science and Technology, 48(5), 1033-1047 
177.Mai, C., Donath, S., Weigenand, O., Militz, H. (2005) Aspects of wood modification with silicon compounds: material properties and process development. In: Proceedings of the Second European Conference on Wood Modification, H. Militz, C. Hill (Eds.), Göttingen, pp. 222-231.

178. Mai, C.; Militz, H. (2004) Modification of wood with silicon compounds. Inorganic silicon compounds and sol-gel systems: A review. Wood Sci. Technol., 37(5), 339-348.

179.Mai, C.; Militz, H. (2004) Modification of wood with silicon compounds, Treatment systems based on organic silicon compounds - A review, Wood Sci. Technol. 37(5), 453-461.

180.Daud, N., Shanks, R. (2014) Epoxy-silica composites replicating wood cell structure, Compos. Part AAppl. S., 62, 11-15.

181.Brebner, K.I., Schneider, M.H. (1985) Wood-polymer combinations: Bonding of alkoxysilane coupling agents to wood, Wood Sci. Technol. 19(1), 75-81

182.Campbell, B.M. and Luckert, M.K. (2002) Towards understanding the role of forests in rural livelihoods. People and Plants Conservation Series In: Uncovering the hidden harvest: valuation methods for woodlands and forest resources. London, UK, Earthscan Publications, pp. 1-12.

183.Gustafsson, L. et. al (2012) Retention Forestry to Maintain Multifunctional Forests: A World Perspective, BioScience, 62 (7): 633-645

184. Engelhardt, G. et al (1977) Zeit. fur Anorg. and Allg. Chem., 428, 43

185.Ulrika Råberg et al. (2005) Testing and evaluation of natural durability of wood in above ground conditions in Europe - an overview. Journal of Wood Science, Volume 51, Issue 5, pp 429-440

186. Calderón, A. D. Preservación de Maderas, Cátedra Dasonomía, Facultad de Ciencias Agrarias, Universidad Nacional de Cuyo, 33 pp.

187. Brischke, C. et al. (2014) Wood natural durability testing under laboratory conditions: results from a round-robin test European Journal of Wood and Wood Products, 72, (1): 129-133

188. Rafael Capuz Lladró (2005) Materiales orgánicos: maderas, Ed. Univ. Politéc.Valencia, 279 pp.

189. Bulian F. and. Graystone J (2009) Wood Coatings Theory and practice, Ed. Elsevier, 320pp. ISBN: 978-0-444-52840-7

190.Engelhardt, G. et al (1977) Zeit. fur Anorg. and Allg. Chem., 428, 43 


\section{Capítulo II}

\section{Materiales y}

Métodos 


\section{II.1 Materiales}

Como se mencionó en el primer capítulo, el material en estudio es la madera, específicamente maderas de coníferas perteneciente a la familia de las gimnospermas entre las que se encuentra la especie elegida para llevar a cabo este estudio Pinus ponderosa. Esta especie se utilizó por su gran demanda en el mercado maderero.

Por otra parte, en el capítulo anterior también se desarrolló la descripción del material bajo una visión minimalista, centrándonos en la pared celular del leño. Esto se debe a que los procesos de deterioro elegidos en este estudio, implican fundamentalmente cambios en esta estructura.

En cuanto a los agentes modificantes o protectores, como cita el título de la presente tesis, involucran silanos y nanopartículas. El fundamento de la elección de estos compuestos fue, principalmente, su carácter inorgánico y la capacidad para reaccionar químicamente con el sustrato. Por otro lado, para los nanocompuestos la elección estuvo basada en el tamaño de la partícula (que permite que penetre mejor en el sustrato) y su elevada área superficial (que da mayor probabilidad de interacción).

Los silanos constituyen un nuevo campo de la ciencia y tecnología de los recubrimientos superficiales y de impregnantes debido a sus amplias propiedades en el campo de la protección de los materiales. Éstos polimerizan mediante el proceso sol-gel, el cual involucra reacciones de hidrólisis y condensación con una gran dependencia de $\mathrm{pH}$. Ello permite controlar las reacciones y obtener polímeros con una gran variedad de formas, tales como esferas, conos, barras, fibras, tubos, láminas, etc., otorgando diferentes propiedades al material. Los esfuerzos de numerosos grupos de investigación permitieron el desarrollo de algunos "composites" que constan de nanopartículas inmersas en una red polimérica. Estos "nanocomposites", en este caso nanopreservantes, presentan algunas propiedades inalcanzables por matrices poliméricas convencionales.

Los silanos elegidos fueron por disponibilidad en el país siendo el 3mercaptopropiltimetoxisilano (95\% Sigma-Aldrich), 3-aminopropiltrietoxisilano (99\% SigmaAldrich), metiltrietoxisilano (95\% Sigma-Aldrich) y n-octitrietoxisilano (98\% Xiameter, Dow Corning). Como siloxanos se utilizaron el Sika guard S1 y S700. 
Las elecciones fueron por diferentes criterios aunando todos en la capacidad de estos compuestos de penetrar (por tamaño) y de reaccionar químicamente (por reactividad). Los dos primeros silanos fueron elegidos por tmaño de partícula infiriedo en una primera instancia, que facilitaría su ingreso a la madera. En cuanto al par mencionado a continuación se eligió por su diferente longitud de cadena, ya que como se mencionó en el capítulo anterior, es una variable para el manejo del proceso sol-gel y también, porque esta directamente relacionado a su hidrofobicidad (mayor cadena, más hidrofóbico). Por último, los siloxanos elegidos fueron de procedencia comercial: Sika guard 700S y S1. Estos fueron elegidos por su gran consumo para la protección en materiales de contrucción húmeda, con el objetivo de generar con ellos una formulación del tipo lasur, lo cual permitió generar conocimientos de la ventaja y desventaja entre los diferentes métodos de aplicación: la impregnación y el pintado.

Por otra parte, los nanocompuestos seleccionados fueron a) óxido de nanosílice (o nanosilica o mesoporos Sigma Aldrich 200nm), b) nanoplata (NanoArg-NanoTek S.A. nanoparticula $\leq 50$ $\mathrm{nm}, 30-35 \mathrm{p} / \mathrm{v} \%$ en monoetileter de triethienglicol), c) nanocobre (NanoKupro-NanoTek S.A. en polvo $100 \mathrm{~nm}$ ), y d) óxido de nanozinc (NanoOxZn-NanoTek S.A. en polvo $100 \mathrm{~nm}$ ). Estos se escogieron básicamente por su potencial poder biocida, por no conocerse aún su desempeño como preservantes en maderas y por la disponibilidad en el país.

Lo mencionado fundamenta el uso de estas dos nuevas tecnologías en el presente trabajo para la protección contra el biodeterioro y la acción del fuego de maderas de baja densidad. En este apartado del capítulo se desarrollarán las características de aquéllos elegidos para los tratamientos empleados en esta tesis.

\section{II.1.2 Madera: Especie utilizada}

Como se mencionó en el primer Capítulo, el material de este estudio es la madera, más específicamente maderas de coníferas perteneciente a la familia de las gimnospermas entre las que se encuentra la especie elegida para llevar a cabo este estudio Pinus ponderosa.

Las maderas fueron obtenidas en Maderera Platense y como muestras otorgadas por las diferentes empresas en la feria FITECMA 2011 y 2013, específicamente de las empresas de 
Aserradero Iguazú, Multiplacas S.A., grupo Tapebicuá, Aserradero Corfone S.A y Maderas Trumar S.A.

Por tratarse de un organismo heterogéneo constituido por células dispuestas y organizadas en diferentes direcciones, es muy importante definir el plano en el cual se está trabajando o se está describiendo a la madera. El plano de corte anatómico utilizado en la tesis fue el corte transversal o corte perpendicular al eje del árbol. En este plano se observan los anillos de crecimiento y sus características: ancho de anillos, porcentaje de madera temprana y madera tardía y tipo de transición entre las mismas. Si los radios son lo suficientemente grandes se observan como líneas que cruzan los anillos de crecimiento en ángulo recto.

Otros elementos macroscópicos que se observan en esta sección, agrupación y disposición de las células, tamaño de los radios, tipo de parénquima, textura y el tipo de transición que existe entre albura y duramen. En la latifoliadas se observa los vasos o poros y en las coníferas las traqueidas (células lignificadas con lumen vacío) que al ser cortadas transversalmente pueden observarse como pequeños orificios.

Microscópicamente se pueden observar todas las células que se producen en cada uno de los periodos vegetativos y las diferencias existentes entre células del inicio o del termino de cada crecimiento, ejemplo en el que la mayoría de las especies que crecen en climas templados, permiten determinar con exactitud la cantidad de madera que se agrega en cada periodo de crecimiento anual.

Esto permite definir el porcentaje de madera temprana o tardía de cada una de las muestras permitiendo que esto no sea una variable a la hora de tratar y/o analizar el comportamiento de la madera en servicio.

\section{- Pinus ponderosa}

A nivel macroscópico se la puede describir como una madera con albura amarilla clara a blancuzca, duramen amarillo anaranjado o marrón claro, anillos de crecimiento bien marcados por transición de leño tardío a temprano abrupta. Radios leñosos poco visibles con lupa y parénquima no visible. Canales resiníferos axiales presentes, solitarios o contiguos de 2 o 3 
presentes en la porción central del anillo y en el leño tardío (visibles a ojo desnudo). En cuanto a sus características estéticas y organolépticas podemos decir que presenta un brillo mediano con una textura mediana a fina homogénea, de grano derecho y diseño marcado donde se observa floreada en corte tangencial y veteado en corte radial. El porcentaje de madera temprana o tardía que presentaron los cortes utilizados rondan entre un $25 \%$ y un $30 \%$.

Frente al secado tiene un comportamiento óptimo ya que no tiene tendencia al rajado, agrietado o deformado. Admite normas de un seado acelerado por lo que es industrialmente importante.

Según las pruebas realizadas su durabilidad sin ser tratada en intemperie y enterrada (condiciones de exposición extrema) es de 5 años; por eso se la clasifica como poco durable y esta condición hace que sea una madera seleccionada para su estudio en materia de protección [27].

\section{II.1.3 Modificadores químicos: siloxanos, silanos y nanopartìculas}

\section{$\underline{\text { Silanos }}$}

Los silanos que se emplearon en la tesis fueron escogidos con diferente tamaño molecular y longitud de cadena hidrocarbonada para estudiar su efecto en cuanto a reactividad (modificación química de madera), hidrofobicidad y polimerización tanto en formulaciones impregnantes como en de recubrimientos protectores.

Los elegidos fueron 3-aminopropiltrietoxisilano 99\%, 3-mercaptopropiltrimetoxisilano95 \%, metiltrietoxisilano y n-octiltrietoxisilano (todos los reactivos son de la marca Sigma-Aldrich y NanoTec S.A.), Figura II.1 [1-4].

\section{3-Aminopropiltrietoxisilano 99\% ( ${ }^{\circ} \mathrm{CAS}$ 919-30-2):}

3-Aminopropiltrietoxisilano (APTES) es una aminosilano el cual es usado en el proceso de silanización como agente de acoplamiento: este funciona como sustrato de los alcoxisilanos permitiendo su polimerización. Puede ser empleado en las resinas de rellenos minerales, 
termoplásticos y termoestables, como aldehídos fenólicos, poliéster, epoxi, PBT, poliamida, éster carbónico, etc. Pueden ser utilizados también para mejorar las propiedades físicas, mecánicas y eléctricas de los plásticos, al igual que su resistencia a la flexión, a la compresión y al corte en estado seco y húmedo. Además, también puede mejorar la capacidad de humectación y dispersabilidad de rellenos de polímeros. Como es una especie de promotor de adherencia, el 3-aminopropiltrietoxisilano puede ser ampliamente utilizado en poliuretano, epoxi, nitrilo, aglutinantes fenólicos y materiales de sellado, que puede ser utilizado para mejorar la dispersabilidad de pigmento, así como para mejorar la adhesividad de vidrio, aluminio y hierro, y también se puede aplicar al poliuretano, epoxi y pinturas acrílicas de látex en medio ácido.

$\mathrm{Su}$ formula molecular es $\mathrm{C}_{9} \mathrm{H}_{23} \mathrm{NO}_{3} \mathrm{Si}$. Presenta un aspecto líquido transparente incoloro, una densidad $\left(\rho 25^{\circ} \mathrm{C}\right): 0,946 \mathrm{~g} / \mathrm{cm} 3$, un punto de ebullición de $217^{\circ} \mathrm{C}$ y un índice de refracción $\mathrm{nD} 25$ de 1.420. En cuanto a su toxicidad hay que tener en cuenta que el contenido residual extraíble de 3-aminopropiltrietoxisilano debe ser inferior a $3 \mathrm{mg} / \mathrm{kg}$ de carga cuando se utilice para el tratamiento reactivo de la superficie de cargas inorgánicas y $\mathrm{LME}=0,05 \mathrm{mg} / \mathrm{kg}$ cuando se utilice para el tratamiento de superficie de materiales y objetos es de $12,5 \mathrm{mg} / \mathrm{kg}$ (LD50*, administración oral en ratas) [1-8].

Es soluble en varios solventes orgánicos, pero el tetracloruro de carbono y acetona, es conveniente que no sean usados como diluyentes. Pueden ser hidrolizados en agua para que la solución sea alcalina y esta propiedad fue lo que se implementó en la presente tesis.

\section{3-Mercaptopropiltrimetoxisilano $95 \%$ (MPS, $N^{\circ}$ CAS No.4420-74-0)}

Es un agente de acoplamiento de silano, se utiliza como precursor en el proceso de silica gel. El 3-mercaptopropil trimetoxisilano posee un efecto especial usado como inhibidor de la corrosión de superficies metálicas. Este también puede mejorar la capacidad de adhesión de la resina de polímero. En la industria de la goma, el 3-mercaptopropil trimetoxisilano es comúnmente usado para procesos de llenado inorgánico, como carbón blanco, carbón negro, fibra de vidrio y mica, etc. 
Este puede efectivamente mejorar las propiedades mecánicas y la resistencia del desgaste de la goma. Este producto puede también ser usado en procesos de antiencogimiento finales para fábricas en la industria textil y como materia prima para productos de cuidado del cabello.

Se trata de un silano mercapto funcional que encuentra uso como un agente de acoplamiento en polisulfuro y masillas y selladores de poliuretano. Se puede utilizar como un tratamiento previo sobre los minerales o añadido en el momento de la capitalización. Al ser una especie derivada del azufre que contiene silano en lugar eficiente y rápido, se utilizan niveles de carga de silano normalmente inferiores.

$\mathrm{Su}$ fórmula molecular es $\mathrm{C}_{6} \mathrm{H}_{16} \mathrm{O}_{3} \mathrm{SSi}$. Presenta un peso molecular de 196.34, su forma física es líquida transparente de densidad aproximada a $25^{\circ} \mathrm{C}$ de $1.057 \mathrm{~g} / \mathrm{cm}^{3}$, un punto de ebullición entre $213-215^{\circ} \mathrm{C}$, índice de refracción $\left(\mathrm{nD} 25^{\circ} \mathrm{C}\right)$ de 1.442 y punto de inflamación, Pensky-Martens en vaso cerrado (1) de $88^{\circ} \mathrm{C}$. En cuanto a su toxicidad para el tratamiento de superficie de materiales y objetos es de $20 \mathrm{mg} / \mathrm{kg}$ (LD50*, administración oral en ratas) [1-8].

3-mercaptopropiltrimetoxisilano silano es soluble en metanol, etanol, isopropanol, alcoholes minerales, acetona, benceno, tolueno, xileno, y en agua cuando se siguen los procedimientos de hidrólisis adecuados.

\section{Metiltrietoxisilano (MTES, N ${ }^{0}$ CAS: 2031-67-6):}

Es un compuesto organosilíco con la fórmula $\mathrm{CH}_{3} \mathrm{Si}\left(\mathrm{OC}_{2} \mathrm{H}_{5}\right)_{3}$. Es un líquido incoloro de peso molecular $178.3 \mathrm{~g} / \mathrm{mol}$, su densidad es $0.895 \mathrm{~g} . \mathrm{cm}^{-3}$ y viscosidad de 0,6 cSt. La temperatura de autoignición es de $225^{\circ} \mathrm{C}$ y su punto de ignición $30^{\circ} \mathrm{C}$. Presenta un momento dipolar de 1,72 Debye y una entalpía de combustión, $\Delta$ hcomb de $1831 \mathrm{kcal} / \mathrm{mol}$. Su sensibilidad hidrolítica es 7 ya que Si-O reacciona lentamente con el agua o humedad ambiente. Su toxicidad es de 12,5 $\mathrm{mg} / \mathrm{kg}$ (LD50*, administración oral en ratas).

Es un líquido transparente incoloro, soluble en alcohol, benceno y gasolina. Presenta un peso específico $\left(25^{\circ} \mathrm{C}\right): 0.890 \pm 0.0050 \mathrm{~g} / \mathrm{ml}$, un punto de ebullición: $143.5^{\circ} \mathrm{C} / 760 \mathrm{mmHg}$, un índice de refracción $\left(25^{\circ} \mathrm{C}\right): 1,3832 \pm 0,0020$ y punto de inflamación: $23{ }^{\circ} \mathrm{C}$ 
Se puede combinar con resinas co-reticuladas, también puede manejar como una variedad de carga inorgànica en formulaciones. Su molécula es tetraédrica y a menudo se describe como hibridación sp3. La hidrólisis de MTES procede tanto en condiciones ácidas como básicas. Bajo condiciones ácidas, la tasa de hidrólisis sucesivas para metiltrimetoxisilano disminuye con cada paso. Bajo condición básica sucede lo contrario.

\section{n-octiltrietoxisilano (OTES, $N^{o}$ CAS 2943-75-1)}

N-octiltrietoxisilano es un agente de acoplamiento de silano, es un silano alquilo-functional monomérico de cadena media. Se presenta como un líquido transparente e incoloro y soluble en común no polar disolventes orgánicos (ej. G. éter de petróleo, tolueno). Sin embargo, su baja volatilidad y viscosidad hacen que sea un aditivo fácil de manejar.

Se puede usar como un modificador de superficie para generar hidrofobicidad o como cargas minerales. Las propiedades dadas por la cadena carbonada se ven cuando este silano es incorporado a algún polímero. Los niveles de carga que se recomienda son de 0,5 a 1,5\% en peso.

Este silano también se puede utilizar para mejorar la compatibilidad de las cargas minerales o pigmentos en poliolefinas o para facilitar su dispersión en matrices no polares. Al ser una molécula pequeña permite la penetración profunda en la superficie cuando esta es porosa.

Este compuesto reacciona con la humedad tanto del aire como del sustrato en presencia de un medio alcalino o ácido generando grupos hidroxi como productos de esta reacción. Estos grupos hidroxi se unirán con el sustrato y la misma para producir un tratamiento hidrófobo que inhibe la absorción de agua en el sustrato. Un medio alcalino, tal como hormigón nuevo, catalizará la reacción y la velocidad de la formación de la superficie hidrófoba.

Es un compuesto organosilíco con la fórmula $\mathrm{C}_{14} \mathrm{H}_{32} \mathrm{O}_{3} \mathrm{Si}$, su peso molecular $276.5 \mathrm{~g} / \mathrm{mol}$; aspecto, líquido incoloro; densidad, 0.880 g.cm-3. Su punto de ignición es de $100^{\circ} \mathrm{C}$, su entalpía de vaporización de $44.2 \pm 3.0 \mathrm{~kJ} / \mathrm{mol}$ y su viscosidad de $1.9 \mathrm{cSt}$. Su sensibilidad hidrolítica es 7 ya que reacciona lentamente con la humedad, y el agua. Su toxicidad es de 8002,5 mg/kg (LD50*, administración oral en ratas). 
* LD son las siglas de "Dosis letal". LD50 es la cantidad de un material determinado, que provoca la muerte del 50\% de un grupo de animales de prueba. El LD50 es una forma de medir el envenenamiento potencial a corto plazo (toxicidad aguda) de un material.
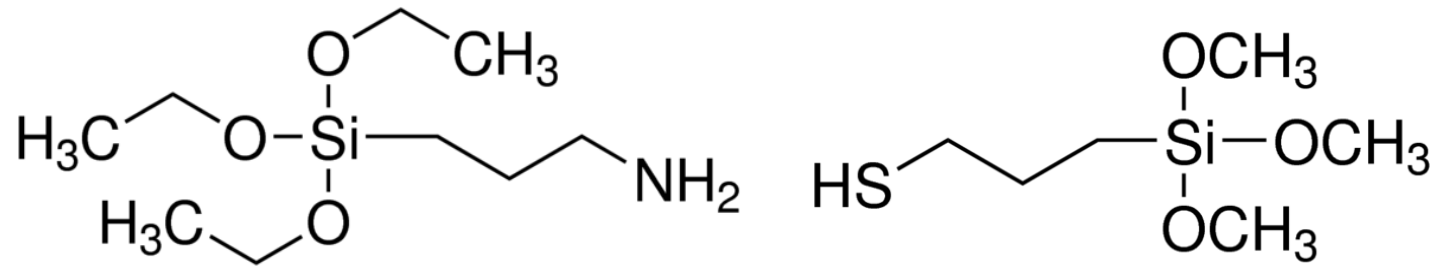<smiles>CCO[Si](C)(OCC)OCC</smiles><smiles>CO[Si]([18OH])(OC)OC</smiles>

Figura II.1. Fórmula molecular de Aminopropiltrietoxisilano (APTES), Mercaptopropiltrimetoxisilano (MPTMS), Metiltrietoxisilano (MTES) y n-octiltrietoxisilano (OTES).

\section{$\underline{\text { Siloxanos }}$}

\section{Sika guard 700S y S1}

La línea Sikaguard es un impregnante monocomponente e hidrófugo de Siloxanos en base agua, para aplicar sobre superficies absorbentes cementosas en obra civil o en estructuras de edificación de hormigón. Penetra en el interior de los poros abiertos, produciendo una hidrofugación duradera al agua, mientras permite la difusión del vapor de agua en ambas direcciones; otras propiedades son:

- $\quad$ Reduce la absorción de agua por capilaridad.

- $\quad$ Reduce la aparición de eflorescencias.

- $\quad$ Reduce la penetración de suciedad en los poros.

- $\quad$ Mejora el aislamiento térmico.

- $\quad$ Se puede recubrir con revestimientos en base disolvente y con dispersiones. 
- $\quad$ No cambia normalmente la apariencia estética del soporte.

- $\quad$ Reduce la penetración y movimiento de iones de cloro.

- $\quad$ No actúa como barrera de vapor.

- Durabilidad y resistencia mayores que los tratamientos convencionales en base silicona.

- Color: Líquido incoloro.

Presentación: Botes (Envases) de 5 litros

La diferencia entre estos radica en que uno es un hidrofungante muy utilizado en el mercado para hormigones (700-S) y el otro se utiliza en ladrillos, pero ambos tienen siloxanos/silanos en su composición.

\section{$\underline{\text { Nanopartículas }}$}

\section{Nanosilice}

Una de las partículas elegidas para esta tesis fue el nanosílice $\left(\mathrm{SiO}_{2}\right)$, se conoce que la aplicación de estos compuestos en la madera a escala micro hace que sea una madera más hidrofóbica que lo normal, dándole una gran estabilidad dimensional (debido a que no absorbe tanta agua) y una alta resistencia a microorganismos (hace que los microorganismos no proliferen en la madera debido a que se forma un ambiente inhóspito, además también previene el desarrollo de las esporas) [9-110].

Fundamentalmente se eligieron las partículas de nanosilice y óxido de nanozinc por las siguientes razones: (i) tienen muy alta actividad de superficie y una estructura porosa resultante lo cual le da propiedades de adsorción, (ii) son partículas de tamaño nanométrico de metales incrustados en una matriz de sílice tienen la menor tendencia a aglomerarse; (iii) su matriz de sílice es químicamente inerte y resistente al ataque microbiano tanto in vitro como in vivo.

Es un producto que parte de sílice precipitada que contiene agua cristalina $\left(\mathrm{SiO}_{2}, \mathrm{nH}_{2} \mathrm{O}\right)$. Presenta una granulometría del polvo de $\leq$ D90 (120-180) nm, con la superficie de las partículas que contienen el enlace iónico $-\mathrm{OH}$ y su superficie específica es superior a $500 \mathrm{~m}^{2} / \mathrm{g}$. El agua cristalina imparte funciones duales: El ión $\mathrm{OH}$ - cuando no esta en presencia de agua se transforma en óxido de sílice con excelente propiedad conductora. Por otro lado, los iones $\mathrm{OH}$ - 
pueden adherirse a diferentes compuestos con el fin de cambiar la propiedad estructural e inducir aislamiento. Esta propiedad es lo que se utilizó en la presente tesis

La adición en formulaciones varía de 3\% a 6\%. Sin embargo, incluso $1 \%$ es suficiente para lograr la mejora de los resultados en el cemento. El procedimiento es de mezcla y agitación normales, seguido de la adición de agua proporcional a la cantidad de aglutinante utilizado [1112].

\section{Nanozinc}

El óxido de zinc es un polvo blanco muy utilizado en numerosas aplicaciones. Una de ellas es en productos cosméticos, como los filtros UV o los colorantes. Su uso se considera por lo general seguro, principalmente porque no penetra en el cuerpo. Recientemente, las nuevas tecnologías han permitido el uso de partículas de óxido de zinc de tamaño nanométrico, lo cuales difieren del óxido de zinc convencional en cuanto a sus propiedades físicoquímicas y toxicidad. [13-18]

El óxido de zinc es uno de los semiconductores que suscitan mayor interés tecnológico debido a sus numerosas aplicaciones. En la actualidad es uno de los semiconductores más estudiados, esto hace que el óxido de zinc adquiera gran interés en diversos nanosistemas como son los dispositivos optoelectrónicos, biosensores, como pigmento en la producción de pinturas, así como su uso en la industria farmacéutica (en especial en el campo de la cosmética, donde se utiliza como filtro de radiación ultravioleta en la producción de cremas solares). También es relevante su uso en transductores acústicos, en varistores, en sensores de gas, en electrodos transparentes, como ventana óptica en células solares, etc. En cuanto a su aplicación como biosensor, se ha demostrado que el $\mathrm{ZnO}$ puede emplearse para detectar el colesterol debido a su afinidad con compuestos $\mathrm{CHO}$.

\section{Nanopartículas metálicas}

Las otras dos nanopartículas elegidas fueron nanometales, nanocobre y nanoplata, debido a que los nanometales tienen muchos mecanismos de acción sobre los microorganismos para actuar como biocida sin necesidad de que haya un contacto directo, en contrastante con el caso de los nanoóxidos que solo actúan si hay contacto directo [19]. 
La nanoplata y el nanocobre se eligieron debido a su conocido poder biocida y por su desconocido comportamiento ignífugo aplicado en maderas; ya que el objetivo de la presente tesis es generar sistemas protectores contra ambos agentes degradadores en simultáneo.

Una breve explicación del mecanismo antimicrobiano de los metales se puede explicar de la siguiente manera: en general, los iones metálicos destruyen o pasan a través de la membrana celular, y se unen al grupo-SH de enzimas celulares; éstos tienen una gran afinidad por los aminoácidos nucleófilicos de proteínas, uniéndose a los grupos sulfhidrilo, amino, imidazol, fosfato y carboxilo de la enzima o de las proteínas de membrana. La consecuente disminución crítica de la actividad enzimática o desestabilidad de la membrana provoca que el metabolismo del microorganismo cambie inhibiendo su crecimiento, hasta provocar la muerte de la célula por donde ingresó. [20-22]

Por otra parte, los iones metálicos también catalizan la producción de radicales de oxígeno que oxidan la estructura molecular llevando a un desequilibrio de cargas citoplasmáticas lo cual produce que todos los componentes solubles se aglomeren llevando también a esa célula a la muerte. Como las células bacterianas y fúngicas se encuentran en contacto directo mediante gapjunction (mayoritariamente en bacterias, pero algunos hongos microscópicos también) el oxígeno activo producido difundirá desde la célula donde se originó hasta el entorno circundante. Por lo tanto, los iones de metal inhiben la multiplicación de todos los microorganismos del medio desestabilizando su ecosistema [23].

En cuanto al nanocobre se han reportado propiedades bactericidas pero claramente menores que la de nanopartículas de plata se han elaborado nanomateriales basado en nanopartículas de cobre y una matriz termoplástica; este novedoso material se caracteriza por retardar y en algunos casos inhibir la proliferación de microorganismos en su superficie [24-26].

El área superficial muy activa de las nanopartículas de cobre, tienen un gran mejoramiento de la eficiencia catalítica. Los nanopolvos o nanopartículas metálicas tienen una mayor razón de volumen de los átomos superficiales, los cuales tienen un alto estado energético. En la industria metalúrgica de polvos se pueden utilizar como aditivo de sinterización para reducir la temperatura en la producción de cerámicos y herramientas con diamante. Nano cobre se puede utilizar ampliamente en la industria médica y como anti bacteriano (E. coli, Salmonella, S. Aeurus). 
En la Figura II.2 se muestran los espectros FT-IR de los precursores de formulación comercialmente adquiridos.

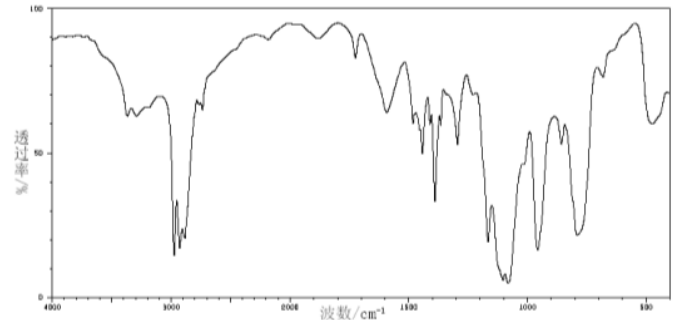

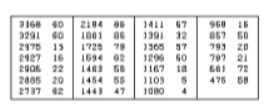

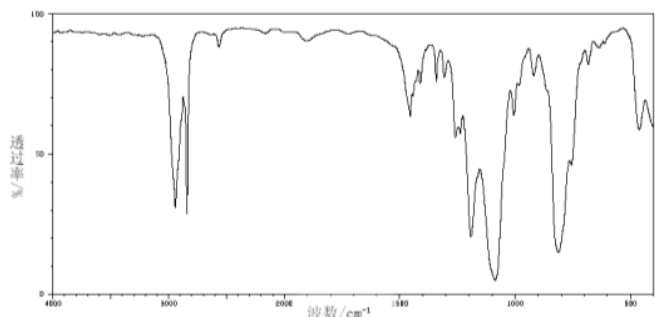

閏闻閣
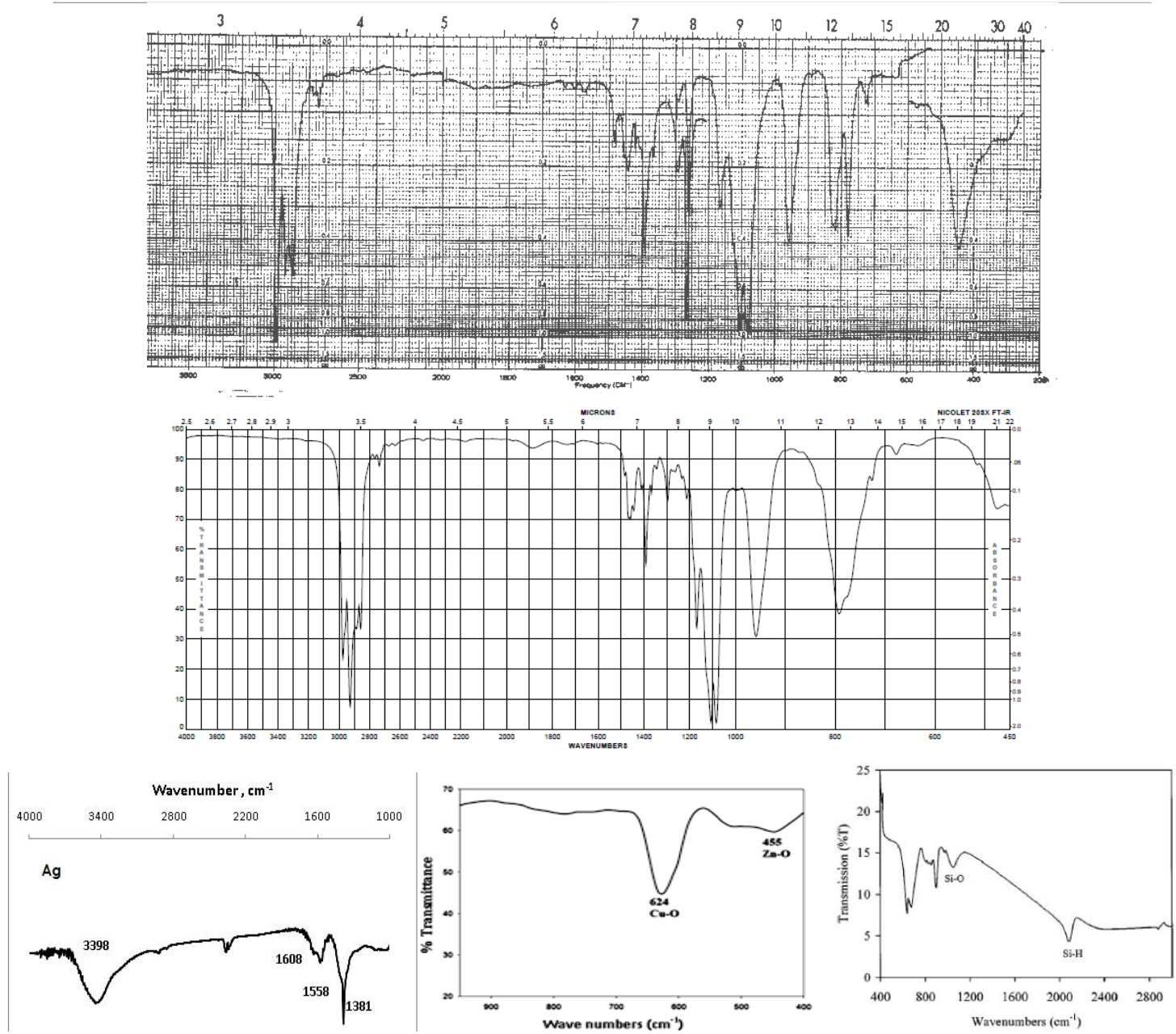

Figura II.2. Espectros FT-IR de los silanos y nanocompuestos utilizados, procedentes de la caracterización comercial: a)APTES, b)MPTMS, c)MTES, d) OTES, e) $\mathrm{Ag}$, f) $\mathrm{CuO} \mathrm{y} \mathrm{ZnO}, \mathrm{g}) \mathrm{SiO}_{2}$ 


\section{II.1.4 Agentes biodeteriorantes a ensayar: hongos xilófagos}

En la presente tesis no se tuvo en cuenta el ataque de moluscos, crustáceos y pájaros ya que son casos muy específicos. En cuanto a la incidencia de insectos no es un factor menor que aporta al biodeterioro, pero no es determinante.

La mayor o menor incidencia del tipo de organismo depende exclusivamente de su distribución geográfica, por ejemplo, en España la mayor incidencia en el biodeterioro es de los insectos, quedando los microorganismos implicados en el biodeterioro en un segundo plano. En nuestro país, la mayor incidencia está dada por los microorganismos. Esto no quiere decir que no existen insectos que afectan, pero lo hacen en un porcentaje menor con respecto a los hongos y, además, en la mayoría de los casos su ataque está asociado al previo ataque fúngico, debido a que este ataque hace que el sustrato esté en las condiciones que el insecto necesita para desarrollarse o por mecanismos simbióticos que facilitan el ingreso y degradación del sustrato [27-30]. Por lo tanto, con tratamientos protectores que disminuyan el contenido de humedad de la madera y el ataque fúngico indirectamente también dará protección al ataque de algunos insectos. Es por ello que la presente tesis se focaliza en el ataque fúngico como agente biótico de deterioro.

- Hongos de la pudrición blanda: se expuso a este tipo de pudrición mediante hongo autóctono como agente degradante. El mismo fue caracterizado en el INMIBO-FCEyN de la Universidad de Buenos Aires, mediante cortes, tinción y observación a microscopio, dado una identificación taxonómica del mismo mediante morfología y apoyo en claves dicotómicas. La especie encontrada fue Chaetomium globosum (Chaetomium globosum Kunze ex Fr., Systema Mycologicum 3: 255 (1829))

- Hongos de pudrición blanca: Este tipo de pudrición fue representada por Phenillus chaquensis.

- Hongos de pudrición parda: esta es la pudrición más importante a estudiar ya que es la más comúnmente hallada en las maderas de edificios antiguos e históricos. Por esto y por su especificidad en coníferas se eligió como agente degradante a la especie Trametes versicolor, Figura II.3. 


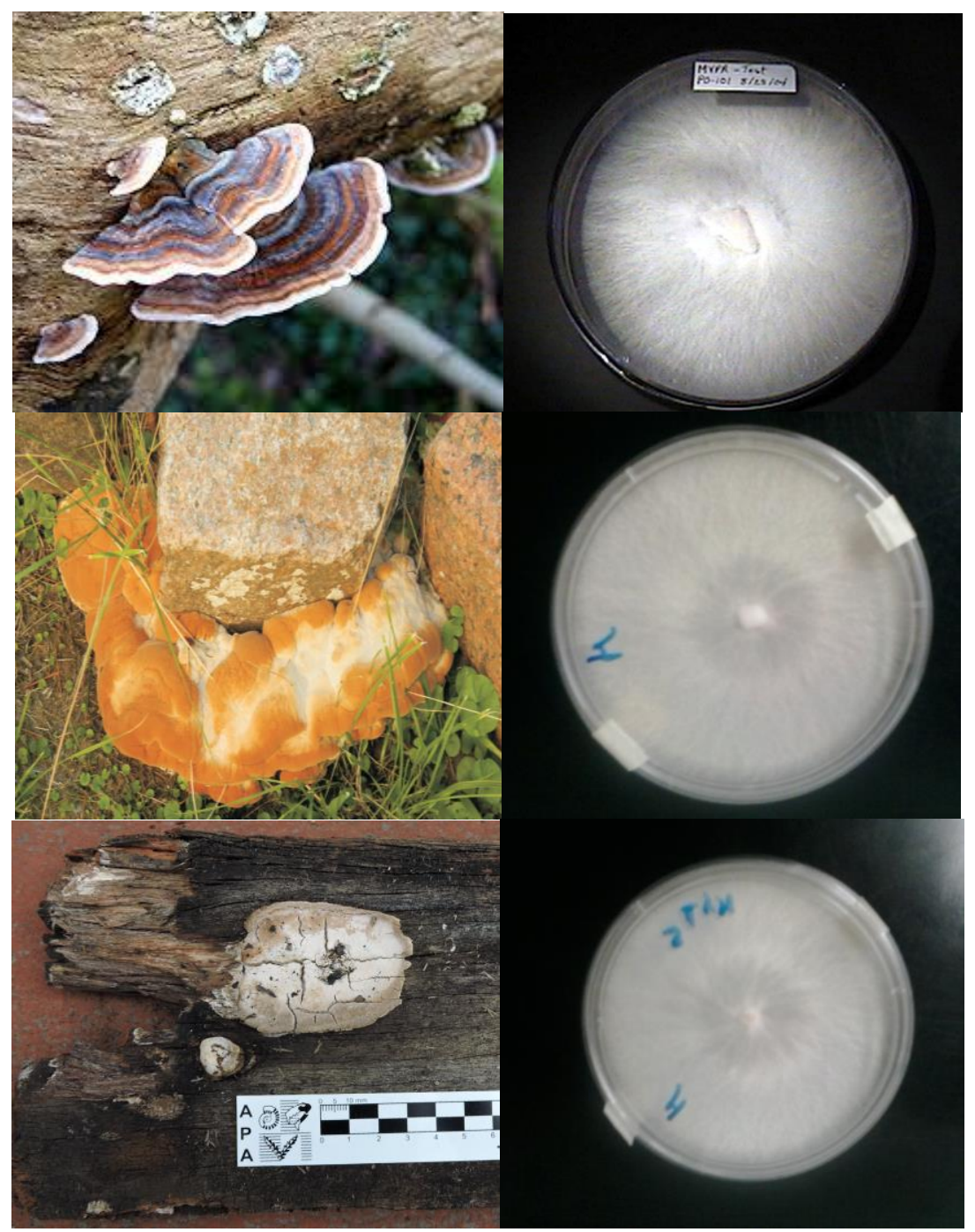

Figura II.3. Especies elegidas para que actúen como agentes degradantes biológicos: En orden de arriba hacia abajo Trametes versicolor, hongo en roble identificado como Chaetomium globosum, hongo Phenillus chaquensis

\section{2. Métodos}

En este apartado se detallarán los métodos de aplicación escogidos para cada uno de los sistemas protectores desarrollados, formulados y estudiados durante el desarrollo de la tesis, así como también se detallarán los ensayos utilizados para analizar la performance de cada formulación frente a los agentes bióticos y abióticos elegidos como representantes para definir un comportamiento de la madera tratada en servicio. 
Como se mencionó en el primer capítulo, los agentes deteriorantes de maderas que se estudiaron en el marco de la tesis fueron los hongos xilófagos (agentes bióticos), la humedad y el fuego (agentes abióticos).

\section{II.2.1 Criterios de formulación y condiciones del proceso sol-gel elegidas}

Los sistemas estudiados de forma general y sintética fueron:

- Silanos

- Silanos/Silanos

- Nanocompuestos

-Silanos/Nanocompuestos

- Siloxanos/siloxanos (comercial, Sikaguard S700 y S1).

En base a lo detallado en el capítulo anterior, se utilizaron diferentes pHs debido que influye en la cinética de la reacción, utilizando los dos extremos; ácido y alcalino.

Las soluciones madres se realizaron a un $\mathrm{pH}$ cercano a $7(\mathrm{pH}=6.8 \pm 0.2)$ ya que la tasa de hidrólisis alcóxidos de silicio presenta un mínimo a $\mathrm{pH}=7$ y aumenta exponencialmente tanto a pH más bajo como más alto, mientras que la condensación es todo lo contrario, presentando un máximo a $\mathrm{pH}=7$. Por lo tanto, los cambios de $\mathrm{pH}$ se manejaron con el agregado de $\mathrm{HCl}$ o $\mathrm{NH}_{4} \mathrm{OH}$ en el momento de ser aplicado.

Por otra parte, se utilizó un $\mathrm{r}$ bajo (agua presente en la madera únicamente) para asegurar que silanos no reaccionen fuera de la madera, siendo esta la condición la óptima para que los silanos ingresen a la madera y reaccionen con ella evitar el aglomeramiento de los silanos antes de ser impregnados, tal como se detalló en el Capítulo I.

Este manejo de variables del proceso sol gel entonces permitió entonces el tratamiento de la madera con silanos en tres estados diferentes:

- Silanos: solución acidificada (con $\mathrm{HCl} 37 \%$ ) => polímero denso pero poco ramificado

- Sol: solución diluida con agua ácida y alcalina => Estados intermedios 
- Silanol. Solución alcalinizada $\left(\right.$ con $\left.\mathrm{NH}_{4} \mathrm{OH}\right)=>$ redes ramificadas y compactas (clusters)

Los métodos de preparación fueron, Tabla II.1:

- Silano: En el primer método (Marcado como silano en la Tabla II.1), el silano se diluyó con etanol, se acidificó con cuatro gotas de ácido clorhídrico al 37\% y se agitó durante 15-20 min justo antes se ser aplicada a la madera, tal como se describe por Donath et al. [31].

- Sol (siloxano): solución diluida con agua. Los silanos (90 g) se mezclaron con $40 \mathrm{ml}$ de etanol y agua en cantidad estequiométrica (Dependiendo del peso molecular del silano usado). La mezcla se agitó a temperatura ambiente durante 20-30 min. Durante la hidrólisis, la mezcla turbia se convirtió caliente y transparente.

- Silanol: Con este procedimiento, los etoxisilanos son hidrolizados a silanoles, el silano se diluyo con etanol alcalinizado: el añadiéndole3 $\mathrm{ml}$ de $\mathrm{NH}_{4} \mathrm{OH}$ (imitando el método Stöber, (17)) y se agitó durante 15-20 min. (como se describe por Donath et al. [31]).

La eficacia de las nanopartículas está esencialmente influenciada por el medio en el que están dispersas, el tamaño de las partículas en dispersión y la estabilidad de la dispersión. La principal limitación la dispersión puede resolverse mediante la identificación de un medio adecuado el cual fue en un medio alcóholico [32].

Las dispersiones donde se encuentran inmersas las nanopartículas también son en base alcohólica y concentración de estas variaron entre un 1 y un $10 \% \mathrm{~m} / \mathrm{v}$. Por otro lado, también se realizaron sistemas mixtos donde se incluyeron una dispersión de nanopartículas en las soluciones de silanos en sus tres formas en un rango de concentración que vario desde 1 al $10 \%$ de las soluciones de nanopartículas antes descriptas.

La preparación de una nanodispersión estable y uniforme, con un tamaño medio de partícula $<100 \mathrm{n}$, es el desafío más importante, ya que cuando las nanopartículas están dispersas en solución, se tienden a aglomerar aumentando así el tamaño de partícula y reduciendo su reactividad. Además, los agregados se estabilizan con el tiempo perdiendo la dispersión. De este modo, la selección de dispersantes, tensioactivos y estabilizante es importante para preparar una 
nanoformulaciones, ya quelas propiedades de las nanopartículas está directamente influenciada por el tamaño y la estabilidad.

Tabla II.1 Las formulaciones impregnantes en base a silanos utilizadas en la tesis

\begin{tabular}{|c|c|c|c|c|}
\hline Id. & Agente & Método & Soluto/ Solvente & $\begin{array}{c}\text { Concentració } \\
\text { n v/v \% }\end{array}$ \\
\hline APTES & 3-Aminopropyltrietoxisilano & \multirow[t]{3}{*}{ Silano } & \multirow[t]{4}{*}{$\begin{array}{l}80 \mathrm{ml} \mathrm{de} \mathrm{etanol+} \\
4 \mathrm{ml} \mathrm{de} \mathrm{Hcl} 37 \%\end{array}$} & \multirow{8}{*}{15} \\
\hline MPTMS & $\begin{array}{c}\text { 3- } \\
\text { (Mercaptopropil)trimetoxisilano }\end{array}$ & & & \\
\hline MTES & Metiltrietoxisilano & & & \\
\hline OTES & n-octiltrietoxisilano & \multirow[t]{4}{*}{ Sol } & & \\
\hline APTES/MPTMS & $\begin{array}{c}\text { 3-Aminopropiltrietoxisilano } \\
\text { 3-Mercaptopropil)trimetoxisilano }\end{array}$ & & \multirow{3}{*}{$75 \mathrm{ml}$ de etanol } & \\
\hline MTES/OTES & $\begin{array}{l}\text { Metiltrietoxisilano } \\
\text { n-octiltrietoxisilano }\end{array}$ & & & \\
\hline APTES/OTES & $\begin{array}{c}\text { 3-Aminopropiltrietoxisilano } \\
\text { n-octiltrietoxisilano }\end{array}$ & & & \\
\hline MTES/MPTMS & $\begin{array}{c}\text { Metiltrietoxisilano } \\
\text { 3-Mercaptopropil)trimetoxisilano }\end{array}$ & Silanol & $\begin{array}{l}80 \mathrm{ml} \mathrm{de} \mathrm{etanol} \mathrm{+} \\
4 \mathrm{ml} \mathrm{de} \mathrm{NH}_{4} \mathrm{OH}\end{array}$ & \\
\hline
\end{tabular}

Las nanopartículas tienen alta energía y carga superficial, la cual cuando se las añade a un medio líquido, las partículas se agregan y precipitan. Se han adoptado diversos métodos para evitar la aglomeración de nanopartículas en una dispersión que incluye la adición de tensioactivoso dispersantes, modificación de la superficie, control del pH o agitación ultrasónica [33-34].

Por todo lo mencionado, en el presente estudio se utilizó una solución alcohólica como fluido base para la preparación de nano-dispersión actuando como un dispersante y estabilizador y los 
dos perfiles de $\mathrm{pH}$ como con los silanos y siloxanos. La concentración de las nanopartículas varió del 1 al 10\% m/v, Tabla II.2.

Tabla II.2 Las formulaciones impregnantes a base de nanocompuestos utilizadas en la tesis

\begin{tabular}{|c|c|c|c|}
\hline Id. & Agente & Solvente & Concentración \\
\hline $\mathrm{nSi}$ & $\operatorname{nanoSiO}_{2}$ & \multirow{4}{*}{$\begin{array}{c}90 / 10 \% \mathrm{v} / \mathrm{v} \\
\text { etanol/agua }(100 \mathrm{ml}) \\
+5 \mathrm{ml} \mathrm{de} \mathrm{HCl}(37 \%)\end{array}$} & \multirow{2}{*}{$\begin{array}{l}1 \% \\
2 \%\end{array}$} \\
\hline $\mathrm{nAg}$ & nanoAg & & \\
\hline $\mathrm{nZn}$ & nanoZn & & \multirow{6}{*}{$\begin{array}{c}6 \% \quad \mathbf{m} / \mathbf{v} \% \\
7 \% \\
8 \% \\
9 \% \\
10 \%\end{array}$} \\
\hline $\mathrm{nCu}$ & nanoCuO & & \\
\hline $\mathrm{nSi}$ & nanoSiO$_{2}$ & \multirow{4}{*}{$\begin{array}{c}90 / 10 \% \mathrm{v} / \mathrm{v} \\
\text { etanol/agua }(100 \mathrm{ml}) \\
+5 \mathrm{ml} \mathrm{de} \mathrm{NH}_{4} \mathrm{OH}\end{array}$} & \\
\hline $\mathrm{nAg}$ & nanoAg & & \\
\hline $\mathrm{nZn}$ & nanoZn & & \\
\hline $\mathrm{nCu}$ & nanoCuO & & \\
\hline
\end{tabular}

Por otro lado, también se realizaron sistemas mixtos donde se incluyeron nanopartículas en las soluciones de silanos utilizando MTES y OTES en un perfil catalítico básico ya que en estas condiciones el hidroxilo o los aniones de silanolato atacan al Si directamente; si bien en este caso los efectos estéricos son probablemente importantes, la cinética inductiva en la hidrólisis de organilalcoxisilanos es mejor.

Por lo tanto, se espera que el efecto estérico sea mejorado con la adición de los nanocompuestos y así aprovechar al máximo los potenciales de ambas tecnologías, Tabla II.3.

En todo el desarrollo de la tesis los tratamientos protectores fueron aplicados de dos maneras: por impregnación (incluye inmersión) o por cubierta superficial. 
Tabla II.3 Las formulaciones impregnantes a base de silanos/nanocompuestos

\begin{tabular}{|c|c|c|c|}
\hline Id. & Agente & Solvente & Concentración \\
\hline MTES/nSi & Metiltrietoxisilano/nanoSiO 2 & \multirow{8}{*}{$\begin{array}{c}80 / 20 \% \mathrm{v} / \mathrm{v} \\
\text { etanol/Hidróxido } \\
\text { de amonio } \\
(100 \mathrm{ml})\end{array}$} & \multirow{8}{*}{$\begin{array}{l}\text { Silano } / \text { nano }=0,3 \\
\text { Silano } / \text { nano }=0,5 \\
\text { Silano } / \text { nano }=0,8\end{array}$} \\
\hline MTES/nAg & Metiltrietoxisilano/nanoAg & & \\
\hline MTES/nZn & Metiltrietoxisilano/nanoZn & & \\
\hline $\mathrm{MTES} / \mathrm{nCu}$ & Metiltrietoxisilano/nanoCuO & & \\
\hline OTES/nSi & n-octiltrietoxisilano/nanoSiO & & \\
\hline OTES/nAg & n-octiltrietoxisilano/nanoAg & & \\
\hline OTES/nZn & n-octiltrietoxisilano/nanoZn & & \\
\hline $\mathrm{OTES} / \mathrm{nCu}$ & n-octiltrietoxisilano/nanoCuO & & \\
\hline
\end{tabular}

\section{II.2.2 Probetas}

Las muestras de madera se secaron antes de la impregnación a $105^{\circ} \mathrm{C}$. Después de la impregnación, las muestras de madera se calentaron en la solución durante $4 \mathrm{~h}\left(100^{\circ} \mathrm{C}\right)$ y luego se secó en estufa a $105^{\circ} \mathrm{C}$.

Las propiedades físicas estudiadas en maderas sin impregnar fueron: contenido de humedad (CH), (IRAM 9532, 1963); densidad aparente anhidra (Do), densidad aparente normal (Dn) y densidad aparente normal corregida al 12\% del CH (Dn12) (IRAM 9544, 1985). 
La determinación del valor de contenido de humedad fue necesaria ya que el material a ser impregnado por los métodos mencionados, requiere un contenido de humedad inferior al $16 \pm 2 \%$ para ser efectivo.

El material para estos ensayos fue obtenido de listones de sección cuadrada de $20 \mathrm{~mm}$ y de 400 $\mathrm{mm}$ de longitud. Posteriormente fueron dimensionadas en probetas cúbicas de $20 \mathrm{~mm}$ de lado.

Las probetas para los ensayos de absorción de agua y resistencia al biodeterioro fueron de 20 $\mathrm{mm} \times 20 \mathrm{~mm}$ x $20 \mathrm{~mm}$ así como también se utilizaron probetas de tamaño no estandarizado (300mm x $20 \mathrm{~mm}$ x $20 \mathrm{~mm}$ ), para ver si esto producía algún efecto en el desarrollo fúngico. Por otro lado, las probetas para los ensayos de fuego fueron de 200x100x3 mm (fuego), cada tratamiento fue realizado por duplicado Todas las probetas se obtuvieron a partir de rodas con 36 anillos de crecimiento por centímetro, libre de defectos y sin que tenga resina ni ningún tipo de crecimiento fúngico visible. Todas las probetas fueron estacionadas hasta conseguir un contenido de humedad de $15 \pm 3 \%$ y una vez alcanzado se colocaron en freezer hasta su tratamiento. Luego de ser tratadas todas las probetas fueron estacionadas nuevamente durante 3 semanas a temperatura y humedad ambiente $\left(20{ }^{\circ} \mathrm{C} \pm 2{ }^{\circ} \mathrm{C}\right.$ and $\left.65 \% \pm 5 \% \mathrm{RH}\right)$. En total, se impregnaron de 16 muestras por tratamiento (7 ensayos por duplicado FT-IR, SEM-EDAX, MO, Hidrorrepelencia, Biodeteroro, OI, intermitente más los controles.

\section{- Controles}

Los controles utilizados fueron maderas expuestas a cada una de las condiciones de formulación y aplicación, pero sin los materiales activos, es decir, sin el agregado de silanos, siloxanos y/o nanopartículas. Esta condición se la mencionará como madera sin tratar a lo largo de la tesis.

\section{II.2.3 Aplicación de los sistemas protectores}

\section{- Impregnación}


En la presente tesis se eligieron dos métodos de impregnación: el conocido como método Lowry (célula vacía) y por inmersión. Ambos métodos fueron elegidos debido a que permiten una impregnación de la madera con bajas absorciones, ya que lo que se desea no es llenar las células de impregnantes sino que este interactúe con la pared celular. Por lo tanto, es mejor que la absorción sea lenta y no en exceso, para que la polimerización sea posible y efectiva, Figura II.4.

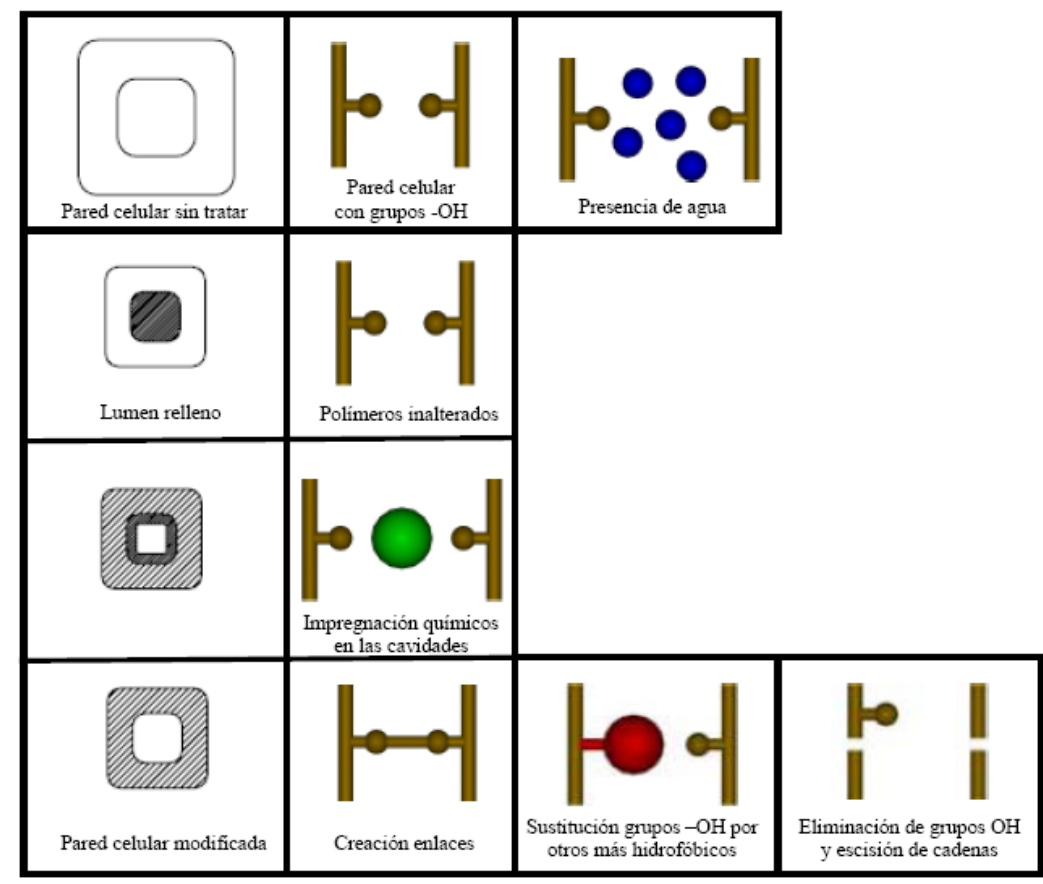

Figura II.4: Diagrama de los diferentes resultados que se obtienen según las condiciones de impregnación que se elijan

El método Lowry se eligió porque permite regular las condiciones del tratamiento y es posible variar la penetración y retención del producto, mientras que el de inmersión se eligió por ser un método más sencillo, menos costoso y aplicable sin necesidad de tener equipamiento específico [35-38].

Para todo proceso de impregnación la madera debe encontrarse seca, a no más del $20-25 \%$ de humedad, es por ello que en este trabajo se trabajo con maderas con una HR de $16 \pm 2 \%$

El método implica que el impregnante se aplique a presión para luego aplicar vacío al final, el cual es el encargado de regular la cantidad de impregnante introducido. Para ello se utiliza un 
autoclave equipado con un compresor y una bomba de vacío, en donde luego de que se introducen las maderas a tratar los pasos siguientes del método son:

- Vacío para extraer parte del aire que se encuentra en los lúmenes celulares de la madera para que no ocupe lugar y facilite el ingreso del impregnante.

- Se inunda el autoclave con la solución impregnante.

- Se presuriza el sistema, logrando de esta manera hacer circular el producto de impregnación a través de la madera, de forma que se impregnen las paredes celulares.

- Luego se equilibran las presiones y se extrae la solución sobrante del autoclave, devolviéndola a un tanque de depósito.

- Vacío nuevamente, para retirar el excedente de producto que ha quedado retenido en las cavidades celulares.

- Finaliza el ciclo de impregnación.

La madera recién impregnada es secada en estufas por algunos días, Figura II.5.
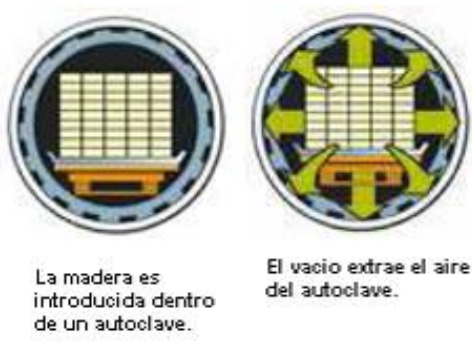

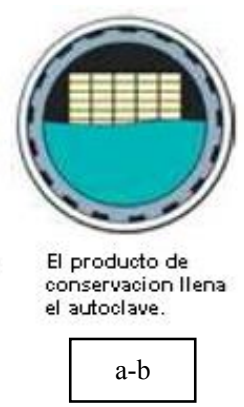

$-b$
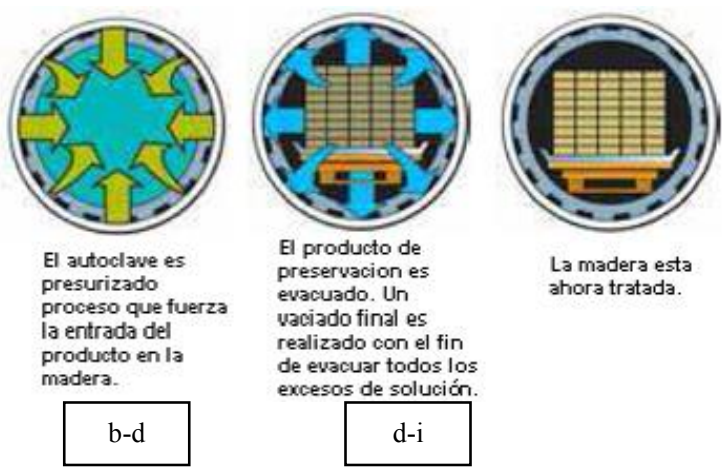

La madera esta ahora tratada.

Fuente: http://www.piscinaprivada.com/

Figura II.6. Proceso Lowry: a-b: Llenado del autoclave con el preservante. b-d: Presión de tratamiento. d-e: Restablecimiento de la presión atmosférica. e-i: Vacío final y fin del proceso

En el presente trabajo este proceso se llevó a cabo bajo condiciones operativas controladas a temperatura ambiente en un dispositivo equipado con bomba de vacío y compresor, Figura II.6. En este, se cargó inicialmente con las probetas de madera, se aplicó un vacío de $500 \mathrm{~mm} \mathrm{Hg}$ durante 10 minutos para eliminar parte del aire y el vapor de agua de las células facilitando así, la penetración de modificador químico. 
Por último, se añadió la solución impregnante correspondiente sin disminuir el nivel de vacío. En todos los casos, se seleccionó una relación de 3/1 v/v solución impregnante/madera para asegurar que las probetas estuvieran completamente sumergidas durante todo el proceso. Luego se presurizó el sistema levemente mediante el compresor y, por último, se aplicó de un ligero vacío (aproximadamente $200 \mathrm{~mm}$ de $\mathrm{Hg}$ durante 10 minutos) para eliminar del exceso de impregnante.

Finalmente, las probetas de madera se retiraron después de alcanzar la presión atmosférica para luego exponerlas en una cámara bajo condiciones de temperatura y humedad controladas $(20 \pm 2$ ${ }^{\circ} \mathrm{C}$ y $60 \pm 5 \%$ de HR) durante tres semanas.

\section{- Inmersión}

Para la aplicación de este método, las muestras se lavaron con etanol durante 10 min y se secaron a $60^{\circ} \mathrm{C}$ durante $6 \mathrm{~h}$. Las muestras limpias se sumergieron entonces en las soluciones preparadas durante 10 minutos y se secaron a $103^{\circ} \mathrm{C}$ durante $1 \mathrm{~h}$. Este procedimiento se repitió 3 veces para conseguir la mayor cantidad de impregnación posible.

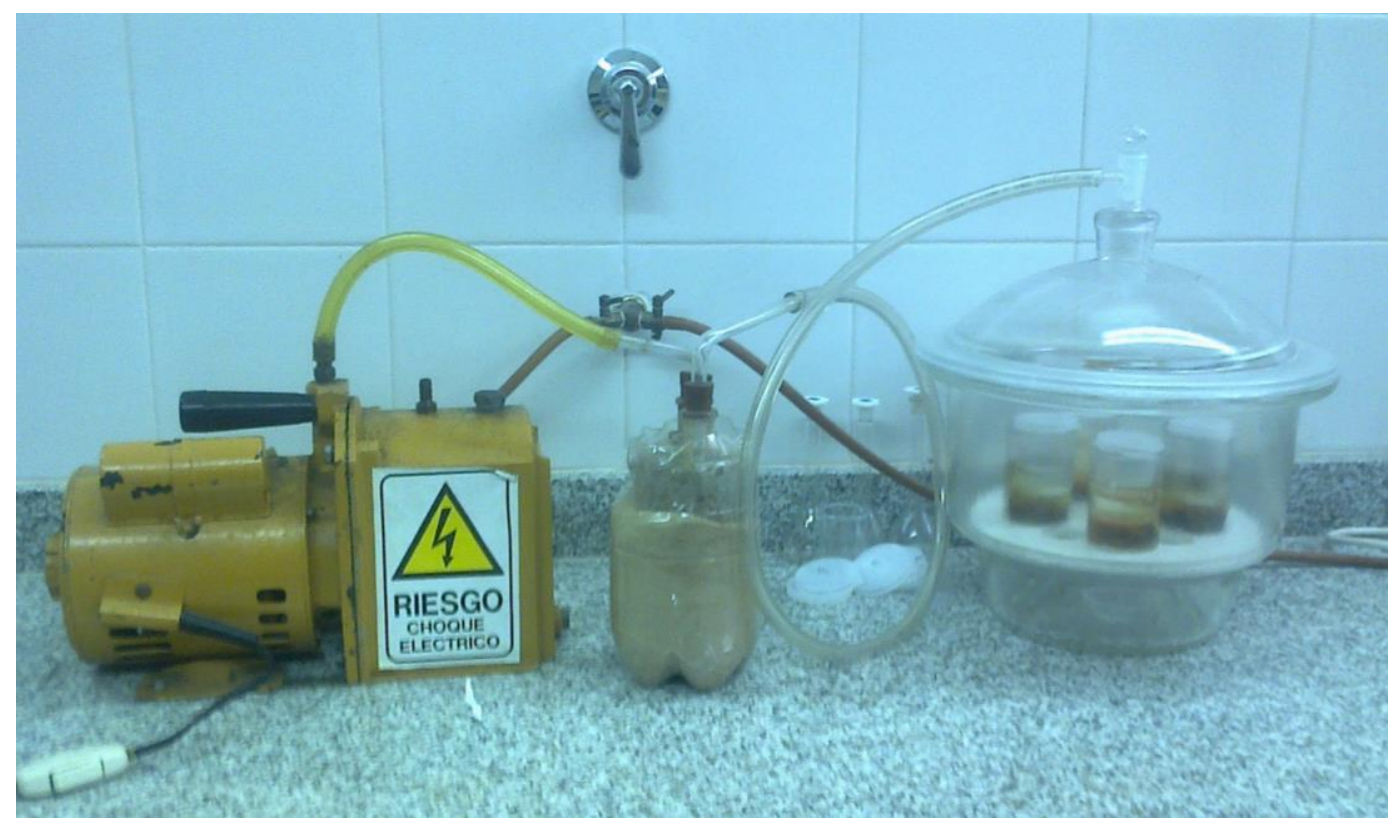

Figura II.6. Dispositivo armado para realizar impregnación por ambos métodos: este consta de una bomba de vacio, un compresor y un disecador que actúa de contenedor para aplicar vacío-presión-vacío del método. 


\section{Recubrimiento superficial}

En la presente tesis nos centraremos en los recubrimientos de tipo lasures o stain, que se destacan por producir una película de muy bajo espesor sobre la superficie del sustrato. Por ello, cotidianamente se los conoce como sistemas que "no forman película". Son originarios de zonas de climas extremos, como el norte de Europa (lasures) o del norte de América (Stains), donde las condiciones en intemperie son extremas (bajas temperaturas, lluvias y nieve) es por ello que se desarrollaron sistemas protectores más eficientes.

Los lasures tienen la característica de resistir los movimientos de la madera por cambios dimensionales producidos por el medio en el que se encuentra, son de fácil aplicación, repintado y requieren un mantenimiento frecuente pero muy sencillo, sin involucrar una preparación del sustrato previa (sin necesidad de remoción o lijado).

Sus formulaciones en general contienen los mismos componentes funcionales que una pintura cubritiva pero se caracterizan por ser formulaciones de bajo contenido de sólidos (micropelícula) y menor viscosidad (mejor penetración). Lo más importante en este tipo de formulaciones es la elección del vehículo para lograr la relación sólidos/viscosidad óptima para lograr la conjunción de una buena protección y una excelente penetración en no más de tres manos.

Los recubrimientos se ajustaron para obtener una tensión superficial menor a $38 \mathrm{din} / \mathrm{cm}$ para permitir una correcta penetración. La aplicación superficial, tratándolas como si esta fuese un lasur, consistió en el uso de pincel, haciendo sucesivas diluciones de la misma para aumentar el proceso de penetración. Todas las soluciones implementadas en la tesis son de base alcohólica por lo cual las diluciones se realizaron con agua, comenzando con un $70 / 30$, seguida de $80 / 20$, 90/10 y 100/0 de solución/agua respectivamente.

Esto fue aplicado solo para los siloxanos de procedencia comercial: se realizó una dilución de este a un $30 \%$ en etanol/aceite de lino en un 70/30\% respectivamente; se aplicó con pincel, tratándolas como si fuesen un lasur: la primera mano fue diluido al $70 \%$, luego al $50 \%$ y por último sin diluir. 


\section{II.3 Ensayos}

En este apartado se detallan todos los ensayos realizados en la tesis para evaluar la capacidad protectora, contra los agentes bióticos y abióticos elegidos, de cada uno de los tratamientos desarrollados y formulados.

El material tratado y no tratado se caracterizará mediante microscopia electrónica de barrido, SEM-EDAX a fin de localizar los impregnantes (silanos y/o nanocompuestos) en el material. Las reacciones químicas producidas entre la madera y los distintos agentes preservadores se tratarán de evaluar mediante FT-IR de manera comparativa; es decir entre las maderas tratadas y sin tratar.

Se expondrá la madera tratada a humedad y temperatura como agentes abióticos y a los cuatro hongos xilófagos mencionados como agentes bióticos (Los ensayos se detallan en la siguiente sección).

\section{II.3.1 Resistencia a la acción fúngica}

Las muestras de madera se expusieron a las tres especies de hongos xilófagos mencionadas representando a cada una de las pudriciones en condiciones de laboratorio, siguiendo los lineamientos generales de la norma ASTM D 2017 [39].

La evaluación del comportamiento se determinará gravimétricamente por pérdida de peso y por observación a micro y macro escala del estado del sustrato.

Los organismos fueron activados previamente al inóculo en $100 \mathrm{ml}$ de medio básico (glucosa 20 $\mathrm{g} / \mathrm{L}$, peptona $5 \mathrm{~g} / \mathrm{L}, \mathrm{CuSO}_{4} 1 \mathrm{~g} / \mathrm{L}, \mathrm{MgSO}_{4} 0.5 \mathrm{~g} / \mathrm{L}$ ) y se cultivaron a $28^{\circ} \mathrm{C}$ una semana antes de inocular la madera. Los pellets miceliales se cosecharon después de 5 días; se añadieron $100 \mathrm{~mL}$ de agua destilada y se mezclaron con un agitador de laboratorio durante 30 segundos a 5000 rpm. Esta suspensión sirvió como inóculo. Las muestras de madera se esterilizaron en un autoclave durante 20 minutos a $121{ }^{\circ} \mathrm{C}$ y después se inocularon con $50 \mathrm{mg}$ de inóculo. Los cultivos inoculados se incubaron estáticamente a $28 \circ \mathrm{C}$ durante 4, 8, 12 y 16 semanas. Los 
sólidos se lavaron y se secaron en un horno a $60{ }^{\circ} \mathrm{C}$ hasta un peso constante. La muestra no inoculada sirvió como testigo. Todos los experimentos se realizaron por triplicado.

Lo inóculos se llevaron a cabo en recipientes con arena esterilizada como superficie de apoyo de las probetas de madera, utilizándola como vehículo de retención de agua para otorgar humedad al sistema. El agregado de agua fue controlado, siendo de $12,5 \mathrm{ml}$ de agua destilada dos veces por semana.

Luego, los paneles fueron extraídos de los frascos de cultivo, se le retiraron los micelos y finalmente, fueron colocados en estufa a $100 \pm 3{ }^{\circ} \mathrm{C}$ hasta peso constante. La pérdida de peso se determinó mediante la siguiente ecuación:

Pérdida de peso, $\%=\left[\left(\mathrm{P}_{\mathrm{o}}-\mathrm{P}_{\mathrm{f}}\right) / \mathrm{P}_{\mathrm{o}}\right] \times 100$

donde $\mathrm{P}_{\mathrm{o}} \mathrm{y} \mathrm{P}_{\mathrm{f}}$ son respectivamente los pesos de las muestras secas sin exposición y con exposición a los hongos.

\section{II.3.2 Estabilidad dimensional frente a humedad}

\section{- Estabilidad dimensional y eficiencia de repelencia al agua}

La estabilidad dimensional se determinó midiendo los valores de la absorción de agua (WA), la hinchamiento (VS) y la eficacia de antihinchamiento (ASE) usando el método de inmersión en agua del ensayo de Rowell y Ellis [40], mediante la aplicación de ciclos de secado-agua-remojo.

Las probetas fueron expuestas a una serie de ocho ciclos, en donde cada uno de ellos incluye el siguiente procedimiento: secado en horno a $103{ }^{\circ} \mathrm{C}$, hasta peso es constante, luego las probetas son colocadas en un recipiente con agua durante destilada 24 horas a temperatura ambiente ( 25 ${ }^{\circ} \mathrm{C}$ ), aquí se mide el cambio de volumen (cambio de longitud radial y tangencial, medido con calibre) y de masa de las muestras pesaje en balanza de precisión). Se vuelve a secar y se mide nuevamente masa y volumen. Según los autores del ensayo, se considera que 8 ciclos son suficientes para obtener la estabilidad dimensional de la madera ensayada. 
Una vez obtenido esos datos se calcularon los coeficientes mencionados mediante las siguientes ecuaciones:

$$
W A=100 \times\left(\frac{M_{2}-M_{1}}{M_{1}}\right)
$$

donde WA es la absorción de agua (\%), $\mathrm{M}_{1}$ es el peso de las maderas secas y $\mathrm{M}_{2}$ es el peso de las maderas saturadas.

$$
V S=100 \times\left(\frac{V_{2}-V_{1}}{V_{1}}\right)
$$

donde VS es el hinchamiento volumétrico (\%), $\mathrm{V}_{1}$ volumen de las maderas secas y $\mathrm{V}_{2}$ es el volumen de las maderas saturadas.

$$
A S E=100 \times \frac{S_{2}-S_{1}}{S_{2}}(3)
$$

donde ASE es la eficiencia antihinchamiento (antiswelling efficiency \%), $\mathrm{S}_{1}$ y $\mathrm{S}_{2}$ son los volúmenes las muestras no tratadas y las tratadas, respectivamente.

\section{II.3.3 Fuego}

El ensayo de determinación del Índice de Oxígeno (OI), objeto de la norma ASTM D 2863 [41], determina la mínima concentración de oxígeno en una mezcla con nitrógeno, que puede mantener la combustión de un material en condiciones de equilibrio, como la combustión de una vela; es decir, que el índice de oxígeno es la mínima concentración de oxígeno, expresada como porciento en volumen, en una mezcla de oxígeno y nitrógeno que logra la combustión de un material a temperatura ambiente y bajo las condiciones de este método. 


$$
\mathrm{n}, \%=\left(100 \mathrm{X} \mathrm{O}_{2}\right) /\left(\mathrm{O}_{2}+\mathrm{N}_{2}\right)
$$

donde $\mathrm{O}_{2}$ es el flujo volumétrico de oxígeno $\left(\mathrm{cm}^{3} \cdot \mathrm{s}^{-}\right)$y $\mathrm{N}_{2}$ es el flujo volumétrico del nitrógeno $\left(\mathrm{cm}^{3} \cdot \mathrm{s}^{1}\right)$.

El equipo está compuesto por un tubo de vidrio, resistente al calor, de unos $75 \mathrm{~mm}$ de diámetro interior y $450 \mathrm{~mm}$ de altura, estando la base inferior fijada a un soporte metálico que contiene esferas de cristal de 3 a $5 \mathrm{~mm}$ de diámetro, en una altura de 80 a $100 \mathrm{~mm}$, destinadas a facilitar la mezcla de los gases y un equipo de control y medida de los gases utilizados, (filtros, manómetros, microválvulas, flotámetros, etc) y un sistema de inflamación constituido por una llama de gas, natural o propano, de 6 a $12 \mathrm{~mm}$ de longitud, Figura II.7.

Para operar el equipo se dispone la probeta en el soporte de tal manera que el borde superior de la misma esté a $100 \mathrm{~mm}$ de la parte superior del tubo. Se selecciona la concentración de oxígeno basada en la experiencia y si ésta es desconocida se debe encender la muestra en el aire para verificar si la combustión comienza inmediatamente; en este caso y en primera instancia, se debe optar por un valor de concentración de oxígeno menor a $22 \%$, pero si enciende con dificultad, o se enciende pero se apaga, es conveniente seleccionar valores comprendidos entre $22 \%$ y $27 \%$.

Por su parte, si la muestra no enciende en condiciones atmosféricas, la concentración inicial debe ser de $28 \%$ o más alta. Una vez determinada la velocidad de flujo de gas (calculada como el flujo total de gas en $\mathrm{cm}^{3} \cdot \mathrm{s}^{-1}$, dividido el área de la columna en $\mathrm{cm}^{2}$ ), se comprueba que la concentración de oxígeno es la correcta si la combustión de la muestra permanece al menos por 3 minutos o si su avance (medido desde la parte superior de la misma) alcanza los $50 \mathrm{~mm}$ de longitud. En el caso de fallar en la elección de la concentración de oxígeno, repetir la experiencia cambiando la misma y con otra muestra.

\section{- Resistencia a la llama intermitente:}

El objetivo de esta experiencia ha sido determinar la resistencia a la llama intermitente de un mechero bunsen, tanto del sustrato desnudo, como del sustrato impregnado. El equipo utilizado para este ensayo ha sido armado con un mechero bunsen y un pie de probeta, en el cual se 
sostuvo cada una de las probetas a ensayar, pudiendo éstas así ser reguladas en cuanto a su posición y ángulo de inclinación, Figura II.7.

La probeta, sostenida por una agarradera desde el extremo superior, se dispuso de tal manera que su eje longitudinal presentara una inclinación de $45^{\circ}$ con respecto al plano de apoyo. El ensayo se ha llevado a cabo en condiciones de laboratorio, para evitar corrientes de aire. Se ha desarrollado sometiendo el frente interior de la probeta, dispuesta por lo antes mencionado en una posición de $45^{\circ}$ respecto a la horizontal, a la acción intermitente de la llama del mechero bunsen, cuyo orificio de salida ha sido colocado a una distancia de $15 \mathrm{~mm}$ de la superficie en examen.

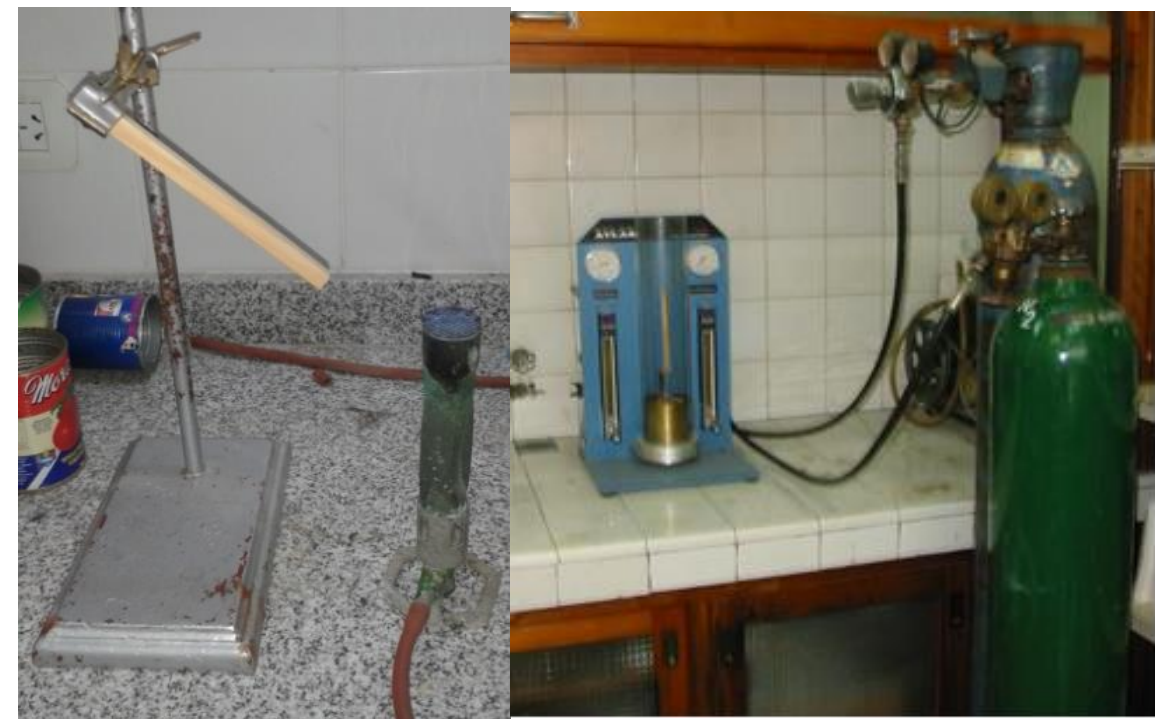

Figura II.7. Dispositivo utilizado para el ensayo de llama intermitente y el equipo de OI del CIDEPINT

La probeta se sometió a la acción de la llama durante 20 segundos, con períodos de descanso de 10 segundos, repitiéndose el ciclo de exposición fuego/reposo si llama se auto extinguiera dentro de los 5 segundos de retirado el mechero y la zona carbonizada no excediera los $8 \mathrm{~cm}^{2}$. Luego, se determinó la resistencia a la llama intermitente de sustratos desnudos e impregnados y se evaluaron los resultados.

Este último se utiliza para complementar la descripción de los sistemas, también se realizó el ensayo de resistencia a la llama intermitente de un mechero Bunsen, método desarrollado en el 
CIDEPINT. Este trata de exponer la probeta tratada a la llama de un mechero Bunsen, a $45^{\circ}$ y ver la propagación de la llama a lo largo de varios ciclos de exposición a llama con duración variable. La muestra a ensayar se sostuvo desde el extremo superior a través de una agarradera; se dispuso de tal manera que su eje longitudinal presente una inclinación de $45^{\circ}$ con respecto al plano de apoyo, mientras que su eje transversal quedará en posición paralela a este último, Figura II.7.

\section{II.3.4 Ensayos generales}

\section{- Microscopio electrónico de barrido, SEM}

Este método permitió la generación de imágenes de alta resolución (entre menos de $1 \mathrm{~nm}$ y 20 $\mathrm{nm}$ ), de un aspecto tridimensional característico, de las superficies externas y áreas de corte radiales, axiales y tangenciales para observar la disposición del material impregnado así como también el estado del material luego de someterlo a los tratamientos protectores.

\section{- Energía de dispersión de rayos X, EDAX}

Esta técnica se empleó para identificar la composición química del sustrato original y luego del tratamiento, en forma integrada al microscopio electrónico de barrido (SEM). La radiografía del análisis dispersivo de la energía permitió establecer la identidad y cantidad de los átomos de los elementos correspondientes al material impregnado, a través del análisis de los picos presentes en el espectro obtenido sobre las superficies.

\section{- Espectroscopía infrarroja, IR}

Esta técnica espectroscópica permitió identificar cambios químicos en la madera, dado que los enlaces químicos tienen frecuencias específicas a las cuales vibran $y$ estas frecuencias varían solamente si cambia su entorno (densidad electrónica). Esto quiere decir que, si hay una variación química, su densidad 
electrónica cambiará y por lo tanto el pico perteneciente a ese enlace dentro del espectro debe cambiar.

\section{II.4 Análisis estadístico}

El coeficiente de correlación de Pearson fue el análisis estadístico fundamental en la tesis ya que este permite calcular las relaciones de comportamiento entre la madera tratada y no tratada.

Además, se establecieron ecuaciones de regresión lineal simple para esperar la calidad de la madera basándose en la comparación entre las propiedades de la madera tratada y no tratada.

Los resultados se analizaron con un nivel de significación de $p<0,05$. Los modelos establecidos fueron evaluados con base en el coeficiente de determinación (R) y niveles significativos. La correlación se refiere a la magnitud y la dirección de la relación y la regresión se centra en el uso de la relación para la predicción. La regla de Guilford (1956) se utilizó para describir la magnitud de las correlaciones $(r<0,2$ : relación despreciable, $r=0,2-0,4$ : relación baja; $r=0,4-$ 0,7: relación moderada; $r=0,7-0,9$ : relación alta; Y r>0,9: relación muy alta).

Con estos valores entonces se pudo analizar si estadísticamente si existen diferencias significativas entre la madera tratada y no tratada y en que magnitud, lo cual facilita la elección del mejor tratamiento. 


\section{Bibliografía}

1. Sigma Aldrich, http://www.sigmaaldrich.com/

2. Dow corning, http://www.dowcorning.com/

3. Fabrisil silicones, http://www.fabriquimica.com/

4. Gelest Inc., http://www.gelest.com/

5. Hardman, B. (1989), Silicones, Encycl. Polym. Sci. Eng., vol. 15, pp. 204.

6. Stark, F.O., et at. (1982) Silicones, Comprehensive Organometallic Chemistry, 2, Pergamon Press, pp. 305.

7. Yilgör, I, McGrath, J.E. (2005) Polysiloxane containing copolymers: A survey of recent developments, Advances in Polymer Science, 86, 1-86.

8. Speier, J.L (1952) The Preparation and Properties of (Hydroxyorgano)-silanes and Related Compounds, J. Am. Chem. Soc., 74 (4), pp. 1003-1010.

9. Takebayashi, T. (1993) Acute inhalation toxicity of high concentrations of silane in male ICR mice, Arch Toxicol., 67(1), 55-60.

10. Aluru, N., et al. (2003) Nanostructure Studies of the $\mathrm{Si}-\mathrm{SiO} 2$ Interface. Handbook of Nanoscience, Ingineering and Technology. Gooddard; Brenner; Lyshevski; Iafrate Ed. CRC Press., Washington D.C., USA, Chapter 11.

11. Kim, S., et al. (2007) Antimicrobial effects of silver nanoparticles, Nanomedicine: Nanotechnology, Biology and Medicine, 3, 95-101.

12. Talebian S. y Zare E. (2014) Structure and antibacterial property of nano-SiO2 supported oxide ceramic, Ceramics International, 40, 281-287.

13. Magar,R.B., Khan, A. Gupta,V., Gupta,V,. Sayed, K. (2017) Effect of Colloidal Nanosilica on High Strength Rice Husk Ash Concretem, International Journal of Concrete Technology, 3 (1)

14. Soltani, M., Najafi, A., Yusefian, S., Naji, H.R., Bakar, E.S., (2013) Water repellent effect and dimensional stability of beech wood impregnated with nano-zinc oxide. BioResources 8, 62806287.

15. Suganthi, K.S., Anusha, N., Rajan, K.S., (2013) Low viscous ZnO- propylene glycol nanofluid: a potential coolant candidate. J. Nanoparticle Res. 15, 1986-16p.

16. Suganthi, K.S., Rajan, K.S., (2014) A formulation strategy for preparation of ZnOpropylene glycol-water nanofluids with improved transport properties. Int. J. Heat Mass Transf. 71, 653663.

17. Traistaru, A.A.T., Timar, M.C., Campean, M., Croitoru, C., Sandu, I., (2012) Paraloid B72 versus Paraloid B72 with nano- $\mathrm{ZnO}$ additive as consolidate for wooden artefacts. Mater. Plast. 49, 293-300.

18. Rahman, A., Ismail, A., Jumbianti, D., Magdalena, D., Sudrajat, H., 2009. Synthesis of copper oxide nanoparticles by using Phormidium cyanobacterium. Indonesian J. Chem. 9, 355-360

19. Soltani, M., Najafi, A., Yousefian, S., Naji, H.R., Bakar, E.S.,(2013) Water repellent effect and dimension stability of beech wood impregnated with nano-Zinc oxide. Bioresources 8 (4), 62806287.

20. Taghiyari, H.R., Malek, B.M., Kookandeh, M.G., (2014) Effects of silver and copper nanoparticles in particle board to control Trametes Versicolor fungus. Int. Biodeterior. Biodegrad. 94, 69-72

21. 120. Song, J. and Jang, J. (2013) Antimicrobial polymer nanostructures: synthetic route, mechanism of action and perspective in Colloid and Interface Science, 1-39 doi: 10.1016/j.cis.2013.11.007

22. . Faria A.F. et al. (2014) Colloids and Surfaces B: Biointerfaces 113, 115- 124

23. Faria, A.F., Martinez D.S.T., Moraes, A.C.M., Maia da Costa, M.E.H., Barros, E.B., Souza A.G., Filho, A.J., Alves, O.L. (2012) Unveiling the role of oxidation debris on the surface chemistry of graphene through the anchoring of Ag nanoparticles, Chem. Mater. 24, 4080-4087

24. Percival, S.L., Bowler, P.G., Russell, D. (2005) Bacterial resistance to silver in wound care, Journal of Hospital Infection, 60, 1-7. 
25. Schuppler, M. (2009) Antimicrobial Properties of a Novel Silver-Silica Nanocomposite Material, Appl. Environ. Microbiol. 75(9), 2973-2976.

26. Cubillo, C., Pecharromán, E., Aguilar, J., Santarén, J.S., (2006) Antibacterial activity of copper monodispersed nanoparticles into sepiolite, Journal of Material Science, 41, 5208-5212.

27. Oliver, M.K and Martinez, A. J (2014) How resident microbes modulate ecologically-important traits of insects, Current Opinion in Insect Science, 4, 1-7.

28. Beaver, R.A (1989) Insect-Fungus Relationships in the Bark and Ambrosia Beetles, Insectfungus Interactions in Symposium of the Royal Entomological Society, 14, 121-143.

29. Müller, M.M., Varama, M., Heinonen, J., Hallaksela, A.M. (2015) Influence of insects on the diversity of fungi in decaying spruce wood in managed and natural forests, Forest Ecology and Management, 166 (1-3), 165-181.

30. Jankowiak, R. ,Kolařík, M., Bilański, P. (2014), Association of Geosmithia fungi (Ascomycota: Hypocreales) with pine- and spruce- infesting bark beetles in Poland, Fungal Ecology, 11, 71-79.

31. Donath et al., (2006) Treatment of wood with aminofunctional silanes for protection against wood destroying fungi Holzforschung 60(2):210-216 .

32. Nair, S., Pandey, K. K., Giridhar, B.N., Vijayalakshmi, G. (2017) Decay resistance of rubberwood (Hevea brasiliensis) impregnated with $\mathrm{ZnO}$ and $\mathrm{CuO}$ nanoparticles dispersed in propylene glycol International Biodeterioration \& Biodegradation 122, 100-106

33. Yu, W., Xie, H., (2012) A Review on nanofluids: preparation, stability mechanisms, and applications. J. Nanomater. 2012, 1-17.

34. Mukherjee, S., Paria, S., (2013) Preparation and stability of nanofluids e a review. IOSR e J. Mech. Civ. Eng. 9, 63-69.

35. Bowyer, J.L., Shmulsky, R. and Haygreen, J.G. (2007) Forest Products and Wood Science: An Introduction, Blackwell Publishing Ltd., 201-221

36. Gracia, C. (2011) Capítulo 11. La madera en Ecología Forestal: Estructura, Funcionamiento y Producción de las masas forestales, 221-259.

37. Sibille, M.A. (2006) Guía de procesamiento industrial. Fabricación de muebles con maderas poco conocida, LKS. $20 \mathrm{pp}$

38. Fromm, J. (2013) Cellular Aspects of Wood Formation Springer Science \& Business Media, pp. 260

39. ASTM D 2017 (2005) Standard Test Method of Accelerated Laboratory Test of Natural Decay Resistance of Woods (Withdrawn 2014)

40. Rowell, R.M. y Ellis, W.D (1978) Determination of dimensional stabilization of wood using the water-soak method. Wood and Fiber 10(2), 104-111.

41. ASTM D2863 (2013) Standard Test Method for Measuring the Minimum Oxygen Concentration to Support Candle-Like Combustion of Plastics (Oxygen Index) 


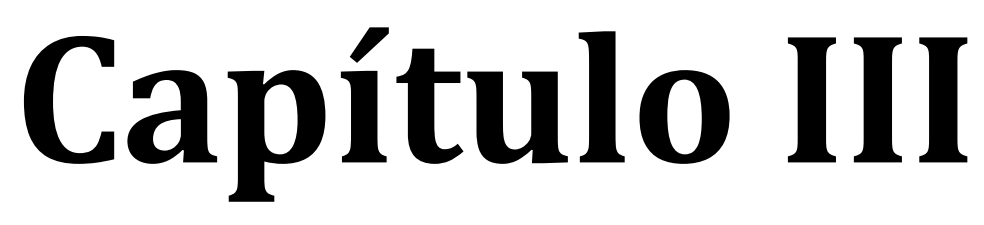

Resultados y

discusión 


\section{1 Caracterización de la madera}

En primera instancia se caracterizó la madera en estudio en cuanto a propiedades naturales y comportamiento frente a los agentes deteriorantes propuestos.

Para el análisis y caracterización química y microestructural dado por los diferentes tratamientos y métodos de aplicación, se realizaron FT-IR, SEM, SEM-EDAX de las probetas y observaciones a microscopio óptico de cortes ultradelgados.

En cuanto a sus propiedades físicas de la madera en estudio podemos decir que posee una densidad aparente con una HR de $15 \pm 3 \%$ de $0,440 \mathrm{~g} / \mathrm{cm} 3$, contracción total de $6,3 \%$ tangencial, 3,9\% radial, $9,7 \%$ volumétrica, $28 \%$ de punto de saturación de fibras y un $71 \%$ de porosidad. Por otra parte, presenta un coeficiente de retractibilidad tangencial de $0,22 \%$, radial $0,14 \%$, volumétrica $0,37 \%$ y un índice T/R de 1,58\% y una compacidad de 29\% (los valores son la media de una población de $n=20)$.

Es una madera de durabilidad baja, muy susceptible a ser atacada por hongos e insectos crambicidos, anibidos y termitas. Su albura es muy susceptible al ataque de hongos cromógenos por lo que es necesaria su intervención inmediata luego de la poda. Con respecto a sus propiedades mecánicas esta se clasifica como madera blanda por su baja resistencia a la compresión, presenta un MOR de $75 \mathrm{Nt} / \mathrm{mm}^{2}$, un MOE de $8.9 \mathrm{Nt} / \mathrm{mm}^{2}, \mathrm{CS}=4 \mathrm{Nt} / \mathrm{mm}^{2}$

\section{2 Estudio de la modificación química}

\section{- $\quad F T-I R$}

Los espectros de FT-IR se realizaron en el CIDEPINT, a temperatura ambiente, con un rango de lectura de longitud de onda entre 4000 y $600 \mathrm{~cm}^{-1}$ y con una resolución de $4 \mathrm{~cm}^{-1}$. Estos espectros fueron realizados por reflectancia total atenuada, utilizando el accesorio U-ATR (attenuated total reflactance), el cual permite irradiar la muestra directamente, sin preparación previa. El tamaño de muestra utilizado fue de 200x200x200mm. 
Este análisis se utilizó para evidenciar la existencia de una reacción química entre la madera y los impregnantes. Esto se demuestra mediante los cambios revelados en las bandas y picos característicos de los grupos hidroxilo de la pared celular de la madera en los espectros de las maderas tratadas y sin tratar, cuando estos son analizados de manera comparativa .

Para esto, en una primera instancia, se identificaron las bandas características de la madera sin tratar teniéndose en cuenta solamente, aquellas relevantes de cada uno de los componentes involucrados. Esto último se realizó mediante los espectros brindados de la caracterización comercial, los cuales se incluyeron en el Capítulo I.

Las banda que caracteriza a los $-\mathrm{OH}$ es la de $\operatorname{los} 3400 \mathrm{~cm}^{-1}$, la cual es de fuerte absorción (pico alargado y ancho), para los $-\mathrm{OH}$ de la pared celular además se encuentra una banda de menor absorción a los $2950 \mathrm{~cm}^{-1}$ que representa el estiramiento de enlace $\mathrm{O}-\mathrm{H}$, otra a los $1.650 \mathrm{~cm}^{-1}$ que representa la banda de deformación de $-\mathrm{OH}$ y por último, se observa una banda ancha en el intervalo de 1000-1200 $\mathrm{cm}^{-1}$ debido a la flexión O-H de grupos hidroxilos primarios y secundarios de celulosa [1], Figura III.1.

En la Figura III.1A se muestran los espectros de las maderas tratadas con los silanos. Comparativamente se ve que hubo cambios químicos por parte de todos estos tratamientos ya que las curvas difieren entre sí, lo que se traduce en cambios en las densidades electrónicas de los compuestos de la pared celular y confirman su participación en de esta en la modificación química.

Las bandas típicas de enlaces de celulosa y silanos son detectables, aunque se superponen en gran medida. Las bandas características de los silanos son: a los $800 \mathrm{~cm}^{-1}$ (estiramiento simétrico Si$\mathrm{O}-\mathrm{Si}$ ), a los $1070 \mathrm{~cm}^{-1}$ (estiramiento asimétrico Si-O-Si), a los $1270 \mathrm{~cm}^{-1}$ (deformación simétrica $\mathrm{Si}-\mathrm{CH}_{3}$ ) y a los $1108 \mathrm{~cm}^{-1}$ (estiramiento $\mathrm{Si}-\mathrm{O}-\mathrm{R}, \mathrm{R}=$ grupo etoxi) [2].

La banda ancha debido a la flexión O-H mencionada, no posibilita una clara atribución de las señales correspondientes a los enlaces Si-O-Si y Si-O-C en el mismo intervalo como se mencionó, pero se observa una disminución en su intensidad, por lo que podría atribuirse a una modificación química debido a las pérdida de detección de las flexiones de los - $\mathrm{OH}$ y a una no detección de los enlaces $\mathrm{Si}-\mathrm{O}-\mathrm{C}$. Esto último, se debe a que los grupos $\mathrm{Si}-\mathrm{O}-\mathrm{C}$ son muy reducidos respecto a los $\mathrm{OH}$, por lo que se produce enmascaramiento de banda [3]. Además, se observa la frecuencia de 
estiramiento a los $1180 \mathrm{~cm}^{-1}$ corresponde a la unidad Si-O-C, donde el átomo de carbono pertenece a los monómeros de glucosa de celulosa, con esto, se podría confirmar la interacción química entre el siloxano y la celulosa.

En cuanto a APTES y OTES, se observa que si bien no hay una disminución marcada de la intensidad de la banda de estiramiento de los $-\mathrm{OH}$ pero si difiere en las bandas de flexión y deformación de los -OH esto era de esperar debido a que son los dos silanos de mayor tamaño molecular debido a sus sustituyentes, por lo cual puede deberse a un impedimento estérico haciendo que se formen puentes de hidrogeno para estabilizarse pero no se completa el proceso sol -gel en gran medida.

En la Figura III.1 C se observan los espectros de las maderas tratadas con las mezclas de silanos, se observa que no difieren demasiado a los espectros obtenidos individualmente, salvo en la mezcla MTES/OTES, donde se observa un aumento en la banda de los 1000 (mayor transmitancia respecto al control). Esto da un indicio de que hubo mayor cantidad de enlaces Si-O-C y, por ende, mayor modificación química de la pared celular.

Esto puede ser atribuible a las diferencias en el tamaño de partícula: MTES por ser pequeña serviría de anclaje a OTES y generarían una red polimérica con la pared celular incluida.

En el caso de las nanopartículas, Figura III.1B, los espectros se muestras muy semejantes entre sí, repitiendo el hecho de que se modifica la flexión, estiramiento o deformación de los $-\mathrm{OH}$ de la celulosa, pero no todos a la vez. En particular se observa que, para las nanoparticulas de plata y dióxido de silicio no modifican las bandas de la celulosa como si lo hacen las nanoparticulas de óxido de cobre y óxido de zinc.

Cuando la sustitución no es lo suficientemente alta para eliminar los grupos hidroxilo, estas bandas están siempre presentes, donde todas las bandas de - $\mathrm{OH}$ permanece intacta en cuanto a forma e intensidad [4]

Además, se observa en todos los casos la aparición de variaciones en los picos que se encuentran en la zona de los $1200 \mathrm{~cm}^{-1}$ y en $\operatorname{los} 800 \mathrm{~cm}^{-1}$ respecto al control; de las cuales la primera se corresponderían a moléculas de agua adsorbida por las nanopartículas en la dispersión que 
arrastran al interior de la madera y para la segunda banda, cabe señalar que las nanoparticulas vibran alrededor de las zonas del $600-900 \mathrm{~cm}^{-1}$ por lo que probablemente sea un indicador de la presencia de las mismas [5].

Por otro lado, la mayor intensidad de uno de los dos picos característicos de la celulosa, también podría indicar una mayor cantidad de $-\mathrm{OH}$ disponibles, lo que a su vez indicaría una reactividad más fuerte del sistema.

Esto podría traducirse entonces en la presencia de una densidad electrónica capaz de desestabilizar la estructura polimérica de la celulosa lo que permitiría que cualquier nanopartícula con carga altamente densa en este grupo se inmovilizara (principio de la inmovilización de drogas) [6-8]. Este fenómeno podría ser una explicación de los espectros de las muestras impregnadas con las nanoparticulas de $\mathrm{Ag}$ y $\mathrm{SiO}_{2}[9,12]$.

Para los espectros de las muestras impregnadas con silanos/nanopartículas, se observan los picos a 3400 y $1500 \mathrm{~cm}^{-1}$ en el espectro de todas las muestras se atribuyen a las vibraciones de estiramiento de los grupos hidroxilo [13], que son principalmente enlaces químicos que interactúan con los silanos como se mencionó anteriormente [14, 15], Figura III.1.

Los picos a $1400 \mathrm{~cm}^{-1}$ y $1112 \mathrm{~cm}^{-1}$ en ambas muestras se atribuyen a la vibración de flexión de los enlaces [27] y la asimétrica estirando la vibración de los enlaces Si- O- Si [16]. El nuevo espectro emergente a $600 \mathrm{~cm}^{-1}$ se atribuye a la vibración del enlace Si- O- Si [17]. El pico a $2900 \mathrm{~cm}^{-1}$ corresponde al estiramiento y vibración asimétrica de $-\mathrm{CH}_{3}[18]$.

La aparición de $-\mathrm{CH}_{3}$ es debido a la hidrólisis y polimerización de entre la madera y los silanos, lo cual muestra que la mezcla de silanos/nanopartículas produce la modificación química más eficiente, Figura III.1 D.

Por otra parte, no se ha observado en ningún espectro el pico de los grupos C-C a $1664 \mathrm{~cm}^{-1}$ [18], lo que indica su ruptura [19], traduciéndose esto en la formación polimérica por hidrólisis y condensación de componentes de la madera con los componentes de los impregnantes. 

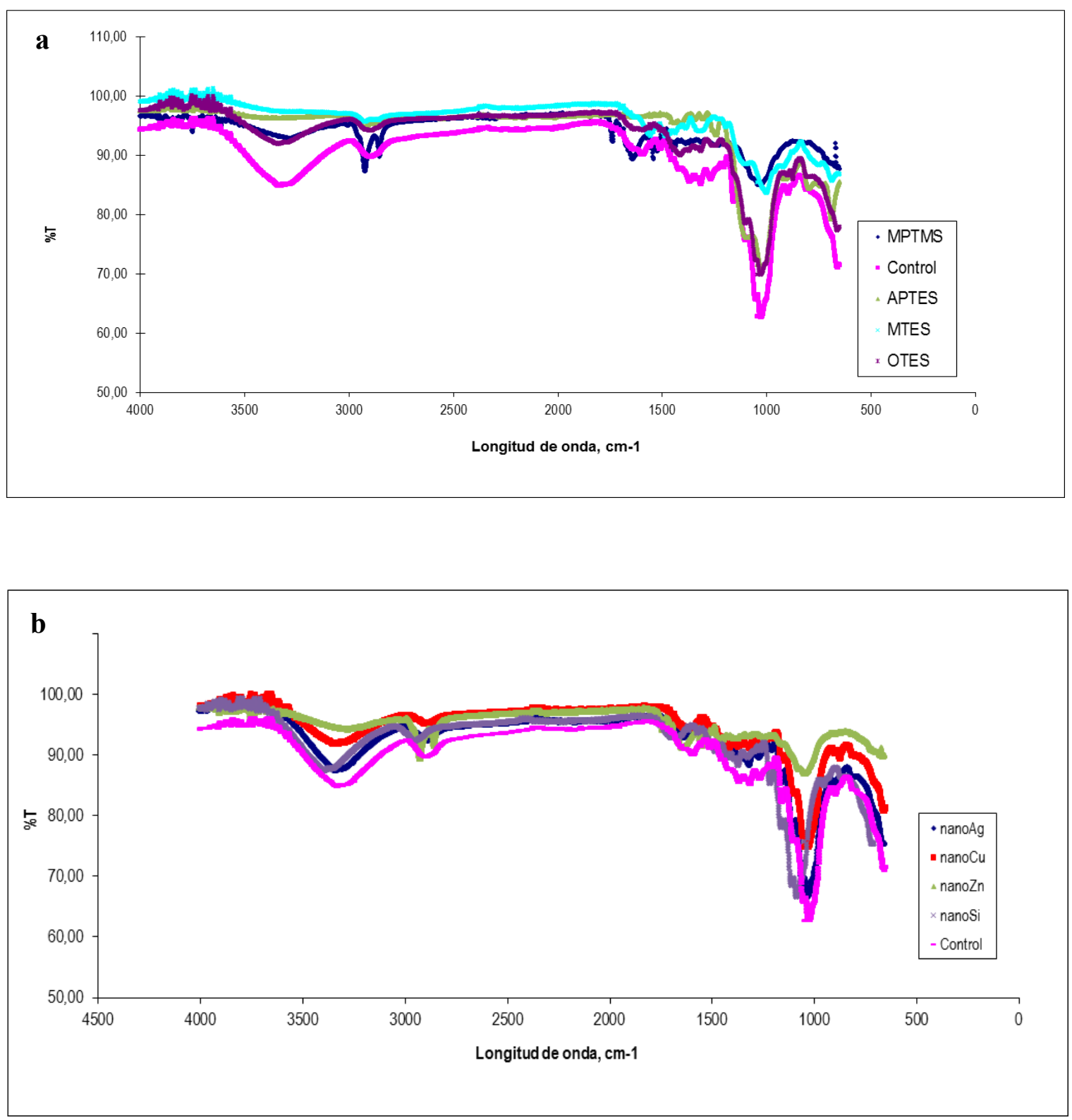

Figura III.1. Espectroscopia de infrarrojo por transformada de Furier (FT-IR)

A) Maderas tratadas con impregnantes basados en silanos, B) Maderas tratadas con impregnantes basado en nanopartículas 

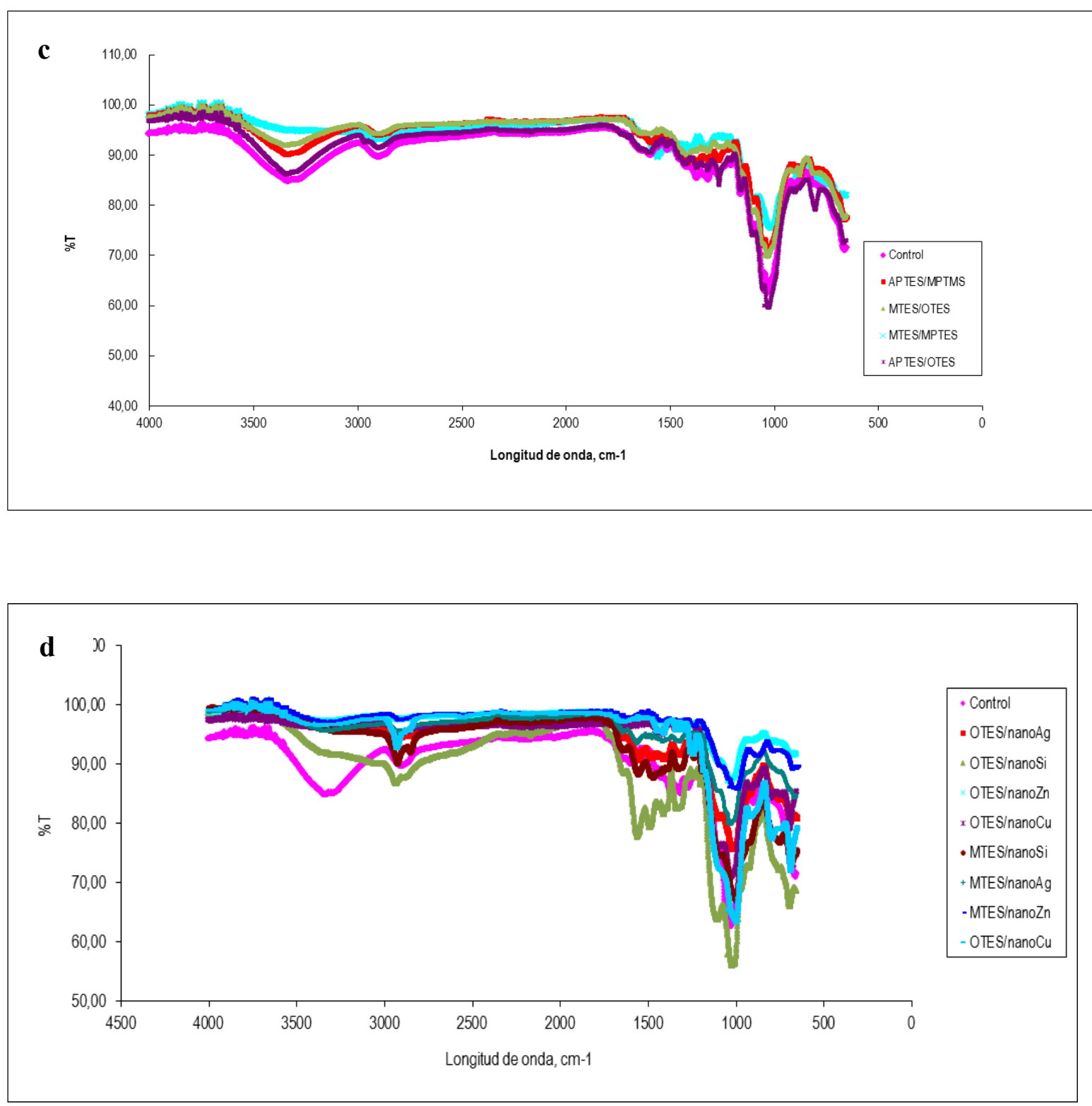

Figura III.1. C) Maderas tratadas con impregnantes basados en mezcla de silanos y D) Maderas tratadas con impregnantes basados en mezcla de silano/nano. 
- Microanálisis estructural: Microscopia electrónica de Barrido - Espectroscopia de dispersión de energías de rayos X (SEM-EDAX) y Microscopía óptica (MO)

Para corroborar todas las hipótesis planteadas, teniendo en cuenta los espectros, se realizó SEM para observar la estructura de las paredes celulares de la madera. En el caso de las maderas impregnadas con nanopartículas se realizó con módulo EDAX. Está técnica se realizó fundamentalmente para corroborar fehacientemente la presencia de éstas debido a la escasa o nula información obtenida de los espectros FT-IR. Por otra parte, se realizaron cortes con tinción para ser observados a microscopio óptico.

En primera instancia en la Figura III.2 se presenta todo lo mencionado de la madera sin tratar como base para poder realizar el estudio comparativo planteado. En estas imágenes se puede observar las estructuras características de las coníferas, donde sus células son como tubos huecos perfectamente ordenados, también se muestran las punteaduras de las traqueidas otra estructura característica de esta clase.

En cuanto a las maderas tratadas, comenzando por las nanopartículas, en la Figura III.3 se observa imágenes SEM de las muestras impregnadas con nanopartículas (a-d) en ambos perfiles de pH (I y II). Las imágenes muestran un claro aglomerado de nanopartículas disperso uniformemente en las fibras de la madera (Figura III.2), corroborando la eficiencia de aplicación de los tratamientos. En la Figura III.3, III se observa el análisis químico semicuantitativo mediante el uso de la sonda EDAX. Como se observa en los espectros, el particulado corresponde a las nanopartículas, corroborando la eficiencia de las impregnaciones realizadas.

Estructuralmente se puede observar diferencias significativas, tanto entre las diferentes nanopartículas (Figura III.3, a-d) como entre los dos perfiles de pH (Figura III.3, I-II) y la madera sin tratar (Figura III.2). En cuanto al pH, se observa que a pH alcalino (Figura III.3, I) las fibras están más desorganizadas y una mayor presencia de nanopartículas distribuidas casi uniformemente en todas las traqueidas, mientras que, a pH ácido (Figura III.3, II), tanto la desorganización de las fibras como la presencia de las nanopartículas es mucho menor. 

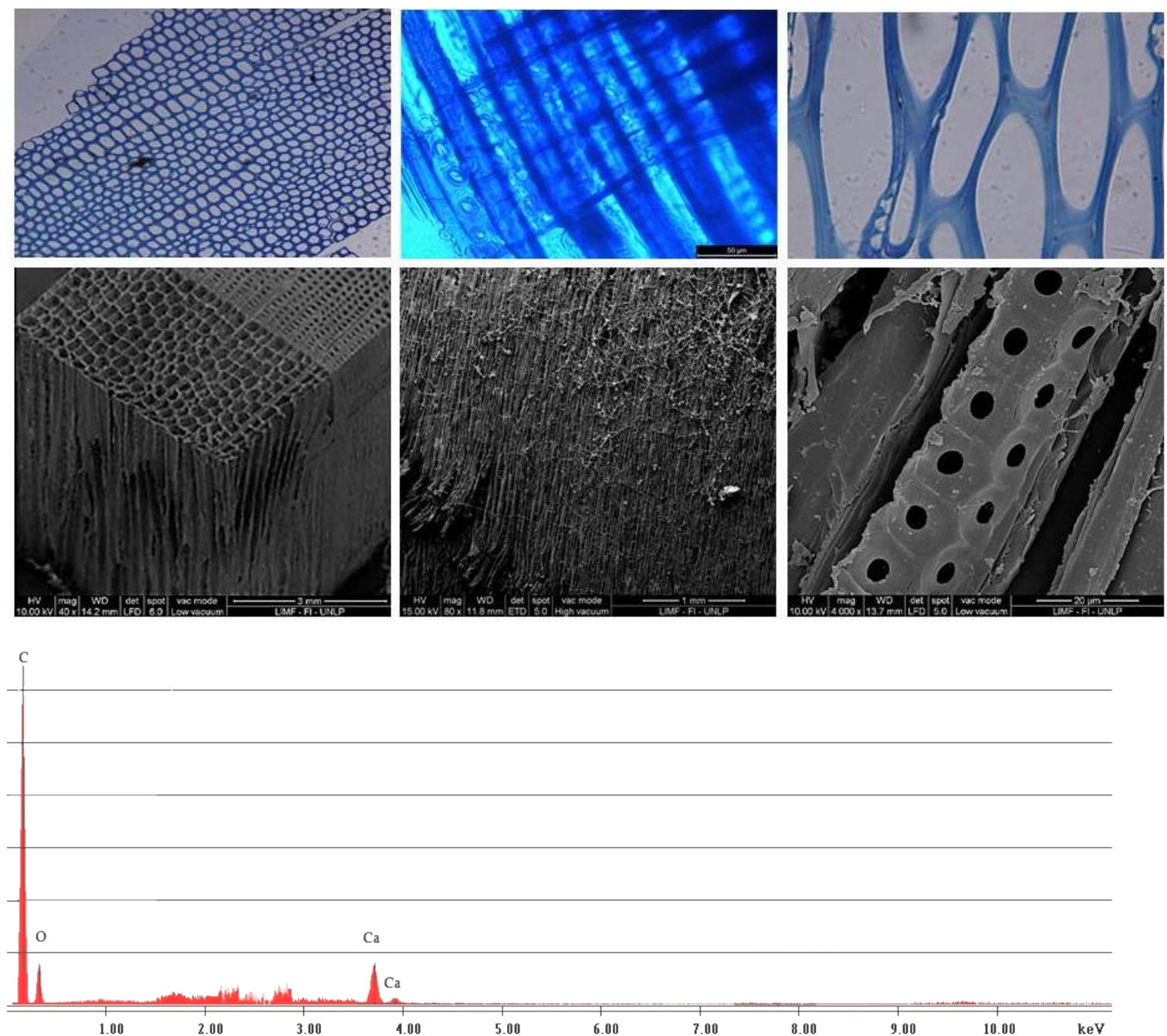

Figura III.2 Microscopía óptica con y sin fijación (arriba, Microscopia de barrido electrónico (SEM) (medio) y módulo EDAX de madera sin tratar

Por otra parte, también se observan diferencias entre las nanopartículas: si se asume el criterio de que mayor presencia de nanoparticulas en las fibras implica una mayor reactividad de las mismas en las condiciones planteadas se puede afirmar entonces que las nanopartículas más reactivas a pH básico son el nanodióxido de sílice y la nanoplata (Figura III.3, I a-b respectivamente) y el nanoóxido de cobre y nanoóxido de zinc a pH ácido (Figura III.3, II c-d respectivamente). Esto puede afirmarse con el análisis conjunto de la estructura y la densidad electrónica del sistema analizada por FT-IR (Figura III.1). Observando los espectros FT-IR arriba discutidos, se puede 
remarcar que las bandas en las maderas impregnadas con nanoplata y nanodióxido de sílice daban picos de mayor intensidad en uno de los dos picos característicos de la celulosa $\left(3400 \mathrm{~cm}^{-1}\right)$ cuando se trataba de las muestras impregnadas con estas dos nanoparticulas (Figura III.1, B), lo cual se mencionaba que podría deberse indicar una mayor cantidad de $-\mathrm{OH}$ disponibles traduciéndose en una mayor reactividad del sistema. La observación de un mayor particulado en las fibras de la madera corroboraría la hipótesis planteada.

Por otro lado, siguiendo con el fundamento arriba mencionado, en el espectro FT-IR de las impregnaciones con nanopartículas indica que la reactividad sería $\mathrm{Si}-\mathrm{Ag}-\mathrm{Cu}-\mathrm{Zn}$ (Figura III.1, B), lo cual se condice con la mayor presencia del particulado alrededor de las paredes celulares de la madera en las imágenes SEM (Figura III.2 y 3). También se mencionó que no hubo diferencias entre los espectros a diferentes $\mathrm{pH}$, por lo tanto, la reactividad fundamental del sistema es la de la madera y no el del impregnante: es conocido que a $\mathrm{pH}$ alcalino, la estructura de la pared se desintegra [20-21].

Esto implica una exposición mayor de las capas S1-S3 de las paredes celulares (estructura detallada en el Capítulo I), donde se encuentra la mayor concentración de celulosa cristalina y hemicelulosas. Esta estructura, muy organizada, es debido a la formación intramolecular entre las microfibrillas de la celulosa de puentes de hidrogeno; estos puentes de hidrógeno, son uniones muy lábiles y frente a cualquier cambio en la densidad electrónica se modifican generando nuevos enlaces [21-30].

Es en este punto donde entra en juego la reactividad y carga superficial de las nanopartículas: la estructura cristalina se desorganiza por la reactividad y carga de las nanoparticulas, aumentando la energía del sistema, este aumento entrópico hace que haya un nuevo microarreglo polimérico entre la celulosa cristalina, la amorfa y las nanopartículas, generando el cambio químico de la pared celular (FT-IR y EDAX) y modificando entonces la estructura de las fibras de la madera $(\mathrm{SEM})$ 

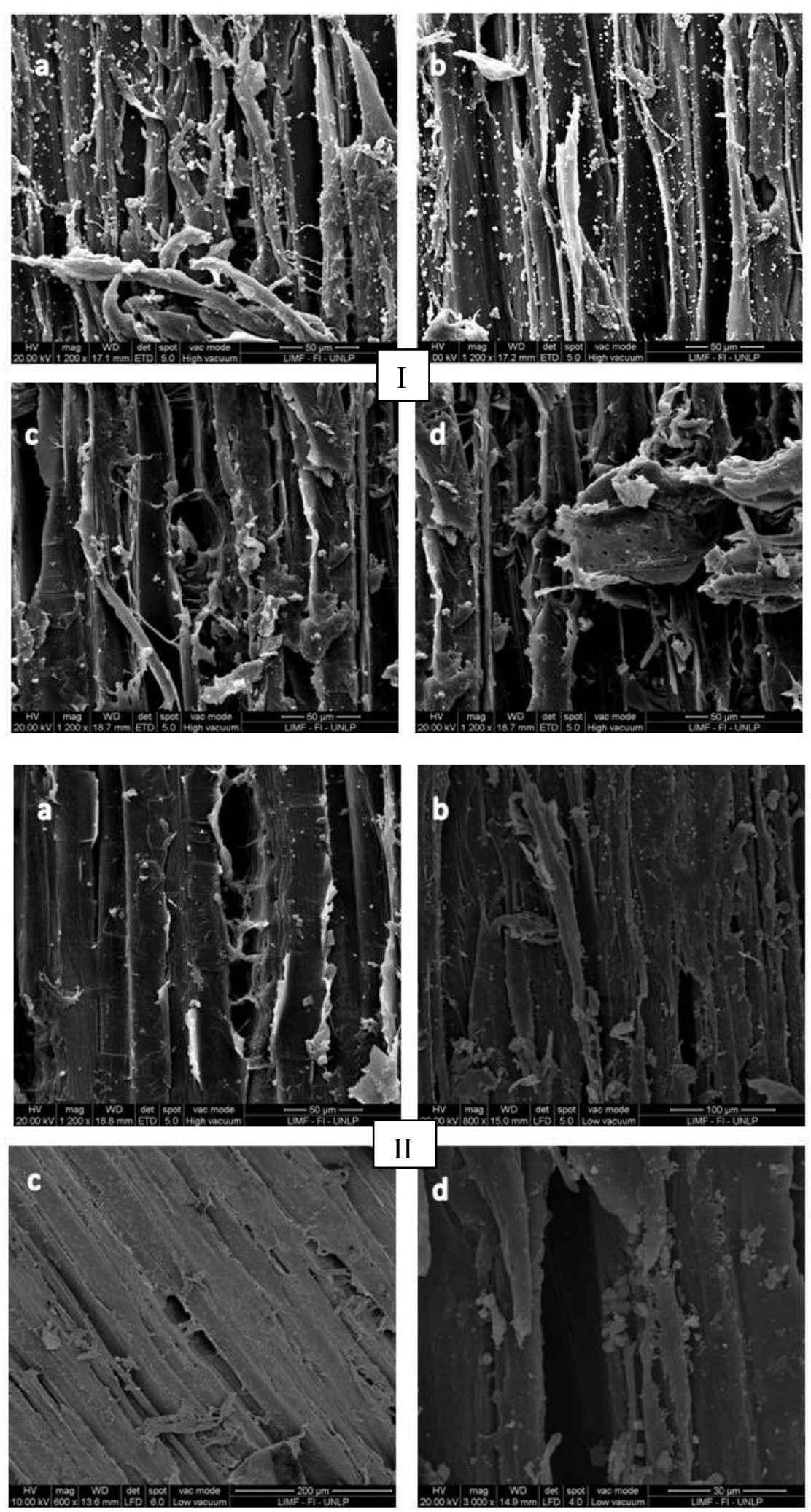


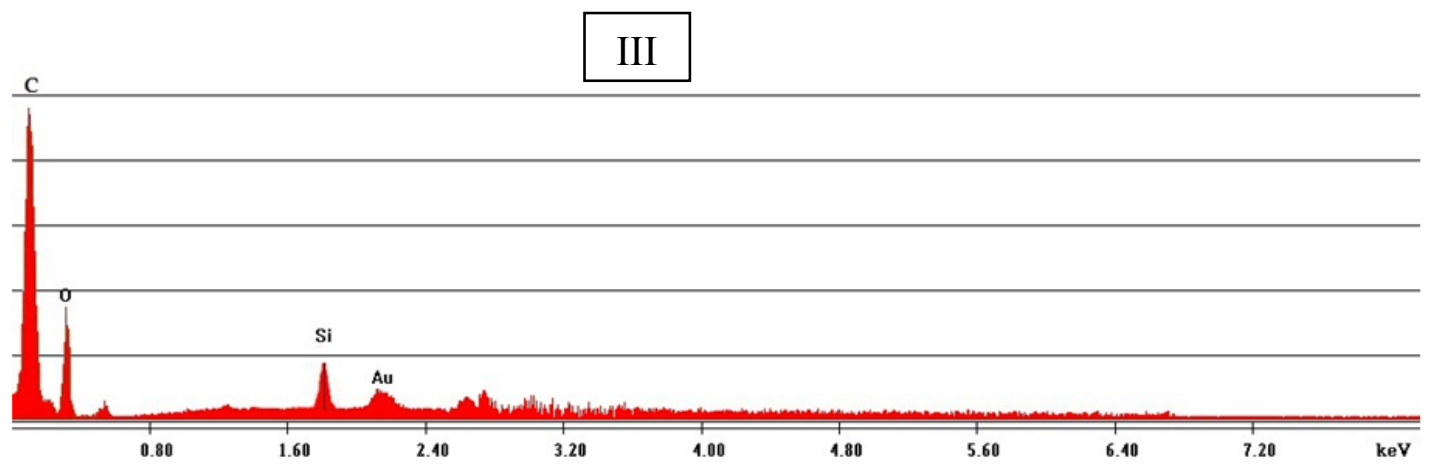

b

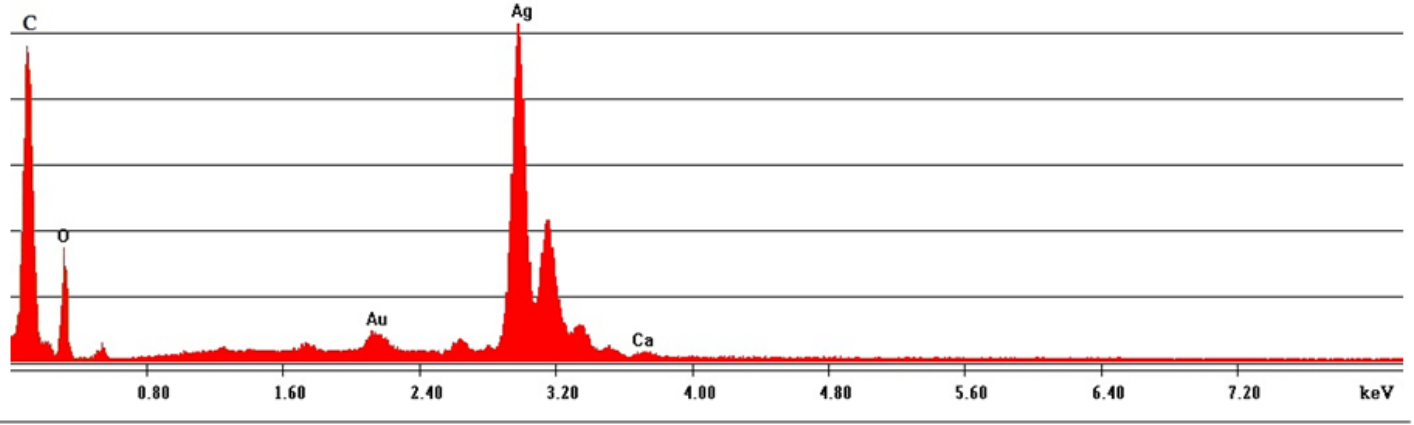

C

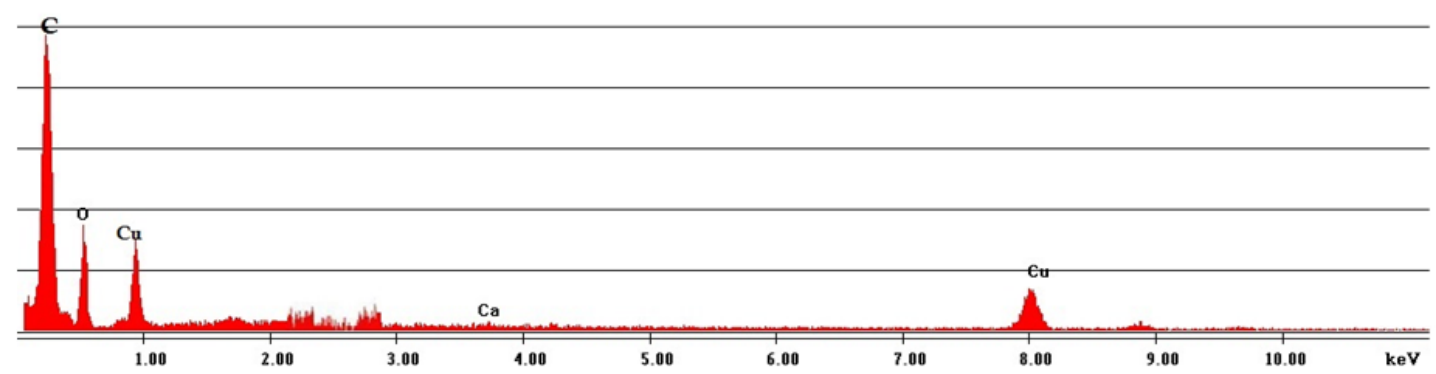

d

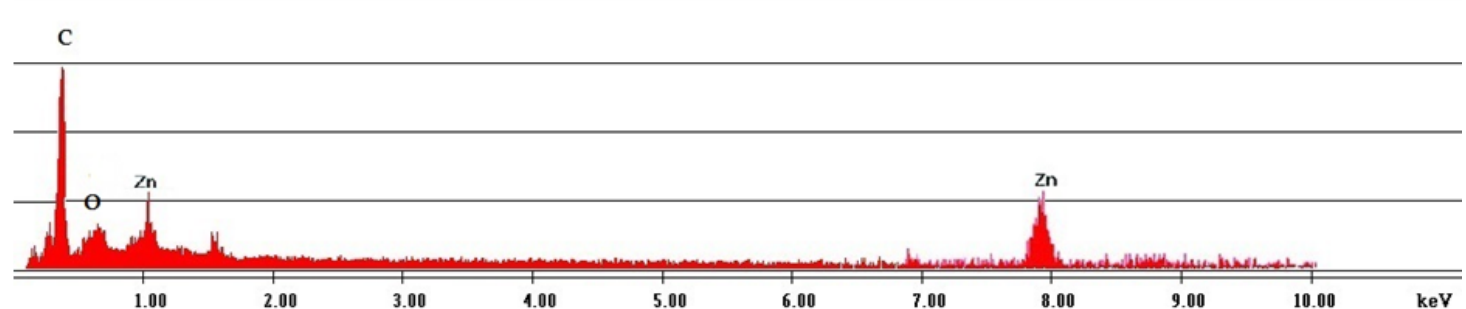

Figura III.3 Microscopia de barrido electrónico (SEM) con módulo EDAX de las muestras impregnadas con nanopartículas, I) pH alcalino, II) pH ácido, III) EDAX. a) $\mathrm{Si}, \mathrm{b}) \mathrm{Ag}, \mathrm{c}) \mathrm{Cu}$, d) $\mathrm{Zn}$

En la pared celular, en general, la modificación química ocurre entre la laminilla media y la $\mathrm{S}_{2}$ cuando el $\mathrm{pH}$ es ácido y entre $\mathrm{S}_{1}$ y $\mathrm{S}_{2}$ cuando el $\mathrm{pH}$ es alcalino. Esto último se debe a que a $\mathrm{pH}$ alcalino la laminilla media se despolimeriza o en su defecto se vuelve más laxa y deja disponible 
las capas más internas de la pared celular [31]. Para corroborar esto último, se realizaron cortes delgados $(1 \mathrm{~mm})$ y ultradelgados $(20 \mu \mathrm{m})$ con fijación química, lavado, deshidratación en series de concentraciones crecientes de alcohol o acetona, inclusión en resina, tinción, polimerización y corte mediante micrótomo (realizado en el servicio de Microscopia de Transferencia electrónica, TEM de la Facultad de Ciencias Veterinarias de la UNLP) con el fin de analizar la estructura de la pared celular, Figura III. 4.

En esta se observa imágenes de maderas tratadas con nanoóxido de silicio (todas las nanopartículas dieron imágenes similares), se observa en primera instancia que no hay cambios significativos en la estructura celular en general entre una madera tratada y sin tratar (Figura III.2), esto es debido a las bajas concentraciones utilizadas hace que no toda la estructura de la madera se modifique químicamente.

En cuanto a la diferencia en cuanto a pH se puede observar que efectivamente se cumple lo antes mencionado: se observa que el tratamiento con nanopartículas a $\mathrm{pH}$ ácido (c, d y e) hay modificación de la capa en las laminillas medias y/o en el lumen celular $\left(\mathrm{S}_{3}\right)$, tal como se mencionara, las nanopartículas interaccionan con la laminilla (intracelularmente) o en el lumen celular (flechas) que es por donde ingresan; mientras que a $\mathrm{pH}$ alcalino ( $\mathrm{f}, \mathrm{g} \mathrm{y} \mathrm{h}$ ) se observan desintegraciones parciales y/o totales de las laminillas medias y se observa inclusión de las nanopartículas en las capas $S_{1}$ y $S_{2}$ (flechas). En los cortes delgados (j, k, l) también se puede observar nanopartículas distribuidas uniformemente a lo largo de toda la traqueida.

Por lo tanto, se concluye que la modificación química a diferentes $\mathrm{pH}$ es completamente diferente a nivel estructural y penetración celular; lo cual fundamenta entonces la importancia del manejo de $\mathrm{pH}$ en el uso y reactividad de nanopartículas ya que, con un buen manejo de las variables del sistema (vehículo, solvente, $\mathrm{pH}$, etc.), se pueden obtener diferentes sistemas y eficiencia con los mismos elementos. 

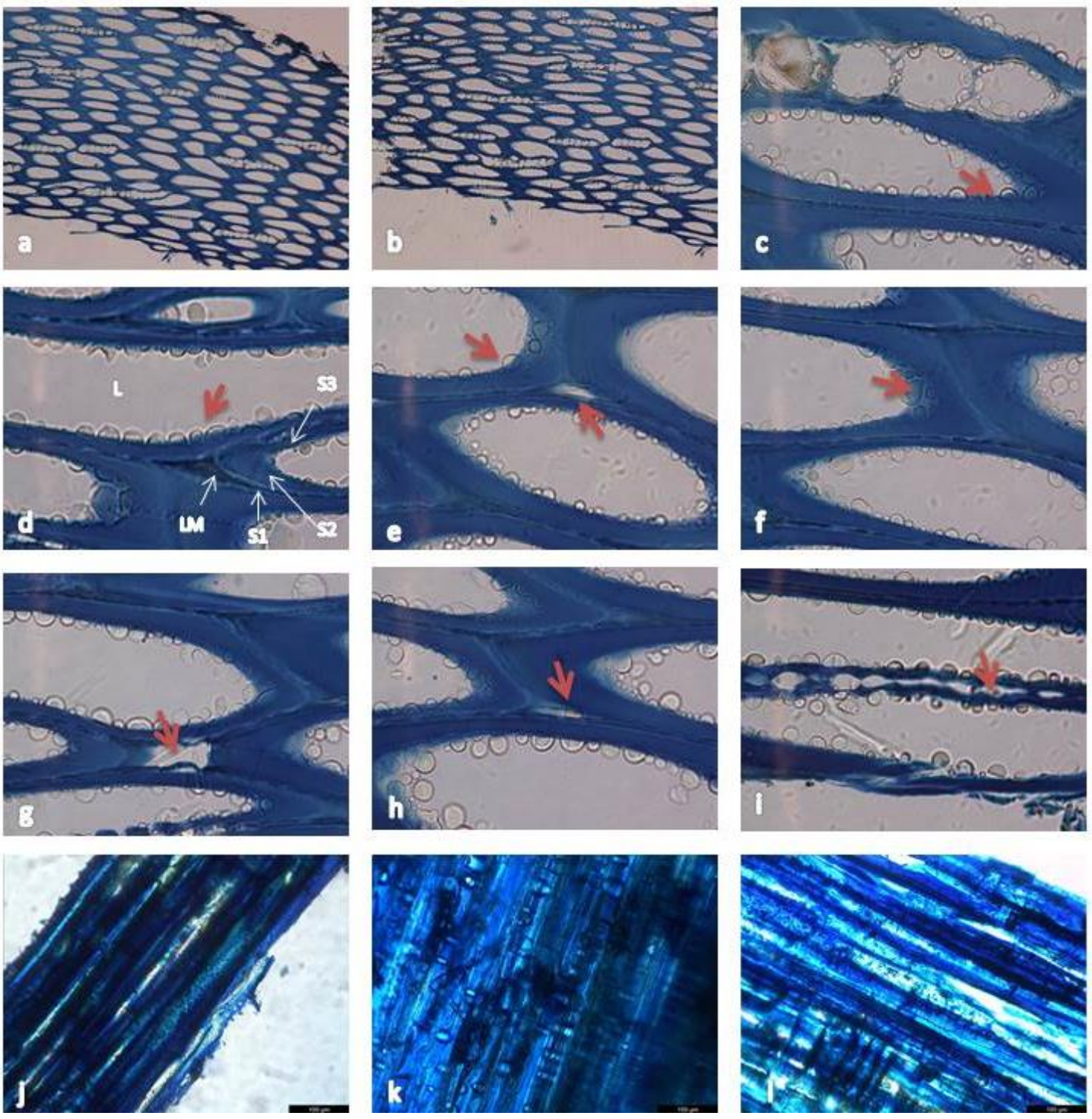

Figura III.4 Microscopia óptica de preparados delgados (j-l) y ultradelgados (a-i) con fijación, deshidratación, inclusión en resinas epoxi, ultramicrotomía, contraste del tratamiento con nanopartículas: vista general de a) madera tratada con nanoplata y b) madera tratada con nanodióxido de silice. En c, dy e, maderas tratadas con nanoparticulas a pH ácido, las fechas indican la modificación en las laminillas o el lumen celular $\left(S_{3}\right)$. $f, g$ y h nanopartículas a pH alcalino se observa la modificación de las capas $S_{1}$ y $S_{2}$ (flechas). $j$, $k$, l muestra los cortes delgados. LM laminilla media, S1, S2 S3 capas de la pared celular, L lumen celular.

En cuanto a los silanos, también se observó cambios estructurales, como eran de esperar basándose en la modificación química que se observó en los espectros FT-IR (Figura III.1 A). 
En las Figuras III. 5 y III.6 se puede observar los cambios estructurales de las células de la madera en los tres perfiles de $\mathrm{pH}$ utilizados, basados exclusivamente en la diferente estructura molecular de los oligómeros de silano al ingresar en la madera lugar donde se completará el proceso sol-gel. Esta es una de las variables fundamental debido a que las poros intercelulares tienen solo $4 \mathrm{~nm}$ de diámetro, por lo tanto, las partículas sólidas en la solución coloidal deben tener un diámetro adecuado para infiltrarse en las células de madera [32].
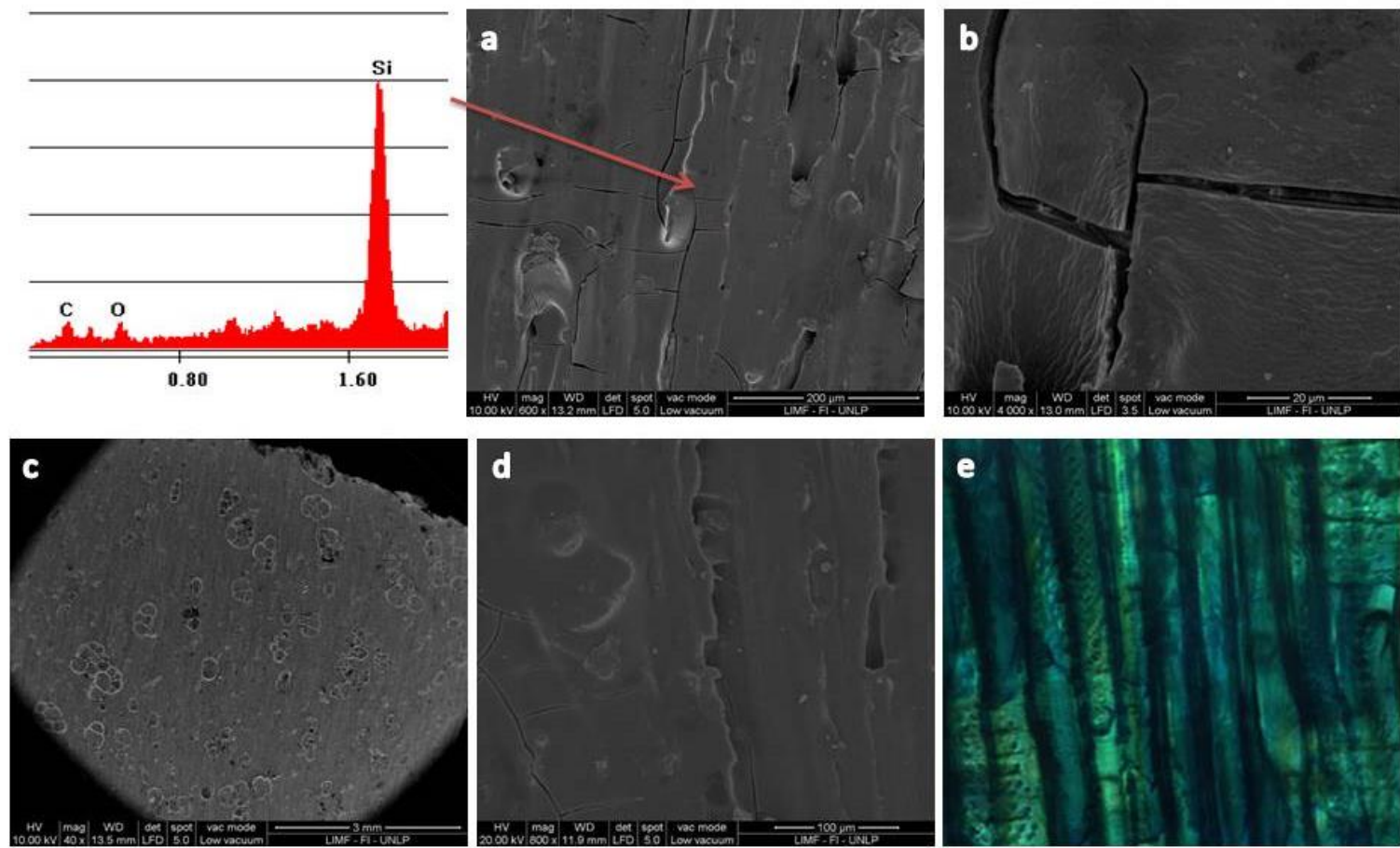

Figura III.5 Microscopia de barrido electrónico (SEM) con módulo EDAX de las muestras impregnadas con silanos en forma sol ( $\mathrm{pH}=$ neutro): a)madera tratada con MTES, b) madera tratada con MTES con mayor magnificación, c) madera tratada con OTES, d) madera tratada con OTES con mayor magnificación, e) microscopia óptica de madera tratada con APTES teñida con azul de metileno se observa una tinción amarillenta que representa a los silanoscubriendo las células de la madera.

Se observa una diferencia significativa a nivel de impregnación en el caso de $\mathrm{pH}$ neutro (Figura III.5) respecto a otros dos perfiles de $\mathrm{pH}$ (Figura III. 6): Se observa que a $\mathrm{pH}$ neutro no hay ingreso de impregnante en la madera, sino que forma una película que recubre a la madera. Esto se puede ver tanto en la microscopía electrónica de barrido como en la microscopia óptica (capa amarillenta). Esto se debe a que a pH cercano a 7 la tasa de hidrólisis alcóxidos de silicio presenta 
un mínimo y aumenta exponencialmente tanto a pH más bajo como más alto, contrariamente a la condensación que a ese $\mathrm{pH}$ presenta una tasa máxima, por lo tanto y como se muestra en la Figura I.20 hay formación polimérica previo ingreso y esto impide que este pueda penetrar por impedimento estérico dimensional (cabe recordar que en uno de los métodos no se utilizó presión, por lo tanto el tamaño de partícula es un factor limitante), Figura III.5.

En cuanto al pH ácido y alcalino, se puede observar que hubo ingreso del impregnante debido a que se observa las estructuras de las traqueidas pero con una textura superficial diferente. Se comprobó si este recubrimiento que se observaba eran silanos mediante el análisis EDAX, Figura III.6.

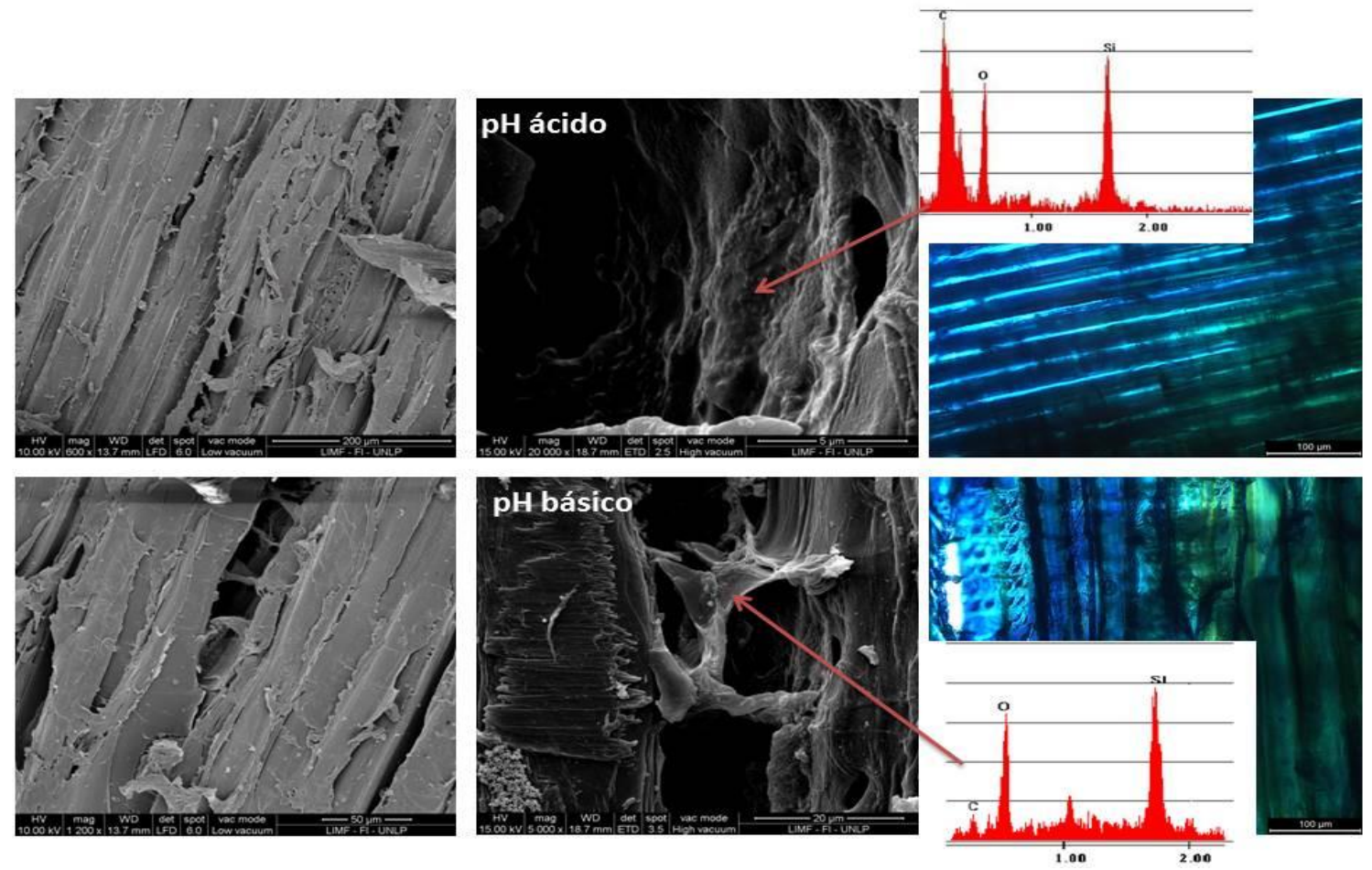

Figura III. 6. Maderas tratadas con MTES a pH ácido (arriba) ya pH básico (abajo).

También se observa diferencias entre los dos perfiles de $\mathrm{pH}$ : a $\mathrm{pH}$ ácido hay formación de una película cubriendo las paredes celulares, mientras que a $\mathrm{pH}$ alcalino se puede observar la formación de una estructura intracelular. Esta estructura se observó en reiteradas observaciones 
por lo que se le realizó EDAX para ver su procedencia química: se observa presencia de C, O y Si por lo que se puede hipotetizar un microarreglo de la pared en conjunción con los silanos para disminuir la energía del sistema al desorganizarse la estructura cristalina de la misma, por lo que se mencionó anteriormente que a $\mathrm{pH}$ alcalino se desintegra la laminilla media de la pared celular, mientras no ocurre a $\mathrm{pH}$ ácido.

Teniendo esto en cuenta es posible que la desintegración de la misma permita la formación de esta estructura debido a una exposición mayor de las capas $\mathrm{S}$ de la pared celular generando un composite orgánico-inorgánico madera-silano.

Para corroborar esto, también se realizaron cortes delgados y ultradelgados con fijación química, lavado, deshidratación en series de concentraciones crecientes de alcohol o acetona, inclusión en resina, tinción, polimerización y corte mediante micrótomo (realizado en el servicio de Microscopia de Transferencia electrónica, TEM de la Facultad de Ciencias Veterinarias de la UNLP) con el fin de analizar la estructura de la pared celular, Figura III. 7.

Este método se escogió porque, además de permitir un mejor análisis estructural, también permite ver indirectamente que hay una unión covalente fuerte entre los impregnantes y la madera, ya que, si esto no fuera así, con el mismo método de fijación, se lixiviarían o se solubilizarían en los solventes.

Las imágenes de la microscopia óptica de preparados delgados y ultradelgados de tratamientos con silanos pH alcalino (a-c) a pH ácido (d-f) se observa la formación polimérica de los silanos que se distingue por una estructura transparente continua que se observa en los cortes. En cuanto a reacción química y formación polimérica no se ven grandes diferencias, pero si se observa diferencias en el sitio de la modificación: como se mencionara en el caso de las nanopartículas, la desintegración de la laminilla media en el tratamiento con $\mathrm{pH}$ alcalino (flechas) y la reacción de los silanos con la laminilla media y en el lumen con el tratamiento a pH ácido (flechas). Solo se muestran algunos silanos porque los patrones de las imágenes obtenidas todos eran similares. 

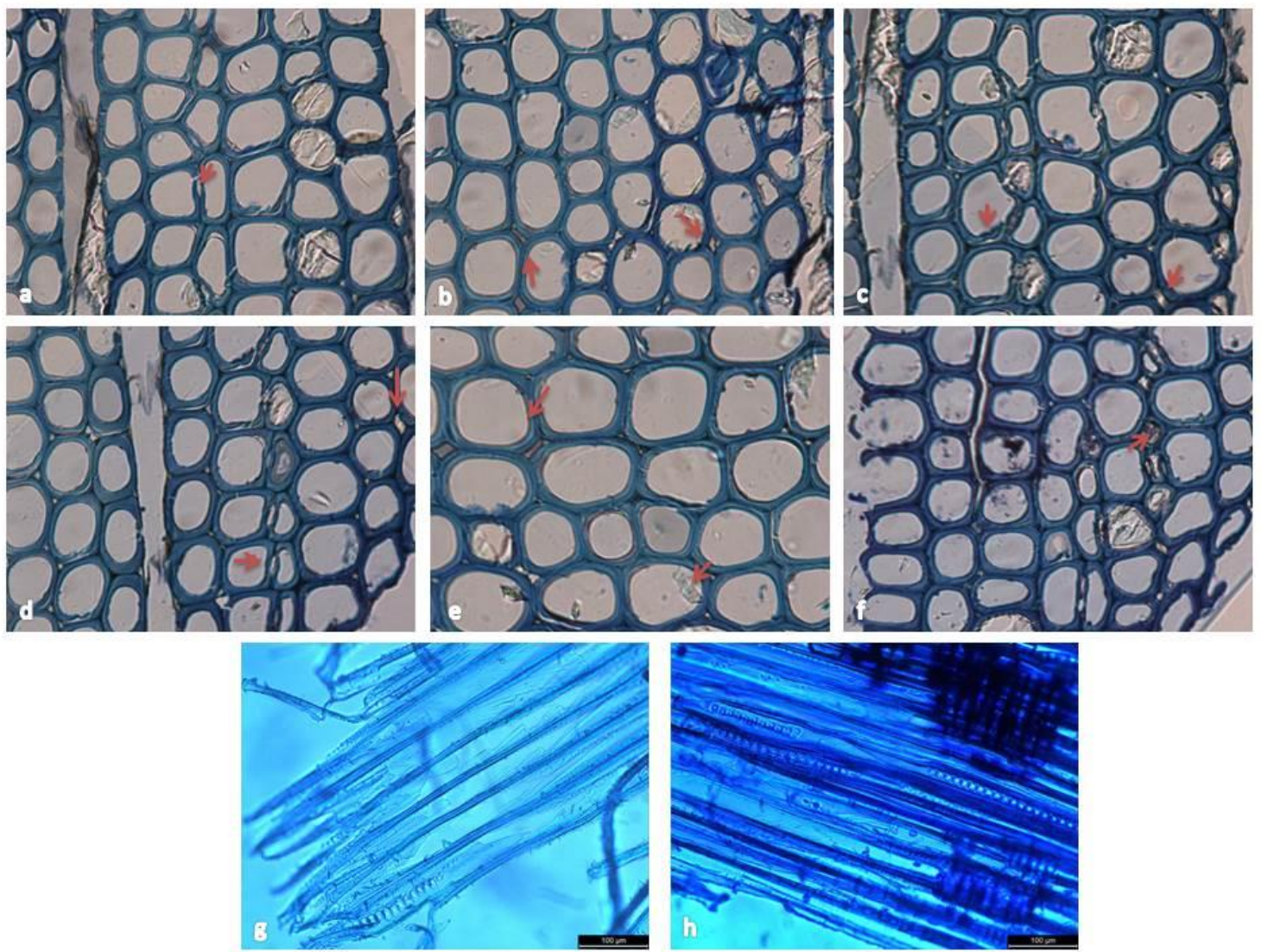

Figura III.7 Microscopia óptica de preparados delgados y ultradelgados con fijación, deshidratación, inclusión en resinas epoxi, ultramicrotomía, contraste de tratamientos con silanos (APTES, MTES y OTES) Silanos: a-c a pH alcalino y d-f e-h a pH ácido de APTES $(a, d), \operatorname{MTES}(b, e)$ y OTES $(c, f)$. Se observan diferencias en el sitio de la modificación (flechas).

En cortes delgados (g-h) se observa también la formación de una película continua rodeando todo el lumen (g), mientras que en el alcalino, se observan diferencias estructurales de las traqueidas (h), se observa paredes más gruesas y lúmenes obliterados, esto se debe a la modificación de las capas más internas de la pared celular $\mathrm{S}_{1}$ y $\mathrm{S}_{2}$ tal como se mencionó anteriormente.

Con esta observación, podemos afirmar entonces que el cambio químico producido se debe al proceso de sol-gel y que mediante este método se ha logrado que se produzca dentro de la madera generando el mencionado composite. Muchos investigadores han estudiado modificaciones químicas que implican la reacción de los grupos hidroxilo: los enlaces $\equiv \mathrm{Si-OC} \equiv$ surgirían de la hidrólisis de los alcóxidos y la subsiguiente condensación de $\equiv \mathrm{Si}-\mathrm{OH}$ con el -OH de la madera 
como se explicó con anterioridad [33-41]. Si bien la tecnología sol-gel es ampliamente conocido y aplicado por muchos investigadores en los últimos años para impregnar madera con materiales inorgánicos (principalmente óxido) o híbridos (orgánicos / inorgánicos), en muchos casos, estas impregnaciones a base de sol-gel se llamaron composites de madera debido a la presencia de una cantidad relativamente alta de nuevos ingredientes en la madera y el cambio resultante en las propiedades. Sin embargo, se debe considerar que estas impregnaciones no siempre modifican químicamente la madera ya que no es probable una fuerte unión química entre el dispersante y la matriz de madera se conserva.

Las investigaciones estructurales indican que la impregnación puede dar como resultado la incorporación de materiales inorgánicos o híbridos de más de $4 \mathrm{~mm}$ de profundidad en la estructura de álamo o madera de pino quedando como precipitados que se localizan en la mayoría de los casos en la luz celular rellenando, pero no modificando químicamente [33]. Dado esta reseña bibliográfica es que se hizo especial hincapié en donde se producía el cambio y si realmente se estaba modificando químicamente la madera. Según los resultados analizados de los espectros FTIR, en la localización estructural de los silanos y en la modificación estructural de las celulosa puede afirmar entonces que se produjo modificación química de la madera.

Como se puede observar, a pH ácido se produce un recubrimiento en de las paredes celulares, probablemente debido a la reacción de los silanos con la laminilla media (no hay modificación estructural de las células de la madera), mientras que a pH básico se observa una desorganización estructural de las fibras, lo cual hace que los silanos reaccionen con la capa $S_{1}$ y $S_{2}$ de la pared celular $[23-41]$.

Además, las diferencias de $\mathrm{pH}$ priman más su efecto en la solución impregnante que en la madera en sí, contrariamente a lo que sucedió con las nanopartículas: en este tipo de tratamiento hay que primar el tamaño molecular de los oligómeros a impregnar más que la activación de la madera, porque si estos no ingresan, la modificación química no es posible.

Por otro lado, es importante destacar que no hubo diferencias en los resultados mediante los dos métodos de impregnación utilizados: esto indica que el manejo correcto de los parámetros de formulación del impregnante independiza la elección posterior del método de aplicación, esto es fundamental para que las formulaciones puedan tener multiusos tanto en construcciones nuevas, 
en estructuras armadas y elementos y construcciones patrimoniales. En la presente tesis, dos de los tres métodos no necesitan de la aplicación de presión para la impregnación, con lo cual tiene una aplicabilidad mayor, ponderando la importancia de este estudio por su aplicabilidad.

Por último, se analizó la potencialidad de la conjunción de las dos tecnologías anteriormente estudiadas: la mezcla de silanos y nanopartículas, con el fin estudiar algún posible efecto sinérgico. En este caso, solo se formuló a pH alcalino, dado las observaciones mencionadas anteriormente; con esto entonces, se aseguró llegar a las capas más internas de la pared celular.

La Figura III. 8 muestra las imágenes SEM de la impregnación con silanos/nanopartículas y su respectivo análisis EDAX En este caso, se puede observar cambios estructurales mucho mayores que los sistemas anteriores y más aun con la madera sin tratar. En todos los casos (Figura III.8 ac), menos en el uso de nanozinc (Figura III.8 d), se observó formación de microestructuras entre las paredes celulares de las traqueidas de la madera. En el caso del nanozinc, se observó la formación de un recubrimiento, similar a lo que sucedía a pH ácido cuando solo se utilizaba silanos.

Esto podría deberse a que el nanozinc reaccionaría rápidamente con el cambio de $\mathrm{pH}$ al agregar en la formulación el $\mathrm{NH}_{4} \mathrm{OH}$ reaccionando con los silanoles por lo que, en este caso, solo los silanos estarían reaccionando con los $-\mathrm{OH}$ de la madera generando esta distribución uniforme. En cambio, las otras nanopartículas, generarían anclajes celulosa-silano/silano-celulosa, generando una red polimérica mayor, por ello puede evidenciarse mediante microscopia electrónica. También se puede observar que hay una mayor formación polimérica en todas las muestras, lo que conlleva a pensar que se produjo un mayor ingreso de moléculas a la madera.

Esto podría deberse a que, en la formulación la presencia de los silanos genera una estabilidad de la emulsión por reducción de la energía superficial que tienen las nanopartículas, por formación de enlaces no covalentes (puentes de hidrogeno y dipolo-dipolo).

Esta situación, haría que las nanopartículas y los oligómeros de silanos se mantengan estables en la emulsión, evitando su aglomeración y precipitado. Una vez que se produce el ingreso a la madera, este equilibrio se perdería en primera instancia, por la presencia de moléculas de agua que dan inicio a las reacciones de hidrolisis y condensación y en un segundo plano, por atracción de 
los $-\mathrm{OH}$ de la celulosa que acaba de ser atacada por el $\mathrm{pH}$ de la solución y la reactividad de las nanopartículas.

Este aumento de la energía entrópica del sistema hace que todo el sistema tienda a disminuirla generando enlaces covalentes entre las nanopartículas, la celulosa y los silanos en proceso de condensación, generando un composite trimétrico orgánico-inorgánico-nanometal [42-51].

Para observar la estructura de la pared celular, se realizó cortes ultradelgados, con fijación química y contraste, Figura III.9.

En las imágenes se puede observar la formación polimérica sin contraste con el anclaje nanoparticulado en las capas internas de la pared celular (a-c) menos en el caso del nanozinc que se observa la formación de una película que recubre la capa S3 localizándose en el lumen celular (d). En este último se observa la formación de una película que recubre la capa S3 localizándose en el lumen celular (d).

En los cortes delgados, se observa un lumen obliterado y una falta de delimitación entre las traqueidas debido a la formación de la mencionada red polimérica madera-silano-nanopartícula intra e intercelular (e-f).

Las imágenes entonces corroboran lo antes planteado en cuanto a sitio de modificación y cantidad de moléculas que ingresaron a la madera. En todos los casos, las imágenes fueron de similar estructura, por ello se muestra solo algunos ejemplos relevantes.

En resumen, se puede decir que todos los tratamientos y métodos de aplicación propuestos generaron la modificación química de la madera, objetivo principal de la presente tesis como método de protección. 

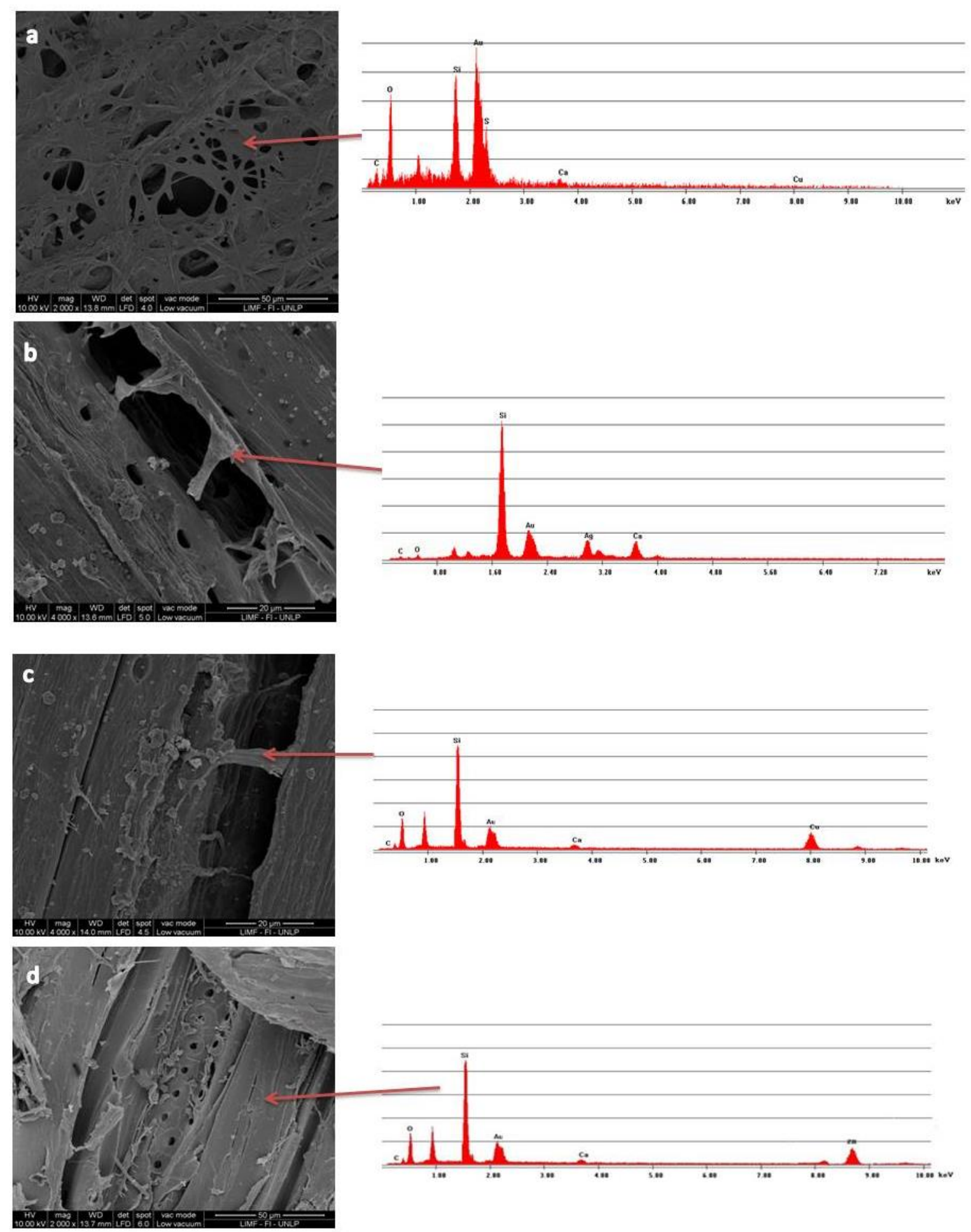

Figura III.8 SEM-EDAX de impregnantes basados en Silanos y nanopartículas: madera impregnada con MTES y a) nanoSi, b) nanoAg, c) nanoCu y d) nanoZn. 


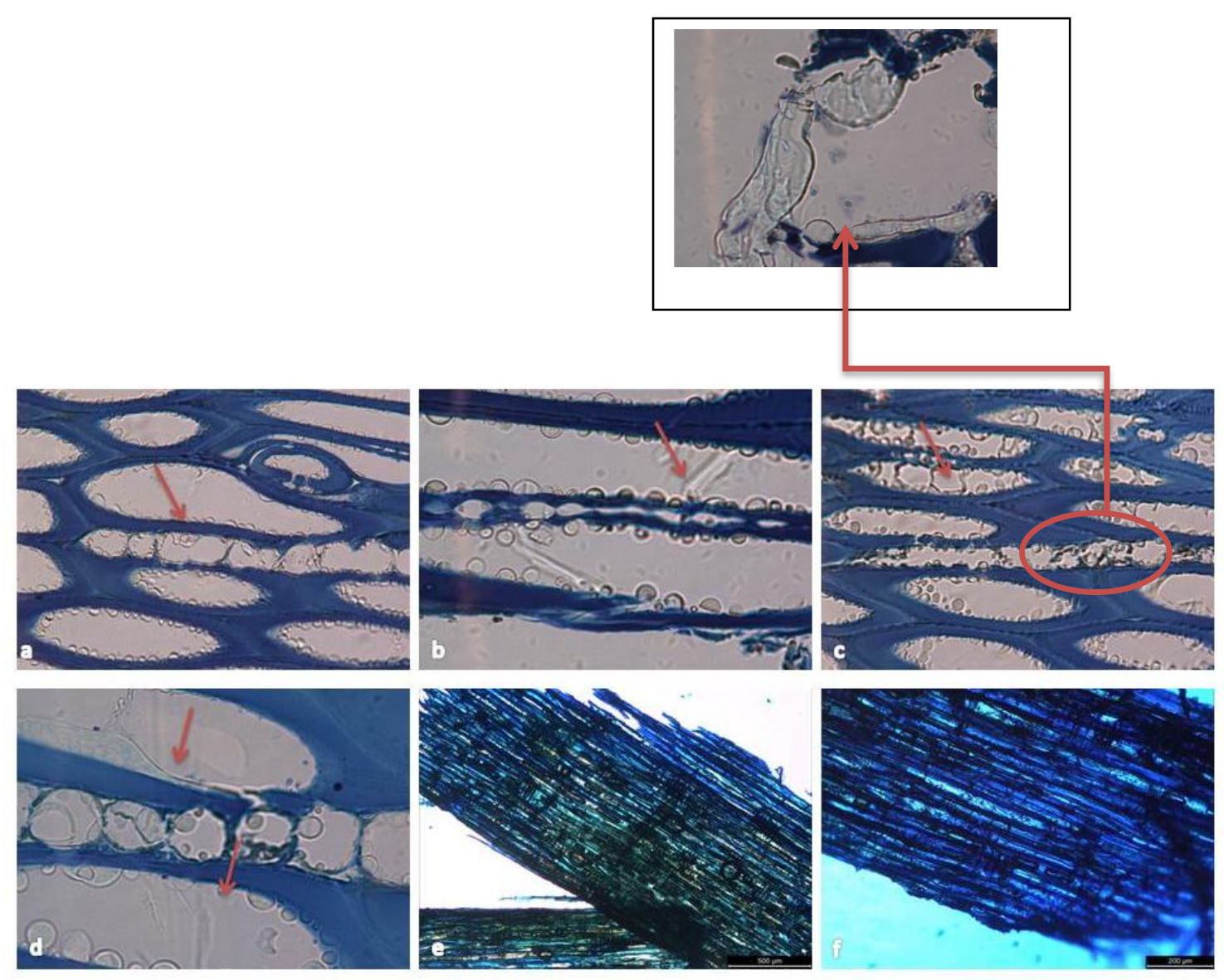

Figura III.9. Microscopia óptica de preparados ultradelgados con fijación, deshidratación, inclusión en resinas epoxi, ultramicrotomía, contraste de tratamientos con silanos/nanoparticulas a pH alcalino a) OTES/nanoSi, b) OTES/Ag, c) OTES/Cu, d) OTES/Zn y preparados de cortes delgados de OTES/nanosilice (e) y OTES/nanoplata (f). Las flechas indican sitio donde se produjo la modificación química

Si bien todos generan modificación, hay diferencias estructurales de la microestructura cuando se modifica el $\mathrm{pH}$, pero todos siguen un patrón común: estabilización energética del sistema. Esto es debido a un aumento en la movilidad de la cadena molecular en las regiones no cristalizadas de la celulosa, lo cual hace que las microfibrillas se reordenen en una nueva cadena molecular en las regiones donde el polímero original atacado quedó más laxo.

El ingreso del impregnante, desorganiza las microfibrillas de celulosa y abre los anillos de los monómeros que la forman perdiendo la estructura de la pared celular, dejando así a las moléculas de celulosa con elevada energía libre. 
Posteriormente en el curado se produce la disminución de la entropía por reacción y consecuente polimerización de los principios activos de las formulaciones (silanos) y los $-\mathrm{OH}$ de celulosa. El entramado intra e intermolecular, por cuestiones espaciales, se debe a las probabilidades de encuentro de las especies reactivas (es más probable que se encuentre con una especie reactiva enfrentada que con una adyacente o contigua, resultando en un microarreglo que deja los lúmenes obliterados. Los modelos de estos mecanismos se muestran en la Figura III.10.

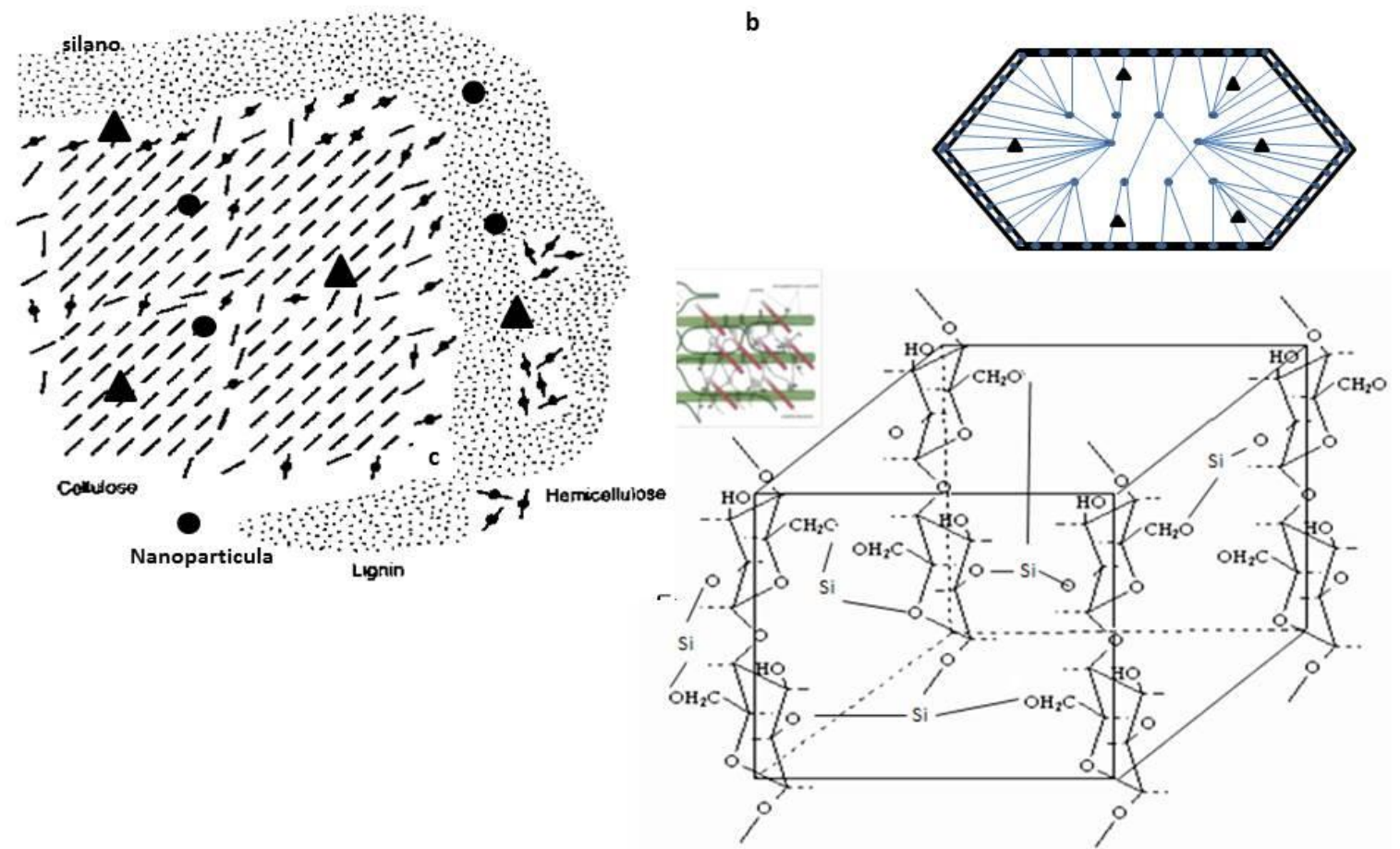

Figura III.10. Modelo de los mecanismos de modificación química propuestos: El modelo composite pensándolo que los silanos y las nanoparticulas actuarían como fibras de refuerzo (a). La nueva microestructura de la madera se grafica en b (silanos) donde se representa la formación de nuevos microarreglos de las paredes celulares con composición celulosa-silano-nanoparticula.

En cuanto a los siloxanos comerciales, Figura III. 11, se puede observar como era de esperar, que genera una película superficial de características estructurales similares independientemente de la concentración. Se puede ver que el tipo de recubrimiento que forma, es de un área superficial mayor que el de la madera, debido a la rugosidad de la misma debido a la estructura polimérica 
que presentan los polisiloxanos (largas cadenas poliméricas de silanos). Cabe mencionar, que Sikaguard 700-S es un impregnante monocomponente e hidrófugo de Siloxanos en base agua, para aplicar sobre superficies absorbentes cementosas en obra civil o en estructuras de edificación de hormigón.
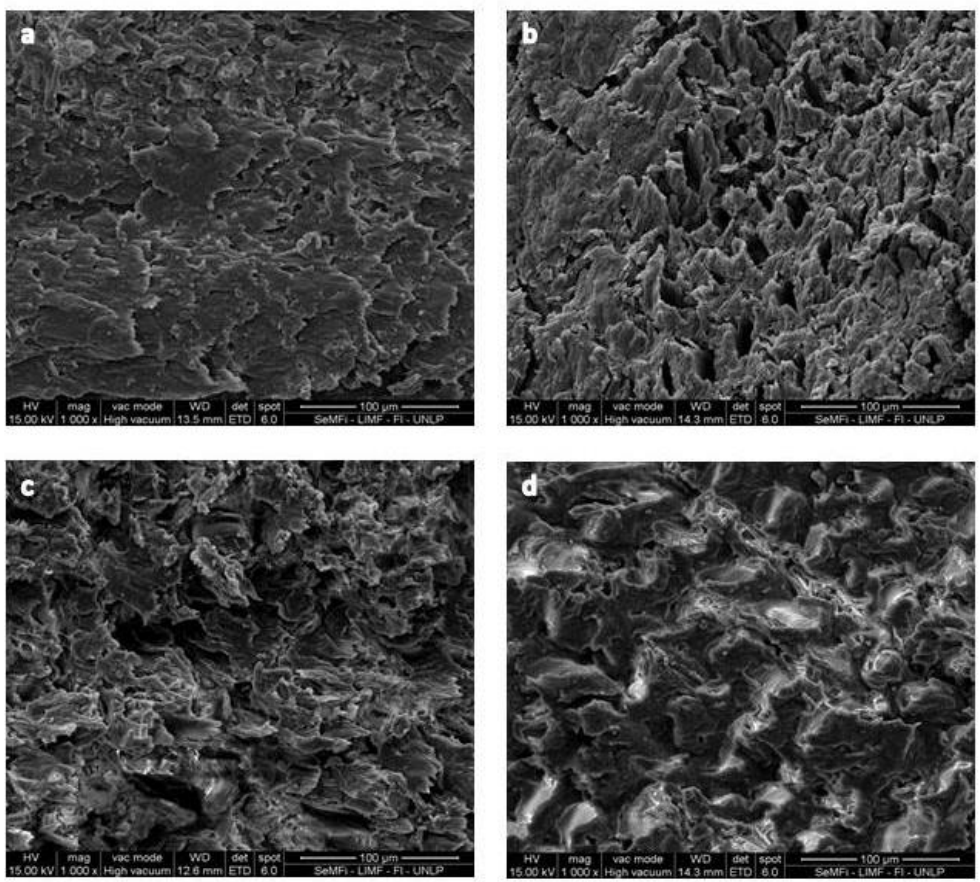

Figura III.11 Impregnación con siloxanos comerciales a-b (Sika guard S700) y c-d (Sika guard S1).En las imágenes se puede observar una película de Siloxanos cubriendo la superficie de la madera, con un aumento en el área superficial respecto a los silanos a pH neutro.

\section{3 Hidrorrepelencia y estabilidad dimensional}

En general, los tratamientos para reducir o evitar la absorción de agua en madera se pueden dividir en dos categorías: tratamientos hidrorrepelentes o estabilizadores dimensionales [52].

Aunque estos dos términos en general son utilizados como sinónimos en realidad son enfoques completamente diferentes para el control de la humedad en la madera. La eficacia hidrófuga de un tratamiento puede definirse como la capacidad de prevenir o controlar la velocidad de absorción de agua líquida, mientras que, la eficacia del tratamiento estabilizador dimensional puede ser 
definida como su capacidad para reducir o prevenir el hinchamiento y contracción de la madera resultante absorción de la humedad [52-54].

La Figura III.12 explica lo que se espera de un tratamiento hidrorrepelente eficiente. La curva superior muestra como en una muestra de madera no tratada toma agua rápidamente y se hincha para hasta la extensión máxima, mientras que la curva inferior muestra un gráfico teórico de una muestra de madera tratada donde se observa que la tasa de absorción de agua se redujo (mayor repelencia) así como la reducción de la hinchazón (mayor estabilidad): este tratamiento parece mejora ambas propiedades [52-56]. Este tipo de tratamiento puede dividirse tres tipos:

- Tipo I: Tratamiento reduce la tasa de absorción de agua, pero no el proceso de hinchazón (es casi la misma que la madera sin tratar). Tal tratamiento mejoraría la repelencia al agua pero no estabilidad.

- Tipo II: Reduce el grado de hinchazón, pero no la velocidad a la que la madera absorbe la humedad. Tal tratamiento únicamente mejoraría la estabilidad dimensional

- Tipo III: Reduce tanto la tasa de absorción de agua y la hinchazón. Tal tratamiento mejoraría la repelencia al agua y estabilidad dimensional.

En general, se busca de un sistema protector que sea de tipo III ya que ambas variables afectan la durabilidad de la madera. Por lo tanto el objetivo de la búsqueda de sistemas protectores que enmarca la presente tesis, fue desarrollar sistemas con esta performance: hidrorrepelentes y estabilizadores dimensionales, entre otras características.

La relevancia de la humedad como agente deteriorante se fundamenta en la interacción existente entre el agua y la madera: como se desarrolló en el Capítulo I, la pared celular de la madera se compone principalmente de polímeros con hidroxilo y otros grupos que contienen oxígeno, los cuales tienen la capacidad de atraer la humedad ambiente a través de enlaces puentes de hidrógeno. A medida que se añade agua a la pared celular, el volumen de madera aumenta casi proporcionalmente al volumen de agua añadida. Esto hace que la madera se hinche hasta que la pared celular se satura. Este punto se denomina punto de saturación de la fibra, y varía de 20 a 50 
por ciento en ganancia de peso. El agua, más allá de este punto, es agua libre en la estructura y no contribuye al aumento de volumen de la madera. Este proceso es reversible, y la madera se contrae a medida que pierde humedad por debajo del punto de saturación de la fibra [56-57].

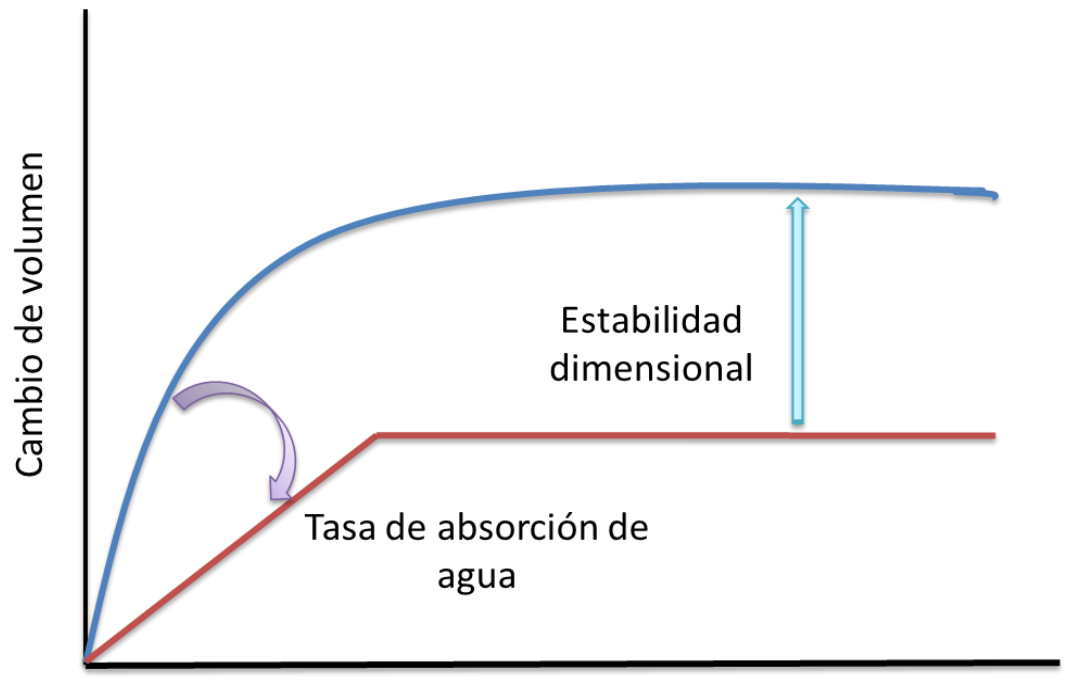

Tiempo

Figura III.12. Hidrofilia de la madera e hidrorrepelencia: gráfico que representa la absorción de agua natural de la madera (curva superior). La curva inferior muestra un gráfico teórico de la respuesta de la madera tratada con un sistema hidrorrepelente eficiente donde se observa que la tasa de absorción de agua se redujo (mayor repelencia) así como la reducción de la hinchazón (mayor estabilidad)

La estabilidad dimensional se determinó midiendo los valores de absorción de agua (WA, Water absorption), el hinchamiento (VS, Volume Swelling) y el coeficiente antihinchamiento (ASE, Antiswelling Eficciency) usando el método de inmersión en agua del ensayo de Rowell y Ellis, 1978 [58], mediante la aplicación de ciclos de secado-agua-remojo, tal como se desarrolló en el capítulo anterior.

Los resultados que aquí se presentan son el general de cada uno de los compuestos utilizados: se realizó el promedio de las mediciones por duplicado de cada uno de los tratamientos con diferente aplicación, luego se analizó estadísticamente la diferencia entre los mismos tratamientos mediante t-student, bajo la premisa de corroborar si las medias de dos poblaciones distribuidas en forma 
normal son iguales utilizando un $\mathrm{p}<0.05$. El análisis estadístico arrojo que no había diferencias significativas entre ambos métodos de aplicación.

Por otra parte, se analizó las diferencias a pH ácido y básico de las formulaciones, Figura III.13. Como se puede observar, no hubo diferencias entre estos por lo que se graficó el promedio de todas las muestras para cada formulación.

Para el caso del tratamiento a $\mathrm{pH}$ neutro de silanos tuvo un comportamiento diferente, por ello se excluyó de este y se tratará individualmente.

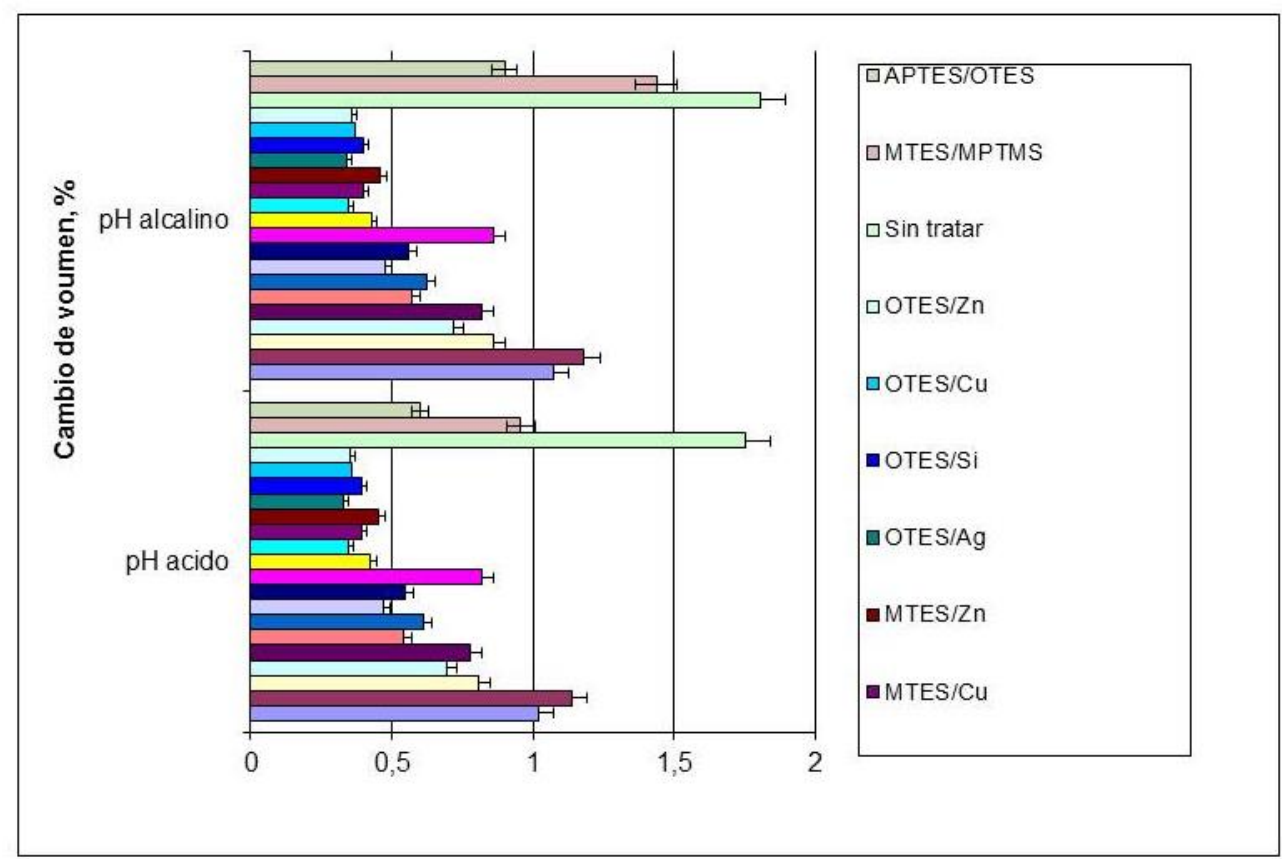

Figura III.13. Cambio de volumen de los tratamientos a diferentes pHs

La Figura III.14, III.15, III.16 y III.17 se observa los resultados del cambio de volumen de todos los tratamientos. Teniendo en cuenta el análisis anterior, de los resultados obtenidos en cuanto al cambio de volumen se puede observar que la mayoría los tratamientos aquí propuestos son del Tipo III, excluyendo a los silanos a pH neutro y los siloxanos comerciales (Figura III.17). Por lo tanto, salvo estos últimos, todos tienen la capacidad de reducir la tasa de absorción de agua y 
mejorar la estabilidad dimensional, ya que todos los volúmenes alcanzados son significativamente menores a los de la madera sin tratar; siendo entonces hidrorrepelentes y estabilizadores dimensionales de manera simultánea (Figuras III.14, III.15 y III.16). En el caso de los siloxanos comerciales y los silanos son del Tipo II, es decir que solo son estabilizadores dimensionales.

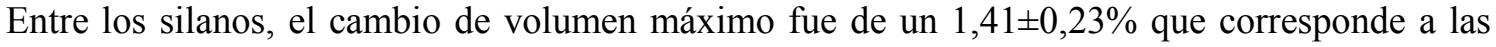
maderas tratadas con MPTMS y a las tratadas con APTES individualmente; un cambio mínimo y de mejor performance del $1,00 \pm 0,18 \%$ el cual corresponde a las maderas tratadas con mezcla de ambos silanos, si ambos los analizamos con respecto a la madera sin tratar, donde se observa un

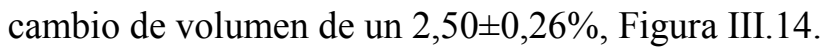

Es importante mencionar, que si bien al final de los ciclos de inmersión el MPTMS y el APTES se comportaron de la misma manera tanto individualmente como en las mezclas, se observa que las curvas difieren mucho entre sí, lo cual refleja un mecanismo de acción que también difiere en cuanto a la hidrorrepelencia. El MPTMS tiene una curva con pendiente muy pronunciada de absorción de agua a partir del segundo ciclo y luego se estabiliza en un plateau a partir del tercer ciclo. En cambio, el APTES presenta un aumento de volumen progresivo y mínimo hasta el cuarto ciclo, y luego un aumento brusco al llegar al quinto, estabilizándose luego en el mismo valor que el MPTMS. Esta diferencia es muy importante a la hora de elegir un tratamiento protector, porque si bien la estabilidad dimensional final es la misma, la tasa de absorción de agua no lo es, por lo cual dependerá de la exposición de la madera a utilizar, cuál de estos se utilizará: por ejemplo, si es una madera que estará en contacto con una superficie con humedad relativa alta y en posición longitudinal respecto al eje (perpendicular a la superficie) se deberá utilizar el APTES o las mezclas, ya que disminuye la tasa de absorción de agua, lo cual es lo que prima en la madera cuando las fibras están perpendiculares a la fuente de humedad (absorción capilar); mientras que si el tratamiento es para una madera que se encuentre paralelamente a la fuente de humedad, o solo a exposición de humedad ambiente, el MPTMS (el de mayor cambio volumétrico) será también eficiente [53-58]. 

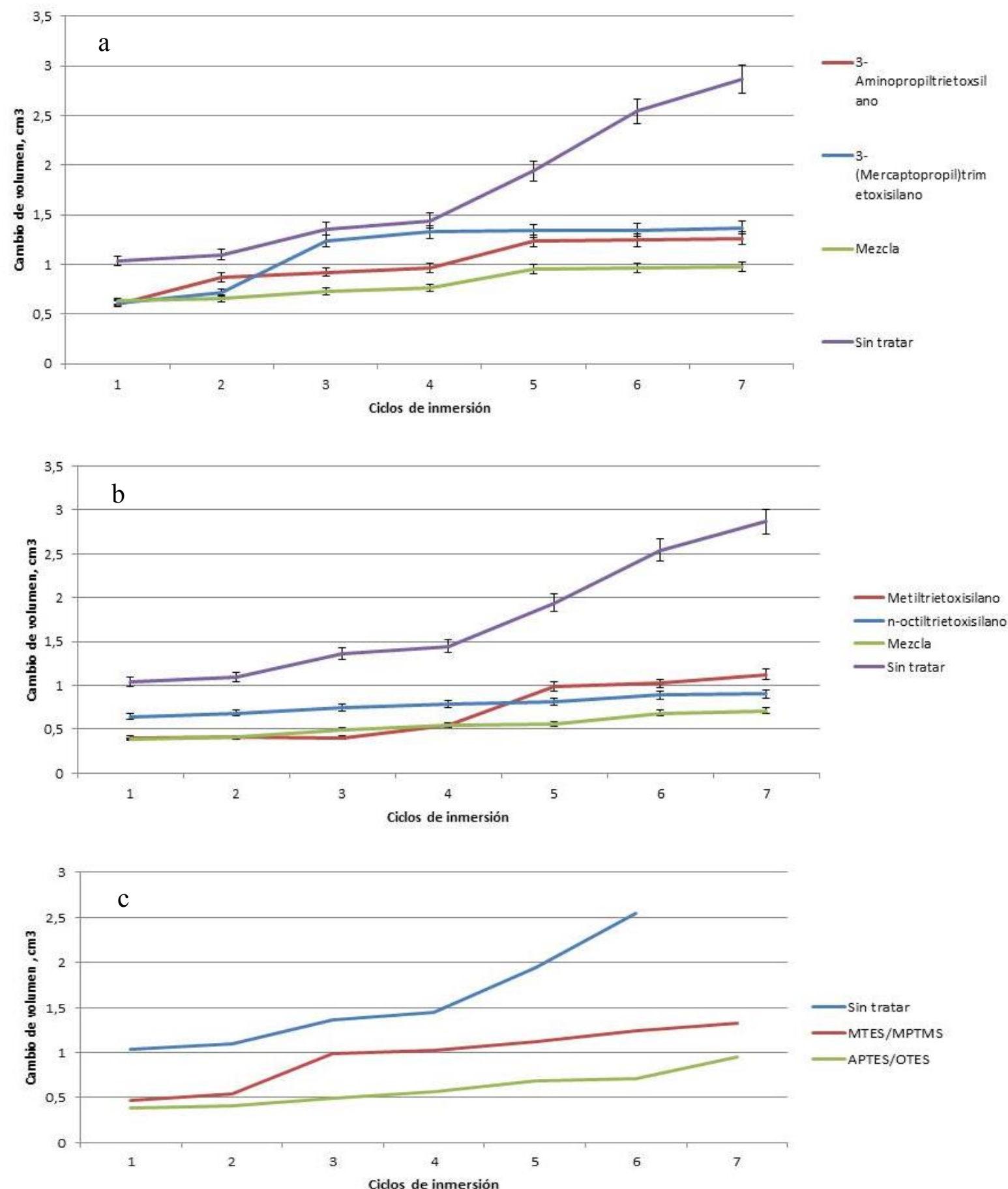

Figura III.14 Eficiencia hidrorrepelente de los impregnantes basados en silanos a) APTES y MPTES y sus respetivas mezclas, b) APTES y MPTES y sus respetivas mezcla, c) APTES/OTES y MTES/MPTMS

En cuanto a la mezcla, además de ser la mejor en cuanto a mantenimiento de estabilidad dimensional también lo es en la regulación de la tasa de absorción de agua, ya que se observa que 
la curva posee aumentos con pendientes mínimas y estables a lo largo de los ciclos, haciendo que este sea el mejor las formulaciones individuales.

La diferencia entre estos dos silanos estaría dada por la presencia del n-tiol del MPTES, este es un compuesto que contiene el grupo funcional formado por un átomo de azufre y un átomo de hidrógeno (-SH). Siendo el azufre análogo de un grupo hidroxilo (-OH), este grupo funcional es llamado grupo tiol o grupo sulfhidrilo. El átomo de azufre de un tiol es muy nucleofílico (más que el alcohol), por ello es que el mercapto al ser un grupo $\mathrm{S}-\mathrm{H}$, tiende a comportarse como un radical libre por resonancia electrónica debido al momento dipolo entre ambas moléculas, esto generaría una modificación en la cinética del proceso sol-gel, generando una menor reacción con la madera y por lo tanto refleja una menor eficiencia hidrorrepelente que APTES. APTES tiene un el grupo organofuncional, $\mathrm{NH}_{2}$ que favorece a las reacciones de hidrolisis y condensación del proceso solgel y en la activación de la madera, por lo que esto se refleja en el comportamiento obtenido.

Dado estas dos situaciones, en la mezcla, la conjunción de ambas propiedades generaría un manejo de la cinética de reacción del proceso sol-gel, que permitiría generar un polímero continuo, lo que se traduce en una mejor hidrorrepelencia y estabilidad dimensional [2, 38, 60-64].

En cuanto a MTES y OTES (Figura III.14.b) se observa que el cambio máximo de volumen obtenido es de $1,0 \pm 0,2 \%$ obtenido con el tratamiento de MTES y un mínimo de $0,72 \pm 0,15 \%$ con el uso de la mezcla de MTES y OTES, al igual que el otro par de silanos, se observa una mejora cuando son mezclados. En cuanto a la tasa de absorción de agua se puede observar que tanto el OTES como su mezcla con el MTES tiene el mismo comportamiento, en cuanto a la estabilización dimensional pero mejora sustancialmente la hidrorrepelencia, por lo que podría atribuirse entonces un efecto sinérgico entre ambos compuestos. En el caso de solo MTES, la tasa de absorción es elevada a partir del cuarto ciclo de inmersión, estabilizándose recién en el quinto ciclo, para luego continuar en una tendencia de aumento de volumen. Esto último, corrobora que la hidrorrepelencia en la mezcla está dada por OTES como era de esperar, dada su cadena hidrocarbonada larga como sustituyente y que la estabilización dimensional se logra con la presencia de ambos. Estos resultados indican que la madera modificada sólo con MTES, conformaría un recubrimiento denso y compacto sobre la pared celular como se observó en las imágenes del SEM pero no impediría la entrada de agua en estado líquido por no presentar elevada hidrorrepelencia. Por ello es que, con la mezcla con OTES mejora el comportamiento ya que se obtiene un recubrimiento compacto pero 
con más hidrofobicidad dada por las propiedades individuales de OTES. Por su parte, la madera tratada sólo con OTES también formaría un recubrimiento reactivo pero discontinuo por impedimento estérico con características hidrofóbicas. Por ello, es que en su mezcla mejora el comportamiento, ya que se logra una estabilización dimensional por poder cubriente de mayor área superficial de las paredes celulares e hidrorrepelencia por la presencia de la cadena hidrocarbonada de OTES [55, 59-65].

Por otro lado, se puede afirmar que las formulaciones con MTES únicamente son hidrorrepelente pero no estabilizador dimensional, ajustándose más a un sistema protector del tipo II.

En general entonces, la mejor performance tipo III está dada por MTES/OTES, OTES APTES/OTES, APTES/MPTMS, APTES, MTES/MPTMS y MPTMS. Acotando más la exigencia del sistema protector el mejor sistema es la mezcla APTES/MPTMS ya que tiene buena eficiencia y es el de menor costo (el OTES es uno de los más costos dentro de los silanos disponibles en el mercado seguido por MTES).

La performance de los nanocompuestos se observa en la Figura III.15. Estos resultaron mejores como tratamiento hidrorrepelentes que los silanos o sus oligómeros (Figura III.14) ya que se obtuvo un cambio de volumen máximo de $0.8 \pm 0,13 \%$ y un mínimo de $0,5 \pm 0,11 \%$ respecto a los casi $3 \pm 0,09 \%$ de la madera sin tratar. Dentro de este grupo se observa que los dieron mayor estabilidad dimensional fueron el nanodióxido de sílice y el nanoóxido de cobre, teniendo una tasa de absorción de agua mínima (casi no presenta cambios de pendiente las curvas, o cambios muy progresivos a lo largo de los ciclos).

No se obtuvo lo mismo en el caso de la nanoplata ni del nanoóxido de zinc, donde se observa que el primero tiene una alta tasa de absorción en los primeros ciclos y luego entra en un plateau, mientras que el segundo la tasa máxima de absorción de agua lo presenta entre el cuarto y quinto ciclo, siendo esto un mejor comportamiento hidrorrepelente. 


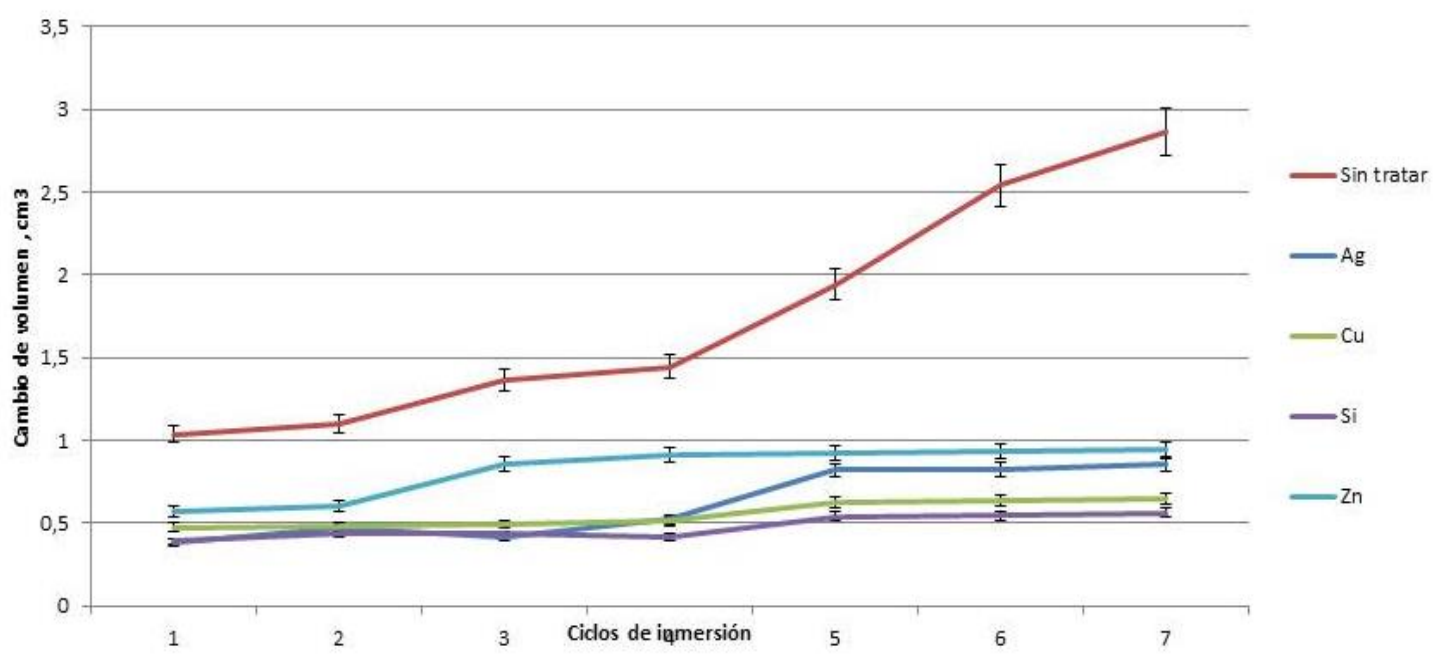

Figura III.15 Eficiencia hidrorrepelente de los impregnantes basados en nanocompuestos

Posiblemente este comportamiento este dado por lo observado en el SEM (Figura III. 3) donde se observa una distribución uniforme de nanopartículas a lo largo de las fibras, lo cual, implicaría un cambio en la capilaridad de la madera: las nanopartículas obstruyen los $-\mathrm{OH}$ de la celulosa encargados de absorber agua mediante la formación de puentes de hidrógeno, por lo tanto, las moléculas de agua no se adsorben atribuyendo a la hidrorrepelencia y a la estabilidad dimensional. Este último por ausencia de aumento de volumen. En cuanto a los silanos, la diferencia en comportamiento está dada porque en el caso de los silanos, la hidrorrepelencia está dada por oclusión de capilaridad por formación polimérica: ahora la hidrofilia está dada entonces por el composite que se ha formado y no por la madera per sé. Además, la estabilidad dimensional, en el caso de los silanos, también está dada por la estructura polimérica que limita su expansión natural, dado las estructuras intra e intermoleculares observadas en las imágenes SEM y MO, Figura III. 6 y 7. Esta diferencia en el mecanismo propuesta, explicaría porque los nanocompuestos son más eficientes que los silanos [12, 65-72].

Por último, se estudió la performance de la mezcla de silanos y nanocompuestos, Figura III.16. Esto se realizó bajo la hipótesis de que podría haber algún efecto sinérgico entre estos dos componentes los cuales individualmente han sido útiles para proteger a la madera del agente abiótico en cuestión. 

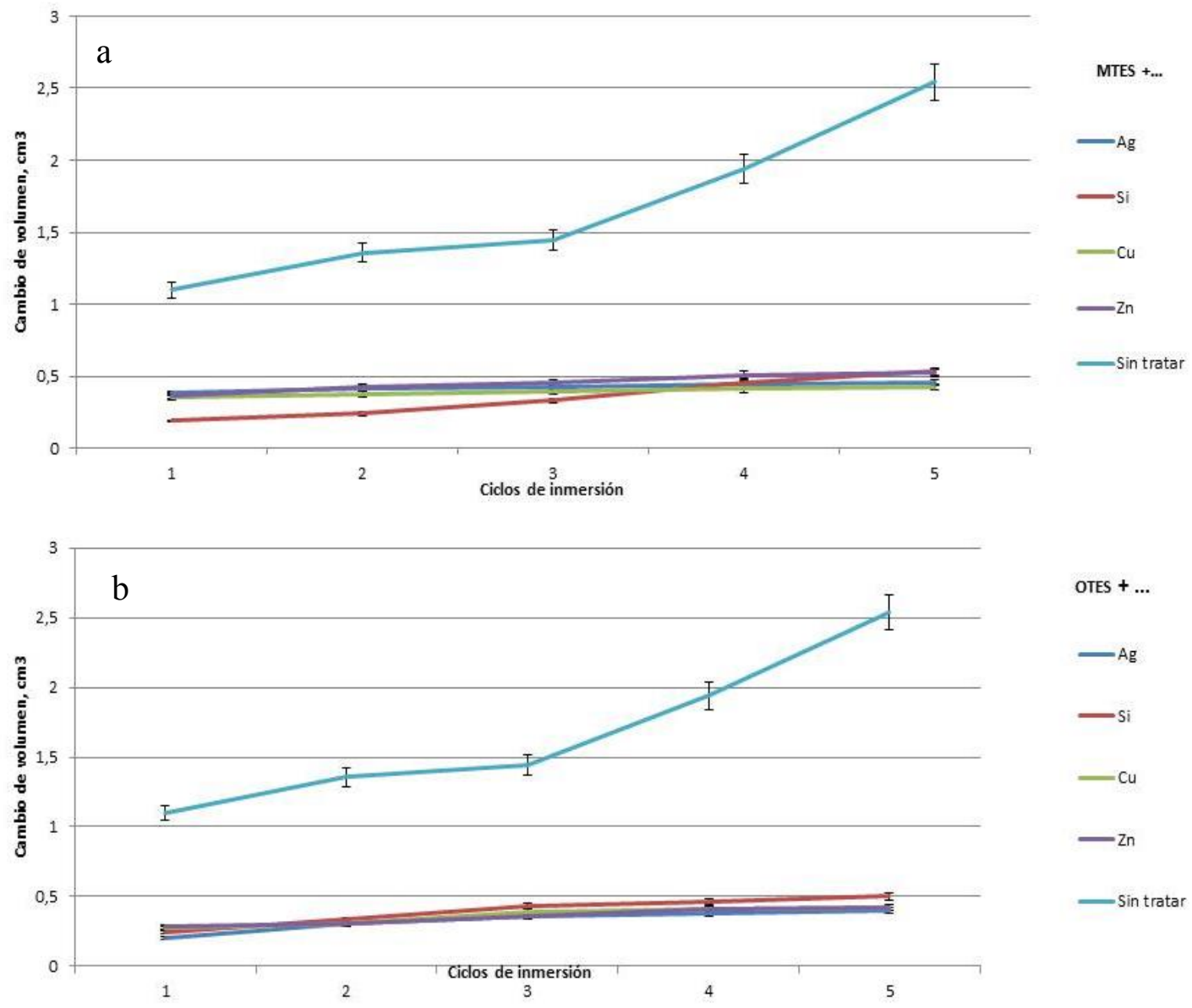

Figura III.16. Eficiencia hidrorrepelente de los impregnantes basados en la mezcla de silanos y nanocompuestos a) MTES y b) OTES.

Se puede observar que la hipótesis se cumple ya que independientemente de la mezcla el comportamiento del sistema es el mismo: tanto para ambos silanos como para todos los nanocompuestos en cuestión el cambio de volumen máximo obtenido fue de $0,48 \pm 0,12 \%$ y la tasa de absorción de agua fue menor con respecto a cada uno de los tratamientos individuales. En este caso, la conjunción de ambas tecnologías generaría tales cambios que se comportan de manera independiente del origen químico de cada uno de los compuestos individuales, esto indicaría que hay un cambio en la capilaridad química y física tan eficiente que la absorción de agua es casi nula [70-76]. 
Con esto se puede concluir que la mezcla de los silanos y los nanocompuestos, son los mejores tratamientos para la hidrorrepelencia, actuando como estabilizadores dimensionales y reductores de la tasa de absorción de agua, en la misma proporción, algo que no es común de conseguir.

Por último, se analizó el cambio de volumen y la tasa de absorción de agua de los siloxanos comerciales, Figura III.17. En esta se puede observar que hay una mejora en la tasa de absorción de agua y en la estabilidad dimensional, pero se comporta como un Tipo II y con una eficiencia menor que los demás tratamientos.

Este mismo comportamiento se observó en el tratamiento de las maderas con silanos a pH neutro: ambos ejercen protección por efecto barrera (recubrimiento superficial), por lo que esto da una protección menos eficiente que la modificación química.

Esto se evidencia, en que todos los resultados fueron similares, independientemente del silano en cuestión, por lo tanto, es una protección meramente física la que se produce cuando hay una polimerización externa de silanos comportándose como una película de pintura.

En cuanto a los siloxanos, la diferencia radica en que estos ya están polimerizados en el envase y en que este además tiene aditivos tanto por la formulación madre como los de origen oleoso agregado para permitir una fácil aplicación, esto hace que el comportamiento sea menos eficiente que los silanos a pH neutro. Esto además, lleva a pensar que si bien no hay una gran activación del sistema, el proceso sol-gel se produciría a nivel superficial, habiendo interacción química con la madera.

Por último, se calculó el coeficiente de eficiencia de repelencia al agua (WA\%) y el coeficiente de eficiencia antihinchamiento (ASE\%), lo cual caracterizará a cada tratamiento, Figura III.18. Estos se correlacionan con el análisis de los gráficos de las Figuras III.14, III.15, III.16 y III.17. Se puede observar que, en todos los tratamientos, la eficiencia hidrorrepelente y la de antihinchamiento se correlacionan, afirmando la aseveración que son tratamientos hidrorrepelentes y estabilizadores.

En orden de mejor performance a menor performance de ambas características los mejores son la mezcla silano/nanopartícula donde presentaron un coeficiente ASE de 81,2\%, y un coeficiente 
WA de $18,45 \%$ de seguido por la mezcla de silanos, silanos individuales y por último, los de peor performance, los siloxanos comerciales quienes presentaron un coeficiente ASE de $35,2 \%$ y un coeficiente WA $67,5 \%$.
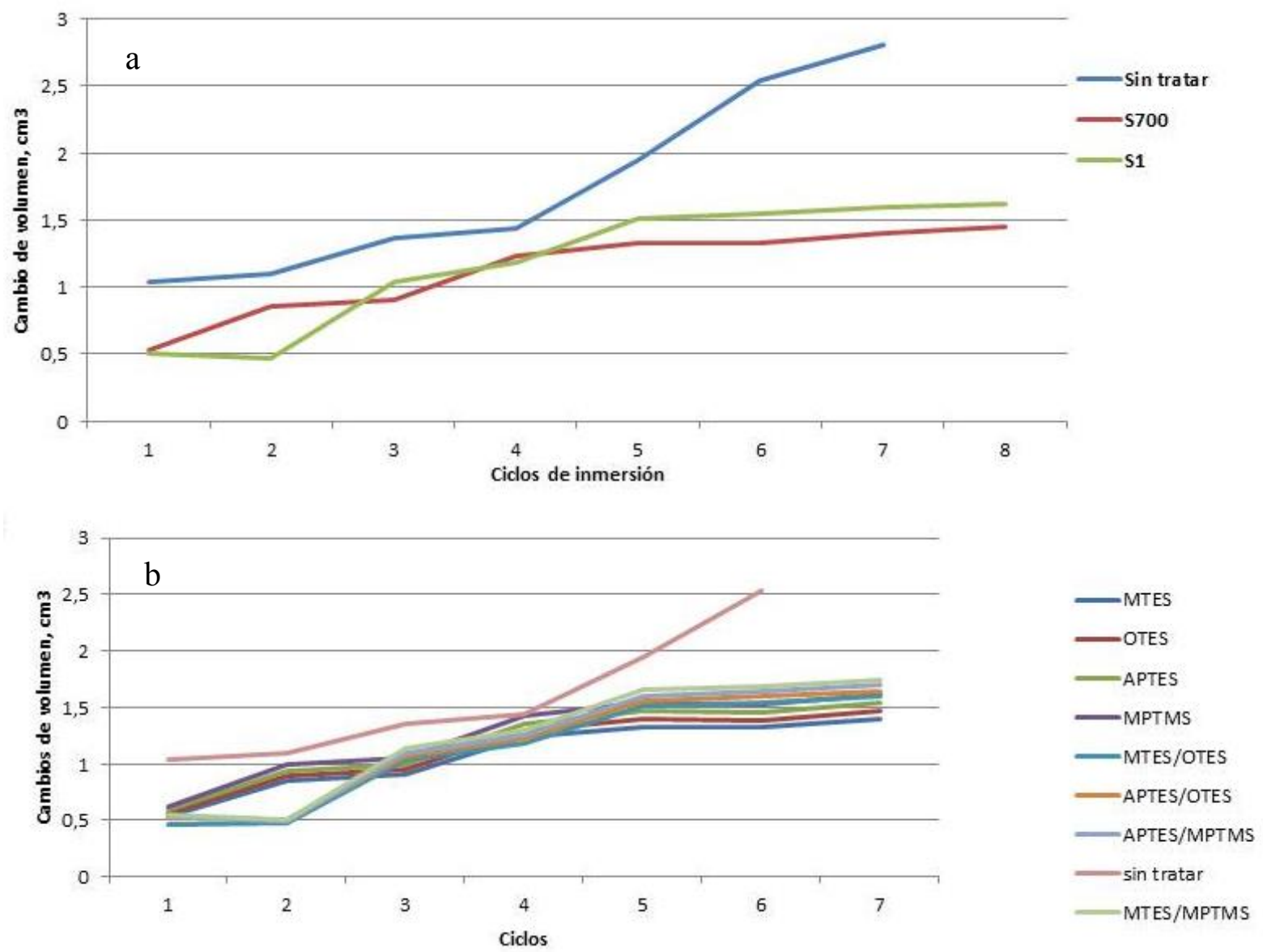

Figura III.17. Eficiencia hidrorrepelente de los impregnantes basados a) siloxanos comerciales y b) silanos a pH neutro

Se concluye entonces que todos los tratamientos son eficientes para la hidrorrepelencia y la estabilidad dimensional en mayor o menor medida respecto a la madera sin tratar. Además, se observó que cuando existe modificación química de la madera su performance es mejor que una cubierta superficial aunque tenga el mismo origen químico (caso de silanos a diferentes $\mathrm{pH}$ ). Esto último reafirmaría entonces que el método de protección eficiente es un cambio químico y físico 
de las traqueidas lo cual anularían su capilaridad y por lo tanto generarían un material con propiedades completamente diferente a las naturales.
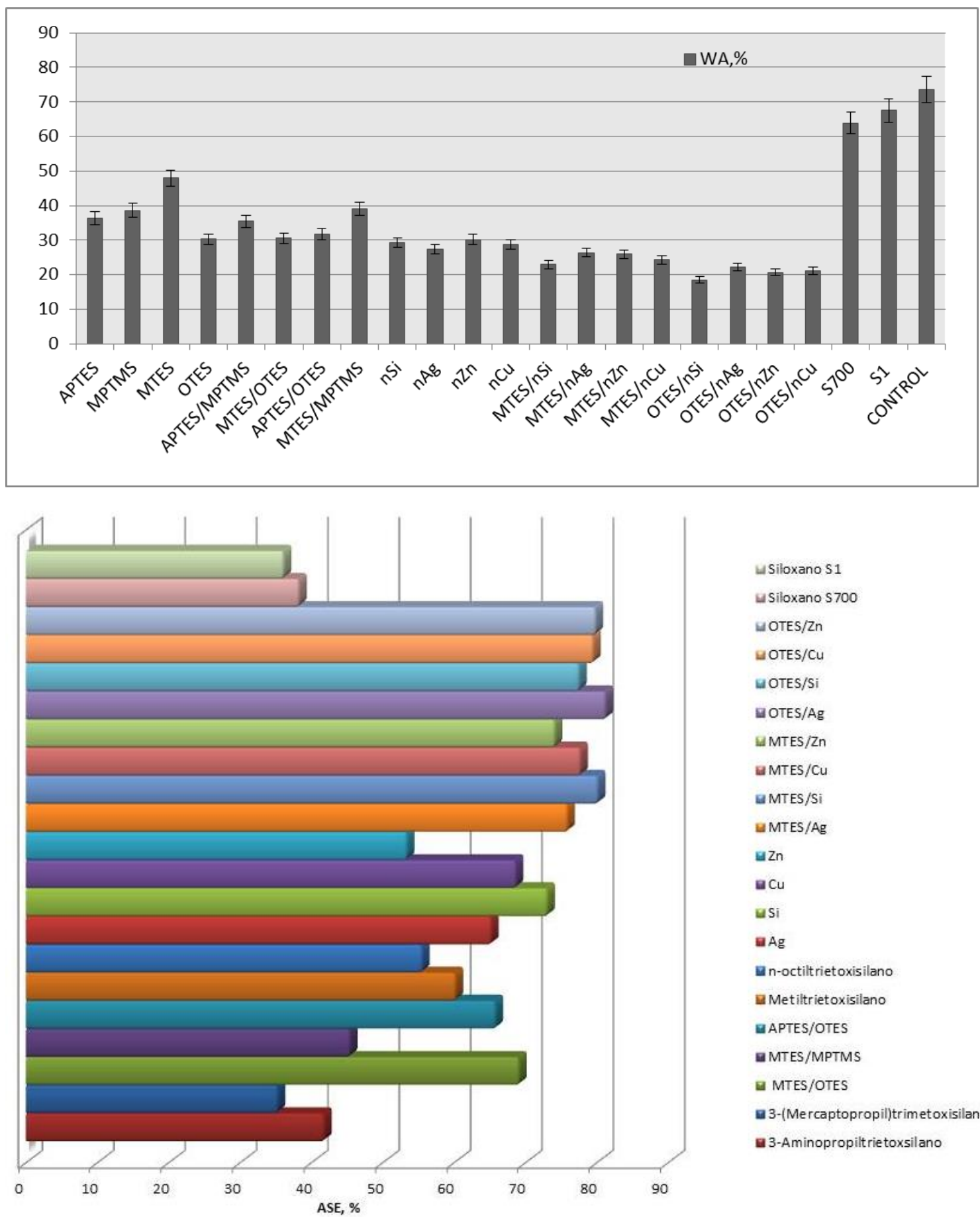

USiloxano S1

uSiloxano 5700

$\square O T E S / Z n$

$\triangle O T E S / C U$

MOTES/Si

$\square O T E S / A g$

LMTES/Zn

MTES/CU

MTES/Si

I MTES/Ag

$\square \mathrm{Zn}$

$\mathrm{aru}$

asi

ag $\mathrm{Ag}$

n-octiltrietoxisilano

Metiltrietoxisilano

$\square$ APTES/OTES

MTES/MPTMS

a MTES/OTES

3-(Mercaptopropil)trimetoxisilano

3-Aminopropiltrie toxsilano

Figura III.18. Coeficientes de eficiencia antihinchamiento (ASE\%) y absorción de agua (WA\%) 
Por otro lado, también reafirma la importancia del correcto manejo de las variables de formulación: los principios activos mal empleados pueden perder de manera total y parcial su potencialidad protectora si no se tiene encuentra las variables ambientales en las cuales se van a exponer. Por último, también hay que recalcar la variabilidad del sustrato: la madera posee diferencias estructurales a nivel celular tanto entre especies como en la misma especie con variables en el crecimiento, tal como se mencionó en el Capítulo I.

Partiendo entonces de un objeto de estudio variable, se priorizó la formulación y desarrollo de sistemas también variables para que estas puedan ser ajustables a los diferentes sustratos (si tomamos a cada variabilidad de la madera como un sustrato diferente). El estudio exhaustivo que presenta esta tesis en cuanto a variables de formulación, estructura de la madera y resultante comportamiento frente a agentes degradadores, permite que esta sea una base de conocimiento de formulación y protección de la madera y no solo un estudio acotado de algunos sistemas de protección estancos.

\section{4 Resistencia al biodeterioro}

Las muestras de madera se expusieron a las cuatro especies de hongos xilófagos mencionadas en el capítulo III, representando a cada una de las pudriciones en condiciones de laboratorio, dos de estos agentes son autóctonas ( $P$. chaquensis y Chaetomium globosum) y fueron extraídas de sus hábitats naturales. La exposición de la madera a los agentes degradantes se realizó siguiendo los lineamientos generales de la norma ASTM D 2017 [77].

La evaluación del comportamiento se determinará gravimétricamente por pérdida de peso y por observación a micro y macro escala del estado del sustrato.

El proceso de aislamiento de las especies se describe en la Figura III. 19. El aislamiento de especies autóctonas incluyó la toma de muestras de la especie en su hábitat natural (se buscó madera con proceso de deterioro activo): una de las especies fue extraída de quebracho colorado, listón de madera perteneciente a la mesa de giro de locomotoras de Estación Meridiano V, de la Ciudad de La Plata identificada como Phenillus chaquensis y otra de las especies utilizada fue una aislada de un tocón de Roble situado en la Escuela Policial Juan Vucetich, frente al edificio principal, ubicada 
en Parque Pereyra Iraola, partido de La Plata, esta especie se identificó como Chaetomium globosum en el INMIBO tal como se indicó en el Capítulo I. Mientras que la tercera Trametes versicolor especie fue obtenida de cepario y esta fue escogida por ser una especie contemplada en la norma.

Los aislamientos se realizaron bajo los lineamientos de las técnicas de Nobles [78]. Básicamente mediante el cultivo de trozos de maderas con parte de micelio en placas con PDA (agar dextrosa de papa) en una primera instancia como una separación inicial y luego por morfología micelar y tiempo de crecimiento, se eligieron micelios para inocular en placas de cultivo con medio MEA (agar con extracto de malta), más específico para este tipo fúngico.

AISLAMIENTO DE ESPECIES AUTÓCTONAS
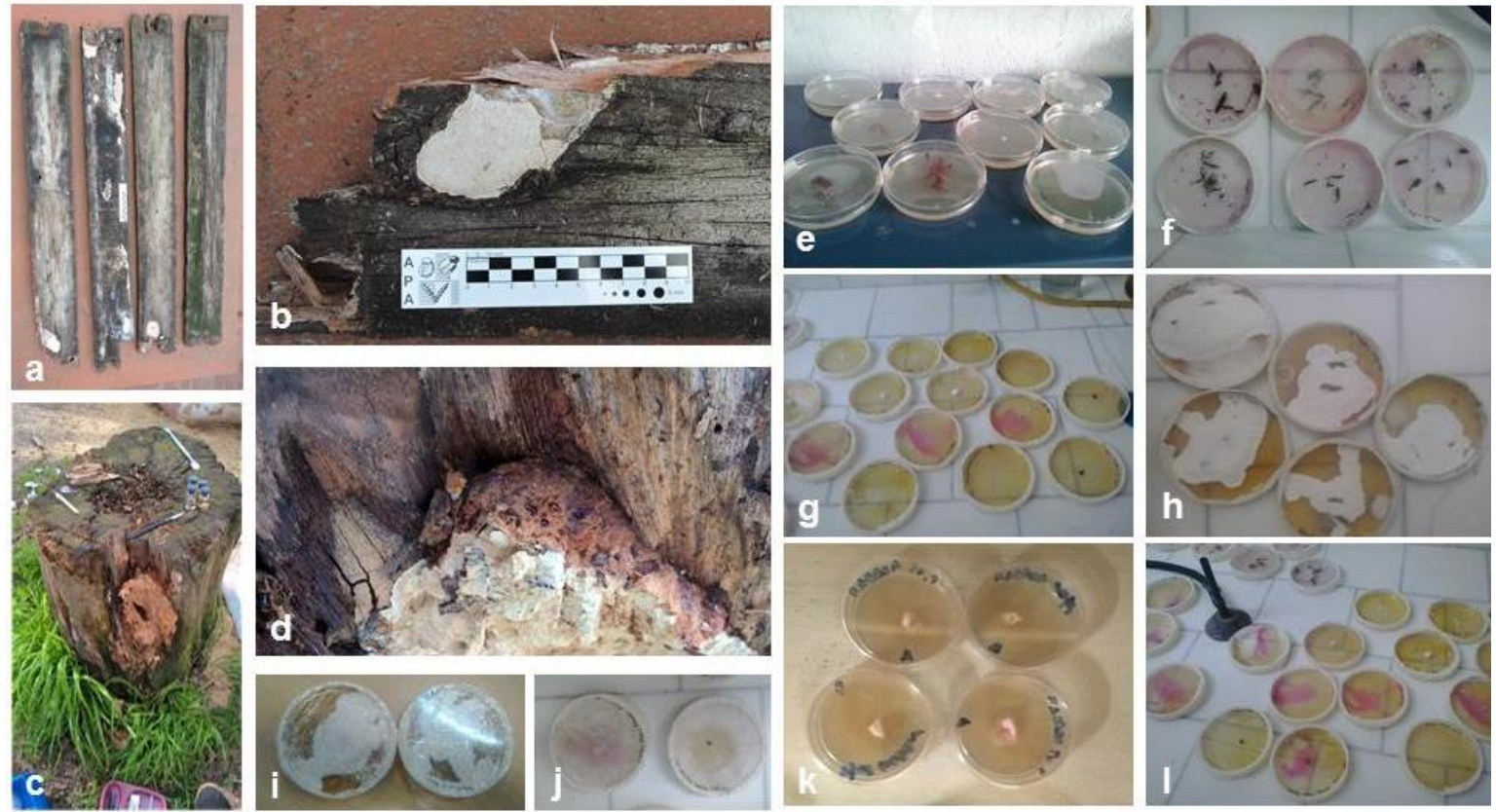

Figura III. 19. Aislamiento de especies autóctonas: Incluyo el aislamiento de su hábitat natural (a-d, a$b$ pertenece a $P$. chaquensis y c-d al $C$. globosum), mediante el cultivo de trozos de maderas con parte de micelio en placas con PDA (e, $f$ ), luego se pasaron a placas de cultivo con medio MEA y el colorante rosa de bengala (g-l)

En una segunda ronda de plaqueo, se agregó el colorante rosa de bengala utilizado como limitante del crecimiento del micelio, siguiendo el mismo criterio de elección. El uso del colorante se debe 
a que es un inhibidor fungistático de crecimiento, es decir limita el mismo haciendo que el desarrollo micelar sea más lento, por lo cual pasar lo cual evita la colonización de toda la placa de la o las especies presentes facilitando el aislamiento. Luego de sucesivos plaqueos, se logró obtener la especie de hongo xilófago deseado [79-83].

Para corroborar si se trataba de una especie viable de degradar, esta se cultivó en medio líquido con extracto de malta y se inoculó en madera desde la placa para ver su viabilidad y especificidad de sustrato, Figura III.20.

GENERACION DE BIOMASA EN MEDIO DE CULTIVO Y EN MADERA (VIABILIDAD DE CRECIMIENTO)
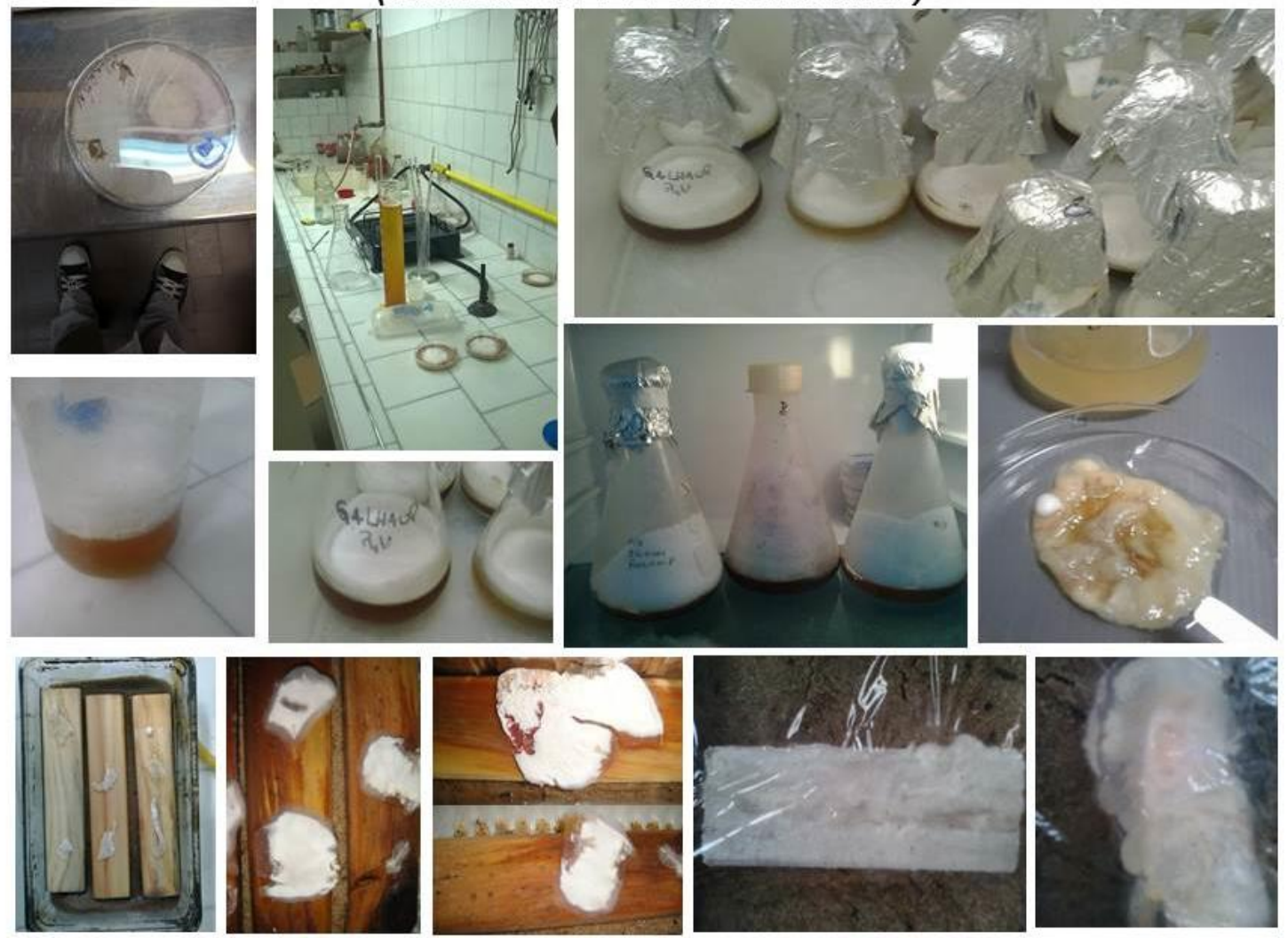

Figura III.20. Obtención de biomasa mediante cultivo en medio líquido (arriba) y reservorio en maderas (abajo)

Las muestras de madera fueron cultivadas durante 2 meses a temperatura y humedad controladas, visualizando su crecimiento por cubrimiento de la probeta de madera con el micelio. 
Una vez pasado ese período, se observó la viabilidad de degradación mediante la punción de la madera con una aguja de disección, con el fin de evaluar la dureza de la madera expuesta. Se eligió este método para que sea el menos perturbador para el crecimiento y desarrollo del ser vivo.

La corroboración entonces era medir la profundidad que podía insertarse la aguja con respecto a la madera sin tratar, dado que la pérdida estructural generada por esos organismos, situación que provoca que la madera se vuelva frágil y/o corchosa.

Una vez corroborado, solo se mantuvo la generación de biomasa en medio líquido, mediante recambios de media cada una semana y refrigerando luego de replicar. La madera paso a cuidados de cultivo como reservorio natural de la especie. Ya obtenida la biomasa necesaria, se procedió a inocular las maderas según indica la norma, Figura III.21. En la Figura se muestra la forma de inoculación realizada con una de las especies (P. Chaquensis) y cantidad de muestras por inoculación empeladas: se utilizaron en total 240 muestras inoculando 80 probetas por especie. Las probetas una vez inoculadas fueron cultivadas a humedad y temperatura controlada $\left(25 \pm 2{ }^{\circ} \mathrm{C}\right.$, $60 \pm 5 \% \mathrm{HR}$ ) durante 16 semanas.

El deterioro producido se midió gravimétricamente. Además, se realizó un análisis visual del tipo de efecto biocida de los tratamientos: se determinó que un tratamiento era fungiestático cuando hay desarrollo en etapas tempranas del cultivo, pero este no prolifera en el tiempo y fungicida cuando hay inhibición inmediata del crecimiento.

Los resultados se muestran en la Figura III. 22, donde se representa el porcentaje de pérdida de peso de cada tratamiento a las 16 semanas de exposición de cada una de las especies que representan los tres tipos de pudrición más importantes. 


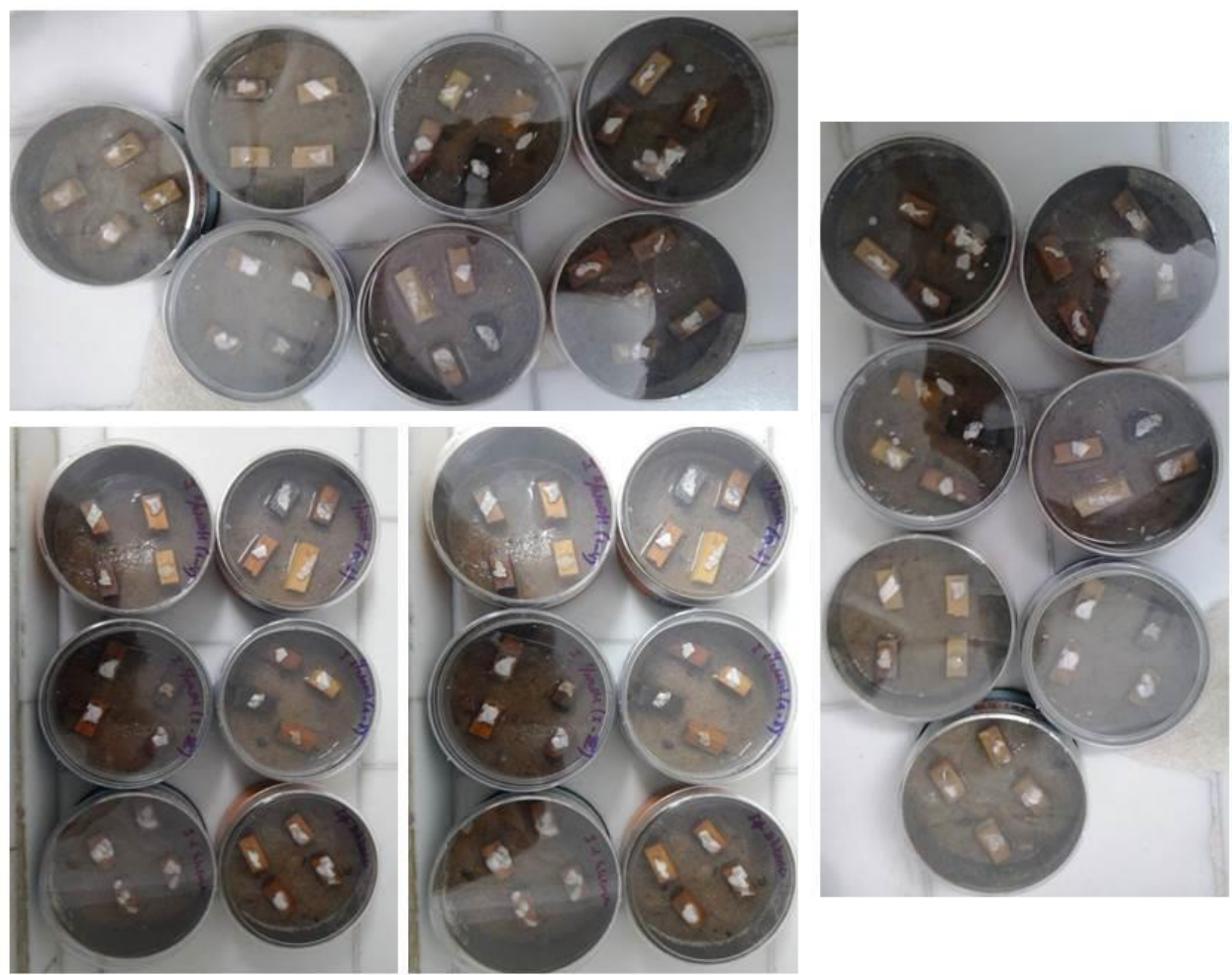

Total de muestras tratadas: 80 (con duplicados)

Blancos: 24 (incluyendo los diferentes pHs)

Muestras totales por ensayo: 104

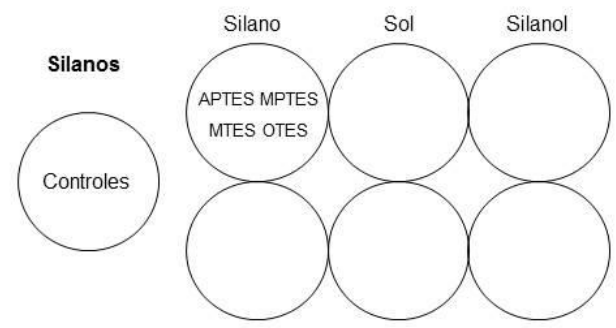

Nano

$\mathrm{pH}$ Acido $\mathrm{pH}$ bàsico
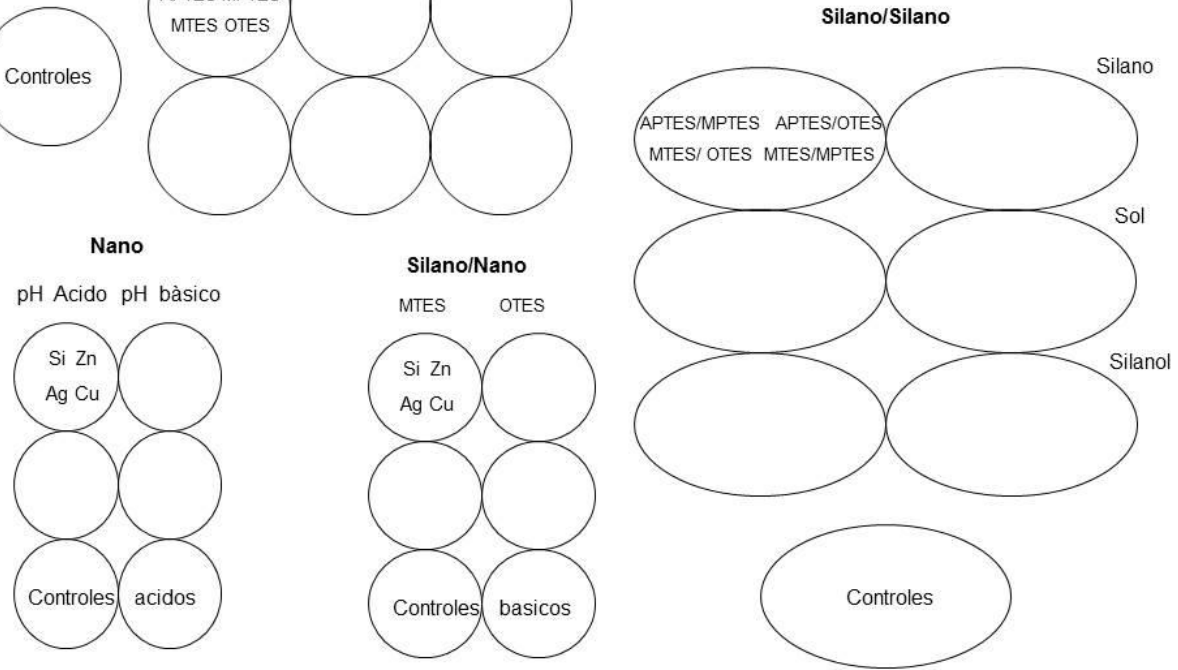

Figura III.21. Inoculación de muestras de madera con las especies fúngicas que representan cada una de los principales tipos de pudrición que generan pérdida estructural: T. versicolor (obtenida de cepario) y dos autóctonas aisladas de su hábitat natural. 
Se puede observar que en todos los casos los tratamientos redujeron la pérdida de masa de todas las probetas, independientemente de la especie a la que fue expuesta, por lo tanto, se puede afirmar que todos los tratamientos tienen la capacidad de proteger a la madera de la degradación fúngica, independientemente del tipo de pudrición que este produzca. Esto último, lleva a pensar que la modificación química efectivamente se produce en las diferentes capas de la pared celular, ya que la diferencia de pudrición, está dada básicamente por el polímero que los hongos atacan [84-98].

Dentro de las especies, se puede observar analizando la pérdida de peso diferencial de los controles según a la especie que fue expuesta que la más agresiva es $P$. Chaquensis (Pudrición blanca degrada lignina), seguido de T. versicolor (Pudrición parda o cubica degrada celulosa) y por último C. globosum (pudrición blanda, degradación de laminillas medias). Este orden se condice con el tipo de pudrición identificada q estos producían.

De un análisis global por tipo de impregnante implementado se pudo discriminar que grupo se obtiene mejor performance en resistencia a la degradación biológica, Figura III.25.

En el gráfico se muestra el promedio obtenido de la pérdida de masa luego de las 16 semanas de exposición de las variables de principios activos de las formulaciones. Para esto se promediaron las pérdidas de peso de las tres pudriciones para cada variable de formulación. Este análisis permite discriminar que la mejor performance en cuanto a resistencia fúngica está dada por la mezcla de silanos/nanocompuestos, seguido de los nanocompuestos, luego por los silanos y por último por lo siloxanos.

En la Figura III.23. se puede observar que las formulaciones siguen el mismo patrón de performance, independientemente del tipo de pudrición: la menor pérdida de masa son las basadas en la mezcla de silanos/nanocompuestos (con pérdidas de $3,13 \pm 2,34 \% ; 2,45 \pm 2,23 \%$ y $1,58 \pm 0,96 \%$ para $P$. chaquensis, $T$. versicolor y C. globosum respectivamente), seguido por las formulaciones basadas en nanocompuestos (con pérdidas de $8,65 \pm 1,73 \% ; 5,81 \pm 3,2 \%$ y $4,65 \pm 0,49$ $\%$ para $P$. chaquensis, $T$. versicolor y $C$. globosum respectivamente) seguido los silanos (con

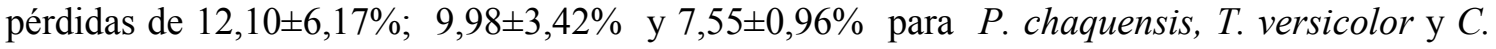

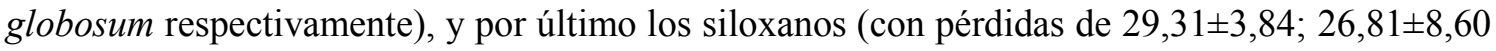
y $9,88 \pm 1,06 \%$ para $P$. chaquensis, $T$. versicolor y $C$. globosum respectivamente). 


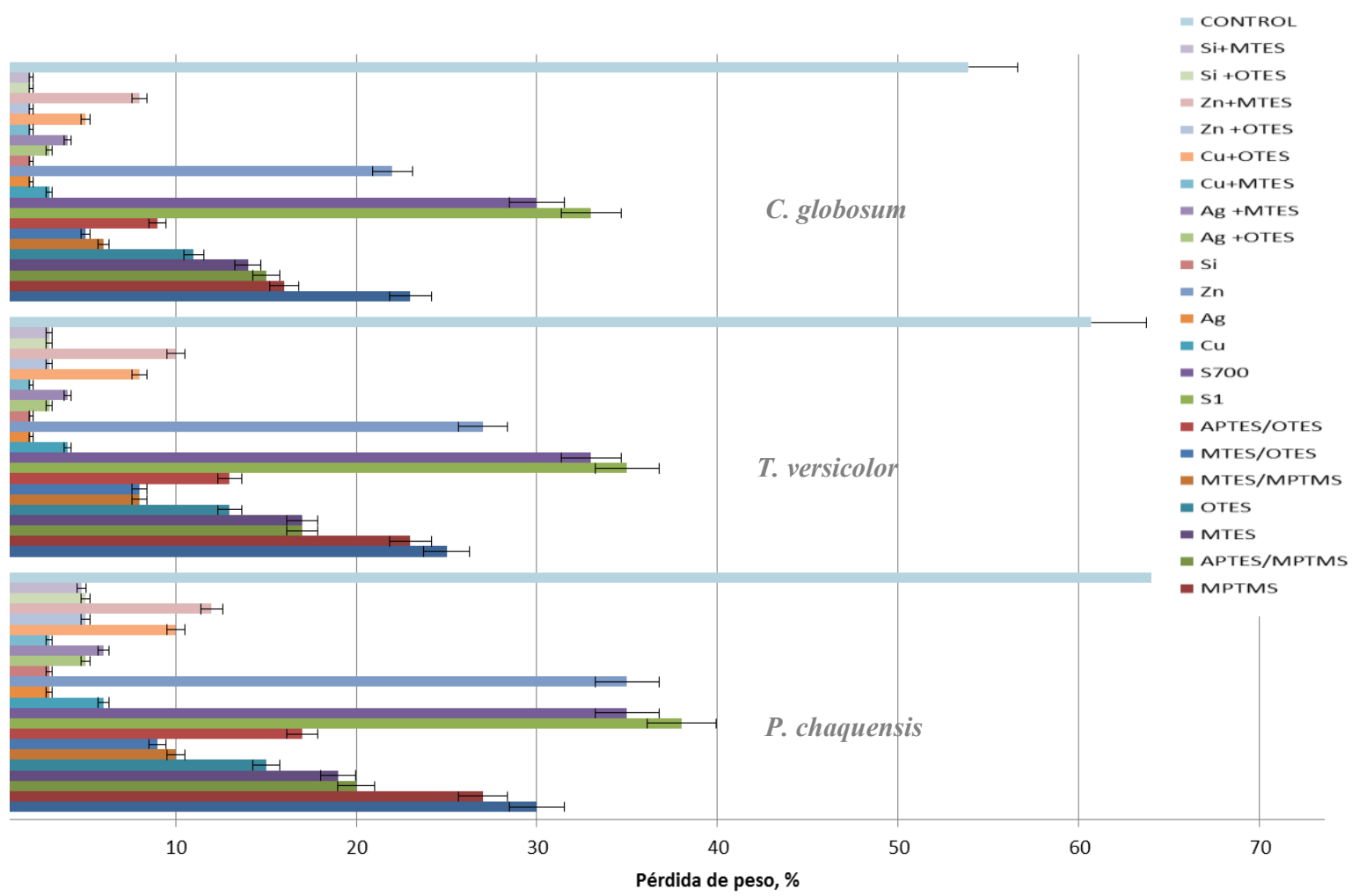

Figura III. 22. Porcentaje de pérdida de peso de cada tratamiento a las 16 semanas de exposición de cada una de las especies que representan los tres tipos de pudrición más importantes.

En cuanto al crecimiento diferencial, se pudo observar que dentro de los tratamientos hay diferencias en cuanto al tipo de protección: todas las formulaciones que presentaban nanopartículas como principio activo presentaron un comportamiento fungicida, mientras que aquellas formulaciones a base de silanos o alcóxisilanos presentaron un comportamiento fungiestático, Figura III. 24. Este comportamiento se condice con la mayor pérdida de masa de los fungiestáticos respecto a los de comportamiento fungicidas.

Por último, la Figura III. 25 muestra la degradación según cada una de las formulaciones, donde se presenta el promedio de las pérdidas de masa de las tres pudriciones. El listado presente a la izquierda de las barras es el orden decreciente de pérdida de masa de las probetas, es decir orden creciente de performance de tratamiento en cuanto a capacidad de resistencia a la degradación fúngica. 

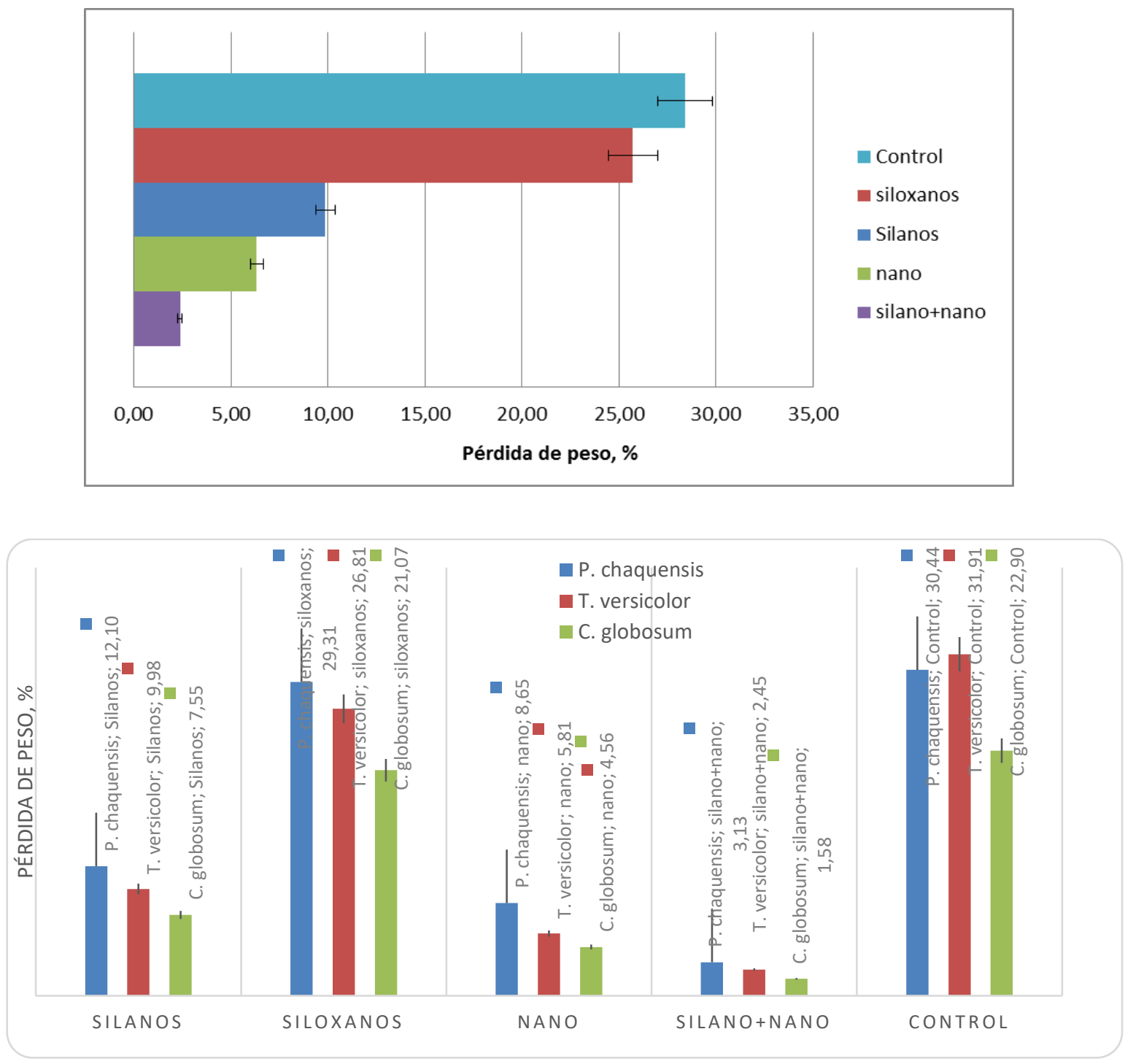

Figura III.23.Porcentaje de pérdida de peso a las 16 semanas de exposición los principios activos de las formulaciones para todas las pudriciones (arriba) y discriminando por tipo de pudrición (abajo)

De este análisis, se puede observar que en general la mejor performance está dada por las formulaciones con nanopartículas (solas o en mezcla con silanos), seguido por la mezcla de silanos, tal como se observó en el análisis global y en concordancia con su comportamiento fungicida o fungiestático. 

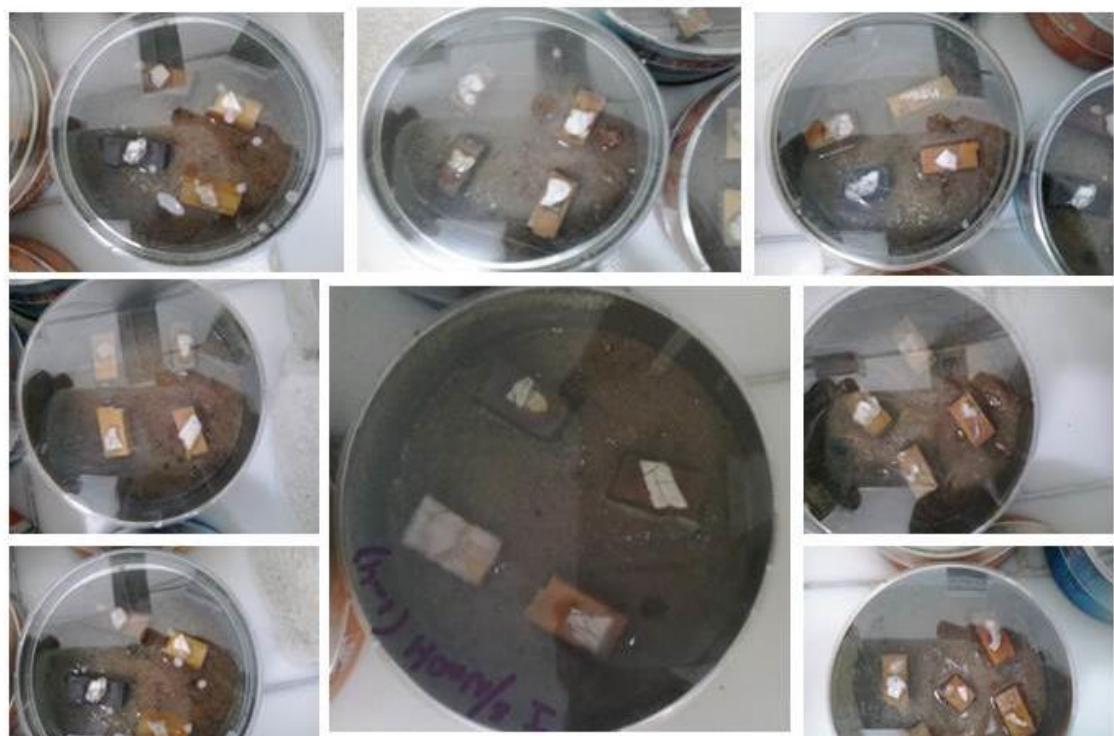

PROTECCIÓN FUNGICIDA
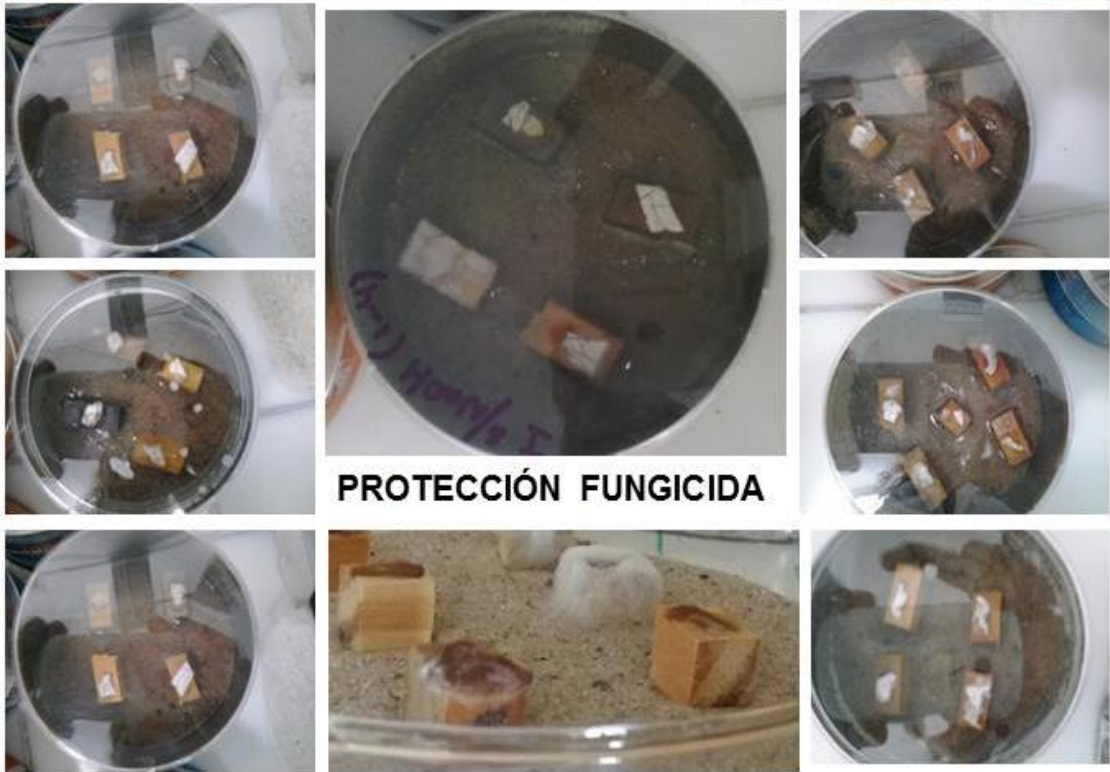

PROTECCIÓN FUNGIESTÁTICA
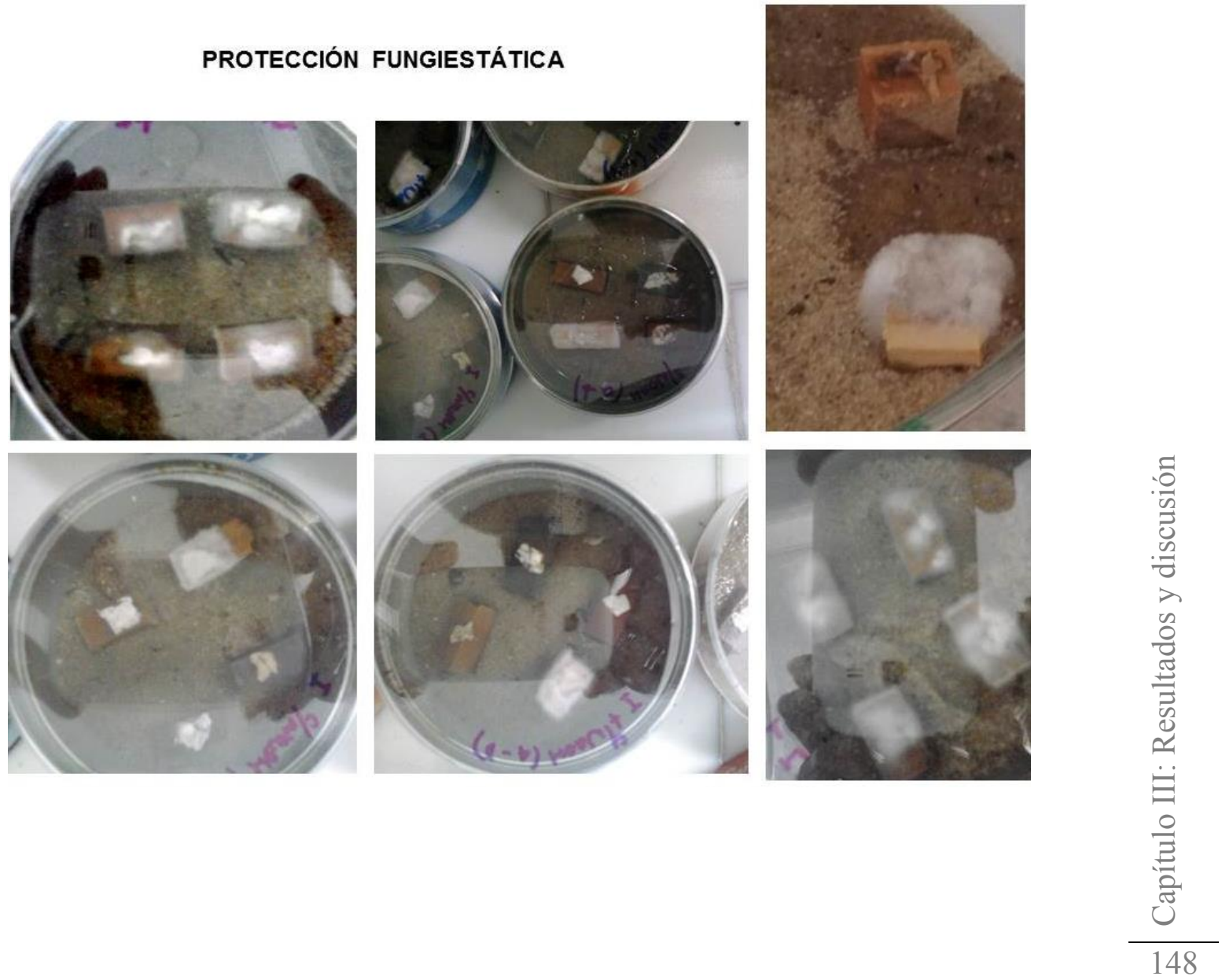


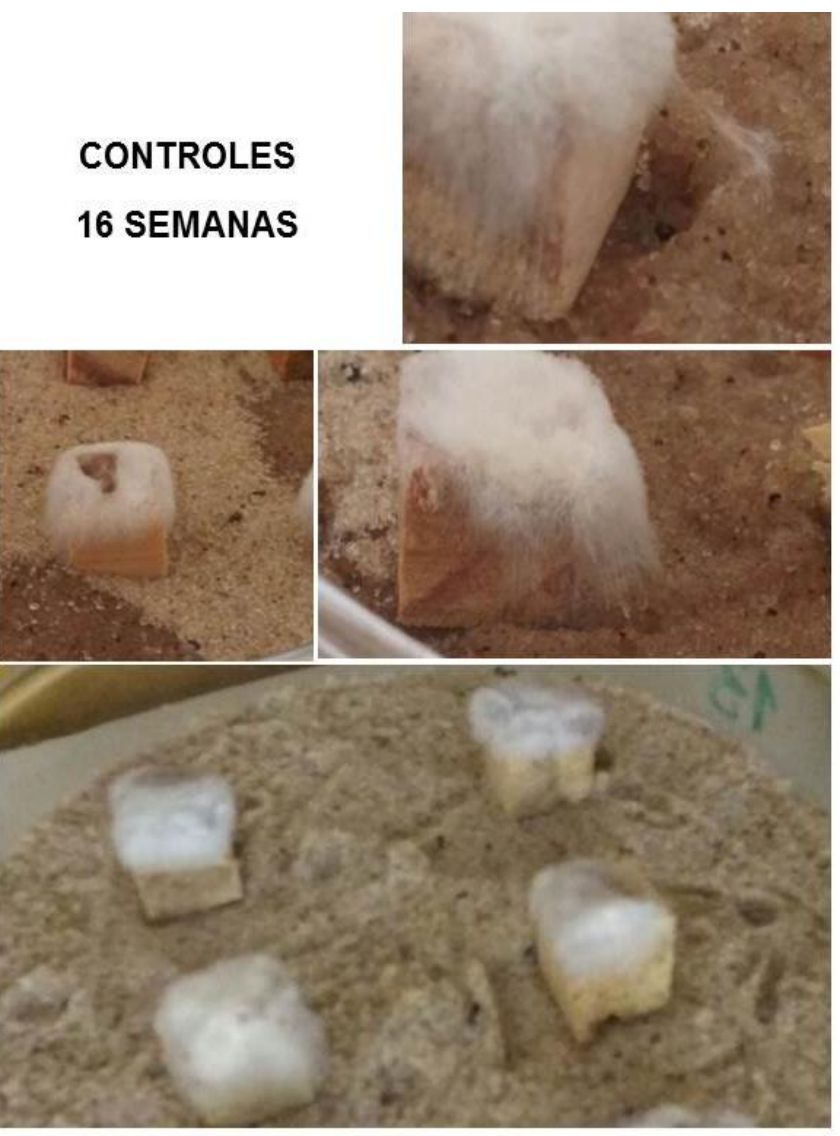

Figura III. 24. Desarrollo morfológico y crecimiento diferencial de las especies fúngicas frente a los diferentes tratamientos respecto a los controles (madera sin tratar)

En este caso la performance de los tratamientos frente agentes bióticos, se observa un efecto sinérgico al igual que en la hidrorrepelencia: cuando en la formulación se conjugan los silanos y los nanocompuestos, ya que se comportan con una performance mayor que la sumatoria de cada uno individualmente. Esto permite inferir, que la modificación química de la madera es la que estaría otorgando la resistencia a la degradación y no así la presencia de los compuestos. Esto quiere decir, que la protección en este caso se logra por el cambio en la estructura química y física de la madera, impide que el hongo pueda utilizarla como fuente de carbono: el cambio estructural y químico de los polímeros de la madera hace que no se produzca la hidrólisis enzimática, debido a que sus baterías no los "reconocerían" como sustratos enzimáticos (modelo llave-cerradura, el complejo enzima-sustrato, es muy específico, por lo cual cualquier cambio impide su función), impidiendo su desarrollo [99-101]. 


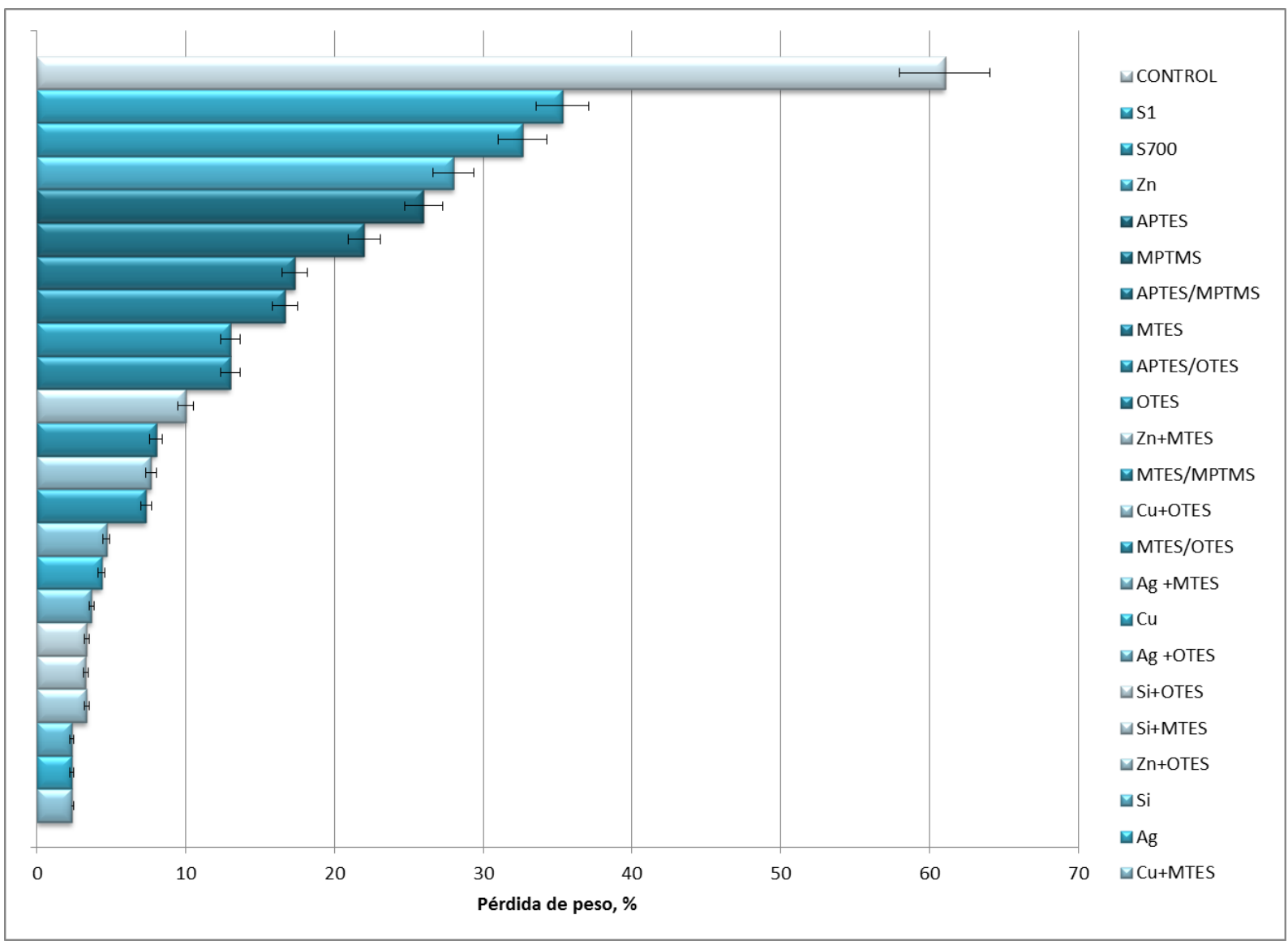

Figura III. 25 Pérdida de masa de cada una de las formulaciones, donde se presenta el promedio de las pérdidas de masa de las tres pudriciones. El listado presente a la izquierda de las barras es el orden decreciente de pérdida de masa de las probetas, es decir orden creciente de performance de tratamiento en cuanto a capacidad de resistencia a la degradación fúngica.

Por otra parte, habría una inhibición enzimática por impedimento estérico: las bacterias enzimáticas específicas (celulasas, peroxidasas, lacasas, etc.) son moléculas de tamaño considerado que se conoce necesitan una distancia mínima de $4 \AA$ entre el sitio activo y el sustrato para anclarse mediante puentes de hidrógeno y comenzar con las hidrólisis correspondientes [102]. Como se observó en el análisis de microscopía óptica y electrónica, se han generado microarreglos de los polímeros de la madera y polimerizaciones internas silano-madera-silano, nao-maderanano, madera-nano-silano-madera, según el caso, lo cual el espacio inter e intracelular fue acotado. Esto entonces evitaría la unión enzima-sustrato y en algunos casos también la penetración de las hifas que las transportan. 
Esta último, también explicarían las diferencias entre los comportamientos fungiestáticos y fungicidas: en los casos fungiestáticos las hifas pueden penetrar el sustrato de manera acotada, pero pueden hacerlo, por lo que el organismo comienza su desarrollo mediante oxidaciones no enzimáticas obteniendo energía rápida de fuentes de carbono disponibles que necesita para generar su batería enzimática específica, la que le permite el mayor desarrollo y es allí cuando se produce el crecimiento de biomasa exponencial [95-101]. Una vez que generó las enzimas y las libera, estas no pueden llegar a los polímeros orgánicos porque se encuentran con los composites formados, el hongo entonces entra en fase de letargo y se produce el detenimiento del crecimiento observado, Figura III.24.

Por otra parte, en el caso de los fungicidas, estos no permiten el desarrollo micelar debido al impedimento de la penetración de las hifas fúngicas al sustrato, esto impide que el organismo genere la absorción de nutrientes y de agua, y es por ello, que el hongo directamente no se desarrolla y muere. Como se mencionara, esto se produce en presencia de nanopartículas, ya sean solas o en la mezcla con silanos. En el caso de la mezcla, se observó que este formaba polímeros más ramificados que cubrían un área superficial mayor, por lo tanto, esto ocuparía todos los posibles espacios de penetración.

En el caso de las nanopartículas, se observa que no hay una formación polimérica ni microarreglos de los polímeros de la madera relevantes, sino que hay una disposición ordenada de estas a lo largo de la pared celular, en las distintas capas de la misma. Esto permite inferir, que la hifa cuanodo quiere generar los surcos entre las paredes (laminillas) o en las paredes celulares (dependiendo el tipo de pudrición) se encontraría con las nanopartículas, las cuales impedirían el reconocimiento del sustrato (ambiente químicamente diferente), por lo que la penetración sería inviable [99-110]. Se puede concluir entonces que para los fungicidas hay dos mecanismos actuando, el no reconocimiento del sustrato por modificación química y el impedimento estérico. La conjunción de estos dos mecanismos más el impedimento estérico en las mezclas podría explicar entonces el efecto sinérgico logrado con la mezcla de silano/nano.

Cabe destacar, que algunas de las formulaciones se escapan de la clasificación recién otorgada, como la del nanozinc. Esto podría deberse a que el zinc es un cofactor enzimático, por lo cual es un compuesto conocido por los organismos biológicos y al ser concentraciones bajas las utilizadas, estos pueden metabolizarlo sin inconveniente. Además hay datos bibliográficos donde demuestran 
su lixiviación paulatina a través del tiempo $[2,45,110,111]$. Probablemente en este caso, la performance este dada por la reducción de la absorción de agua que este genera, como se analizó anteriormente.

Otro caso para destacar, es el comportamiento del nanodioxido de sílice y la nanoplata, las cuales se comportan igual o mejor que la mezcla silano/nano, como se predijo anteriormente. En este caso, se trataría de un polímero de contacto activo: como se observó, las nanopartículas se depositan en las diferentes capas de la pared celular debido a la alta energía y carga superficial natural de estas por su composición electrónica más la que estas tomaron al ser formuladas, esta energía disminuye al interactuar con los componentes de la madera pero queda un "back-up" de carga remanente la cual cuando entra en contacto con membranas biológicas tendría la capacidad de desestabilizarlas por cambio electrónico de su superficie, desintegrándola o en su defecto, no permitiendo que la hifa fúngica se siga proliferando [112]. Esto entonces impediría la absorción de nutrientes y desarrollo fúngico [113-116].

En cuanto a los siloxanos y silanos a pH neutro, su performance está dada por un efecto barrera lo cual no solo impide el ingreso de las hifas a la madera sino que también imposibilita la adhesión superficial del micelio. Dado que los recubrimientos generados por esta técnica no son continuos, el hongo tiene la posibilidad de llegar al sustrato y degradarlo, pero de manera limitada también por la falta de humedad. Esto explicaría los valores de pérdida de peso elevados con respecto a los demás tratamientos $[42-50,64,120]$

Del análisis global de estos compuestos, podemos definir que, por costos, a la hora de elegir un tratamiento eficiente contra el biodeterioro, es conveniente la elección de la impregnación con nanopartículas al 3\%.

Resulta oportuno mencionar que, tanto en el análisis hidrorrepelente como en el de biodeterioro, los resultados analizados en cuanto a las nanopartículas fueron en esta concentración. Del análisis preliminar del comportamiento de las soluciones en el rango de concentraciones del $1-10 \%$, se obtuvo que a partir de una emulsión del 3\% de nanopartículas existían diferencias significativas en el comportamiento de las muestras y que, al aumentar la concentración, recién se observaba una diferencia en la performance general de un 1,8\% con una concentración de nanopartículas de 
7\%, manteniéndose así hasta el 10\%. Por lo tanto, a partir de este, solo se trabajó con la mínima concentración.

\section{III.5 Resistencia al fuego}

Se realizó el ensayo de determinación del Índice de Oxígeno (OI) y tal como se mencionó en el Capítulo II, se complementó con el ensayo de llama intermitente, Figura III.26. De este ensayo descriptivo, se observó una intermitencia mucho menor respecto al control y además ausencia de llama en todas las muestras tratadas. La intermitencia que más tiempo duró fue la de los siloxanos (35 s), los demás se comportaron de manera similar, con una intermitencia de (10s) luego de la exposición a 10 ciclos, todas mejores que el control (consumo total de la probeta y presencia de 1lama).

En la Tabla III.1 se presentan los valores obtenidos para el índice de oxígeno. La importancia de la determinación del OI, no sólo radica en medir la facilidad de combustión de los sustratos para comparar resultados, sino que un OI mayor a 28 permite clasificar al sustrato como incombustible en condiciones atmosféricas. Es importante mencionar que este método no es representativo del comportamiento real de un material en contacto con el fuego, pero es uno de los métodos preferidos en el desarrollo de tratamientos retardantes del fuego debido a que permite la obtención de valores numéricos reproducibles

En la tabla se puede observar que todos los tratamientos resultaron ignífugos respecto al control, debido a que el consumo de oxígeno necesario para que la muestra entre en combustión es mucho mayor al disponible en la atmósfera, por lo cual, podemos decir que todos tienen un comportamiento ignífugo.

En este caso, se observa un claro efecto sinérgico cuando se conjugan ambas tecnologías (silanos/nanos) respecto a las mismas individualmente: es conocido que los silanos y siloxanos son buenos tratamientos ignífugos debido a su naturaleza inorgánica que aporta a la formación del char natural con mayor aporte inorgánico, generando una capa aislante de mejor calidad.

Además, al encontrarse polimerizado dentro de la madera, el composite de naturaleza orgánica/inorgánica tiene un punto de ignición que solo el orgánico (madera sin tratar) por lo que 
la energía de activación necesaria para que la combustión se inicie es mayor, quitando este lado del triángulo del fuego [122-130].

En cuanto a las nanopartículas, se observa que se comportan básicamente como la madera sin tratar, esto es debido a que se utilizaron muy bajas concentraciones como para que puedan por si solas aportar cambios al sistema.
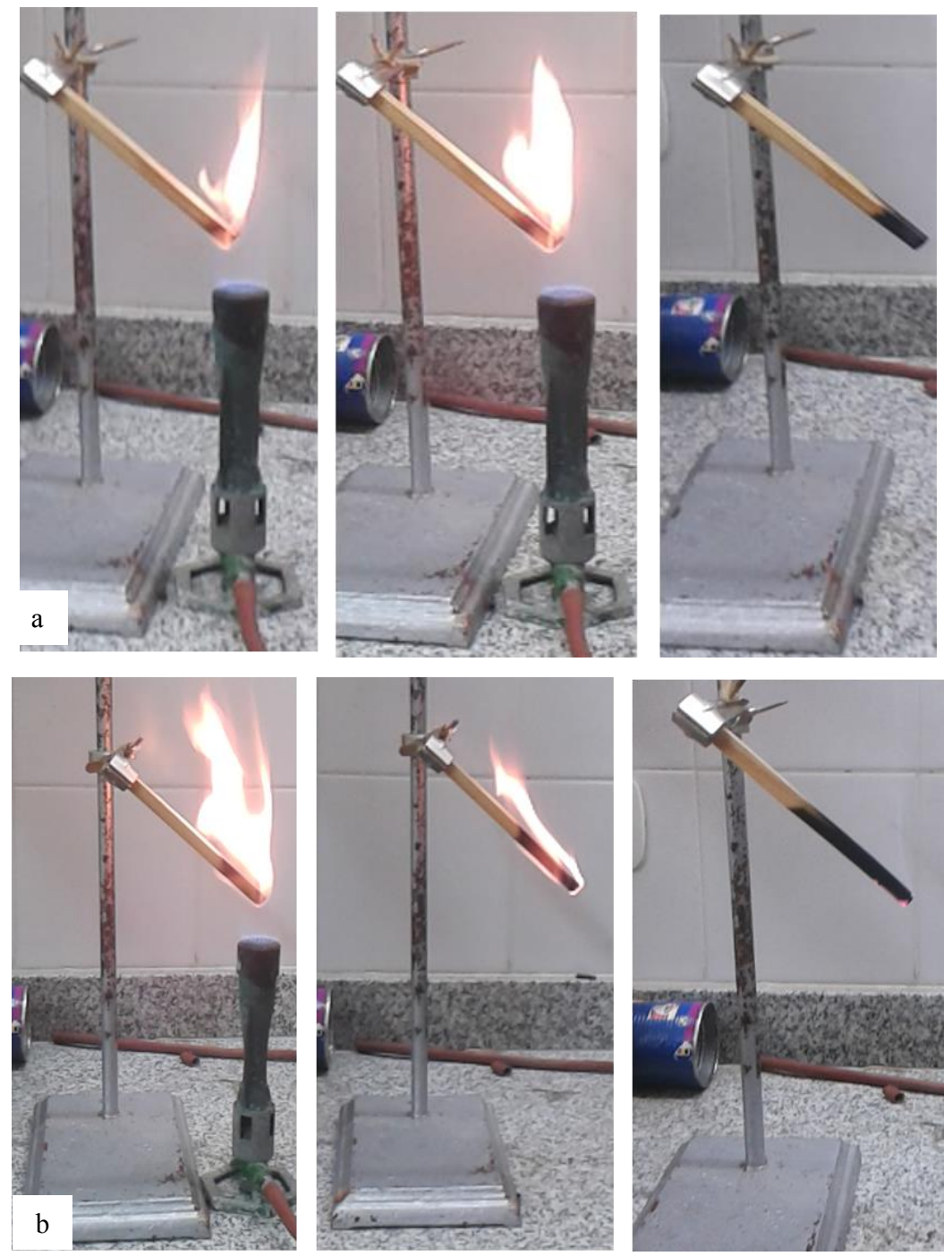

Figura III.26. Resistencia a la llama del mechero Bunsen: a) muestra tratada con OTES/nSi, b) madera sin tratar 
Tabla III.1. Resultados de índice de oxígeno. Todas las muestras resultaron ignífugas

\begin{tabular}{|c|c|}
\hline Tratamiento & $O I, \%$ \\
\hline CONTROL & 18 \\
\hline nZn & 25 \\
\hline $\mathrm{nCu}$ & 27 \\
\hline nAg & 29 \\
\hline nSi & 29 \\
\hline APTES & 30 \\
\hline MPTMS & 31 \\
\hline OTES & 33 \\
\hline MTES & 36 \\
\hline OTES/nZn & 37 \\
\hline MTES/nSi & 38 \\
\hline S700 & 38 \\
\hline APTES/MPTMS & 40 \\
\hline MTES/nAg & 40 \\
\hline OTES/nCu & 40 \\
\hline S1 & 40 \\
\hline MTES/MPTMS & 42 \\
\hline APTES/OTES & 43 \\
\hline MTES/nCu & 43 \\
\hline OTES/nAg & 44 \\
\hline MTES/OTES & 45 \\
\hline MTES/nZn & 45 \\
\hline OTES/nSi & 45 \\
\hline CONTROL & 18 \\
\hline
\end{tabular}

Para el caso de los sistemas silano/nanocompuestos el efecto sinérgico podría explicarse por el siguiente mecanismo: la modificación química genera un sustrato hibrido orgánico/inorgánico que genera que el punto de ignición se modifique, el área superficial comienza a calentarse, comenzando a aumentar la temperatura del sistema y con ella la energía disponible para la activación de la combustión, la primera capa del sustrato empieza a combustionar generando una capa carbonosa como en cualquier madera que actúa como aislante, pero con el agregado de polímeros inorgánicos y nanopartículas, esto hace que se disipe calor y baje la energía del sistema, 
esto hace que no haya energía de activación suficiente para la reacción de combustión se produzca y por ello no hay demanda de oxígeno en el sistema.

A continuación, el calor penetra en la capa adyacente más profunda donde los componentes inorgánicos pueden fundir o ablandarse nuevamente retardando la conducción del calor, mientras que los orgánicos pueden ser degradados en productos más pequeños aportando a la formación más del residuo carbonoso ("char"). El calor sigue penetrando y llega a otra capa más profunda aún, provocando también su degradación y formando productos que se transfieren a la zona de combustión a través del residuo carbonoso: la cinética del proceso parece disminuir a medida que el sistema forma un material carbonoso con alto contenido inorgánico que se acumula en las interfases durante la combustión, aísla el material subyacente y disminuye la pérdida de masa de los productos de descomposición dándole de esta manera un carácter autoextinguible.

La alta resistencia de los inorgánicos es debido a su alta estabilidad molecular frente a la energía entregada por el fuego [131-132].

\section{6 Análisis global de resultados}

Para el análisis global de resultados se realizó un promedio del comportamiento de la performance de cada tratamiento frente a los diferentes agentes degradantes expuestos y se le otorgó un puntaje siendo 10 el de mejor comportamiento y 1 el de peor, luego a partir de estos extremos definidos, se ponderó a los valores intermedios. Con esto podremos discriminar de manera general el comportamiento de los tratamientos frente a agentes bióticos y abióticos, Figura III.27.

Como se puede ver, todos los tratamientos mejoraron la performance de la madera frente a los tres principales agentes a los que este material se expone cotidianamente cuando es utilizado en obras de construcción como en material mobiliario.

Por otra parte, se ve que la eficiencia de un mismo tratamiento varía según el agente en cuestión: los de mayor variación fueron los siloxanos donde se destaca su protección frente al fuego respecto a la hidrorrepelencia y a la resistencia a la degradación biológica, esto se debe a la protección superficial que estos proveen, lo cual para el fuego es muy útil, porque la llama se encuentra en 
primera instancia con un componente inorgánico lo cual disminuye la propagación de energía al sistema, pero también demuestra que una barrera física no es una buena elección para proteger madera de la absorción de agua, estabilidad dimensional y agentes bióticos.
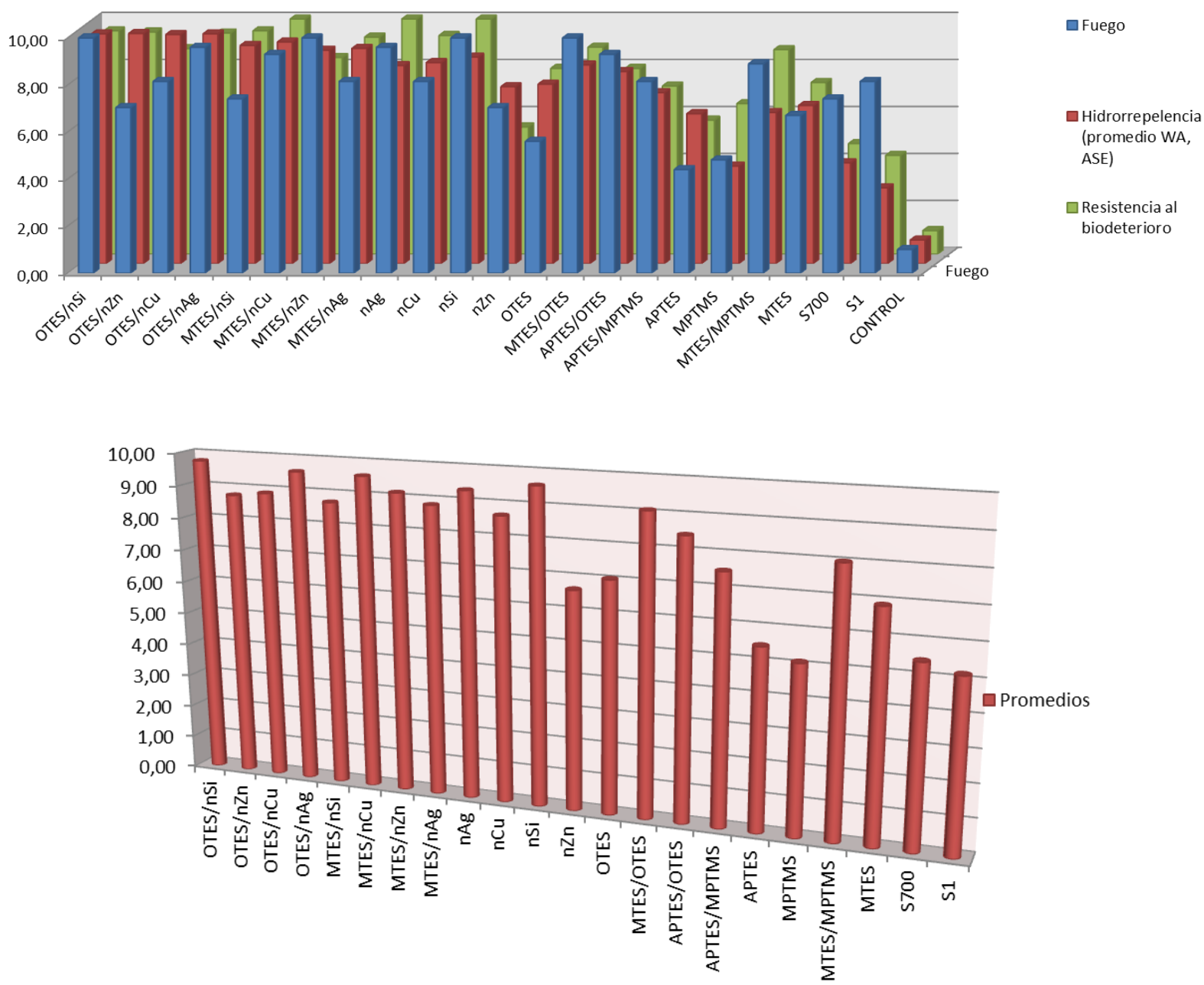

Figura III.26. Análisis global de resultados. Arriba discriminado por agente degradante y abajo la performance general de cada tratamiento frente a agentes bióticos y abióticos

Esto se debe a que no tiene que ver solamente con el componente químico que se le otorga al material, sino como este se comporta dentro del sistema como un todo. Como se observó en los silanos a pH neutro, una misma formulación ubicada espacialmente en otro lugar del sustrato, cambia completamente su eficiencia protectora. Esto tiene que ver con la heterogeneidad del 
material dentro de un mismo plano y en diferentes planos, en cuanto a estructura y composición química, sus movimientos naturales, entre otros, lo cual hace que los tratamientos más eficaces sean aquellos que modifican esta estructura haciéndola más homogénea; lo cual otorga en simultáneo, la capacidad de predecir el comportamiento del material. Es por ello, que con la modificación química se logra una protección completa frente a todos los agentes. Con esto concluimos, que la aplicación de cubiertas superficiales en general, en sustratos de maderas no son métodos de protección eficientes.

Por otro lado, se puede observar el efecto sinérgico que se produce al generar las mezclas de silano/nanocompuestos, generando sistemas protectores con una excelente eficiencia para todos los agentes degradantes. Para corroborar esta hipótesis se realizó una regresión lineal múltiple, planteando como hipótesis que al confrontar los resultados de los componentes individuales nano/silanos debería dar una regresión muy cercana a la lineal, ya que, si la mejora de los resultados es dada por la suma de los componentes individuales, la performance no debería ser muy lejana en las mezclas. Los resultados de los sistemas arrojaron un $\mathrm{R}=-0.14766$ y un $\mathrm{p}>0.76$ lo cual indica que no existe una regresión lineal entre estos resultados, por lo tanto, comprueba que en la mezcla se comportan como un sistema independiente y no como la sumatoria de ambos independiente, demostrando la sinergia mencionada.

Los dos mejores fueron la mezcla OTES/nanosilice con un puntaje de 9,75, seguido por la nanosilice con 9,6 puntos, seguido de las mezclas silano/nano las cuales rondaron en un rango de 9,6-9 puntos (siendo el mayor la mezcla OTES/Ag y el menor de esta serie MTES/nanosilice), seguido por las nanopartículas con 8,5 puntos, seguido por la mezcla de silanos, con un puntaje de 8-7, luego los silanos solos obteniendo alrededor de 7-6 puntos y por último, los siloxanos con 65 puntos.

Es importante destacar el comportamiento de las nanopartículas de sílice, la cual escapa al patrón observado, ya que estas dan la misma performance que la mezcla con silano-nano cuando se encuentra sola pero no genera un efecto sinérgico cuando esta conjuntamente con silanos. Esto lleva a inferir que su eficiencia protectora está dada por la cantidad de carga y energía superficial de esta nanopartícula, por ello, en contacto con los silanos, esta energía disminuye por polimerización y esto haría que disminuya su eficiencia. 
Otra particularidad observada es la importancia de los sustituyentes en los silanos: se puede observar es que, en la hidrorrepelencia, todos los sistemas con OTES fueron mejores que cualquier otro silano con cadenas hidrocarbonadas más cortas. Esto permite inferir que es importante conocer, caracterizar y estudiar cada uno de los componentes de una formulación por separado, para poder explotar todos sus potenciales. Este manejo hace que no sea necesario el uso de altas concentraciones de principios activos, sino poder encontrar relaciones sinérgicas que den capacidades protectoras a bajos costos.

Por último, se observa que las mejores performances de resistencia al biodeterioro estuvo dado con la presencia de nanopartículas, lo cual permite inferir que el composite formado por nanomadera, nano-silano-madera, son de carácter bioactivos.

Se concluye entonces, que los tratamientos mostraron excelente performance protectora frente a agentes bióticos y abióticos, siendo de fácil aplicación (inmersión), utilizando bajas concentraciones, lo cual se traduce en bajos costos.

Básicamente la modificación química permitió generar un nuevo material con propiedades de durabilidad mejoradas con respecto a la madera sin tratar. 


\section{Bibliografía}

1. Cappelletto, E, Callone, E, Campostrini, R, Girardi, F, Maggini, S, ella Volpe, C, Siboni S, Di Maggio, R (2012) Hydrophobic Siloxane paper coatings: the effect of increasing methyl substitution. J Sol-Gel Sci Technol 62(3):441-452. doi:10. 1007/s10971-012-2747-1

2. Mukherjee, S., Paria, S., (2013) Preparation and stability of nanofluids e a review. IOSR e J. Mech. Civ. Eng. 9, 63-69.

3. Wickholm K, Larsson PT, Iversen T (1998) Carbohydr Res 312:123-129

4. Abdelmouleh M, Boufi S, Belgacem MN, Duarte AP, Ben Salah A, Gandini A (2004) Int J Adh Adhes 24:43-54

5. Rowell, R. G. (1983) Chemical Modification of Wood review Forest Products Abstracts 1983 Vol. 6 No. $12,363-382$

6. Rahman, A., Ismail, A., Jumbianti, D., Magdalena, D., Sudrajat, H., (2009) Synthesis of copper oxide nanoparticles by using Phormidium cyanobacterium. Indonesian J. Chem. 9, 355-360.

7. Wim H De Jong and Paul JA Borm, Drug delivery and nanoparticles: Applications and hazards. Int J Nanomedicine. 2008 Jun; 3(2): 133-149.

8. Singh, R. and Lillard, J.W. Jr. (2009) Nanoparticle-based targeted drug delivery. Exp Mol Pathol. 2009 Jun; 86(3): 215-223. Published online 2009 Jan 7. doi: 10.1016/j.yexmp.2008.12.004

9. Zahedi, P., DarrehchiShima, M-F, Robabeh, A.N., Bagheri, Al.L., Najafi, M. (2017) Morphological, thermal and drug release studies of poly (methacrylic acid)-based molecularly imprinted polymer nanoparticles immobilized in electrospun poly ( $\varepsilon$-caprolactone) nanofibers as dexamethasone delivery system Korean Journal of Chemical Engineering, 34, 7, pp 2110-2118.

10. Huang S, Yu Z, Zhang Y, Qi C, Zhang S (2017) In situ green synthesis of antimicrobial carboxymethyl chitosan-nanosilver hybrids with controlled silver release. International Journal of Nanomedicine Volume: 12 Pages 3181-3191

11. Hana, Y. and Wang, L. (2016) Improved water barrier and mechanical properties of soy protein isolate films by incorporation of SiO2nanoparticles DOI: 10.1039/C6RA23461E (Paper) RSC Adv., 6, 112317-112324

12. Yang, L, Jiang, H., Feng, X., Shen, Y. and Ji, L. (2016) J. Sol-Gel Sci. Technol., 2016, 79, 520524.

13. Tian, H, Xu,G., Yang, B. and Guo, G. J. Food Eng., 2011, 107, 21-26.

14. Jin, C., Yao, Q.,Li, J., Fan, B., Sun, Q. (2015) Fabrication, superhydrophobicity, andmicrowave absorbing properties of the magnetic -Fe2O3/bamboocomposites, Mater. Des. 85, 205-210

15. Barata, M.A.B., Neves, M.C., Neto, C.P., Trindad, T. (2005) Growth of BiVO4 particles incellulosic fibres by in situ reaction, Dyes Pigm. 65, 125-127

16. Hübert, T., Unger, B., Bücker,M. (2010) Sol-gel derived TiO2wood composites, J. Sol-Gel Sci. Technol. 53 384-389

17. T.M. Parrill (1992) Transmission infrared study of acid-catalyzed sol-gel silicacoatings during room ambient drying, J. Mater. Res. 7, 2230-2239

18. Mantanis, G., Terzi, E., Kartal, S.N., Papadouplos, A.N., (2014) Evaluation of mold, decay and termite resistance of pine wood treated with zinc and copper based nanocompounds. Int. Biodeterior. Biodegrad. 90, 140-149.

19. Donath et al., (2006) Treatment of wood with aminofunctional silanes for protection against wood destroying fungi Holzforschung 60(2):210-216 •

20. Fengel D, Jakob H, Storobel C (1995) Influence of the alkali concentration on the formation of cellulose. Horzforschung 49: 505-511

21. Yildiz S, Gümu"s,kaya E (2007) Effects of thermal modification on crystalline structure of cellulose in soft and hardwood. Build Environ 42(1):62-67.

22. Zanuttini M, Citroni M, MartõÂnez M J, Marzocchi V (1997) Chemimechanical pulping of poplar wood. Alkaline wood pretreatment at low temperature. Holzforschung 51: 251-256

23. Vinogradova, E., Estrada, M., Moreno, A. (2006) Colloidal aggregation phenomena: spatial structuring of TEOS-derived silica aerogels, J. Colloid Interf. Sci. 298: 209-212

24. Pandey, K.K. (1999) A study of chemical structure of soft and hardwood and wood polymers by FTIR spectroscopy, J. Appl. Polym. Sci. 71, 1969-1975. 
25. Rowell, R. (2006) Chemical modification of wood: A short review, Wood. Mater. Sci. Eng. 1(1), 29-33. DOI: $10.1080 / 17480270600670923$

26. Tjeerdsma, B., Boonstra, M., Pizzi, A., Tekely, P., and Militz, H. (1998) Characterisation of thermally modified wood: Molecular reasons for wood performance improvement,Holz. Roh. Werkst. 56(3), 149-153. DOI: 10.1007/s001070050287

27. Chen et al. (2016). Pretreated pine wood, BioResources 11(2), 5285-5298

28. Liu C. et al. (2011) Fabrication of superhydrophobic wood surfaces via a solution-immersion process Applied Surface Science 258, 761- 765.

29. Boonstra M.J, Tjeerdsma B.F (2006) Chemical analysis of heat treated softwoods. Holz Roh Werkst 64:204-211.

30. Garrote G, Dominguez H, Parajo JC (1999) Hydrothermal processing of lignocellulosic materials. Eur J Wood Wood Prod 57(3):191-202.

31. Ebadi S.E (2016) mechanical behavior of hydrothermally treated oil palm wood in different buffured $\mathrm{pH}$ media. Wood and fibers science, 48 (3) 1-9.

32. Hill CAS, Papadopoulos AN. A review of methods used to determine the size of the cell wall microvoids of wood. J Inst Wood Sci. 2001;90:337-45.

33. Thomas H€ubert and Muhammad Shabir Mahr (2016) Wood (Sol-Gel) Composites for Fire Retardancy Chapter Sol-gel Wood Preservation Springer International Publishing Switzerland 2016 L. Klein et al. (eds.), Handbook of Sol-Gel Science and Technology, DOI 10.1007/978-3319-19454-7_106-1

34. U.S. Department of Agriculture (2013) The Encyclopedia of Wood, Skyhorse Publishing, Inc., 496 $\mathrm{pp}$

35. Novoa Robles L.A (2006) Manual de buenas prácticas de manufactura para la preservación de madera aserrada; acorde a los estándares expresados en las propuestas de normas pp. 41.

36. Apiolaza L.A. (2000). Multiple trait improvement of radiata pine, Massey University, Palmesrton North143 pp.

37. Pinheiro A. C. et al. (2013) Identification of a fungal community on gilded wood carved heritage, Journal of Cultural Heritage, 14 (1), 76-81

38. Brock, T.D. and M.T. Madigan (1991) Biology of Microoganisms. 6th Edn., Prentice-Hall Inc., Englewood Cliffs, N.J., ISBN-13: 9780130838179 , pp: 874

39. Papadopoulos, A.N Militz H.y Pfeffer A. (2010) The biological behaviours of pine wood modified with linear chain carboxylic acid anhydrides against soft rot fungi: International Biodeterioration \& Biodegradation, 64, 409-412

40. Papadopoulos, A.N. y Hill C.A.S. (2002) The biological effectiveness of wood modified with linear chain carboxylic acid anhydrides against Coniophora puteana; Holz als Roh-und Werkstoff 60, 329-332

41. Bücker M, Jäger C, Pfeifer D, Unger B. (2014) Evidence of Si-O-C bonds in cellulosic materials modified by sol-gel-derived silica. Wood Sci Technol.;48:1033-47

42. Chang, H., Tu, K.,Wang, X., Liu,J. (2015) Fabrication of mechanically durable superhydrophobic wood surfaces using polydimethylsiloxane and silica nanoparticles, RSC Adv. 5 30647-30653.

43. Jia, S., Liu, M., Wu, J., Luo, S., Qing, Y., Chen, H. (2016) Facile and scalable preparation of highly wear-resistance superhydrophobic surface on wood substrates using silicananoparticles modified by VTES Applied Surface Science 386, 115-124

44. Kartal, S.N., Green, F., Clausen, C.A. (2009) Do the unique properties of nanometals affectleachability or efficacy against fungi and termites? Int. Biodeterior. Biodegrad.63, 490-495, http://dx.doi.org/10.1016/j.ibiod.2009.01.007.

45. Clausen, C.A., Green, F., Nami, S.K. (2010) Weatherability and leach resistance of wood impregnated with nano-zinc oxide, Nanoscale Res. Lett. 5: 1464-1467, http://dx.doi.org/10.1007/s11671-010-9662-6.

46. Mantanis, G., Terzi, E., Kartal, S.N. Papadopoulos, A.N. (2014) Evaluation of mold,decay and termite resistance of pinewood treated with zinc- and copper-based nanocompounds, Int. Biodeterior. Biodegrad. 90, 140-144, http://dx.doi.org/10.1016/j.ibiod.2014.02.010. 
47. Lykidis, C., Bak, M., Mantanis, G., Németh, R. (2016) Biological resistance of pine wood treated with nano-sized zinc oxide and zinc borateagainst brown-rot fungi, Eur. J. Wood Wood Prod. 74 (2016) 909-911,http://dx.doi.org/10.1007/s00107-016-1093-3.

48. Zhang, Z., MacMullen, J., Dhakal, H., Radulovic, J., Herodotou, C., Totomis, M., Bennett, N. (2013) Biofouling resistance of titanium dioxide and zinc oxide nanopar-ticulate silane/siloxane exterior facade treatments, Build. Environ. 59, 47-55, doi: dx.doi.org/10.1016/j.buildenv.2012.08.006.

49. Miliani, C., Velo-Simpson, M.L., Scherer, G.W. (2007) Particle-modifiedconsolidants: a study on the effect of particles on sol-gel prop-erties and consolidation effectiveness, J. Cult. Herit. 8 1-6, http://dx.doi.org/10.1016/j.culher.2006.10.002.

50. Mattos B.D., Magalhaes, W.L.E. (2017) Design and preparation of carbendazim-loaded alumina nanoparticlesas a controlled-release biocide for wood protection International Biodeterioration \& Biodegradation 123 (2017) 174-181.

51. Lionetto, F., Sole, R.D., Cannoletta, D., Vasapollo, G., Maffezzoli, A., (2012). Monitoring wood degradation during weathering by cellulose crystallinity. Materials 5, 1910-1922

52. Rowell, R., M.; Banks, W. (1985) Water repellency and dimensional stability of wood. Gen. Tech. Rep. FPL-50. Madison, WI: U.S. Department of Agriculture, Forest Service, Forest Products Laboratory; 1985.24 p.

53. Flynn, K.A.,(1995) A review of the permeability, fluid-flow, and anatomy of spruce(Picea spp.). Wood Fiber Sci. 27 (3), 278-284.

54. Goethals, P., Stevens, M., (1994) Dimensional Stability and Decay Resistance of Wood upon modification with Some New Type Chemical Reactants (IRG/WP94-40028). International Research Group on Wood Preservation, StockholmSweden.

55. Shah S. M., Zulfiqar, U., Hussain S.Z., Ahmad ,I., Rehman, H., Hussain, I., Subhani, T. (2017) A durable superhydrophobic coating for the protection of wood Materials Materials Letters 203 1720.

56. Zlahti ${ }^{\sim}$ c, M., Humar, M., (2016) Influence of artificial and natural weathering on thehydrophobicity and surface properties of wood. BioResources 11 (2), 4964-4989.

57. Rowell, R., Dickerson, J. (2014) Deterioration and Protection of Sustainable Biomaterials Chapter 18 Acetylation of Wood, pp 301-327 Chapter DOI: 10.1021/bk-2014-1158.ch018 ACS Symposium Series, Vol. 1158 ISBN13: 9780841230040eISBN: 9780841230057 American Chemical Society

58. Rowell, R.M. y Ellis, W.D (1978) Determination of dimensional stabilization of wood using the water-soak method. Wood and Fiber 10(2), 104-111.

59. Giudice, C. A.; Alfieri, P.V.; Canosa G. (2013) Decay resistance and dimensional stability of Araucaria angustifolia using siloxanes synthesized by sol-gel process International Biodeterioration \& Biodegradation; Año: 2013 vol. 83 p. 166 - 170

60. Canosa G.; Alfieri, Paula V.; Giudice Carlos A. (2013) Dimensional stability, fire performance and decay resistance in wood impregnated with alkylalkoxysilanes. International Journal of Engineering and Innovative Technology; vol. 3 p. $394-400$

61. Broda, M., Mazela, B., Królikowska-Pataraja, K., Hill, C.A.S (2015) The use of FT-IR and computed tomography non-destructive technique for waterlogged wood characterisation Wood Research Volume 60, Issue 5, Pages 707-722

62. Wu, G., Lang, Q., Chen, H., and Pu, J. (2012) Physical and chemical performance of eucalyptus wood with impregnated chemicals", BioResources, vol. 7, no. 1, pp. 816-826.

63. Liu, C., Wang, S., Shi, J. and Wang, C., (2011) Fabrication of superhydrophobic wood surfaces via a solution-immersion process, Applied Surface Science, vol. 258, pp. 761-765.

64. Xie, Y, Hill, C.A.S., Xiao, Z., Militz, H., Mai, C. (2010) Silane coupling agents used for natural fiber/polymer composites: A review Composites Part A: Applied Science and Manufacturing 4( 7), 806-819

65. Bengtsson, M., Oksman, K. (2006) The use of silane technology in crosslinking polyethylene/wood flour composites Compos Part A - Appl Sci, 37, 752-765. 
66. Soltani, M., Najafi, A., Yousefian, S., Naji, H.R., Bakar, E.S.,(2013) Water repellent effect and dimension stability of beech wood impregnated with nano-Zinc oxide. Bioresources 8 (4), 62806287.

67. Taghiyari, H.R., Malek, B.M., Kookandeh, M.G., (2014) Effects of silver and copper nanoparticles in particleboard to control Trametes versicolor fungus. Int. Biodeterior. Biodegrad. 94, 69- 72.

68. Temiz, A., Terziev, N., Jacobsen, B., Eikenes, M. (2006). Weathering, water absorption and durability of silicon, acetylated and heat-treated wood. J. Appl. Polym. Sci. 102, 4506-4513.

69. Nemeth, R., Bak, M., Mbouyem Yimmou, B., Csupor, K., Molnar, S., Csoka, L., (2012) Nanozink as an agent against wood destroying fungi. In: Kúdela, J., Babiak, M.(Eds.), Proc. Of the Annual IAWS Meeting "Wood the Best Material for Mankind", 5th International Symposium on the Interaction of Wood with Various Forms of Energy (Zvolen, Slovakia: International Academy of Wood Science, Technical University), Sept. 26-28, pp. 59-63.

70. Deka M, Saikia CN. Chemical modification of wood with thermosetting resin: effect on dimensional stability and strength property. Bioresour Technol 2000; 73: 179-81.

71. 1Gabrielli CP, Kamke FA. Phenol-formaldehyde impregnation of densified wood for improved dimensional stability. Wood Sci Technol 2009; 44:95-104

72. Liu, M., Qing, Y., Wu, Y., Liang, J., Luo, S. (2015) Facile fabrication of superhydrophobic surfaces on wood substrates via a one-step hydrothermal process, Applied Surface Science 330, 332-338

73. Fransman, W., Bekker, C., Tromp, P., Duis, W. (2016) Potential Release of Manufactured Nano Objects During Sanding of Nano-Coated Wood Surfaces The Annals of Occupational Hygiene, 60 (7), 875-884 https://doi.org/10.1093/annhyg/mew031

74. Hsieh, C.T., Chang, B., Lin, J. (2011) Improvement of water and oil repellency on wood substrates by using fluorinated silica nanocoating, Appl. Surf. Sci. 257, 7997-8002.

75. Ding, X., Zhou, S., Gu, G., Wu, L. (2011) A facile and large-area fabrication method of superhydrophobic self-cleaning fluorinated polysiloxane/TiO2nanocompositecoatings with longterm durability, J. Mater. Chem. 21, 6161-6164

76. Scheffer, T.C.; Morrell, Jeffrey J. (1998) Natural durability of wood: a worldwide checklist of species Forest Research Laboratory, Oregon State University. Research Contribution 22, 58p.

77. ASTM D 2017 (2005) Standard Test Method of Accelerated Laboratory Test of Natural Decay Resistance of Woods (Withdrawn 2014)

78. Nobles, M. K. \& Nodin, V. J. (1955) Studies in wood in habiting hymenomycetes. II. Corticium vellereum Ellis and Cragin. Can. J. Bot. 33: 105-112.

79. Robles, C., Lopez, S. y Carmarán, C. (2015) Basidiomicetes endofíticos de madera en Platanus acerifolia (Platanaceae) de Argentina: notas y estudios de cultivo Bol. Soc. Argent. Bot. vol.50 no. 4

80. Errasti, A., Carmarán, C. \& Novas, M.V. (2010) Diversity and significance of fungal endophytes from living stems of naturalized trees from Argentina. Fungal Divers. 41: 29-40.

81. Deschamps, J. R. \& Wright, J. E. (1975) Clave para el reconocimiento en cultivo de las especies xilófagas de Basidiomycetes argentinae. Rev. Invest. Agrop. INTA, S V, Patología Vegetal 12: 7787.

82. Gotz, M., Nirenberg, H., Krause, S., Wolters, Draeger, H. S., Buchner, A., H. S. Lottmann,J., Berg, G. \& Smalla, K. (2006) Fungal endophytes in potato roots studied by traditional isolation and cultivation-independent DNA-based methods. FEMS Microbiol. Ecol.58: 404-413.

83. Nakasone, K. K. (1990) Cultural studies and identification of wood-inhabiting Corticiaceae and selected Hymenomycetes from North America. Mycologia Memoir 15: 1-412.

84. Boddy, L., and Rayner, A.D.M. (1983) Origins of decay in living deciduous trees: The role of moisture content and a re-appraisal of the expanded concept of tree decay. New Phytology 94:623641.

85. Gilbertson, R. L., and Ryvarden, L. (1986) North American Polypores, Volume 1. Fungiflora, Oslo, Norway.

86. Gilbertson, R. L., and L. Ryvarden (1987) North American Polypores, Volume 2. Fungiflora, Oslo, Norway.

87. Hepting, G.H. (1971) Diseases of Forest and Shade Trees of the United States. Agricultural Handbook No. 386. USDA Forest Service, Washington, DC. 
88. Hickman, G.W., and Perry, E. (1997) Ten Common Wood Decay Fungi on California Landscape Trees. Western Chapter, International Society of Arboriculture. Sacramento, CA.

89. Luley, C.J. (2005) Wood Decay Fungi Common to Urban Living Trees in the Northeast and Central United States. Urban Forestry LLC. Naples, NY.

90. Manion, P.D. (1981) Tree Disease Concepts. Prentice Hall, Englewood Cliffs, NJ.

91. Overholts, L.O. (1977) The Polyporaceae of the United States, Alaska, and Canada. University of Michigan Press, Ann Arbor, MI.

92. Pearce, R.B. (1996) Antimicrobial defenses in the wood of living trees (Tansley Review No. 87). New Phytology 132:203-233.

93. Schwarze, F.W.M.R., Engels, J. and Mattheck, C. (2000) Fungal Strategies of Wood Decay in Trees. Springer, New York, NY.

94. Shaw III, C.G., and Kile G. (1991) Armillaria Root Disease. Agricultural Handbook No. 691. USDA Forest Service, Washington, DC.

95. Shigo, A.L. (1991) Modern Arboriculture. Shigo and Trees, Associates. Durham, NH.

96. Sinclair, W.A., Lyon, H.H. and Johnson, W T. (1987) Diseases of Trees and Shrubs. Cornell University Press. Ithaca, NY.

97. Weber, K., and Mattheck C. (2003) Manual of Wood Decays in Trees. The Arboricultural Association. Hampshire, UK.

98. Wilcox, W.W. (1978) Review of the literature on the effects of early stages of decay on wood strength. Wood and Fiber 9:252-257.

99. Saparrat, M.C.N., Arambarri, A.M., Balatti, P.A. (2007) Growth response and extracelular enzyme activity of Ulocladium botrytis LPSC 813 cultured on carboxymethylcellulose under a pH-range, Biology and Fertility of Soils, 44, 383-386.

100.García-Rivero,M., Peralta-Pérez, M.R. (2008) Cometabolismo en la biodegradación de hidrocarburos, Revista Mexicana de Ingeniería Química, 7, 1-12.

101.Chaparro, D.F., Rosas, D.C., Varela, A. (2009) Isolation of wood-decaying fungi and evaluation of their enzymatic activity (Quindío, Colombia) Revista Iberoamericana de Micología 26,(4), 238243.

102.Domınguez, R., Souchon, H., Lascombe, M.B. and Alzari, P.M. (1996) The Crystal Structure of a Family 5 Endoglucanase Mutant in Complexed and Uncomplexed Forms Reveals an Induced Fit Activation Mechanism, J. Mol. Biol., 257, 1042-1051.

103.Pandey, K.K., Pitman, A.J. (2003) FTIR studies of the changes in wood chemistry following decay by brown-rot and white-rot fungi. Int. Biodeterior. Biodegrad. 52, 151- 160.

104.Rahman, A., Ismail, A., Jumbianti, D., Magdalena, D., Sudrajat, H., 2009. Synthesis of copper oxide nanoparticles by using Phormidium cyanobacterium. Indonesian J. Chem. 9, 355-360.

105.Rowell, R.M. (1983) Chemical modification of wood. For. Prod. Abstr. 6, 363-382.

106.Schwarze, F.W.M.R., (2007) Wood decay under microscope. Fungal Biol. Rev. 21, 133-170.

107.Soltani, M., Najafi, A., Yusefian, S., Naji, H.R., Bakar, E.S., (2013) Water repellent effect and dimensional stability of beech wood impregnated with nano-zinc oxide. BioResources 8, 62806287.

108.Taghiyari, H.R., Malek, B.M., Kookandeh, M.G., (2014) Effects of silver and copper nanoparticles in particle board to control Trametes Versicolor fungus. Int. Biodeterior. Biodegrad. 94, 69-72

109. Suganthi, K.S., Anusha, N., Rajan, K.S., (2013) Low viscous ZnO- propylene glycol nanofluid: a potential coolant candidate. J. Nanoparticle Res. 15, 1986-16p.

110. Suganthi, K.S., Rajan, K.S., (2014) A formulation strategy for preparation of ZnOpropylene glycol-water nanofluids with improved transport properties. Int. J. Heat Mass Transf. 71, 653-663.

111.Traistaru, A.A.T., Timar, M.C., Campean, M., Croitoru, C., Sandu, I., (2012) Paraloid B72 versus Paraloid B72 with nano-ZnO additive as consolidate for wooden artefacts. Mater. Plast. 49, 293 300 .

112.Song, J. and Jang, J. (2013) Antimicrobial polymer nanostructures: synthetic route, mechanism of action and perspective in Colloid and Interface Science, 1-39 doi: 10.1016/j.cis.2013.11.007

113.Faria A.F. et al. (2014) Colloids and Surfaces B: Biointerfaces 113, 115- 124 
114. Faria, A.F., Martinez D.S.T., Moraes, A.C.M., Maia da Costa, M.E.H., Barros, E.B., Souza A.G., Filho, A.J., Alves, O.L. (2012) Unveiling the role of oxidation debris on the surface chemistry of graphene through the anchoring of Ag nanoparticles,Chem. Mater. 24, 4080-4087

115. Verdejo, R., Lamorinierea, S., Cottam, B., Bismarck, A., Shaffer, M. (2007) Removal of oxidation debris from multi-walled carbon nanotubes, Chem. Commun. 7, 513-515

116.Stéfani, D., Paula, A.J., Vaz, B.G. Silva, R.A., Andrade, N.F., Justo, G.Z. Ferreira, C.V. , Filho, A.G.S., Eberlin M.N., Alves, O.L. (2011) Structural and proactive safety aspects of oxidation debris from multiwalled carbon, J. Hazard. Mater. 189 (2011)391-396.

117.Panov, D., Terziev, N. (2009) Study on some alkoxysilanes used for hydrophobation and protection of wood against decayInternational Biodeterioration \& Biodegradation 63, 456-461

118. Broda, M. Mazela, B. (2017) Application of methyltrimethoxysilane to increase dimensional stability of waterlogged wood Journal of Cultural Heritage 25, 149-156

119.Smith, C.W., Hamilton, D.L. (2001) Treatment of waterlogged wood using hydrolyzable multifunctional alkoxysilane polymers, in: Proceedings of the 8th ICOMgroup on wet organic archaeological materials conference, Stockholm, 614-615.

120. Hill CAS. (2002) How does the chemical modification of wood provide protection against decay fungi ? Presentation for COST E22, Finland.

121.ASTM 2863. 13 standard test method for measuring the minimum oxygen concentration to support candle-like combustion of plastics (oxygen index).

122. Giudice, C.A., Alfieri, P.V., Canosa, G. (2013) Siloxanes synthesized "in situ" by sol-gel process for fire control in wood of Araucaria angustifolia Fire Safety Journal 61, 348-354

123.Canosa, G , Alfieri, P.V.,, Giudice, C.A., (2013) Nano lithium silicates as flame-retardant impregnants for Pinus radiate Journal of Fire Sciences 29(5) 431-441

124.Green III y A. Arango (2007) Wood Protection by Commercial Silver Formulations against Eastern Subterranean Termites"; The International Research Group on Wood Protection, 3, 304-322

125.Zhou, L., Gu, C.o and Li,L. (2011) Influence of ammonium polyphosphate modified with 3(methylacryloxyl) propyltrimethoxy silane on mechanical and thermal properties of wood flourpolypropylene composites", Journal of Applied Polymer Science, 122, 2, 849-855.

126.Drysdale, D. (2004) Fire safety design requirements of flame-retarded materials, In: Horrocks and Price (ed.), Fire Retardant Materials, Cardiff, UK, CRC Press, pp. 378-397.

127.Karlsson, O. Sidorova, E. and Morén, T. (2011) Influence of heat transferring media on durability of thermally modified wood, BioResources, vol. 6, 1, 356-372.

128.Saka, S., Miyafuji H. and Tanno, F. (2001) Wood-inorganic composites prepared by the sol-gel process", Journal of Sol-Gel Science and Technology, 20, 213-217

129. De Vetter L, Depraetere G, Stevens M, Janssen C, Van Acke J. (2009) Potential contribution of organosilicon compounds to reduced leaching of biocides in wood protection. Ann For Sci.; 66

130. De Vetter L, Van den Bulcke J, De Windt I, Stevens M, VanAcker J. (2009) Preventive action of organosilicon treatments against disfigurement of wood under laboratory and outdoor conditions. Int Biodeter Biodegr.;63: 1093-101

131.Liu L, Qian M, Pa Song, Huang G, Yu Y, Fu S (2016) Fabrication of green lignin-based flame retardants for enhancing the thermal and fire retardancy properties of polypropylene/wood composites. ACS Sustain Chem Eng 4(4):2422

132. Youming D, Xiaoyan S, Shifeng Z, Jianzhang L (2015) Dynamic mechanical properties and thermal stability of furfuryl alcohol and nano-SiO2 treated poplar wood. IOP Conf Ser Mater Sci Eng 87(1):012027 


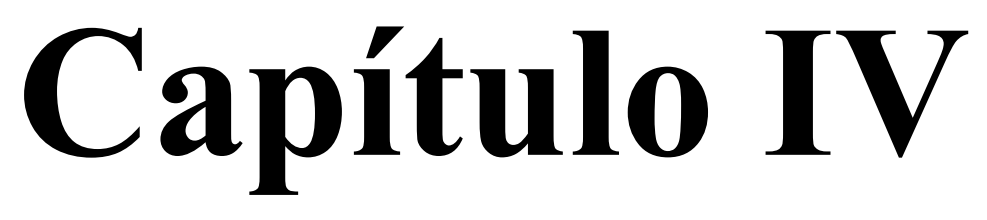

Conclusiones 
La hipótesis que se planteó al presentar el plan de tesis fue "La modificación química de los elementos constituyentes de la madera sería un tratamiento eficaz, a largo plazo y sin mantenimiento contra el deterioro y la degradación causados por los diferentes agentes bióticos y abióticos cuando esta se encuentra en servicio. El agente químico que se escoja mejorará diferentes propiedades dependiendo de su naturaleza química y las propiedades fisicoquímicas que esté presente, sin descartar posibles efectos sinérgicos en el sistema."

Los objetivos para demostrar esto fue la investigación de metodologías y procesos de protección de maderas, a largo plazo, contra el deterioro y la degradación causados por diversos agentes bióticos y abióticos. Fundamentalmente, se busca estudiar mecanismos de acción mediante la formulación y desarrollo de formulaciones reactivas con el fin de modificar químicamente los componentes de la madera y así generar conocimientos de los procesos de interacción entre reactivos, madera y sistema protector. Eso se da en el marco de la protección de maderas que constituyen el patrimonio cultural de la provincia de Buenos Aires así como también las maderas que forman parte de nuevas construcciones sustentables.

A medida que se fue avanzando en el proyecto, se logró:

- Desarrollar y formular tratamientos protectores reactivos basados en nanocompuestos y silanos para modificar químicamente maderas de coníferas.

- Estudiar los mecanismos de acción de la modificación química cuando se expone la madera frente a la acción de agentes atmosféricos y agentes biológicos, particularmente hongos xilófagos.

- $\quad$ Estudiar y analizar el efecto que produce cada agente degradante y deteriorante en la madera con el fin de correlacionar el aspecto visual con un estado de degradación, para obtener indicadores visuales de degradación y por lo tanto, establecer la necesidad de consolidación, protección o reemplazo de maderas en servicio.

- Generar aportes de conocimiento y herramientas de análisis del estado de la madera en servicio para prevenir pérdidas de estructuras o riesgos de derrumbe. 
Luego de concluir con las tareas de campo, el análisis de los resultados obtenidos en esta formación académica de especialización, se puede afirmar que la hipótesis plateada fue cumplida.

El hecho de haber estudiado la modificación química permitió discernir que, la reactividad fundamental del sistema es la de la madera y no el del impregnante: es conocido que a $\mathrm{pH}$ alcalino, hay una exposición mayor de las capas $\mathrm{S}_{1}-\mathrm{S}_{3}$ de las paredes celulares (estructura detallada en el Capítulo I), donde se encuentra la mayor concentración de celulosa cristalina. Esta estructura, muy organizada, es debido a la formación intramolecular entre las microfibrillas de la celulosa de puentes de hidrogeno; estos puentes de hidrógeno, son uniones muy lábiles y frente a cualquier cambio en la densidad electrónica se modifican generando nuevos enlaces. Es en este punto donde entra en juego la reactividad y carga superficial de las nanopartículas: la estructura cristalina se desorganiza por la reactividad y carga de las nanoparticulas, aumentando la energía del sistema, este aumento entrópico hace que haya un nuevo microarreglo polimérico entre la celulosa cristalina, la amorfa y las nanopartículas, generando el cambio químico de la pared celular y modificando entonces la estructura de las fibras de la madera.

En cuanto a los silanos, también se observó cambios estructurales, como eran de esperar basándose en la modificación química ya conocida que estos producen. Se pudo observar que hubo cambios estructurales diferenciales de las células de la madera en los tres perfiles de $\mathrm{pH}$ utilizados, basados exclusivamente en la diferente estructura molecular de los oligómeros de silano al ingresar en la madera lugar donde se completará el proceso sol-gel. Esta es una de las variables fundamentales debido a que las células de madera tienen solo $4 \mathrm{~nm}$ de diámetro, por lo tanto, las partículas sólidas en la solución coloidal deben tener un diámetro adecuado para infiltrarse en las células de madera. Se observa una diferencia significativa a nivel de impregnación en el caso de $\mathrm{pH}$ neutro respecto a otros dos perfiles de $\mathrm{pH}$. Se observó que a $\mathrm{pH}$ neutro no hay ingreso de impregnante en la madera, sino que forma una película que recubre a la madera. Esto se debe a que a pH cercano a 7 la tasa de hidrólisis alcóxidos de silicio presenta un mínimo y aumenta exponencialmente tanto a $\mathrm{pH}$ más bajo como más alto, contrariamente a la condensación que a ese $\mathrm{pH}$ presenta una tasa máxima, por lo tanto, hay formación polimérica previo ingreso y esto impide que este pueda penetrar por impedimento estérico dimensional (cabe recordar que no se utilizaron métodos de presión, por lo tanto, el tamaño de partícula es un factor limitante) 
También se logró discernir la ubicación de las modificaciones químicas producidas: a pH ácido se produce un recubrimiento en de las paredes celulares, probablemente debido a la reacción de los silanos con la laminilla media (no hay modificación estructural de las células de la madera), mientras que a $\mathrm{pH}$ básico se observa una desorganización estructural de las fibras, lo cual hace que los silanos reaccionen con la capa $\mathrm{S}_{1}$ y $\mathrm{S}_{2}$ de la pared celular.

En cuanto a los sistemas de silanos/nanopartículas se pudo observar que el efecto sinérgico estaría dado por la polimerización diferencial respecto a los componentes individuales: generarían anclajes celulosa-silano/silano-celulosa, generando una red polimérica mayor, por ello puede evidenciarse mediante microscopia electrónica. También se puede observar que hay una mayor formación polimérica en todas las muestras, lo que conlleva a pensar que se produjo un mayor ingreso de moléculas a la madera. Esto podría deberse a que, en la formulación la presencia de los silanos genera una estabilidad de la emulsión por reducción de la energía superficial que tienen las nanopartículas, por formación de enlaces no covalentes (puentes de hidrogeno y dipolo-dipolo).

Un mecanismo posible de la modificación química podría explicarse por una estabilización energética del sistema: al cambiar el pH se produce el aumento en la movilidad de la cadena molecular en las regiones no cristalizadas de la celulosa, lo cual hace que las microfibrillas se reordenen en una nueva cadena molecular en las regiones donde el polímero original atacado quedó más laxo. El ingreso del impregnante, desorganiza las microfibrillas de celulosa y abre los anillos de los monómeros que la forman perdiendo la estructura de la pared celular, dejando así a las moléculas de celulosa con elevada energía libre. Posteriormente en el curado se produce la disminución de la entropía por reacción y consecuente polimerización de los principios activos de las formulaciones (silanos y nanopartículas) y los $-\mathrm{OH}$ de celulosa. El entramado intra e intermolecular, por cuestiones espaciales, se debe a las probabilidades de encuentro de las especies reactivas (es más probable que se encuentre con una especie reactiva enfrentada que con una adyacente o contigua, resultando en un microarreglo que deja los lúmenes obliterados como se observó en las microscopias.

En cuanto a los siloxanos, la diferencia radica en que estos ya están polimerizados en el envase y en que este además tiene aditivos tanto por la formulación madre como los de origen oleoso agregado para permitir una fácil aplicación, esto hace que el comportamiento sea menos 
eficiente que los silanos a pH neutro. Esto, además, lleva a pensar que, si bien no hay una gran activación del sistema, el proceso sol-gel se produciría a nivel superficial, habiendo interacción química con la madera.

Como sistemas protectores, se puede concluir que el método de protección más eficiente para la madera es un cambio químico y físico de las traqueidas lo cual anularían su capilaridad y por lo tanto generarían un material con propiedades completamente diferente a las naturales. Por otro lado, también reafirma la importancia del correcto manejo de las variables de formulación: los principios activos mal empleados pueden perder de manera toral y parcial su potencialidad protectora si no se tiene encuentra las variables ambientales en las cuales se van a exponer.

Por otro lado, es importante destacar que no hubo diferencias en los resultados mediante los dos métodos de impregnación utilizados: esto indica que el manejo correcto de los parámetros de formulación del impregnante independiza la elección posterior del método de aplicación, esto es fundamental para que las formulaciones puedan tener multiusos tanto en construcciones nuevas, en estructuras armadas y elementos y construcciones patrimoniales. En la presente tesis, ambos métodos no necesitan de la aplicación de presión para la impregnación, con lo cual tiene una aplicabilidad mayor, ponderando la importancia de este estudio por su aplicabilidad.

Por último, es importante destacar que dejando de lado la modificación química de la madera, otro aporte de los impregnantes por sé es la reducción del lumen celular, lo cual, hidrofobicidad y funcionalidad de las nanopartículas como agentes desestabilizantes de membranas biológicas. Para estas partículas, si existe reacción con la madera, es un efecto secundario ya que por sí solas, presentan estas particularidades. El hecho que hayan reaccionado químicamente entonces, hace que la eficiencia sea mayor, mejorando su capacidad como sistema protector.

Cabe destacar además que, si bien los silanos y el proceso sol- gel, así como las nanopartículas están estudiado, fue necesario retomarlo también para poder demostrar el hipotético efecto sinérgico inicial de estas dos tecnologías, lo cual pudo demostrarse a lo largo de la tesis.

Además, también se logró que todo el estudio tenga aplicabilidad a las problemáticas de protección actuales, como es el caso de protección de bienes patrimoniales. 
Por último, el estudio exhaustivo que presenta esta tesis en cuanto a variables de formulación, estructura de la madera (cabe destacar lo importante de partir del conocimiento completo del material a conservar para poder discernir en el mejor método) y el resultante comportamiento frente a agentes degradadores, permite que esta sea una base de conocimiento de formulación y protección de la madera y no solo un estudio acotado de algunos sistemas de protección estancos. 


\section{Publicaciones que enmarcan esta tesis:}

Revistas indexadas:

1. Canosa, G., Alfieri, P., Giudice, C. A.

Nano lithium silicates as non-flammable impregnants for Pinus radiata

Journal of Fire Sciences, ISSN 0734-9041, Pennsylvania, USA

Editorial SAGE Publications LTD

URL: http://jfs.sagepub.com

DOI: $10.1177 / 0734904111404652$

29(5), 431-441, 2011

Factor de impacto: 1,130

2. Canosa, G., Alfieri, P., Giudice, C. A.

Hybrid intumescent coatings for wood protection against the fire action

Industrial \& Engineering Chemistry Research, ISSN (printed) 0888-5885, ISSN (electronic) 1520-5045, American Chemical Society, Estados Unidos de América

Editorial ACS (American Chemical Society) Publications

URL:http//pubs.acs.org

DOI: 10.1021/ie200015k, publicacado "on line" el 21 de setiembre de 2011

2011, 50 (21), pp 11897-11905

Factor de impacto: 2,206

3. Giudice, C. A., Alfieri, P., Canosa, G.

Decay resistance and dimensional stability of Araucaria angustifolia using siloxanes synthesized by solgel process

International Biodeterioration \& Biodegradation, ISSN: 0964-8305

DOI: 10.1016/j.ibiod.2013.05.015

83, 166-170, 2013

Factor de impacto: 2,059

5. Giudice, C. A., Alfieri, P., Canosa, G.

Siloxanes synthesized "in situ" by sol-gel process for fire control in wood of Araucaria angustifolia Fire Safety Journal, ISSN 0379-7112

Editorial Elsevier Ltd. URL: http://www.journals.elsevier.com/fire-safety-journal/

DOI: 10.1016/j.firesaf.2013.09.013 
61, 348-354, 2013

Factor de impacto: 1,222

6. Guadalupe Canosa, Paula V. Alfieri and Carlos A. Giudice

Dimensional stability, fire performance and decay resistance in wood impregnated with alkylalkoxysilanes International Journal of Engineering and Innovative Technology, ISSN 2277-3754 ISO 9001:2008 International Journal Certified

URL: http://www.ijeit.com/

3 (5), 394-400, 2013

Factor de impacto: 1,89

7. Paula V. Alfieri, Renato A. García, Vilma G. Rosato, María V. Correa

Biodegradation and biodeterioration of wooden Heritage: role of fungal succession International journal of conservation science

Volume 7, Issue 3, July-September 2016: 607-614

http://www.ijcs.uaic.ro/volume_7.html\#Issue3

\section{Paula V. Alfieri and María Verónica Correa}

Fungi observation in the biodegradation of wooden heritage: analysis using different image techniques

Revista Argentina de Microbiología, Vol. 49 (1), 2017

ISSN; 0325-7541

http://www.aam.org.ar/ram.php

9. Canosa G., Alfieri P.V., Giudice A.A.

Low Density Wood Impregnation with Water-Repellent Organosilicic Compounds Journal of Materials Science and Chemical Engineering 06(01):39-51, 2018

\section{Capítulos de libros:}

1. Giudice C.A. y Alfieri P.V.

Biocidas, hidrofugantes y consolidantes para materiales de la construcción (págs. 54-71) manual "Pinturas y recubrimientos para sustratos diversos", Editorial edUTecNe, Universidad Tecnológica Nacional, 320 páginas. Publicado en marzo de 2015, ISBN 978-987-1896-30-1

2. Alfieri P.V. y Correa M.V. 
Generalidades sobre aspectos tecnológicos y biodeterioro de las maderas (págs. 17-25)

Capítulo II del libro Deterioro biológico de materiales y técnicas para su limpieza y preservación: Anales

LEMIT. Serie III, Año 3, N ${ }^{\circ}$. Laboratorio de Entrenamiento Multidisciplinario para la Investigación Tecnológica (LEMIT). ISBN 978-987-3838-06-4. Editor: Vilma G. Rosato. Editorial: Comisión de Investigaciones Científicas de la Provincia de Buenos Aires (CICBA), 101 p.

Publicado julio 2016

\section{Alfieri P.V. y Correa M.V.}

Protección de la madera contra agentes bióticos y abióticos (págs. 87-100)

Capítulo XI del libro Deterioro biológico de materiales y técnicas para su limpieza y preservación: Anales LEMIT. Serie III, Año 3, N ${ }^{\circ}$. Laboratorio de Entrenamiento Multidisciplinario para la Investigación Tecnológica (LEMIT). ISBN 978-987-3838-06-4. Editor: Vilma G. Rosato. Editorial: Comisión de Investigaciones Científicas de la Provincia de Buenos Aires (CICBA), 101 p.

Publicado julio 2016 